\title{
Is habitat enhancement a viable strategy for conserving New Zealand's endemic lizards?
}

\author{
Sarah Maree Herbert
}

\author{
A thesis \\ submitted to the Victoria University of Wellington \\ in fulfilment of the requirements for the degree of \\ Doctor of Philosophy
}

Victoria University of Wellington

2020 
This thesis is dedicated to Trent Bell, who opened my eyes to the wonderful world of New Zealand's lizards, and who always kept believing in me no matter how many mistakes I made.

Toitū te marae a Tāne-Mahuta,

Toitū te marae a Tangaroa,

Toitū te tangata.

If the land is well

and the sea is well,

the people will thrive.

From the New Zealand Biodiversity Action Plan 2016-2020, p2. 


\section{Acknowledgements}

Embarking on a PhD reminds me strongly of the well-worn fairy tale plot where a person is sent forth into the wilderness to retrieve something of importance; whether it be knowledge, new understanding, or a tool. On the long and winding path ahead, the incumbent will encounter many adventures, misadventures, and gremlin-esque creatures intent on boiling them up for dinner. However, the adventurer never goes alone; but with guidance from those in both their past and present. I would like to thank those people who have been my guides and allies on the journey that has been my PhD.

Firstly, I would like to thank my supervisors Nicky Nelson and Stephen Hartley. You've both been immensely important sources of encouragement, support, and constructive feedback - this thesis is all the better because of your input. Thank you too for all the opportunities you've made available during my time as a student, and also for helping me to clarify my priorities.

My past and present colleagues in the Nelson lab group (FIXIT) provided many helpful comments on the research proposal and chapter drafts, and have been wonderfully helpful and supportive fellow travellers: Brittany Florence-Bennett, Carter, Chris Woolley, Douglas Rands, Ellen Irwin, Florence Kelly, Kelly Hare, Liam McAuliffe, Lin Lin Liu, Lisa Casasanto, Michelle Goh, Ox Lennon, Patty Ramírez, Sarah Lamar, Steph Price, Sue Keall, Sydney Dean, and Vaughn Stenhouse. SBS staff Mel Dohner, Nev Higgson, and Sue Keall generously provided their time to help me obtain the resources needed to do the fieldwork.

I feel very privileged to have had the opportunity of co-supervising students. My two wonderful summer scholars Liz Panteleeva and Florence Kelly contributed directly to data collection for this thesis and helped to keep me sane in the field. Masters students Florence Kelly, Harry Stephens, and Björn Koch have produced some really nice additional research on the lizards of Wellington, and taught me as much as I taught them.

I had some really good input at the research proposal stage and beyond from the DOC Lizard Technical Advisory Group, particularly from Jo Monks, James Reardon, Rod Hitchmough, Marieke Lettink and Lynn Adams. Anita Benbrook from Wellington City Council (WCC) gave invaluable help with plant species selection for the restoration sites.

Many of the staff from Greater Wellington Regional Council (GWRC), WCC, and DOC were instrumental in organising land access, boats, accommodation, and helping to solve field-related niggles: Angus Hulme-Moir, Myfanwy Emeny, Daniella Biaggio, Owen 
Spearpoint, Ricky Clarkson, Mark McAlpine, Jeff Hall, Evan Ward, Otis Berard, Chris Bell, Mara Nydegger, Nick Fisentzidis, Genevieve Spargo, Dave Wrightson, Brian Thomas, and Frank Williams (Brian and Frank also helped move the enhancement rocks!). Thank you to Ngāti Toa, Taranaki Whānui, Ngāti Kahungunu, and Rangitāne o Wairarapa for granting permission to work in your rohe. Access to Turakirae Head was granted by Jacinda Absalom of Orongorongo Station. Dale Shirtliff let me hitch-hike rides on the Friends of Mana Island boat trips. Paula Warren from Friends of Baring Head organised accommodation in volunteers' shed. I would also like to thank Danielle Shanahan and Jo Ledington for access to ZEALANDIA and organising volunteer help for lizard surveys - it's a shame that I didn't get more lizards in the forest quadrats and that this bit of the work didn't make it into the thesis.

Thank you to Owen Spearpoint, Philippa Crisp, and Roger Uys (GWRC) for generously sharing the lizard and pest mammal datasets for Baring Head. Likewise to Lynn Adams (DOC) and Don Newman for the Pukerua Bay lizard monitoring data. Thank you too to all the people who collected these data over the years.

I had a huge amount of volunteer help during this project. I would like to thanks Natalie Jones from Conservation Volunteers New Zealand for organising volunteer working bees. Also special mention to volunteers Paul Callister, Dale Shirtliff, Alex Horvat, Jason Kenny, Kanako Ito, Brittany Florence-Bennett, Albi Rovellini, Frances Wilson, Andrew Baird, Marina Marin, David Mobbs, Pauline Joe, Maya Ando, Sydney Dean, Tommy Leung, Amanda Healey, Amanda Rogers, Jina Sagar, Mary-Anne Hawes, Gillian Candler, Kat de Silva, Jon Terry, Jarrod Hosnell, and Heather Kingcott.

Many thanks to the staff and owners of EcoGecko Consultants Ltd for providing me with a supportive work environment, and even loaning me field gear while I was doing my thesis: Trent Bell, Asha Fernandez, Cameron Thorp, Jina Sagar, and Florence Kelly.

This research was funded by a Victoria University of Wellington (VUW) Doctoral Scholarship, an Our Natural Capital grant from Wellington City Council (WCC), joint funding from the VUW Faculty of Sciences and WCC that supported two summer scholarship students, the Centre for Biodiversity and Restoration Ecology (CBRE) at VUW, the New Zealand Herpetological Society (NZHS), the Royal Society / Te Apārangi Hutton Fund, the Society for the Study of Reptiles and Amphibians in New Zealand (SRARNZ), the People, Cities and Nature programme, and the VUW Faculty Strategic Research Grants fund. I am also grateful for in-kind help from: Gotcha Traps NZ Ltd who donated 100 ink tracking cards to the project, Ngā Ururoa and Whitireia Park Restoration Group who shared the cost of Onduline shipping, the WCC Berhampore Nursery for donating 700 native plants for the lizard restoration experiment, the DOC Kapiti Area Office for lending me a vehicle, and the Kapiti MenzShed who did the massive job of cutting the Onduline up for only a donation and some baked goods in return! I also wish to acknowledge the open-source software used for production of this thesis that would otherwise go 
unmentioned: LibreOffice, Notepad++, MiKTeX 2.9, TeXstudio, GIMP 2.10, and the Xubuntu (Linux) operating system (the latter of which made life easier for my geriatric computers). And thanks to Raj Fernandez for initially suggesting LaTeX as a thesis writing platform - this is one tool that shall definitely stay in my belt!

Glenda Herbert, Sydney Dean, and Alex Horvat all did a great job of proof-reading my thesis. To my mum Glenda, nana Beryl, and my 'extended family' Pinny, Tommy, and Jase: thanks for all of your support and agony aunty-ing through this process. Finally, I would like to acknowledge my husband Alex who has provided me with so much love (sometimes tough!) and support throughout this entire thesis journey. I wonder what our next adventure will be? 


\section{Abstract}

In our current era, the Anthropocene, species are disappearing at an unprecedented rate due to the impact of humans on Earth's environments. Of the many causes of these extinctions, habitat loss is thought to be the most severe. Three habitat management strategies are available for halting habitat loss: reservation, restoration and reconciliation. The latter two of these strategies actively seek to improve the ability of degraded or lost habitats to support species. If successful on a large enough scale, use of restoration and reconciliation (hereafter referred to collectively as 'habitat enhancement') could reverse the effects of habitat loss.

I evaluated the viability of habitat enhancement for the conservation of New Zealand's lizard fauna. $83 \%$ of New Zealand's 106+ endemic species are threatened or at risk of extinction. While habitat loss is one key driver of declines, predation by invasive mammals is the other. Neither of these processes are well understood. Habitat enhancement is increasingly being employed in New Zealand by landowners, community groups, conservationists, and businesses as a strategy for mitigating lizard declines, but outcomes are rarely investigated comprehensively. This is concerning because habitat manipulation potentially affects both exotic and native species, which has led to unexpected negative effects on threatened fauna in New Zealand and overseas. I posed four questions to help address this knowledge gap. (1) What habitat enhancement strategies are available for reptiles, and have they produced successful conservation outcomes? (2) How do habitat characteristics affect populations and communities of endemic New Zealand lizards? (3) How does the presence of invasive mammals affect populations and communities of endemic New Zealand lizards over intermediate to long-term time frames? (4) Can habitat enhancement produce positive conservation outcomes in the presence of invasive mammals?

A review of the global literature on habitat enhancement for reptiles identified 75 studies documenting 577 responses of 251 reptile species. For outcome evaluation, I adapted an existing stage-based framework for assessment of translocation success. High levels of success (84-85\%) at Stages 1 (use of enhanced habitat) and 2 (evidence of reproduction in enhanced habitat) suggested that enhancement could be useful for creating areas that can be inhabited, and reproduced in, by reptiles. Fewer cases were successful at Stage 3 (30\%; improvement of at least one demographic parameter demonstrated in 
enhanced habitat) or Stage 4 (43\%; self-sustaining or source population established in enhanced habitat). Additionally, only $1 \%$ of the 577 cases sufficiently examined or modelled long-term population trends to allow evaluation against the Stage 4 criterion. Thus, there was a lack of evidence indicating that enhancement could result in higher population growth rates, or reduced extinction risk, of reptiles.

I conducted field work in the Wellington region to investigate the effects of habitat characteristics and mammals on terrestrial lizards inhabiting coastal environments. Surveys conducted in two mammal-invaded mainland areas and on two mammal-free offshore islands showed that presence or absence of invasive mammals had a stronger effect on lizard community structure than habitat variables. However, occupancy probabilities of northern grass skinks Oligosoma polychroma and Raukawa geckos Woodworthia maculata were positively correlated with increasing cover of divaricating shrubs. O. polychroma were also more likely to occupy patches with increasing cover by non-Muehlenbeckia vines. Mark-recapture studies were conducted at two mammal-invaded mainland sites to investigate the current abundance of lizard species: Turakirae Head and Pukerua Bay. Estimated densities of O. polychroma ranged between 3,980 and 4,078 individuals / ha and W. maculata between 4,067 and 38,372 individuals / ha. Other species known to occur, at least historically, at each site were either not detected or comprised only a small proportion of total lizard captures. Analysis of longitudinal lizard monitoring data available for Pukerua Bay, Turakirae Head, and an additional mammal-invaded site, Baring Head, did not reveal a significant decline in abundance, occupancy, or catch rates of $O$. polychroma over time periods ranging between six and 34 years, nor of $W$. maculata over six to 49 years. Habitat information available for Baring Head showed that the probability of local extinction of W. maculata was significantly lower at rocky sites.

Finally, I conducted a before-after-control-impact habitat enhancement experiment on lizard communities inhabiting $100 \mathrm{~m}^{2}$ plots on the mammal-invaded Miramar Peninsula. After a six-month pre-enhancement monitoring period, native plants and gravel piles were added to enhancement plots and lizard monitoring continued for a further nine months. Enhancement did not significantly affect plot use, body condition, or evidence of reproduction in Oligosoma aeneum, O. polychroma or W. maculata, but were considered successful at Stages 1 and 2 due to the absence of a negative effect. Neither the abundance, probability of entry into plots by birth or immigration, nor apparent survival of O. aeneum was significantly affected by enhancement (Stage 3). Apparent survival of O. polychroma increased significantly in response to enhancement, but this did not result in increased abundance.

Adding gravel and native vegetation (especially divaricating shrubs and vines) may be a suitable strategy for creating habitat in invaded coastal landscapes for O. polychroma and W. maculata. However, most of the other lizard species that would have historically occurred in mammal-invaded coastal areas of Wellington appeared to be sensitive to 
sustained mammal presence, even with low-to-moderate levels of control in operation. Therefore, habitat enhancement without intensive mammal control or eradication is not expected to benefit these species, nor be capable of restoring coastal lizard communities. In invaded landscapes it is, at best, a reconciliation measure that could allow co-existence of an endemic lizard community comprised of common species with invasive mammals. However, habitat enhancement could still be useful for restoring lizard communities in mammal-free sanctuaries. 


\section{Contents}

1 General introduction $\quad 1$

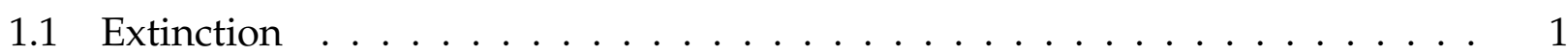

1.2 Managing habitats for minimisation of extinction risk . . . . . . . . . . . 4

1.2.1 Habitat management in invaded landscapes . . . . . . . . . . 8

1.3 New Zealand's lizard fauna . . . . . . . . . . . . . . . . . . . . 9

1.3.1 Habitat loss and species introductions in New Zealand . . . . . . . . . 9

1.3.2 Conservation of New Zealand lizards . . . . . . . . . . . . . . . . . 10

1.3.3 Enhancing habitat for New Zealand's lizards: why, and how? . . . . . 10

1.4 Study sites and species . . . . . . . . . . . . . . . . . . 11

1.5 Key questions and thesis outline . . . . . . . . . . . . . . . . . 19

1.5.1 Notes on presentation . . . . . . . . . . . . 20

1.6 Contributions to research $\ldots \ldots \ldots \ldots \ldots \ldots$

1.7 Permits and ethics . . . . . . . . . . . . . . . . . 21

2 Evaluating conservation outcomes $\quad 23$

2.1 Introduction . . . . . . . . . . . . . . . . . . . 23

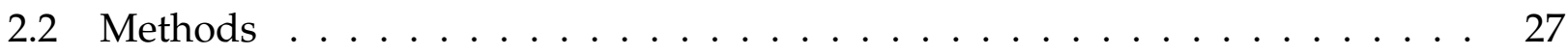

2.2 .1 Literature search . . . . . . . . . . . . . . . . 27

2.2 .2 Analysis . . . . . . . . . . . . . . . . . . 29

2.3 Results .......................... 31

2.3.1 Overview of the literature . . . . . . . . . . . . . 31

2.3.2 Success rates against criteria . . . . . . . . . . . . 37

2.3.3 Effect of study design on criterion-weighted outcome evaluation . . . 41

2.3.4 Effect of species and enhancement attributes on criterion-weighted outcome evaluation . . . . . . . . . . . . . . . 4 41

2.4 Discussion . . . . . . . . . . . . . . . . . . . . 43

3 Variation in lizard communities among habitats $\quad 51$

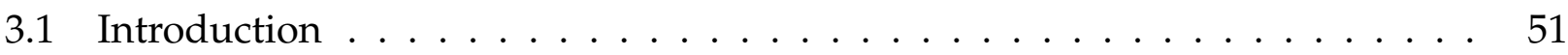

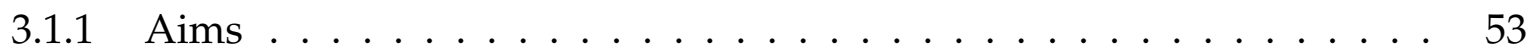

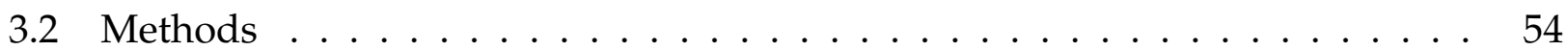


3.2.1 Study sites . . . . . . . . . . . . . . . . . . . . . . . . 54

3.2 .2 Lizard surveys $\ldots \ldots \ldots \ldots \ldots \ldots \ldots \ldots \ldots$

3.2.3 Habitat data collection . . . . . . . . . . . . . . . . . . . . . . 59

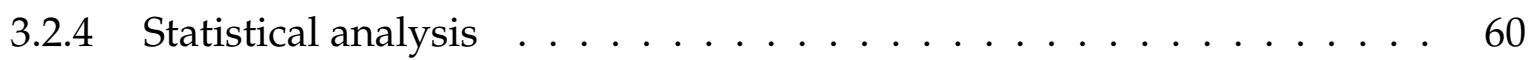

3.3 Results . . . . . . . . . . . . . . . . . . . 66

3.3.1 Available habitat for coastal lizards . . . . . . . . . . . . . . 66

3.3.2 Coastal lizard communities and relationships with habitat and presence/absence of invasive mammals . . . . . . . . . . . 68

3.3.3 Individual and species detection probabilities of frequently encountered lizard species . . . . . . . . . . . . . . . . 75

3.3.4 Associations between habitat characteristics, detection probability and patch occupancy of frequently encountered lizard species _ . . . . 76

3.4 Discussion . . . . . . . . . . . . . . . . . . . . . . . 81

3.4.1 Landscape-scale effects: invasive mammal presence or absence and residual site-level effects . . . . . . . . . . . . . . . . . . . . . 81

3.4.2 Patch-scale habitat effects on lizard species and communities $\ldots . . .83$

3.4.3 Separation between lizard species in multidimensional space: niche partitioning, antagonism, or an indirect interaction mediated by invasive mammals? . . . . . . . . . . . . . . . . . . . 87

3.4.4 Assessment of the repeated VES methodology . . . . . . . . . . . 89

3.4.5 Conclusion and recommendations for habitat restoration . . . . . . 90

4 Effects of invasive mammals $\quad 91$

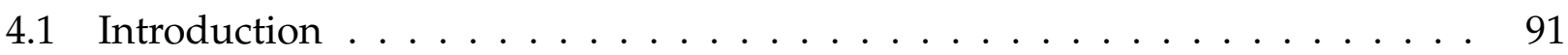

4.2 Methods . . . . . . . . . . . . . . . . . . . . . . . . . 94

4.2.1 Study sites and species . . . . . . . . . . . . . . . . . . . 94

4.2.2 Contemporary (2018-2019) lizard abundance in mammal-invaded environments . . . . . . . . . . . . . . . . . . . 94

4.2.3 Temporal lizard population trends in mammal-invaded environments 101

4.3 Results . . . . . . . . . . . . . . . . . . . . . . . . . . . . 108

4.3.1 Contemporary (2018-2019) lizard species abundance in mammal-invaded environments . . . . . . . . . . . . . . . 108

4.3.2 Lizard population trends in mammal-invaded environments . . . . . 116

4.4 Discussion . . . . . . . . . . . . . . . . . . . . . . . . 127

4.4.1 Effect of invasive mammal species on lizard species . . . . . . . . 127

4.4.2 Mechanisms for persistence of common lizard species in mammal-invaded environments . . . . . . . . . . . . . . . . . . . 129

4.4.3 Potential consequences of mammal invasion for lizard communities . 130 
5 Lizard responses to habitat enhancement $\quad 133$

5.1 Introduction . . . . . . . . . . . . . . . . . 133

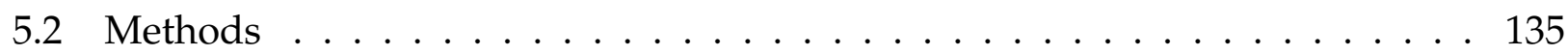

5.2 .1 Study site . . . . . . . . . . . . . . . . 135

5.2 .2 Lizard monitoring . . . . . . . . . . . . . . . 136

5.2 .3 Habitat enhancement . . . . . . . . . . . . . . . . . . . 138

5.2.4 Assessment of enhancement success / failure . . . . . . . . . . . . 138

5.2 .5 Statistical analysis . . . . . . . . . . . . . . . . . 140

5.3 Results . . . . . . . . . . . . . . . . . . . . . 146

5.3.1 Enhancement planting survival . . . . . . . . . . . . . . 146

5.3 .2 Lizard captures . . . . . . . . . . . . . . . . . . . 146

5.3.3 Stage 1 assessment: responses of habitat use and body condition to enhancement . . . . . . . . . . . . . . . . 152

5.3 .4 Stage 2 assessment: reproduction . . . . . . . . . . . . . . . 152

5.3.5 Stage 3 assessment: population responses to enhancement . . . . . . . 154

5.4 Discussion . . . . . . . . . . . . . . . . . . . 164

5.4.1 Apparent survival rates of Oligosoma aeneum and O. polychroma in a mammal-invaded landscape . . . . . . . . . . . . . . . 164

5.4.2 The utility of habitat enhancement for lizard conservation and mitigation 165

6 General discussion $\quad 167$

6.1 Introduction . . . . . . . . . . . . . . . . . . . . 167

6.1 .1 Research aims and questions . . . . . . . . . . . . 168

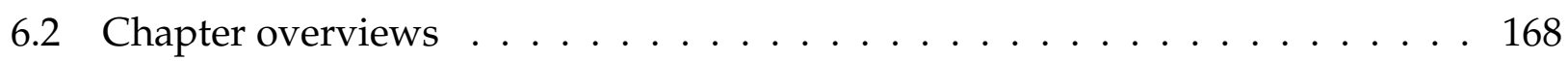

6.3 Conclusion . . . . . . . . . . . . . . . . . . . . 172

6.4 Management recommendations . . . . . . . . . . . . . . . . . . 174

6.4.1 Combine invasive fauna control and habitat management using a species-specific approach . . . . . . . . . . . . . . 174

6.4 .2 Landscape-scale lizard conservation . . . . . . . . . . . . . 176

6.5 Limitations and future research directions . . . . . . . . . . . . . . 176

6.5.1 Identifying lizard associations with habitat . . . . . . . . . 176

6.5.2 Obtaining demographic information from small, cryptic reptiles . . . . 178

6.5.3 What is a 'natural' lizard community? . . . . . . . . . . . . . . 179

$\begin{array}{lr}\text { Bibliography } & 184\end{array}$

$\begin{array}{ll}\text { A Appendix for Chapter } 2 & 227\end{array}$

B Appendix for Chapter 3 $\quad 241$

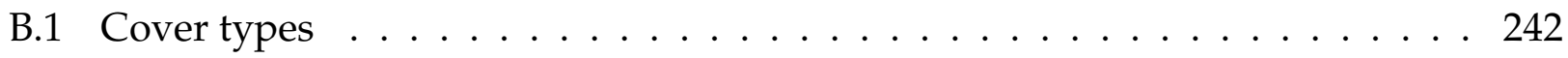


B.2 N-mixture models . . . . . . . . . . . . . . . . . . . . . 244

$\begin{array}{lll}\text { C Appendix for Chapter 4 } & 247\end{array}$

C.1 Density estimates for Turakirae Head . . . . . . . . . . . . . . . . . . . . 247

C.2 Baring Head . . . . . . . . . . . . . . . . . . . . . . . . . . . . . . . 248

C.2.1 Mark-recapture lizard monitoring conducted at Baring Head . . . . 248

C.3 Field observations of daytime refuge use . . . . . . . . . . . . . . . 252

D Appendix for Chapter 5

D.1 Pre-existing habitat in experimental plots . . . . . . . . . . . . . . . . . 253

D.2 Experimental plot maps and planting plans . . . . . . . . . . . . . . 255 


\section{Chapter 1}

\section{Can habitat enhancement minimise extinction risk in New Zealand's endemic lizards?}

Our current era, the Anthropocene, has been termed 'the sixth wave of extinction', as species are disappearing at an unprecedented rate due to the effects of the human population on Earth's environments (Rosenzweig, 2003). While there have been severe extinctions in the past that have exterminated more than 95\% of the earth's species, life recovered because the perturbation was temporary (Rosenzweig, 2003). The Anthropocene extinctions are different because there is no reason to expect that biodiversity will recover. Rather, the extinction crisis will last as long as humans continue to inhabit the planet in current numbers and continue lifestyles that render a proportion of the Earth's surface uninhabitable by most other species (Rosenzweig, 2003).

Perhaps a good starting place for addressing the current wave of biodiversity loss is through understanding how and why the extinctions are occurring. There are many drivers, including habitat loss, fragmentation and degradation, emerging diseases, invasive species, overharvesting, and climate change, but these can be broadly classified as systematic (i.e. deterministic) pressures or random (i.e. stochastic) perturbations (Shaffer, 1981; Fahrig, 2003; Hanski, 2011; Ohmer and Bishop, 2011; Doherty et al., 2015, 2016). Drivers sometimes work in synergy and the outcomes can be difficult to predict (Doherty et al., 2015; Thuiller et al., 2019).

\subsection{Extinction processes across ecological scales of organisation}

The erosion of global biodiversity is the cumulative outcome of extinctions occurring at increasingly larger demographic scales (Royle and Dorazio (2008); Hanski (2011); Table 
1.1). An intuitive place to start when considering extinction, and how to prevent it, is at the population level. On the most foundational level (an exponential population growth scenario), population change $(r)$ between two time periods is defined as the number of individuals entering a population, minus the number of individuals leaving a population, which can be parametrised as:

$$
r=(\text { births }+ \text { immigration })-(\text { deaths }+ \text { emigration })
$$

and can be re-expressed as the effective proportional population growth rate:

$$
r=p_{\text {ent }}-(1-\phi)
$$

where $p_{\text {ent }}$ is the probability of entry into the population by birth or immigration and $\phi$ is apparent survival; the proportion of individuals that did not die or leave the population (Schwarz and Arnason, 1996; Schwarz, 2001; Owen-Smith, 2007). Within this deterministic scenario, a negative population growth rate will inevitably lead to extinction. Therefore it follows that an increase in $p_{\text {ent }}$ and/or survival could reduce population extinction risk. Additionally, larger populations generally have lower extinction risks (Hanski, 1999). Numerically, a population with a large initial size will take longer to reach extinction than a small one subject to the same rate of decline (Fig. 1.1). Small populations also tend to be more sensitive to genetic, demographic, and stochastic problems that increase their rate of decline (Shaffer, 1981).

Table 1.1: Demographic scales of organisation. $\mathrm{s}=$ the number of sites, $\mathrm{Pr}=$ probability of. Adapted from Royle and Dorazio (2008), p8.

\begin{tabular}{lll}
\hline \hline Scale & Static system & Dynamic system \\
\hline Population of individuals & $N=$ population size & $\begin{array}{l}\phi=\text { survival } \\
\gamma=\text { recruitment }\end{array}$ \\
\hline $\begin{array}{l}\text { Population of populations } \\
\text { (metapopulation) }\end{array}$ & $\begin{array}{l}N(s) \\
\psi(s)=\operatorname{Pr}(N(s)>0)=\text { site } \\
\text { occupancy }\end{array}$ & $\begin{array}{l}1-\phi=\epsilon=\text { local extinction } \\
\gamma=\text { local colonisation }\end{array}$ \\
\hline $\begin{array}{l}\text { Population of species } \\
\text { (community) }\end{array}$ & $N=$ species richness & $\phi, \gamma$ \\
\hline $\begin{array}{l}\text { Population of communities } \\
\text { (metacommunity) }\end{array}$ & $N(s), \psi_{i}(s)$ & $\phi, \gamma$ \\
\hline \hline
\end{tabular}

While the assumption of exponential population change may hold for short time periods, this scenario is often not realistic over the long-term. Firstly, it does not take density dependence of population growth into account (Caswell, 2001). For example, environments have a finite number of resources (termed the carrying capacity, $K$ ) that will ultimately limit the number of individuals it can support (Owen-Smith, 2007). Secondly, environmental conditions are more commonly stochastic than constant and influence birth 


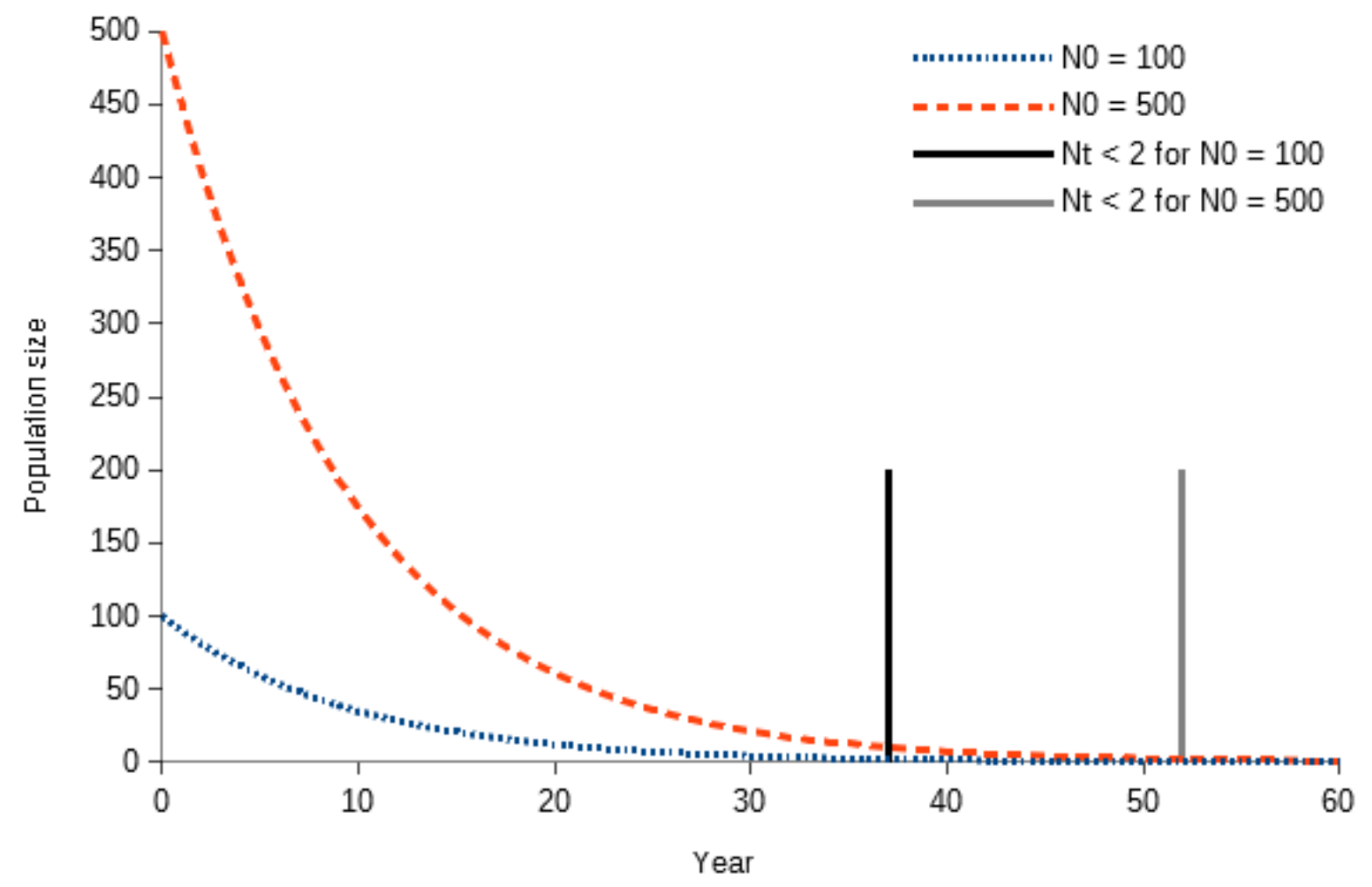

Figure 1.1: Projected time to extinction of two hypothetical populations with initial abundances of 100 and 500. Both populations follow an exponential population growth function, where $N_{t+1}=N_{t}(1+r)$ and the population growth rate $(r)$ is -0.1. It is assumed that reproduction is sexual, and a 1:1 male:female sex ratio is conserved throughout years, therefore functional extinction is at $N_{t}<2$. 
and death rates. Reformulation of deterministic growth models to reflect a more realistic scenario that incorporates stochasticity suggested that the variance of population growth rate and carrying capacity are at least as important as the mean population growth rate for determining extinction risk (Goodman, 1987a,b). This view of population dynamics provides three parameters that could theoretically be manipulated to reduce extinction risk.

Unless it occurs in isolation, for instance in a small patch surrounded by an uninhabitable matrix, the dynamics of one population will interact with those of surrounding populations, forming a 'metapopulation'. One of the predictions of metapopulation theory is that more abundant species are more widely distributed and vice versa, species covering a larger area tend to exist in larger populations, although the mechanism behind this relationship is debated (small-population scenario; Connor and McCoy (1979); Lawton (1993); Hanski (1999)). Another is that a metapopulation spread across a larger area will be less likely to become extinct because the average rate of population growth across multiple populations is less variable than for a single population (Goodman, 1987a,b). Also, the direction and magnitude of environmental pressures on each population are unlikely to be homogenous across space (changing environment scenario; Goodman (1987a); Hanski (1999)). Spatially separated populations are likely to have independently fluctuating growth rates, so at one point in time some populations could be in decline whereas other may be growing (metapopulation scenario; Holt (1992)). If there is enough dispersal between populations, then even declining populations within a metapopulation may survive for a long time due to a 'rescue effect' where individuals dispersing from growing populations bolster the numbers of otherwise declining populations (Holt, 1992; Hanski, 1999). While the small-population scenario is more likely for large vertebrates, the changing environment scenario is more likely for small invertebrates (Hanski, 1999).

\subsection{Managing habitats for minimisation of extinction risk}

Of the multitude of factors driving the Anthropocene extinctions, habitat loss is considered to be the most severe (Tilman et al., 1994; Brooks et al., 2002; Hanski, 2011). More than onefifth of the Earth's total land area has been converted to human-dominated uses, rendering it less able, or unable, to support natural communities (Hoekstra et al., 2005). However this proportion is not geographically consistent. For example, if the ice-bound terrestrial biomes are excluded from analysis, the proportion of habitat lost from more productive and speciose temperate to tropical ecosystems rises to between $30 \%$ and $50 \%$, painting an even more sobering picture for biodiversity (Vitousek et al., 1997; Hoekstra et al., 2005). Future estimates of habitat loss are expected to expand due to intensification of the pressures put on environments by a growing global human population (Rosenzweig, 2003).

The impact of habitat loss is perhaps so severe because of the scale at which it has 
Pristine habitat

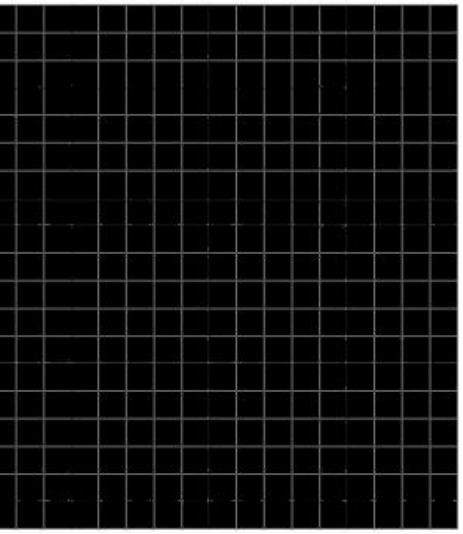

$\mathrm{K}$ unit $=10$ animals

K landscape $=20 \times 17 \times 10$

$=3,400$ animals

\section{Habitat loss and fragmentation}

Total habitat loss

Affects occupancy

E.g. effect of deforestation

on forest specialists

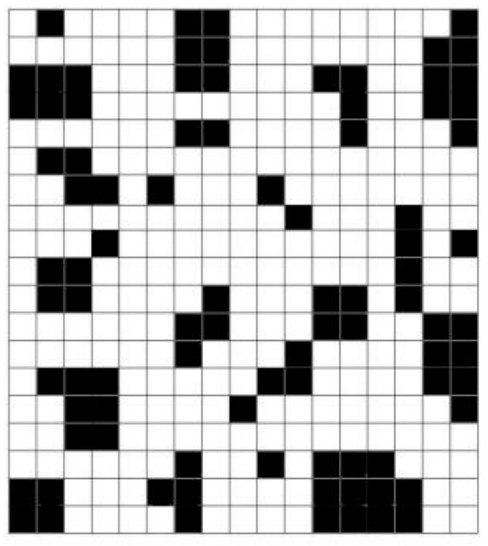

$\mathrm{K}$ unit $=10$ animals

$\mathrm{K}$ unit $=0$ animals

$\mathrm{K}$ landcsape $=90 \times 10=900$ animals
Habitat loss, fragmentation and degradation

Reduction of habitat quality Affects abundance

E.g. introduced predators or weeds, or temporal disturbance

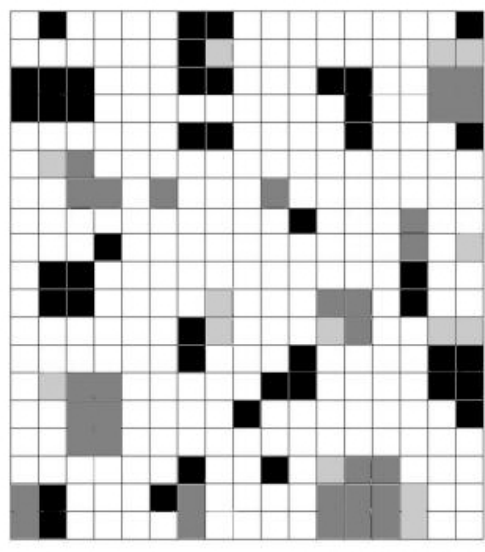

$\mathrm{K}$ unit $=10$ animals

K unit $=5$ animals

$\mathrm{K}$ unit $=3$ animals

$\mathrm{K}$ landscape $=10 \times 44+5 \times 32+3 \times 14$

$=642$ animals

Figure 1.2: Diagram of a hypothetical landscape showing how the effects of habitat loss, fragmentation and degradation can occur in synergy to degrade metapopulations. Habitat patches are conceptualised as grid squares. $K$ refers to the carrying capacity of a patch.

occurred. Given that the number of species that an area can support is constrained by its size, Rosenzweig (2003) inferred that protecting the Earth's remaining pristine areas no longer provides a large enough area to prevent further species extinctions. Rather, habitats also need to be actively rehabilitated if we are to halt the effects of habitat loss on biodiversity (Rosenzweig, 2003; Croak et al., 2013).

To facilitate understanding of how habitat loss endangers populations and metapopulations, Figure 1.2 illustrates a hypothetical landscape that has experienced habitat loss per se, and visualises the roles of the related issues of habitat degradation and fragmentation. Habitat loss in the strict sense refers to cases where a natural habitat is destroyed or damaged so drastically that it can no longer support one or more species. Degradation refers to habitat change that does not preclude species occupancy, but one in which individual fitness, and thus population growth rate, is compromised (Hanski, 2011). When fragmentation occurs, suitable habitat patches become increasingly separated by inhospitable habitat, thus preventing individuals from dispersing (Fahrig, 1997, 2003). 
It is important to understand the processes culminating in habitat-driven extinctions in order to predict the ultimate outcomes of habitat destruction. In the short-term, compromised viability of demographic units are often obscured by "extinction debt": the temporal lag between an episode of habitat loss and extinction (Tilman et al., 1994; Hanski, 2011). This is because individuals, particularly those of long-lived species, will persist for some time in an area after habitat has been destroyed or degraded, even though the population growth rate has become negative and will ultimately lead to extinction via one or more demographic, genetic, and/or stochastic processes (Shaffer, 1981; Tilman et al., 1994; Kuussaari et al., 2009). When combined, knowledge of the processes of habitat loss and extinction also offers a series of suggestions for how habitat could be managed to facilitate persistence of demographic units, as follows:

- Increasing the total area of suitable habitat for a metapopulation, or species, is expected to decrease extinction risk (Connor and McCoy, 1979; Hanski, 1999).

- Where the total area covered by a metapopulation or species is large enough, manipulating habitat to increase heterogeneity may create insurance from negative effects from widespread environmental perturbations (Goodman, 1987b; Hanski, 1999).

- In some (but not all) cases, habitat fragmentation can increase extinction risk of metapopulations because increasing isolation of populations disrupts spatially dependent demographic and genetic processes (Fahrig, 2003; Berry et al., 2005). In these cases, management of matrix habitat to better facilitate dispersal between populations is expected to decrease extinction risk (Holt, 1992; Hanski, 1999; Jackson and Sax, 2010).

- Improving habitat quality for a population could result in higher and less variable birth and/or survival rates, which will likely result in higher population growth rates (within the upper bound of the intrinsic growth rate dictated by the life history of the species) and longer persistence times (Goodman, 1987a,b).

- If the colonisation rate, $\gamma$, and the extinction rate, $\epsilon$, are, respectively, increasing and decreasing functions of patch quality, the overall fraction of empty patches will increase with increasing $h$, the fraction of $\gamma / \epsilon$ (Gyllenberg and Hanski, 1997). Therefore, improving habitat quality within patches is predicted to result in more occupied patches, which would improve metapopulation resilience under the small population and changing environment scenarios (Connor and McCoy, 1979; Goodman, 1987b; Hanski, 1999).

- Improving habitat quality in localised patches within a connected population could result in increasing the number of source populations with positive growth rates that 
produce individuals capable of colonising neighbouring areas with declining or locally extinct populations (that is, a 'rescue effect'; Holt (1992); Hanski (1999); Jackson and Sax (2010)).

Three distinct habitat management strategies have arisen in the scientific literature to address the triple threat of habitat loss, degradation and fragmentation: reservation, restoration and reconciliation. Within landscapes that are a mosaic of land use types, these three strategies applied at the patch scale could be complementary for conserving wildlife metapopulations that are negatively affected by habitat loss; an idea similar to mixed habitat management models posed by other ecologists (Hobbs et al., 2009; Hanski, 2011; Hobbs et al., 2014). These management strategies differ in that reservation focuses on the protection of a large enough area of suitable habitat for wildlife, whereas restoration and reconciliation require direct manipulation to improve habitat quality (Goodman, 1987b; Dobson et al., 1997; Smallwood, 2001; Rosenzweig, 2003; Kremen, 2015). The key difference between restoration and reconciliation is that restoration seeks to return habitat to an 'original' or 'natural' state and may only benefit species historically existing within an area, whereas the end-goal of reconciliation is to improve the ability of a habitat to support biodiversity without reference to an original state (Rosenzweig, 2003; SER, 2004; Mcdonald et al., 2016). Despite this difference, I have grouped restoration and reconciliation together as types of 'habitat enhancement' throughout this dissertation because they both effectively improve habitat quality for species. The word 'reconciliation' has recently gained a somewhat loaded meaning in New Zealand: that is, the value judgement that perhaps the nation should reconcile itself to accepting novel ecosystems comprised of mixtures of alien and native species (Steer, 2015). Throughout this thesis I use the term reconciliation as defined by Rosenzweig (2003).

In the complementary land management model detailed in Figure 1.3, reservation is used to protect the remaining patches of natural habitat. Degraded habitat patches adjacent to reserves are restored to increase the area of high quality habitat available. Existing land use of the remaining patches may preclude restoration (for example, if they contain important agricultural or urban land), but their continued human use could be reconciled with wildlife needs so that they are inhabitable by wildlife and connect patches of better quality habitat (Fig. 1.3). With these strategies used in concert, the carrying capacity of the landscape could be increased (Fig. 1.3) and extinction risk of the metapopulations inhabiting it decreased. 


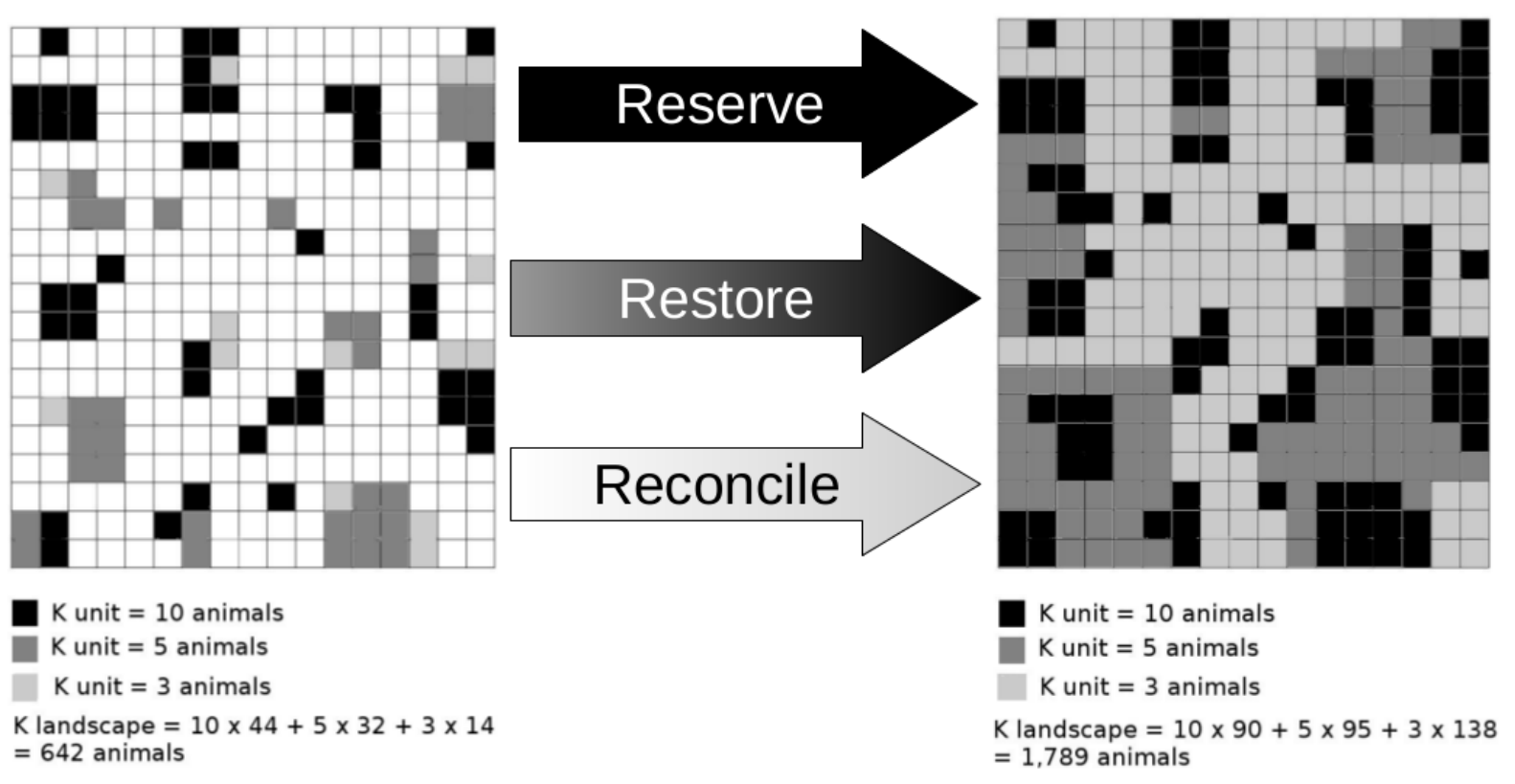

Figure 1.3: Diagram of how reservation, restoration and reconciliation could be applied for habitat conservation in a hypothetical landscape that is subjected to habitat loss, fragmentation and degradation. Reservation is illustrated as keeping the pristine black cells black. Restoration is illustrated by improving the quality of the degraded grey cells so that they become black or darker grey. Reconciliation is illustrated as improving the quality of the uninhabitable white cells so that they can support some organisms - illustrated as conversion to grey shading.

\subsubsection{Habitat enhancement for conservation of native species in invaded landscapes: an inconvenient paradigm?}

Any modification made to a habitat will affect all species within it, not just the target species (Didham et al., 2007). Therefore, the outcome of habitat modification on the target species may be different from expected due to the simultaneous impact on sympatric species, or on the relationships between them (Didham et al., 2007). For example, planting vegetation strips to protect grey partridge (Perdix perdix) from raptor predation in France proved to be ineffective because the strips acted as 'predation traps' instead of prey refuges (Bro et al., 2004). In New Zealand, establishment of vegetation buffers to deter predators from visiting yellow-eyed penguin (Megadyptes antipodes) sites had the opposite effect and resulted in increased abundance of house mice (Mus musculus), an invasive mesopredator (Alterio et al., 1998; Ratz, 2000).

Fauna on oceanic islands probably represent the extreme end of this complicating effect of invasive species on habitat restoration efforts. Island-endemic fauna are evolutionarily naïve to taxa (particularly mammals and amphibians) that are less capable of dispersing long distances over oceans (MacArthur and Wilson, 1963; Heaney, 1986; Doherty et al., 2016). Because of the lack of co-evolution, alien predators have twice the effect size on native prey 
in comparison to that of native predators (Salo et al., 2007; Smith et al., 2017). Therefore it is expected that changes to predator-prey relationships driven by habitat manipulation will have a larger effect on alien-native predator-prey pairs in comparison to native-native predator-prey pairs.

\subsection{New Zealand's lizard fauna: a case study for habitat enhancement for island endemics co-existing with invasive fauna}

New Zealand's lizards are a good model for exploring the dilemma of 'doing' habitat enhancement for conservation of a fauna jointly threatened by habitat loss and invasive species (Hitchmough et al., 2016a,b). Reptiles (together with amphibians) are recognised as the most sensitive vertebrate taxa to local habitat changes due to their ecological and physiological constraints, low dispersal capacity, and small home ranges (Huey, 1982; White et al., 1997; Anadón et al., 2006b; Castellano and Valone, 2006; Ribeiro et al., 2009; Lagarde et al., 2012; Carter et al., 2015). New Zealand is an under-recognised global biodiversity hotspot for lizards, with at least 106 endemic species originating from a single dispersal event of one skink and one Diplodactylid gecko (Chapple et al., 2009; Nielsen et al., 2011; Chapple, 2016). The progeny of these two original lineages have since adaptively radiated to fill almost every available niche in the New Zealand environment, from shoreline to alpine areas above the snowline (Hare et al., 2016). There are only four documented extinctions, but $83 \%$ of the extant species are acutely or chronically threatened, primarily by habitat loss and the introduction of mammalian predators (Towns and Daugherty, 1994; Hitchmough et al., 2016a,b; Melzer et al., 2019).

\subsubsection{Habitat loss and species introductions in New Zealand}

Prior to human settlement, 85-90\% of New Zealand was covered in temperate forest (McGlone, 1989). Deforestation began after arrival of the Polynesian ancestors of Māori around $1280 \mathrm{AD}$, but had slowed by about $1600 \mathrm{AD}$ to result in a mosaic comprised of $\mathrm{c}$. $50 \%$ of the original forest cover interspersed by native grassland, scrub, fernland or swamp (McGlone, 1989; Fuller et al., 2015). By this time, two exotic animals had arrived: the Pacific rat (Rattus exulans) and domestic dogs (Canis lupus familiaris) (McGlone, 1989). Another three rodents, the house mouse (Mus musculus) and the rats Rattus rattus and $R$. norvegicus were accidentally introduced during the European exploration phase between the late 1700s and early 1800s (King, 1990). A resurgence in deforestation occurred after European settlement began around $1800 \mathrm{AD}$ due to extensive land clearance and logging (McGlone, 1989; Fuller et al., 2015). By the 1920s, European settlers had deliberately introduced a suite 
of exotic mammal and bird species for various reasons including hunting, agriculture, pets, acclimatisation, and biocontrol (King, 1990). Today, about one-quarter of the original forest cover of New Zealand is left and earlier-successional native vegetation communities have been heavily modified and further habitat loss is ongoing (Ewers et al., 2006; Monks et al., 2019). Mice, rats, hedgehogs (Erinaceus europaeus), mustelids (Mustela furo, M. erminea, and M. nivalis) and cats (Felis catus) appear to be the most damaging lizard predators (Towns, 1991; Newman, 1994; Cuthbert et al., 2000; Gillies and Clout, 2003; Jones et al., 2013; Norbury et al., 2014b). Introduction of mammals has, for the most part, extirpated the larger-bodied lizard species from the mainland, which has potentially resulted in a dominance switch in lizard communities to favour smaller species that can evade larger-bodied predators (Tingley et al., 2013; Woolley et al., 2019). The onset of the Anthropocene has thus brought a dramatic change in the environmental pressures on New Zealand's lizard fauna, and it is likely that today's reptile communities poorly reflect those that occurred in pre-human times (Tingley et al., 2013; Worthy, 2016).

\subsubsection{Conservation of New Zealand lizards}

Eradication and intensive control of invasive 'pest' animals, and translocation to pest-free areas, has proven successful for the conservation of New Zealand's lizards and other endemic fauna (Towns and Ferreira, 2001; Towns et al., 2001; Reardon et al., 2012; Hitchmough et al., 2016b; Nelson et al., 2016). These successes have fuelled a substantial political and public appetite for creating a 'predator-free New Zealand' by 2050 (Russell et al., 2015; Linklater and Steer, 2018). However, if predator-free status is not achievable and pest control is to secure lizard species from extinction in the long term, it may need to intensively suppress or eradicate mice and rats along with larger predators (Towns, 1991; Newman, 1994; Cuthbert et al., 2000; Gillies and Clout, 2003; Knox et al., 2012; Jones et al., 2013; Norbury et al., 2014b; Hitchmough et al., 2016b). Furthermore, this level of suppression or pest-free status would need to be maintained in perpetuity; a resource-intensive undertaking (Norbury et al., 2014a). For this reason, many lizard species do not currently have any populations within established or proposed pest-free areas (Hitchmough et al., 2016a).

\subsubsection{Enhancing habitat for New Zealand's lizards: why, and how?}

Using habitat enhancement to conserve lizards is an attractive notion because it would require substantially less ongoing maintenance compared with pest control regimes to ensure permanence of any benefits reaped by lizards. Internationally, habitat enhancement has generated positive outcomes for some reptile populations (for example, Webb and Shine (2000); Michael et al. (2004); Souter et al. (2004)). However, the effect of enhancement 
on New Zealand lizards has not been rigorously evaluated, even though it is being recommended for conservation of lizards by the public and private sectors (DOC, 2005; Romijn, 2007; Check and Bowie, 2009; DOC, 2009a,b,c,d; Davies et al., 2010a,b; Lettink and Knox, 2011; Herbert et al., 2015; Bell and Herbert, 2017a). This is concerning because successful habitat enhancement in New Zealand may not be straightforward due to the evolutionary naivety of its endemic reptiles to mammalian pests. For example, Lettink et al. (2010) found that only predator exclusion, and not the addition of artificial retreats, improved survival of McCann's skinks (Oligosoma maccani). Habitat enhancement can also result in increased rodent and mustelid abundances, which has a negative effect on several New Zealand lizard species (Whitaker, 1973; Towns, 1991; Newman, 1994; Alterio et al., 1998; Ratz, 2000; Michael et al., 2004; Innes et al., 2010; Knox et al., 2012; Norbury et al., 2013).

Habitats provide three key services to reptiles: opportunities for thermoregulation, food, and refuge from predators (Vitt et al., 1998; Santos et al., 2008). Therefore a high quality habitat would probably be one that is able to provide all three of these in abundance. New Zealand's lizards display a range of thermal strategies, with cases of heliothermy and thigmothermy recorded along with probable thermoconforming coupled with physiologies adapted for low environmental temperatures in some species (Hare and Cree, 2016; van Winkel et al., 2018). All lizards endemic to New Zealand (except Oligosoma suteri) are viviparous, which means that while they do not rely on thermally optimal egg deposition sites for reproduction, pregnant females must be able to access warm microhabitats for embryonic development (Cree and Hare, 2016). Lizards would have likely fulfilled the role of mesopredators within New Zealand ecosystems; preying on invertebrates and supplementing their diet with plant-based food sources, honeydew, regurgitated fish by seabirds, and scavenged carrion as available (Whitaker, 1987; Markwell, 1999; Stephenson, 2012; Evans et al., 2015; Wotton et al., 2016). In turn, they would have been eaten by native birds and tuatara Sphenodon punctatus (Hare et al., 2016). Rocks, crevices in substrate and trees, and vegetation with complex and/or divaricating structures are thought to provide refuges and opportunities for camouflage from predators (Lettink and Knox, 2011; Romijn et al., 2014; Lennon, 2019). Some New Zealand lizard species can co-exist with mammals, particularly at sites with enclosed microhabitats (Towns, 1996). Presumably, a network of tight spaces exclude larger-bodied mammals to provide safe microhabitats in which lizards can forage, thermoregulate and avoid predators (Vitt et al., 1998; Santos et al., 2008; Lennon, 2019).

\subsection{Study sites and species}

The Wellington region of New Zealand covers the lower half of the southernmost peninsula of the North Island (Te Upoko o te Ika a Māui). The region is ecologically 
diverse, and is inhabited by fifteen lizard species (McEwen, 1987; Romijn et al., 2012; Bell and Wiles, 2015). This number includes seven gecko (Diplodactylidae) species: Duvaucel's gecko Hoplodactylus duvaucelii, Ngahere gecko Mokopirirakau aff. granulatus 'southern North Island', barking gecko Naultinus punctatus, Pacific gecko Dactylocnemus pacificus, Raukawa gecko Woodworthia maculata, Minimac gecko W. aff. maculata 'Marlborough mini', and goldstripe gecko W. chrysosiretica (Romijn et al., 2012). There are eight extant skink species: northern grass skink Oligosoma polychroma, glossy brown skink O. zelandicum, northern spotted skink O. kokowai, McGregor's skink O. macgregori, copper skink O. aenea, ornate skink O. ornata, Newman's speckled skink O. newmani, and Whitaker's skink O. whitakeri (Romijn et al., 2012; Melzer et al., 2019). Two further species, the robust skink O. alani and speckled skink $O$. infrapunctatum, are no longer found in the Wellington region (Romijn et al., 2012; Melzer et al., 2019). Some of these species are found throughout the whole region, whereas others species such as O. zelandicum appear to be biogeographically restricted to one or two ecological districts (EDs; Table 1.4). However, some of the species currently restricted to certain EDs within Wellington would have been historically more widespread prior to the introduction of alien predators and habitat modification, for example W. chrysosiretica, O. macgregori, and O. whitakeri (Towns and Daugherty, 1994; Bell and Wiles, 2015).

To reduce the level of complexity that would be inherent in trying to evaluate habitat enhancement for all lizard species in the Wellington region, the study system was restricted to terrestrial and semi-arboreal lizard species inhabiting coastal habitats. The research for this dissertation was conducted across six study sites, representing a range of pest mammal pressure and terrestrial lizard habitats. The location of each of these sites is shown in Figure 1.4 and a description of each site is provided in Tables 1.2 and 1.3. The relevant life history characteristics of lizard species encountered during this study are detailed in Tables 1.4 and 1.5. A picture of each species is provided in Figure 1.5. 


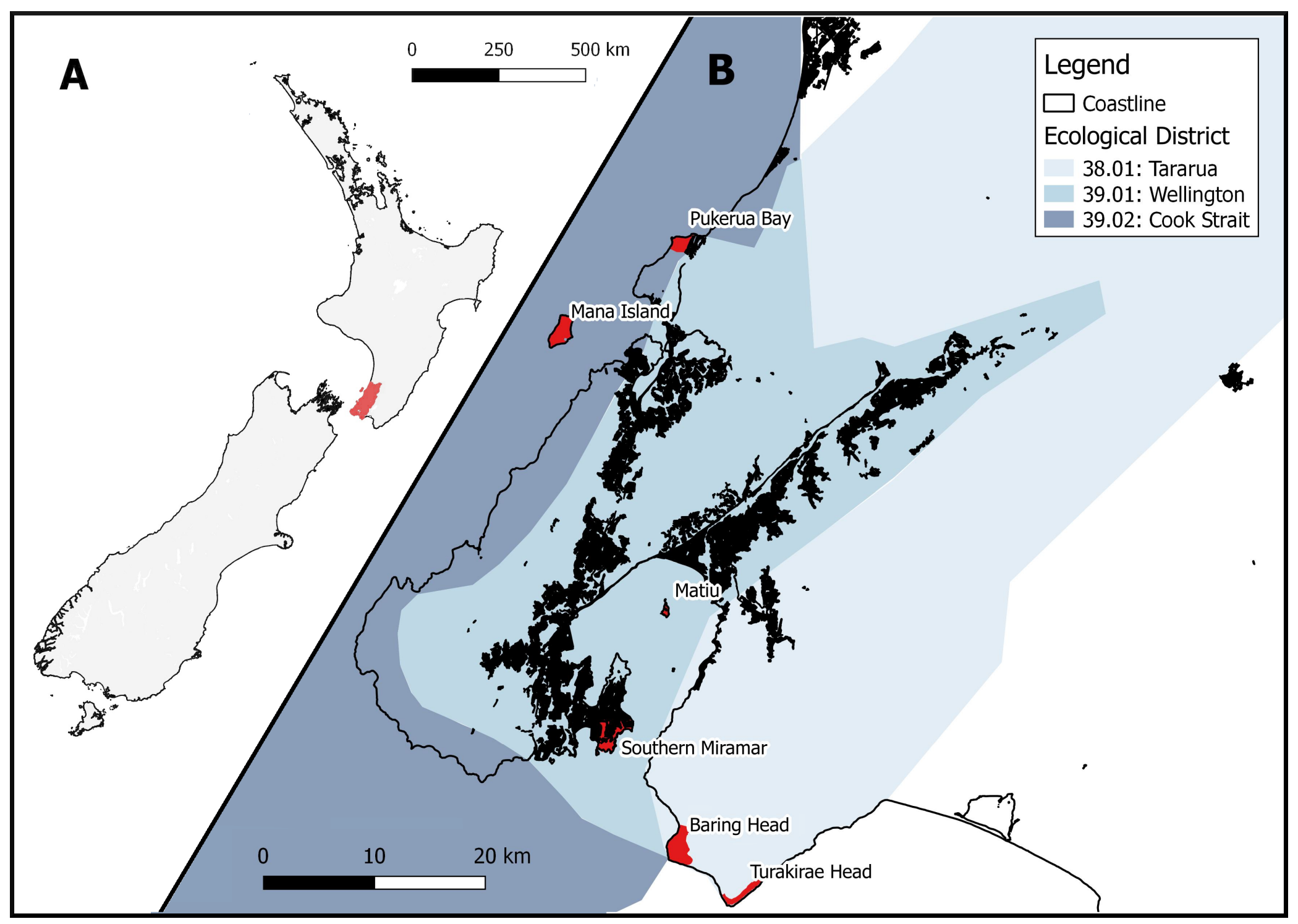

Figure 1.4: A. Location of study region (in red) on the North Island of New Zealand. B. Location of study sites (in red). Ecological District boundaries are drawn from maps in McEwen (1987). Urban and suburban infrastructure are indicated by black shading (cover classes 1 and 5, New Zealand Land Cover Database v. 4.1). Coastline data are from Land Information New Zealand. 
Table 1.2: Study sites. Where both Māori and English names exist for a site these are presented as: Māori name / English name. Use of the term 'rats' refers to Rattus rattus and $R$. norvegicus. Mustelids refers to ferrets Mustela furo, stoats M. erminea and weasels M. nivalis. Lizard species abbreviations are as follows. Geckos (Diplodactylidae): HD = Hoplodactylus duvaucelii, MS = Mokopirirakau aff. 'southern North Island', NP = Naultinus punctatus, WC = Woodworthia chrysosiretica, WM = W. maculata. Skinks: OA = Oligosoma aeneum, $\mathrm{ON}=$ O. newmani, $\mathrm{OK}=$ O. kokowai, $\mathrm{OM}=$ Oligosoma macgregori, $\mathrm{OO}=$ O. ornatum, $\mathrm{OP}=\mathrm{O}$. polychroma, $\mathrm{OW}=\mathrm{O}$. whitakeri, $\mathrm{OZ}=0$. zelandicum. ${ }^{*}$ indicates that the species has been translocated to the study site. ${ }^{A}$ indicates an arboreal lizard species and ${ }^{S}$ a semi-arboreal species. Species listed with no signifier in superscript are terrestrial. Sources: Bagnall (1975); Whitaker (1982); Newman (1994); Towns and Elliott (1996); Hoare et al. (2007a); Miskelly (2010); Romijn (2011); Romijn et al. (2012); van Winkel et al. (2018); Balls (2019); Bell (2019b); Herbert and Bell (2019); Melzer et al. (2019); Uys (2019), and A. Hulme-Moir, B. Tandy, and C. Giddy pers. comm.

\begin{tabular}{|c|c|c|c|}
\hline $\begin{array}{l}\text { Site name(s) } \\
\text { and area }\end{array}$ & Exotic mammals and control operations & Habitat overview & $\begin{array}{l}\text { Lizard species } \\
\text { present }\end{array}$ \\
\hline $\begin{array}{ll}\text { Mana } & \text { Island } \\
(217 \text { ha) } & \end{array}$ & $\begin{array}{l}\text { Mammal-free offshore island. Mice (Mus } \\
\text { musculus) are thought to have arrived in 1834, } \\
\text { and were eradicated between } 1989 \text { and } 1990 .\end{array}$ & $\begin{array}{l}\text { Patches of native shrubland in areas with } \\
\text { and without cobbles, rank grassland and } \\
\text { regenerating coastal broadleaf forest. Grazed } \\
\text { by cattle (Bos taurus) and sheep (Ovis ares) } \\
\text { between } 1832 \text { and } 1986 \text {. }\end{array}$ & $\begin{array}{l}\mathrm{OA}, \mathrm{OM}, \mathrm{OK}^{*}, \\
\mathrm{ON}^{*}, \mathrm{OP}, \mathrm{OZ}, \\
\mathrm{WM}^{S}, \\
\mathrm{HD}^{S *}{ }^{\prime}, \mathrm{WS}^{*}, \\
\mathrm{NP}^{* A},\end{array}$ \\
\hline $\begin{array}{l}\text { Matiu / Somes } \\
\text { Island ( } 24.8 \text { ha) }\end{array}$ & $\begin{array}{l}\text { Mammal-free offshore island. Ship rats }(R . \\
\text { rattus) eradicated in } 1989 .\end{array}$ & $\begin{array}{l}\text { Patches of grass- and flax/grass/shrub-land } \\
\text { and short regenerating coastal broadleaf } \\
\text { forest. Ungrazed (areas currently grazed by } \\
\text { sheep not surveyed). }\end{array}$ & $\begin{array}{l}\mathrm{OA}, \mathrm{OK}, \mathrm{OO}^{*}, \\
\mathrm{OP}, \quad \mathrm{WM}^{S} \\
\mathrm{MS}^{* A}, \mathrm{NP}^{* A}\end{array}$ \\
\hline $\begin{array}{l}\text { Te Motu } \\
\text { Kairangi/ } \\
\text { Miramar } \\
\text { Peninsula } \\
\text { (study area = } \\
474 \text { ha) }\end{array}$ & $\begin{array}{l}\text { Mice, rats, hedgehogs (Erinaceus europaeus) } \\
\text { and mustelids controlled by community } \\
\text { trapping on private and public land. Stoat } \\
\text { and rat eradication programme commenced } \\
\text { in July } 2019 \text {. }\end{array}$ & $\begin{array}{l}\text { Mosaic of patches of short regenerating } \\
\text { mahoe forest, gorse scrub, mixed coastal } \\
\text { shrubland, suburban infrastructure, } \\
\text { grassland and cobble beach. Ungrazed, } \\
\text { but grass mown in places, and rabbits } \\
\text { (Oryctolagus cuniculus) present. Possums } \\
\text { Trichosurus vulpecula eradicated in } 2006 .\end{array}$ & $\begin{array}{l}\mathrm{OA}, \mathrm{OP}, \mathrm{WM}^{S}, \\
\mathrm{NP}^{A}\end{array}$ \\
\hline
\end{tabular}


Table 1.3: Study sites continued.

\begin{tabular}{|c|c|c|c|}
\hline $\begin{array}{l}\text { Site name(s) } \\
\text { and area }\end{array}$ & Exotic mammals and control operations & Habitat overview & $\begin{array}{l}\text { Lizard species } \\
\text { present }\end{array}$ \\
\hline $\begin{array}{l}\text { Pukerua Bay } \\
\text { Scientific } \\
\text { Reserve } \\
\text { (12.3 ha) }\end{array}$ & $\begin{array}{l}\text { Weasels, stoats, rats, mice, and hedgehogs } \\
\text { present. Cats (Felis catus) probably present. } \\
\text { Rodenticide used in 1998-1999 and 2005- } \\
\text { 2010. Mustelid control (DOC 200/250 traps) } \\
\text { increased in intensity between 2004-2010, and } \\
\text { has continued until present. Feral goats } \\
\text { (Capra hircus) controlled from } 1998 \text { onwards. } \\
\text { Rabbits present. }\end{array}$ & $\begin{array}{l}\text { Formerly grazed coastal escarpment with } \\
\text { screes, grey scrub and patches of regenerating } \\
\text { forest. Fenced to exclude stock in } 1987 \text {. }\end{array}$ & $\begin{array}{l}\text { OA, OP, } \\
\text { OW, } W^{S}\end{array}$ \\
\hline $\begin{array}{l}\text { Ōrua-Pouanui/ } \\
\text { Baring Head } \\
(284 \mathrm{ha})\end{array}$ & $\begin{array}{l}\text { Mustelids, cats, rats, mice and hedgehogs } \\
\text { present. Possums are controlled with } \\
\text { traps and bait (brodifacoum). Trapping for } \\
\text { mustelids, cats and hedgehogs commenced } \\
\text { in } 2013 \text {. Mouse control using brodifacoum } \\
\text { in a c. } 12 \text { ha area of the Wainuiomata river } \\
\text { escarpment commenced in 2016. Rabbits, } \\
\text { hares (Lepus europaeus), and feral goats are } \\
\text { also controlled. }\end{array}$ & $\begin{array}{l}\text { Heterogeneous with patches of pasture } \\
\text { grassland and native shrubland with and } \\
\text { without rock cobbles or screes. Intensively } \\
\text { grazed by sheep and cattle in parts. }\end{array}$ & $\begin{array}{l}\text { OA, OK, OP, } \\
\text { WM }^{S}\end{array}$ \\
\hline $\begin{array}{l}\text { Turakirae } \\
\text { Head Scientific } \\
\text { Reserve } \quad(124 \\
\text { ha) }\end{array}$ & $\begin{array}{l}\text { Mustelids, cats, hedgehogs, rats, possums } \\
\text { and mice present. Rabbits and hares likely } \\
\text { present. No control except for a } 1080 \text { (sodium } \\
\text { fluoroacetate) drop in June } 2019 .\end{array}$ & $\begin{array}{l}\text { Mosaic of grey scrub and swampy flaxland } \\
\text { interspersed with rock cobbles and fractured } \\
\text { boulders. Grazed by cattle and sheep } \\
\text { since the late } 1840 \text { s. Currently low-intensity } \\
\text { grazing by domestic sheep and horses, and } \\
\text { feral goats. }\end{array}$ & $\begin{array}{l}\text { OA, } \\
W^{S}\end{array}$ \\
\hline
\end{tabular}


Table 1.4: Life history characteristics of lizard species in this study. Status refers to the conservation status of the species. Sources: Barwick (1959); Whitaker (1982); Anastasiadis and Whitaker (1987); Porter (1987); Towns and Elliott (1996); Cree (1994); Newman (1994); Spencer et al. (1998); Hoare et al. (2007a); Melgren (2012); Bell and Wiles (2015); Hitchmough et al. (2016a); Melzer et al. (2017); van Winkel et al. (2018). Abbreviations: SVL = snout-vent length, Unk = unknown, EDs = ecological districts within the Wellington Region as follows: Tararua 38.01, Wellington 39.01, Cook Strait 39.02 (McEwen, 1987).

\begin{tabular}{|c|c|c|c|c|c|c|c|}
\hline Species & $\begin{array}{l}\text { Max } \\
\text { SVL } \\
(\mathrm{mm})\end{array}$ & Activity & "Habitat and EDs & Status & $\begin{array}{l}\text { Maturity } \\
\text { (yr) }\end{array}$ & $\begin{array}{l}\text { Mean (range) } \\
\text { litter size }\end{array}$ & $\begin{array}{l}\text { Max } \\
\text { known } \\
\text { longevity } \\
(y r) \\
\end{array}$ \\
\hline $\begin{array}{l}\text { Glossy brown } \\
\text { skink Oligosoma } \\
\text { zelandicum }\end{array}$ & 75 & Diurnal & $\begin{array}{l}\text { Generalist, but prefers } \\
\text { damp shaded sites. 39.01, } \\
\text { 39.02. }\end{array}$ & $\begin{array}{l}\text { At } \\
\text { Risk } \\
\text { (Declining) }\end{array}$ & Unk & $5.29(1-7)$ & Unk \\
\hline $\begin{array}{l}\text { Copper skink } \\
\text { O. aeneum }\end{array}$ & 76 & $\begin{array}{l}\text { Diurnal, } \\
\text { occasionally } \\
\text { crepuscular. } \\
\text { Cryptozoic. }\end{array}$ & $\begin{array}{l}\text { Generalist, but appears } \\
\text { to be excluded from tall } \\
\text { forest in the Wellington } \\
\text { region. 38.01, 39.01, 39.02. }\end{array}$ & $\begin{array}{l}\text { Not } \\
\text { Threatened }\end{array}$ & $2-3$ & $2.17(1-7)$ & Unk \\
\hline $\begin{array}{l}\text { Northern } \\
\text { grass skink } \\
\text { O. polychroma }\end{array}$ & 80 & Diurnal & $\begin{array}{l}\text { Generalist in habitats with } \\
\text { an open or short canopy } \\
\text { (not found in forest). 38.01, } \\
39.01,39.02 \text {. }\end{array}$ & $\begin{array}{l}\text { Not } \\
\text { Threatened }\end{array}$ & $1.5-2$ & 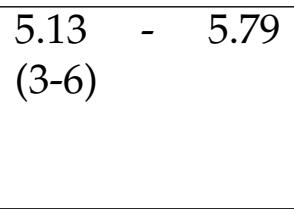 & $\begin{array}{l}\text { 3-4 (wild), } \\
6 \text { (captive) }\end{array}$ \\
\hline $\begin{array}{l}\text { Goldstripe } \\
\text { gecko } \\
\text { Woodworthia } \\
\text { chrysosiretica }\end{array}$ & 80 & Cathemeral & $\begin{array}{l}\text { Forest, scrub and flaxland, } \\
\text { preference for strap-leaved } \\
\text { foliage. } 39.02 \text {. }\end{array}$ & $\begin{array}{l}\text { At } \\
\text { Risk (Relict) }\end{array}$ & $4-5$ & $(1-2)$ & Unk \\
\hline $\begin{array}{l}\text { Raukawa gecko } \\
\text { W. maculata }\end{array}$ & 82 & $\begin{array}{l}\text { Nocturnal, } \\
\text { but sun basks }\end{array}$ & $\begin{array}{l}\text { Generalist. } \\
\text { Often associated with } \\
\text { rock. } 38.01,39.01,39.02 .\end{array}$ & $\begin{array}{l}\text { Not } \\
\text { Threatened }\end{array}$ & $3-4$ & $1.98(1-2)$ & $\begin{array}{l}27 \text { (wild), } \\
37 \text { (captive) }\end{array}$ \\
\hline
\end{tabular}


Table 1.5: Life history characteristics of lizard species in this study continued.

\begin{tabular}{|c|c|c|c|c|c|c|c|}
\hline Species & $\begin{array}{l}\text { Max } \\
\text { SVL } \\
\text { (mm) }\end{array}$ & Activity & Habitat and EDs & Status & $\begin{array}{l}\text { Maturity } \\
\text { (yr) }\end{array}$ & $\begin{array}{l}\text { Mean (range) } \\
\text { litter size }\end{array}$ & $\begin{array}{l}\text { Max } \\
\text { known } \\
\text { longevity } \\
\text { (yr) }\end{array}$ \\
\hline $\begin{array}{l}\text { Northern } \\
\text { spotted skink } \\
\text { O. kokowai }\end{array}$ & 92 & Diurnal & $\begin{array}{l}\text { Generalist in habitats with } \\
\text { an open or short canopy. } \\
38.01,39.01,39.02 \text {. }\end{array}$ & $\begin{array}{l}\text { At } \\
\text { Risk (Relict) }\end{array}$ & Unk & $3.82(1-4)$ & 8-14 (wild) \\
\hline $\begin{array}{l}\text { Whitaker's } \\
\text { skink } \\
\text { O. whitakeri }\end{array}$ & 101 & Nocturnal & $\begin{array}{l}\text { Coastal forest and scrub. } \\
39.02 \text {. }\end{array}$ & $\begin{array}{l}\text { Threatened } \\
\text { (Nationally } \\
\text { Endangered) }\end{array}$ & $5-8$ & $\begin{array}{l}(1-4) . \\
\text { Biennial } \\
\text { reproduction. }\end{array}$ & $\begin{array}{l}18 \text { (wild), } \\
50 \text { (captive) }\end{array}$ \\
\hline $\begin{array}{l}\text { MacGregor's } \\
\text { skink } \\
\text { O. macgregori }\end{array}$ & 114 & $\begin{array}{l}\text { Nocturnal } \\
\text { crepuscular }\end{array}$ & $\begin{array}{l}\text { - Coastal forest, rock } \\
\text { / cobble shorelines, } \\
\text { herbfield, grassland, } \\
\text { scrub. 39.02. }\end{array}$ & $\begin{array}{l}\text { At } \\
\text { Risk } \\
\text { (Recovering) }\end{array}$ & $4-5$ & 2 & Unk \\
\hline
\end{tabular}




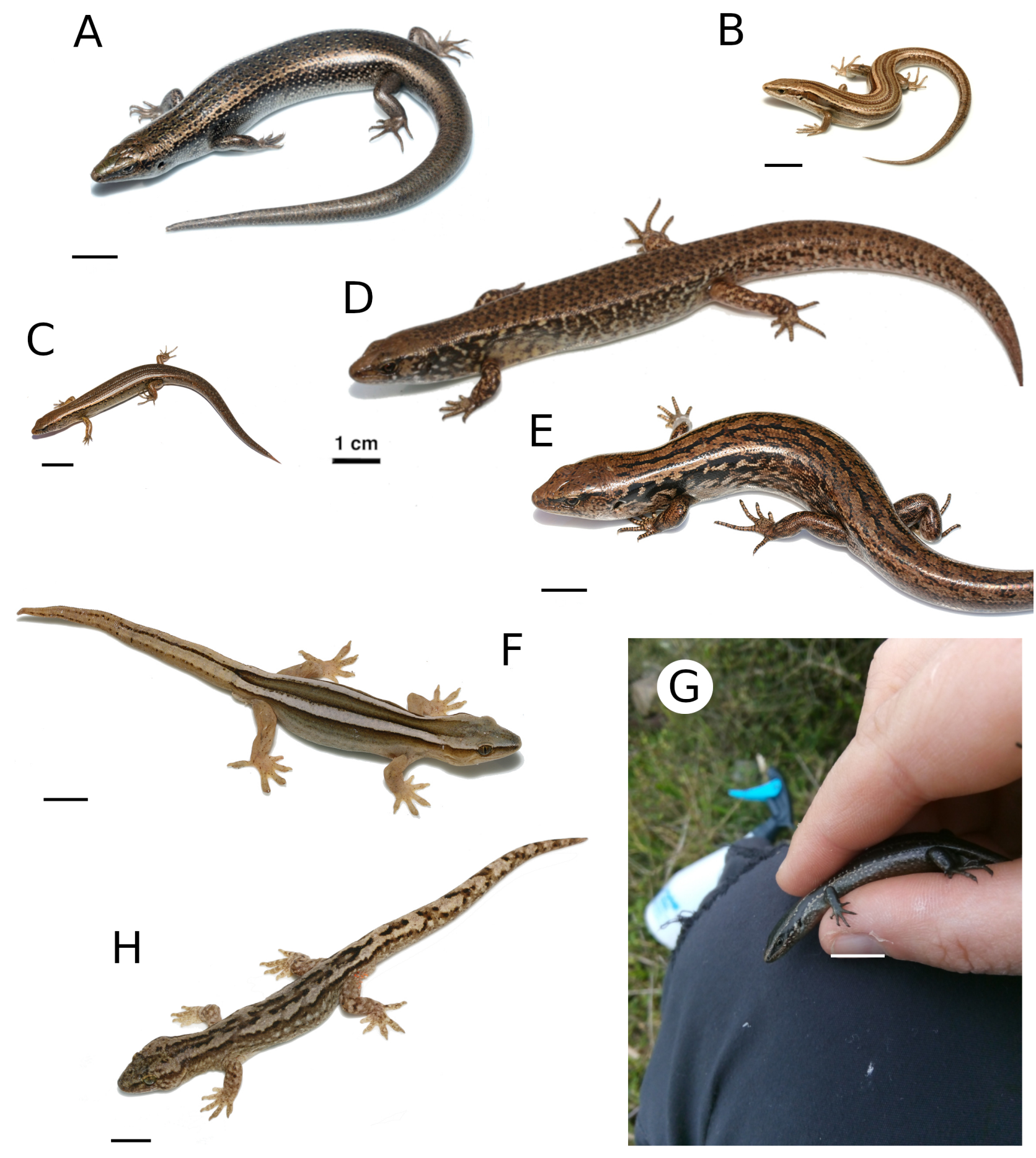

Figure 1.5: Study species. A. Northern spotted skink Oligosoma kokowai. B. northern grass skink O. polychroma. C. copper skink O. aeneum. D. Whitaker's skink O. whitakeri. E. McGregor's skink O. macgregori. F. Goldstripe gecko Woodworthia chrysosiretica. G. Glossy brown skink $O$. zelandicum. H. Raukawa gecko $W$. maculata. Each scale bar is $1 \mathrm{~cm}$, and lizards are shown roughly to scale. All photographs (except for G) by Trent Bell. 


\subsection{Key questions and thesis outline}

I aimed to evaluate whether habitat enhancement is a viable strategy for conserving New Zealand's endemic lizards, using terrestrial lizard communities in coastal areas of the Wellington region as a study system. Because the mechanics of two key threats to this fauna, habitat loss and invasive species, are still not fully understood, it was important to also ask questions that would improve understanding of these issues.

Therefore, the overarching aim was addressed by asking four main questions:

1. What habitat enhancement strategies are available for reptiles, and have they produced successful conservation outcomes?

2. How do habitat characteristics affect populations and communities of endemic New Zealand lizards?

3. How does the presence of invasive mammals affect populations and communities of endemic New Zealand lizards over intermediate to long-term time frames?

4. Can a habitat enhancement strategy based on knowledge of New Zealand endemic lizard species' habitat preferences produce positive conservation outcomes in the presence of invasive mammals?

This thesis is structured as a series of manuscripts for separate publication in peer-reviewed journals. Some information will therefore be repeated to provide adequate context for each chapter to be read as a stand-alone manuscript. However, formatting the thesis in this manner carries the benefit of facilitating publication.

In Chapter 2, I review the global literature on habitat enhancement for reptiles to describe the range of approaches that have been used. I perform a meta-analysis on the information collated from this literature to assess (1) whether habitat enhancement successfully produced positive conservation outcomes for reptile populations, and (2) whether any aspects of the enhancement programme affected success. No standard framework was available for assessing wildlife conservation outcomes from habitat enhancement projects. Therefore, I adapted an existing framework for assessment of translocation success in long-lived herpetofauna (Miller et al. (2014)) for evaluation of enhancement outcomes. In Chapter 3, I examine correlations between the relative abundance and estimated occupancy of terrestrial lizard species and patch-scale habitat characteristics in mammal-invaded and mammal-free coastal environments. Neither the attributes characterising high-quality lizard habitat, nor the composition of lizard species assemblages, is well-understood in coastal environments of New Zealand. This is in part due to the potentially confounding effects of habitat attributes on detection probability, which I seek to address in this chapter by application of hierarchical modelling. Chapter 4 
builds on the findings of Chapter 3 by examining the intermediate- to long-term effects of co-existence with invasive mammals on terrestrial lizard communities. I was also able to examine the correlation of habitat attributes with temporal changes in local abundance and site extinction/colonisation rates over a six-year time period using data made available from a lizard and mammal monitoring programme at Baring Head by the Greater Wellington Regional Council. In Chapter 5, I conduct a before-after-control-impact (BACI) habitat enhancement experiment on lizard communities inhabiting a mammal-invaded area of the Wellington mainland. The evaluation framework developed in Chapter 2 was used to assess the success of enhancement for the three lizard species resident at this site. My main findings are synthesized in Chapter 6 to address my two thesis questions. I discuss whether habitat enhancement is a suitable strategy for conservation of New Zealand's lizard fauna in the context of mammal invasion, and potential applications of this research for designing an effective landscape-level conservation strategy.

\subsubsection{Notes on presentation}

Bilingualism in place names. Several places in New Zealand are named in both Te Reo Māori and English. Where names in both languages exist, the first mention of a place in a chapter is in the format: Māori name / English name, then referred to by the most commonly used name only throughout the rest of the text.

Taxonomy. There has been an upswell of taxonomic research completed on the New Zealand lizards, with several new species being described as a result of new discoveries and revision of former species complexes. As such, the common and scientific names of New Zealand's endemic lizards has changed rapidly over the last 20 years. Throughout this thesis, I endeavour to use the most up-to-date taxonomic classifications and common names for species, following Liggins et al. (2008); Chapple et al. (2009, 2011); Nielsen et al. (2011); Bell (2014); Hitchmough et al. (2016a); Melzer et al. (2017); van Winkel et al. (2018) and Melzer et al. (2019). As a result, species and common names given in the text are not necessarily consistent with those used in the cited literature. This taxonomic note also applies to some of New Zealand's plant species, such as the kānuka (Kunzea) species complex which has been recently split and the now-defunct Hebe genus which has been placed back into the Veronica genus (Garnock-Jones et al., 2007; De Lange, 2014).

Size of ecological scales for the study system. In this thesis, populations and communities are defined at the patch-level scale (0.008 - 0.01 ha plots spaced at least $100 \mathrm{~m}$ apart). This assumes independence from other lizard populations within short time frames (e.g. 2-3 weeks) based on prior knowledge of the movement or home range sizes of the study species or closely related species, or methodology used in previous studies on lizards in New Zealand (Porter, 1982; Whitaker, 1982; Bannock, 1998; Lettink et al., 2010). Metapopulations and metacommunities are defined as spanning across the site-level scale 
(12.3 - $300 \mathrm{ha}$, spaced at least $5 \mathrm{~km}$ apart and subject to different management regimes). For comparison, in a study on Australian reptile communities, landscapes were divided into three nested scales: landscape (100's - 1000's of hectares), patch scale (1-100's hectares), and local scale ( $<1$ ha) (Garden et al., 2010).

\subsection{Contributions to research}

All study designs, data collection, analysis and writing were conducted by Sarah Herbert with advice from supervisors Nicola Nelson and Stephen Hartley, unless stated otherwise below. I acknowledge the following contributions to this thesis:

Jo Monks and James Reardon from the New Zealand Department of Conservation (DOC) advised on the study design and site selection for Chapter 5. The lizard pitfall capture per unit effort data for Pukerua Bay collected between 1984 and 2018 were provided by Lynn Adams from DOC and unpublished reports for the 2015-2018 seasons were shared by Don Newman. These data were collected by numerous staff, contractors, and volunteers for DOC and Friends of Mana Island. The lizard pitfall trapping and small mammal monitoring data data collected between 2012 and 2018 from Baring Head used in Chapter 4 were provided by Owen Spearpont, Roger Uys and Philippa Crisp from the Greater Wellington Regional Council (GWRC). The mammal monitoring data is collected by Friends of Baring Head and reported by Roger Uys from GWRC (see Uys (2019)). The lizard data set hails from a multispecies lizard monitoring programme initially designed by Trent Bell and me in 2012 as an EcoGecko Consultants Ltd (EcoGecko) project contracted by the GWRC. This programme has been jointly run between 2012 and 2019 by either EcoGecko or Wildland Consultants and the GWRC with significant input from Owen Spearpoint, Philippa Crisp, Trent Bell, Ayla Wiles, Sabine Melzer, and me. Owen Spearpoint collected the habitat data for the Baring Head lizard monitoring sites. Single-season repeated count and occupancy data from the lizard monitoring programme has undergone previous analysis (Herbert and Bell, 2012; Herbert et al., 2013a, 2014a; Wiles et al., 2015; Wiles, 2016; Herbert and Bell, 2018, 2019). The analyses performed in Chapter 4 do not duplicate, but do build on, this previous work.

\subsection{Permits and ethics}

This research was carried out with approval from the Victoria University of Wellington Animal Ethics Committee (permit numbers 22347 and 27041) and the New Zealand Department of Conservation (permit number 50568-FAU). Research conducted on council-administered land was carried out with permission from the Greater Wellington Regional Council (Low Impact Collecting Permits issued on 08/04/2017 and 20/09/2018) or from Wellington City Council (Collection and Research Permit issued on 06/12/2016). 


\section{Chapter 2}

\section{Habitat restoration and reconciliation for reptile species conservation: a global meta-analysis}

\subsection{Introduction}

Anthropogenic habitat loss is regarded as the most severe threat to global biodiversity (Tilman et al., 1994; Hanski, 2011). Therefore, its remediation presents a pressing challenge for conservationists. There are several reasons why strategies that maximise the area of inhabitable habitat for a species can decrease its extinction risk. Increasing the amount of habitat available supports more abundant populations that usually have a lower risk of extinction (the 'small population scenario'; Connor and McCoy (1979); Hanski (1999)). Greater abundance is positively correlated with wider distribution (Lawton, 1993; Hanski, 1999; MacKenzie and Nichols, 2004). Species that cover a large range usually occupy a greater heterogeneity of habitats than their narrowly distributed counterparts. Because differing habitat types display varied responses to a perturbation, the more habitat types are inhabited by a species, the more insured it is against stochastic events (the 'changing environment scenario'; Goodman (1987b); Hanski (1999)). However, populations of a species can also fluctuate independently of habitat heterogeneity. Therefore, in species where individuals mix frequently between populations, spatially dependent processes such as dispersal are important for maintaining the species across its range (the 'metapopulation scenario'; Holt (1992); Hanski (1999)). An example is the rescue effect, where sink or extinct populations are recolonised by neighbouring source populations (Hanski, 1999). In general, extinction of sedentary species with small home ranges is more likely to be driven by small population and changing environment scenarios, whereas extinction of species with a high dispersal capability or large home range size is more likely to be driven by the metapopulation scenario (Hanski, 1999). Habitat fragmentation directly 
affects metapopulation processes, whereas loss of total area and degradation of habitat more directly affects species via the small population and changing environment scenarios (Fahrig, 1997; Hanski, 1999; Fahrig, 2003).

Species are often simultaneously subjected to the multiple mechanisms of habitat loss, degradation, and fragmentation triggering complex interactions between population persistence mechanisms across a continuum of localised to broad spatial scales (Fahrig, 2003; Hanski, 2011). Ultimately, remediation of habitat loss to prevent species extinction probably needs to occur at multiple spatial scales. There are currently three distinct strategies for halting habitat loss: reservation, restoration and reconciliation. Reservation uses legal mechanisms to protect relatively intact natural habitats from human impacts (Kremen, 2015). Restoration seeks to assist the recovery of a natural or semi-natural ecosystem that has been degraded, damaged or destroyed (Dobson et al., 1997; SER, 2004; Mcdonald et al., 2016). Reconciliation seeks to increase the capacity of modified environments to support biodiversity by imposing a new direction or form upon it (Rosenzweig, 2003). Applied examples focus on maximising the compatibility of anthropogenic land uses with wildlife habitat requirements, and include fauna-friendly garden landscaping, ecological approaches to agriculture, and installation of green roofs and walls in built environments (Bailey et al., 2006; Rey Benayas et al., 2008; Pilliod and Wind, 2008; Francis and Lorimer, 2011; Linares and Eterovick, 2013; Ferguson and Lovell, 2014; Rosenzweig, 2016). It is possible that all three strategies have complementary roles to play in halting habitat loss (Hanski, 2011; Hobbs et al., 2014). Reservation alone has become insufficient due to the current extent of degradation and the rate at which habitat loss continues (Mcdonald et al., 2016). Additionally, some habitats have been altered too drastically, or are too important for human use, to be feasibly reverted to a historical state, for example; urban, suburban, and certain agricultural landscapes (Rosenzweig, 2003; Hobbs et al., 2014). In this chapter, I focus on how habitats can be manipulated to produce positive outcomes for fauna. Because restoration and reconciliation both seek to improve habitat for species, I hereafter refer to both strategies as 'habitat enhancement'.

Effective habitat enhancement may be of particular importance for reptile conservation because this fauna is extremely sensitive to habitat change, in fact, more so than all other vertebrate taxa except amphibians (White et al., 1997; Ribeiro et al., 2009). This is due to the ecological and physiological constraints imposed by ectothermy coupled with relatively low dispersal capability and small home ranges (Huey, 1982). While their relatively sedentary lifestyles compared to other vertebrates suggests that reptile species persistence would be maintained mostly under the small population and changing environment scenarios, there is evidence that metapopulation dynamics are important (Berry et al., 2005; Gebauer et al., 2013; Nelson-Tunley et al., 2016). Therefore management of patch size and quality, the area and heterogeneity of total suitable habitat, and habitat connectivity are all likely to be important components of habitat management for reptiles. There is some 
evidence to suggest that habitat management can benefit reptiles; for instance, reptiles in semi-arid zones in Australia responded more favourably to site-scale habitat quality than to landscape context, suggesting that reptiles would benefit from enhancing habitat quality at a site (Bruton et al., 2016). Many studies examining reptile use of microhabitat conclude that protection and addition of key microhabitats would benefit the conservation of the study species (Amo et al., 2007; Lagarde et al., 2012; Moulherat et al., 2014; Filazzola et al., 2017). The potential benefit to reptiles from habitat enhancement is thought to be especially important at sites where key resources required by reptiles are scarce, for example in arid or degraded landscapes (Lagarde et al., 2012; Filazzola et al., 2017). Indeed, some of the traits that make reptiles susceptible to habitat loss may also make them good candidates for conservation by habitat enhancement because they can (1) be expected to remain in habitat patches that receive conservation attention, and (2) potentially benefit from interventions covering smaller land areas than needed for species with large home ranges. In addition, the low metabolic rates typical among reptiles mean they can potentially exist in high densities in high-quality habitats, as evidenced in some wildlife reserves (Cheke, 1984; Markwell, 1999; Bullock et al., 2002).

The best habitat features to target for enhancement are probably those that provide key habitat 'services' for reptiles, that is: opportunities for thermoregulation, food availability, and predator avoidance (Vitt et al., 1998; Santos et al., 2008). Microhabitat heterogeneity, environmental refugia and habitat complexity appear to be important structural features for delivery of these services. For example, individual grass snakes (Natrix natrix) in cool temperate environments frequently move between microhabitats in the course of a day to maintain an optimal body temperature during their active season and hibernate in winter, thus require sunny, shaded and refuge microhabitats in close proximity (Isaac and Gregory, 2004). Many oviparous species require distinct habitats for foraging and egg incubation, for example aquatic turtles and snakes lay eggs on land (Bonnet et al., 2009; Buhlmann and Osborn, 2011). Other species, such as the Komodo dragon (Varanus komodoensis), display niche partitioning between juveniles and adults thus require both arboreal and terrestrial habitats (Ciofi et al., 2007). Habitat complexity is important for species that rely on crypsis for predator avoidance or prey ambush. For example, Pygmy blue tongued skinks (Tiliqua adelaidensis) use burrows for ambush of prey and foraging success of Shedao pit vipers (Gloydius shedaoensis) can be improved by canopy manipulation (Shine et al., 2002; Milne et al., 2003b). Fleeing from perceived predators at high speeds in areas lacking cover provided by vegetation or loose rock decreased the body condition of male Iberian rock lizards (Iberolata cyreni) (Amo et al., 2007). Refuges are of primary importance for avoiding lethal environmental conditions and predators. For example, Laticaudid sea snakes favour humid terrestrial refuges to limit evaporative water loss and squamates in cold temperate environments retreat underground or into deep rock crevices to avoid lethal freezing (Bonnet et al., 2009). The arid-zone tortoise Testudo graeca soussensis relies on shade 
provided by large bushes and gopher burrows to avoid lethal overheating to such a degree that refuge scarcity increases the fragmentation and isolation of subpopulations (Lagarde et al., 2012; Moulherat et al., 2014). Use of refuges for predator avoidance appears to be important for the Australian rock-dwelling nocturnal gecko Amalosia [Oedura] lesueurii; individuals favoured retreats that lacked signs of predator presence over warmth (Downes and Shine, 1998). Lack of shelter can also produce sub-lethal negative physiological consequences, for example, the compounded effects of a lack of refugia and cold ambient air temperatures resulted in increased stress and decreased assimilation of food in Aspic vipers Vipera aspis (Bonnet et al., 2013). In addition, use of retreats may confer or reflect social advantages to individuals; for example, in territorial species, smaller individuals are often displaced from thermally optimal and predator-free retreat sites by larger individuals (Downes and Shine, 1998), but in more gregarious species, family groups or unrelated individuals of a range of sizes may share retreat sites (Todd, 2005; Hare and Hoare, 2005; Gardner et al., 2007). It is important to note that the relative need for each 'service' provided to reptiles by habitat varies between populations and species, and microhabitat selection by individuals can be viewed as a trade-off between different environmental pressures (Howard et al., 2003).

While habitat enhancement is a potentially promising tool for reptile conservation, no attempt has been made to review the scope of techniques trialled or evaluate their effectiveness across the global literature. Previous reviews were limited to a review of habitat manipulation techniques for a specific taxa or region (specifically, snakes (Shoemaker, 2007; Shoemaker et al., 2009) and Britain (Edgar et al., 2010)). This reflects a conservation evidence problem that extends beyond the Reptilia; efforts to restore habitat are rarely matched by efforts to evaluate the effects of those restoration attempts, and a cohesive framework for evaluating restoration success for species conservation is lacking (Croak et al., 2013).

To address these knowledge gaps, the global published and grey literature on habitat enhancement for reptile species was surveyed, and the range of habitat enhancement techniques that have been tried for reptile conservation documented. A stage-based framework was developed for evaluating success rates of enhancement attempts for species conservation. Success or failure in the related disciplines of translocation biology and restoration ecology are both evaluated using similar criteria: 'establishment of a self-sustaining population', and 'creation of a self-supporting ecosystem that is resilient to perturbation without further assistance', respectively (Griffith et al., 1989; SER, 2004; Fischer and Lindenmayer, 2000). However given that many species are long-lived, achievement of a self-sustaining population (or ecosystem) may take decades, or centuries, to become evident which is unhelpful in an adaptive management framework (Germano and Bishop, 2009; Miller et al., 2014). This conundrum in reptile translocation biology has led to the development of a series of time-bound criteria for outcome evaluation (Miller 
et al., 2014). The series is comprised of increasingly longer-term criteria that are considered crucial for a translocated population to have achieved in order to ultimately become self-sustaining, somewhat similar to the Society for Ecological Restoration's five-star system for evaluating ecological restoration (Miller et al., 2014; Mcdonald et al., 2016). These criteria proved to be useful in evaluating the reptile translocation literature and have been successfully applied to post-translocation monitoring (Miller et al., 2014; Bell and Herbert, 2017b). Therefore, I modified this framework to construct a stage-based set of criteria based on the range of outcome measurements used by studies in the reptile habitat enhancement literature (Table 2.1). Briefly, these were: (1) habitat use, (2) evidence of reproduction, (3) improvement in demographic parameter(s), and (4) evidence of a self-sustaining population.

The stage-base assessment framework was applied to the reptile habitat enhancement dataset in order to examine: (1) how successful was enhancement when assessed using the proposed stage-based set of criteria; and (2) what factors influence success for reptile species conservation? It was hypothesised that the proportion of successful 'cases' would be constant across all stages of the proposed evaluation criteria. Here, a 'case' was defined as a single enhancement (or package of enhancements) applied to a reptile population that was spatially independent of all other conspecific populations in the dataset. However, I expected that the number of assessable cases against each stage would decrease linearly as one moved through Stage 1 to Stage 4, because evaluation against each additional stage required more intensive data collection. I also hypothesised that enhancement success would depend upon the target species' traits, the study design used for data collection, the enhancement type, and the purpose for doing the habitat enhancement.

\subsection{Methods}

\subsubsection{Literature search}

Published and grey literature documenting the outcomes of habitat enhancement on reptile species were sourced between 28 June 2017 and 12 June 2018. Publicly-available case studies were obtained by performing searches in the following databases: Web of Science, Scopus, Google Scholar, and ProQuest Dissertations \& Theses Global, with the keywords: habitat* AND enhance* OR restor* OR reconcil ${ }^{*}$ OR artificial refug* AND reptile* OR lizard* OR snake* OR tortoise* OR turtle* OR tuatara* OR crocodil* OR amphisbaeni*. Depending on the number of records returned from a search, and how quickly their relevance dropped off, the first 20 to 220 records returned were examined. Additional citation searches (publication's reference list; citations of publication in Scopus) were 
Table 2.1: Proposed time-bound standardized definitions (i.e. 'Stages') of success for evaluating habitat enhancement outcomes for a reptile species, based on translocation success criteria developed by Miller et al. (2014).

\begin{tabular}{|c|c|c|}
\hline Stage & Indicators & Monitoring requirements \\
\hline $\begin{array}{l}1 . \\
\text { Habitat use }\end{array}$ & $\begin{array}{l}\text { Species detected within } \\
\text { enhanced habitat patch(es). }\end{array}$ & $\begin{array}{l}\text { At minimum, monitor enhanced } \\
\text { sites(s) for species occurrence. Pre- } \\
\text { enhancement monitoring required } \\
\text { to detect colonisation. Survey for } \\
\text { species at reference site(s) would } \\
\text { be useful for evaluating occupancy } \\
\text { rates against background and/or } \\
\text { desired levels. }\end{array}$ \\
\hline $\begin{array}{l}2 . \\
\text { Evidence } \\
\text { of } \\
\text { reproduction }\end{array}$ & $\begin{array}{l}\text { Detection of animals born or } \\
\text { hatched out in the enhanced } \\
\text { habitat patch(es). }\end{array}$ & $\begin{array}{l}\text { Monitor enhanced site(s) for } \\
\text { occurrence of neonates/hatchlings, } \\
\text { nests, and/or pregnant/gravid } \\
\text { females. }\end{array}$ \\
\hline $\begin{array}{l}3 . \\
\text { Improvement } \\
\text { in demographic } \\
\text { parameter(s) }\end{array}$ & $\begin{array}{l}\text { In the enhanced habitat } \\
\text { patch(es), evidence of either } \\
\text { (1) sustained population growth } \\
\text { (i.e. } \lambda>1.0 \text { or } r>0.0 \text { ), or (2) } \\
\text { increased abundance, survival } \\
\text { and/or reproductive output } \\
\text { relative to baseline and/or } \\
\text { reference sites. }\end{array}$ & $\begin{array}{l}\text { (1) Repeated post-enhancement } \\
\text { monitoring of estimated or relative } \\
\text { abundance for a sufficient time } \\
\text { period to detect a trend if there } \\
\text { is one, or (2) Post-enhancement } \\
\text { monitoring of marked individuals } \\
\text { or relative abundance in enhanced } \\
\text { site(s) and comparison with } \\
\text { monitoring data collected over the } \\
\text { same period from reference site(s) } \\
\text { and/or pre-enhancement data. }\end{array}$ \\
\hline $\begin{array}{l}4 . \\
\text { Self-sustaining } \\
\text { population }\end{array}$ & $\begin{array}{l}\text { In the enhanced patch(es); (1) } \\
\text { consistently high number of } \\
\text { individuals caught in each } \\
\text { monitoring period (i.e. more } \\
\text { than encountered in stage 1); (2) } \\
\text { immature individuals regularly } \\
\text { observed; (3) negligible } \\
\text { probability of population } \\
\text { extinction, or population } \\
\text { trend spanning multiple } \\
\text { generations, is consistently } \\
\text { stable or increasing; and (4) } \\
\text { same or more individuals } \\
\text { emigrate than immigrate. }\end{array}$ & $\begin{array}{l}\text { Post-enhancement monitoring of } \\
\text { estimated or relative abundance } \\
\text { spanning multiple generations. } \\
\text { Or, sufficient monitoring of } \\
\text { marked individuals to allow } \\
\text { robust estimation of recruitment, } \\
\text { survival, immigration and } \\
\text { emigration (at least) for population } \\
\text { viability analysis. }\end{array}$ \\
\hline
\end{tabular}


performed on particularly relevant or impactful studies, including Shoemaker (2007), Shoemaker et al. (2009), Lettink et al. (2010), and Grillet et al. (2010). Paper titles appearing in the journals: Environmental Management, Asian Herpetological Research, Conservation Evidence, Restoration Ecology, Herpetological Review, Journal of Herpetology, Herpetological Conservation and Biology and publication lists on the websites of prominent authors in the field were browsed for additional case studies of habitat enhancement not identified in the literature database searches. Papers and grey literature already known to the authors on this topic were included in the dataset.

\subsubsection{Analysis}

The literature reporting outcomes of habitat enhancement for reptile species conservation represented a subset of literature on habitat manipulation effects on reptile species. To be considered as a habitat enhancement attempt, the habitat manipulation had to either be instigated with the clear goal of conservation of one or more free-ranging reptile species, or for restoration or reconciliation of an ecosystem that was documented to support one or more reptile species. Habitat manipulation for the purpose of mitigating adverse effects of human activities were categorised as reptile conservation if the manipulation was targeted at one or more reptile species, and as reconciliation if the manipulation sought to minimise effects on an ecosystem. Table A.1 in the appendix for this chapter gives rationale for excluding studies from the data set and examples.

Studies often contained several 'cases', which were added to the data set as separate rows. On occasion, multiple studies reported outcomes from the same case (for example, where the study was written up as both a dissertation and a peer-reviewed publication). These were treated as a single study, with the exception of work on a Blanding's tortoise (Emys blandingii) population near La Grange, New York State, because the enhancements reported in these studies each represented a separate event within a reasonably long time series of ongoing enhancement attempts (Emrich, 1991; Kiviat et al., 2000; Hartwig and Kiviat, 2007; Dowling et al., 2010).

The following data were extracted from studies for each case: species name, the number of individuals or sightings of the species across the study, study site location, duration of post-enhancement monitoring, presence or absence of negative and positive reference sites, presence or absence of a pre-enhancement baseline, purpose of enhancement (reptile conservation, conservation of non-reptilian fauna, reconciliation, or restoration), a brief description of each enhancement trialled, the indicator(s) used to evaluate the outcomes for reptile species, and a description of the evidence presented. Based on descriptions of the enhancement trialled, outcome indicators used, and the evidence presented, cases were then categorised into broad enhancement 'types' (Tables 2.3, 2.4, 2.5, and 2.6) suggested by Shoemaker et al. (2009) and Edgar et al. (2010), and assessed against each of the success 
criteria as 'success', 'failure' or 'insufficient data for assessment'. To ensure consistency, all cases were assessed by a single assessor. The first half of cases (in order of entry into the database) was audited after all cases had been assessed to minimise the risk of inconsistency due to the assessor becoming more experienced with each case assessment.

Additional information on species was sourced in September 2018. Species taxonomy (the Order, Genus and Species) was updated to a current state using The Reptile Database (www.reptile-database.org; Uetz (2019)). Because of the high species richness within Order Squamata, and historical treatment of Squamates, this group was further divided into the sub-groups Sauria (lizards and amphisbaenids) and Ophidia (snakes) (Zheng and Wiens, 2016). Species' conservation status was sourced from the IUCN Red List website (www.iucnredlist.org) by searching for taxonomically determinate species by their current scientific name. All alternative names used since study publication were used to search for taxonomically indeterminate species.

Statistical analysis of the dataset was performed in R version 3.5.1 (R Core Team, 2018). Bias in the reported cases was tested using Pearson's $\chi^{2}$ tests, as the average expected cell counts in each contingency table were $>5$. Expected values for each test were generated from the number of known species in each Order or sub-group (Taxonomy) and the number of known species by geographic region (Geography) was also sourced from The Reptile Database, and number of known species in each IUCN Threat Classification from the IUCN Red List (Conservation status). Order Rhynchocephalia (tuatara) was excluded from the analysis of taxonomic bias, given that there is only one extant species and was only one case in the dataset.

To examine which covariates influenced conservation outcomes for reptiles, each case was assigned an ordinal success score (hereafter, 'Success') of either '1', '2', '3', or '4', according to the highest stage at which success could be demonstrated (Table 2.7). Fixed factors thought to influence Success fell into three categories: species traits, study design and enhancement traits (Table 2.2). Species and study were treated as random factors. Cases with missing data for one or more factors $\left(N_{\text {cases }}=6\right.$ from $\left.N_{\text {studies }}=3\right)$ were excluded from the subsequent analyses. Pairwise Spearman's $\rho$ correlations were calculated to test independence among continuous and binary fixed factors. Independence tests between pairs of continuous (i.e. TimePE) and categorical (i.e. Etype) factors were performed using a log-normal ANOVA, and analysis of deviance with binomial errors to test independence among continuous and binary factors. Factors were considered independent if Spearman's $|\rho|<0.5$ or an omnibus test against the null model had a $\chi^{2}$ or an $F$ value with an associated $p$-value exceeding 0.05 .

I used Bayesian generalised linear mixed-effects modelling (GLMM) and Monte Carlo Markov Chain (MCMC) estimation in the MCMCglmm R package to model Success response variable (Hadfield, 2010). The effects of study design, species traits, and enhancement characteristics on Success were modelled separately to avoid 
multicollinearity. A candidate model set was constructed to examine the effects of study design. Here, the fixed factor structure of the global model included each of the four study design factors and two-way interactions between each pair (Tables 2.2 and 2.8). The candidate model set included all possible simplifications of the global model, and the Deviance Information Criterion (DIC) was used to evaluate the influence of each fixed factor on model parsimony. A single model was constructed for each of the four factors describing species traits and enhancement characteristics (Htaxa, IUCN,Purpose, and Etype; Table 2.2). Random factors included in all models were Study and Species (Table 2.2). All models had noninformative priors and were run for 100,000 iterations with a thinning interval of 10 and a burn-in of 5,000. Model assumptions were assessed graphically using the plot() function in the MCMCglmm package.

\subsection{Results}

\subsubsection{Overview of the literature}

Seventy-five peer-reviewed journal articles, reports and dissertations detailing the type and effect of a habitat modification for conservation purposes were assessed to be in scope. Studies usually failed to be in scope because they lacked a clear wildlife management, restoration or reconciliation goal (for example, studies that examined the effect of commercial logging). Sixty-five of these studies were published in peer-reviewed journals, with the remaining studies existing only as dissertations $\left(N_{\text {studies }}=7\right)$ or reports $\left(N_{\text {studies }}=3\right)$. All studies in scope were published between 1990 and 2017. The number of studies per year increased at the rate of 1.06 over this period of time (Poisson GLM: Untransformed estimate $(Y$ ear $)=0.060, \mathrm{SE}=0.015, z=3.906, p<0.001)$. Ten broad categories of habitat enhancement were identified in the literature reviewed, and are listed against existing frameworks for reptile habitat enhancement (Shoemaker et al., 2009; Edgar et al., 2010) in Tables 2.3, 2.4, 2.5, and 2.6. Most studies $(\mathrm{N}=35)$ documented manipulation of a targeted habitat feature, 27 studies documented the manipulation of the seral stage of the vegetative community within a habitat patch and 14 studies reported manipulation of habitat at a landscape scale. However, studies on a landscape-scale or seral stage manipulation reported the effects on more species per study (mean $=12$ and 10.2 species per study, respectively) than microhabitat manipulations (mean $=3.8$ species per study). 
Table 2.2: Fixed and random factors considered in models of habitat enhancement success.

\begin{tabular}{|c|c|c|}
\hline Factor name & Type & Description \\
\hline \multicolumn{3}{|l|}{ Fixed } \\
\hline Baseline & Study design & $\begin{array}{l}\text { Binary variable for whether or not a baseline } \\
\text { measure of reptiles was taken prior to } \\
\text { enhancement. }\end{array}$ \\
\hline$N e g R$ & Study design & $\begin{array}{l}\text { Binary variable for whether or not a negative } \\
\text { reference site (i.e. no enhancement treatment) was } \\
\text { included in the study. }\end{array}$ \\
\hline PosR & Study design & $\begin{array}{l}\text { Binary variable for whether or not a positive } \\
\text { reference site (i.e. representing the 'natural' or 'best } \\
\text { case' state) was included in the study. }\end{array}$ \\
\hline TimePE & Study design & $\begin{array}{l}\text { Log-normal continuous variable for the maximum } \\
\text { amount of time (in months) that had elapsed } \\
\text { between enhancement completion and the finish } \\
\text { date of post-enhancement reptile monitoring. }\end{array}$ \\
\hline Htaxa & Species trait & $\begin{array}{l}\text { Higher taxonomic classification. } \\
\text { Testudines, Squamata (Lizards), Squamata } \\
\text { (Snakes), Crocodylia. }\end{array}$ \\
\hline$I U C N$ & Species trait & $\begin{array}{l}\text { IUCN Threat Classification, if one exists. Levels: } \\
\text { Critically Endangered, Endangered, Vulnerable, } \\
\text { Near Threatened, Least Concern, Not Assessed. }\end{array}$ \\
\hline Purpose & $\begin{array}{l}\text { Enhancement } \\
\text { characteristic }\end{array}$ & $\begin{array}{l}\text { Primary reason for enhancing habitat. Levels: } \\
\text { Conservation (reptile species), Conservation (other } \\
\text { species), Restoration, Reconciliation. }\end{array}$ \\
\hline Etype & $\begin{array}{l}\text { Enhancement } \\
\text { characteristic }\end{array}$ & $\begin{array}{l}\text { Type of enhancement applied. Levels: Artificial } \\
\text { refuge (Microhabitat), Other targeted microhabitat } \\
\text { feature (which included basking habitat, foraging } \\
\text { habitat and removal of invasive plant species), } \\
\text { Nesting (Habitat feature), Decreased (Seral stage of } \\
\text { plant community), Increased (Seral stage of plant } \\
\text { community), Dispersal habitat (Landscape-scale), } \\
\text { Patch optimisation (Landscape-scale). }\end{array}$ \\
\hline \multicolumn{3}{|l|}{ Random } \\
\hline Study & & $\mathrm{Ca}$ \\
\hline Species & & Categorical variable. Reptile species. \\
\hline
\end{tabular}


Table 2.3: Landscape-scale habitat enhancement types for reptile species.

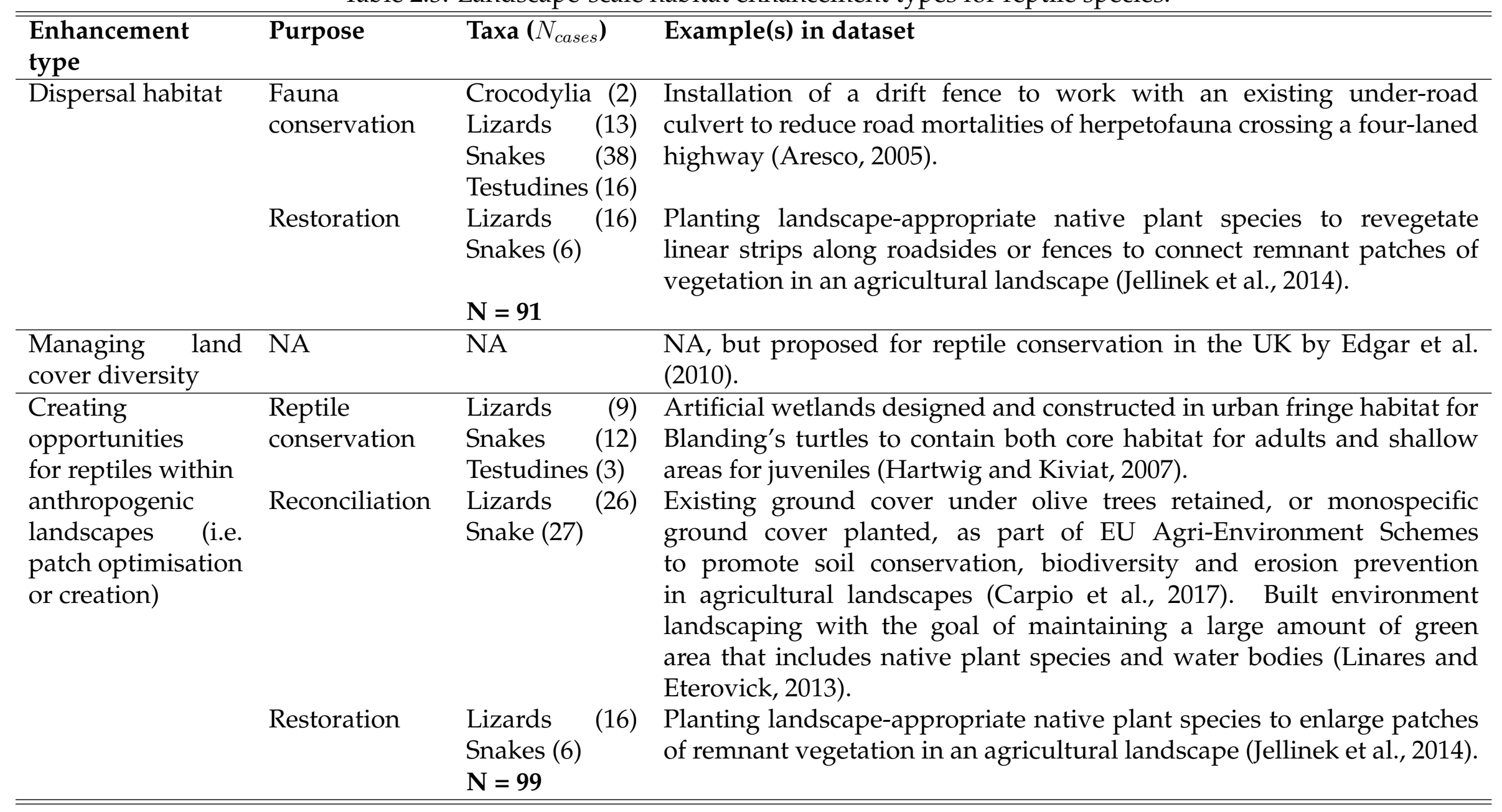


Table 2.4: Habitat enhancement for reptile species types involving manipulation of the seral stage of vegetative communities.

\begin{tabular}{|c|c|c|c|}
\hline $\begin{array}{l}\text { Enhancement } \\
\text { type }\end{array}$ & Purpose & Taxa $\left(N_{\text {cases }}\right)$ & Example(s) in dataset \\
\hline \multirow[t]{7}{*}{$\begin{array}{l}\text { Reversal of seral } \\
\text { stage }\end{array}$} & $\begin{array}{l}\text { Fauna } \\
\text { conservation }\end{array}$ & Snakes (1) & $\begin{array}{l}\text { Habitat restored for reintroduction of the frog Pelophylax lassonae by tree } \\
\text { cover reduction to revert sites from former woodland to more open } \\
\text { habitat (Sewell et al., 2015). }\end{array}$ \\
\hline & $\begin{array}{l}\text { Reptile } \\
\text { conservation }\end{array}$ & Snakes (6) & $\begin{array}{l}\text { Trees mechanically removed to replace closed-canopy forest with shrub } \\
\text { habitat to bolster snake populations (Bonnet et al., 2016). }\end{array}$ \\
\hline & Reconciliation & Snakes (25) & $\begin{array}{l}\text { Right of way (ROW) created for high-voltage powerlines by } \\
\text { experimentation with a variety of techniques (hand-cutting, herbicide } \\
\text { application, mowing) to revert forest to a shrub-forb-grass cover type. } \\
\text { Each method experimentally evaluated to minimise impact on snake } \\
\text { species occupancy in the ROW (Yahner et al., 2001; Yahner, 2004). }\end{array}$ \\
\hline & Restoration & Lizards & Heathland restoration by controlled annual summer cattle grazing \\
\hline & & Snakes & (Reading and Jofré, 2016). Prescribed burning and thinning to restore \\
\hline & & Testudines (4) & $\begin{array}{l}\text { the original low-medium intensity, short interval, fire regime of a fire- } \\
\text { adapted forest community (Kilpatrick et al., 2004). }\end{array}$ \\
\hline & & $\mathbf{N}=160$ & \\
\hline \multirow[t]{8}{*}{$\begin{array}{l}\text { Promotion } \\
\text { of vegetative } \\
\text { succession }\end{array}$} & $\begin{array}{l}\text { Fauna } \\
\text { conservation }\end{array}$ & $\begin{array}{ll}\text { Lizards } & (9) \\
\text { Snakes (8) }\end{array}$ & $\begin{array}{l}\text { Artificial waterholes originally constructed for ungulate conservation, } \\
\text { allowing natural savannah and shrubland communities to revegetate } \\
\text { the surrounding patch of desert (Cutler, 1996). }\end{array}$ \\
\hline & $\begin{array}{l}\text { Reptile } \\
\text { conservation }\end{array}$ & Lizards (5) & $\begin{array}{l}\text { Livestock exclusion fencing of a nature reserve for conservation of a } \\
\text { remnant population of the threatened skink Oligosoma whitakeri (Hoare } \\
\text { et al., 2007a). }\end{array}$ \\
\hline & Reconciliation & Snakes (3) & $\begin{array}{l}\text { Livestock exclusion fencing of farmland riparian zones (Homyack and } \\
\text { Giuliano, 2002). }\end{array}$ \\
\hline & Restoration & Crocodylia (1) & Removal of grazing stock from Chaco forest (Leynaud and Bucher 2005). \\
\hline & & Lizards & Planting hardwood species along a river corridor and delta to restore \\
\hline & & Snakes & the original riparian habitat types (cypress-tupelo and bottomland \\
\hline & & Testudines (13) & hardwood wetlands) (Bowers et al., 2000). \\
\hline & & $\mathbf{N}=115$ & \\
\hline
\end{tabular}


Table 2.5: Habitat enhancement targeting specific habitat features for reptile species.

\begin{tabular}{|c|c|c|c|}
\hline $\begin{array}{l}\text { Enhancement } \\
\text { type }\end{array}$ & Purpose & Taxa $\left(N_{\text {cases }}\right)$ & Example(s) in dataset \\
\hline \multirow[t]{2}{*}{$\begin{array}{l}\text { Artificial } \\
\text { refugia }\end{array}$} & $\begin{array}{l}\text { Fauna } \\
\text { conservation }\end{array}$ & $\begin{array}{l}\text { Lizard (33) } \\
\text { Snake (16) }\end{array}$ & $\begin{array}{l}\text { Addition of roof tiles, galvanized iron, concrete pavers and old fence posts } \\
\text { to currently, or formerly, grazed landscapes to provide refugia for small } \\
\text { vertebrates (Homan, 2012). }\end{array}$ \\
\hline & $\begin{array}{l}\text { Reptile } \\
\text { conservation }\end{array}$ & $\begin{array}{l}\text { Lizard } \\
\text { Snake } \\
\text { Tuatara } \\
\text { Testudines } \\
\mathbf{N}=\mathbf{( 1 )} \\
\mathbf{N}=\mathbf{9 9}\end{array}$ & $\begin{array}{l}\text { Addition of artificial rocks (made from fibre-reinforced cement mixed with } \\
\text { polymer) to conserve the threatened snake Hoplocephalus bungaroides and its } \\
\text { lizard prey in degraded patches of nature reserves prone to rock removal by } \\
\text { the public (Croak et al., 2010, 2013). }\end{array}$ \\
\hline Basking site(s) & $\begin{array}{l}\text { Reptile } \\
\text { conservation }\end{array}$ & $\begin{array}{l}\text { Lizards (12) } \\
\text { Snakes (5) } \\
\mathbf{N}=\mathbf{1 7}\end{array}$ & $\begin{array}{l}\text { Selective removal of trees and branches to open up canopy in small patches } \\
\text { of forest (Pike et al., 2011b,a). }\end{array}$ \\
\hline \multirow[t]{3}{*}{$\begin{array}{l}\text { Foraging } \\
\text { habitat }\end{array}$} & $\begin{array}{l}\text { Fauna } \\
\text { conservation }\end{array}$ & Crocodylia (1) & $\begin{array}{l}\text { Man-made water holes adjacent to islands constructed to create high water } \\
\text { habitat for deer in seasonally flooded marshland were more frequently used } \\
\text { by alligators (Alligator mississipiensis) than natural alligator holes (Campbell } \\
\text { and Mazzotti, 2004). }\end{array}$ \\
\hline & $\begin{array}{l}\text { Reptile } \\
\text { conservation }\end{array}$ & Snakes (1) & $\begin{array}{l}\text { Construction of artificial water pools to supply drinking water for Shedao } \\
\text { pitvipers Gloydius shedaoensis (Sun, 1990; Shine et al., 2002). }\end{array}$ \\
\hline & & $\mathbf{N}=2$ & \\
\hline
\end{tabular}


Table 2.6: Habitat enhancement targeting specific habitat features for reptile species continued.

\begin{tabular}{|c|c|c|c|}
\hline $\begin{array}{l}\text { Enhancement } \\
\text { type }\end{array}$ & Purpose & Taxa $\left(N_{\text {cases }}\right)$ & Example(s) in dataset \\
\hline \multirow[t]{3}{*}{$\begin{array}{l}\text { Invasive plant } \\
\text { control }\end{array}$} & $\begin{array}{l}\text { Reptile } \\
\text { conservation }\end{array}$ & Snakes (1) & $\begin{array}{l}\text { Invasive plant (Pueraria sp.) removal from Shedao pitviper habitat by direct } \\
\text { cutting, herbicide application, and replanting resulting gaps with native } \\
\text { vegetation (Zhao et al., 1990; Shine et al., 2002). Bracken management } \\
\text { suggested for UK reptile conservation by Edgar et al. (2010). }\end{array}$ \\
\hline & Restoration & Snakes (1) & $\begin{array}{l}\text { Exotic plants controlled in managed forest gaps by brush-hogging, mowing, } \\
\text { and herbicide application 1-2 times per year. Clippings and debris } \\
\text { occasionally manipulated and compacted (Carter, 2012). }\end{array}$ \\
\hline & & $\mathbf{N}=2$ & \\
\hline \multirow[t]{3}{*}{ Nesting habitat } & $\begin{array}{l}\text { Reptile } \\
\text { conservation }\end{array}$ & $\begin{array}{ll}\text { Lizards } & (2) \\
\text { Snakes } & (2)\end{array}$ & $\begin{array}{l}\text { Construction of piles of bare soil to act as artificial nesting mounds for } \\
\text { terrestrial turtles (Buhlmann and Osborn, 2011). }\end{array}$ \\
\hline & & Testudines (14) & \\
\hline & & $N=18$ & \\
\hline
\end{tabular}


The 75 studies yielded 603 cases, representing the responses of 251 species to a habitat enhancement event. On average, studies reported 8.04 cases (range: 1 - 44). Most cases represented responses of Squamates (snakes: 45.82\%, lizards: 45.42\%). The remaining responses were comprised of Testudines (turtles and tortoises: 7.97\%), American alligators (Alligator mississipiensis: Order Crocodylia) (0.40\%) and Rhynchocephalians (tuatara Sphenodon punctatus): $0.40 \%$, a single study (Nelson et al., 2002). The proportion of species studied was significantly different from expected counts based on the number of known species (tuatara excluded, $\chi_{3}^{2}=39, p<0.001$ ). The Testudines were the most over-represented taxa, followed by snakes. Lizards were under-represented (Fig. 2.1A). A full species list is provided in Tables A.2-A.12 in the appendix for this chapter.

The majority (78.57\%) of cases involved species in the Least Concern IUCN category, followed by Not Assessed (13.62\%), Vulnerable (3.32\%), Endangered (2.16\%), Near Threatened (2.16\%) and Critically Endangered (one case: the turtle Glyptemmys muhlenbergii (Somers, 2000); 0.17\%). There was evidence of bias by IUCN threat classification (Pearson's $\left.\chi_{6}^{2}=135, p<0.001\right)$, with species with the 'Least Concern' threat status being over-represented, and species in all other threat classifications being under-represented (Figure 2.1B).

Habitat enhancement cases were most frequently reported from North America (USA and Canada: $47.4 \%$ ), followed by Oceania (Australia, New Zealand and the Pacific Islands: 27.2\%), South America and Europe (both 10.8\%), Africa (continental Africa and the Indian Ocean Islands: 3.5\%), and Asia (including Russia and the Indian subcontinent: $0.3 \%$ ), respectively (Fig. 2.1C). No cases were reported from the Middle East, Central America or the Caribbean. Most cases were from continental environments; only $5 \%$ of all cases were located in island or archipelago environments. There was evidence of geographic bias when the observed number of cases were compared against expected values derived from an equal split ( $\left.\chi_{5}^{2}=567, p<<0.001\right)$, and a larger bias when compared with expected values derived from the known number of species known from each region as at August 2015 (Uetz (2019): www.reptile-database.org/db-info/diversity) $\left(\chi_{5}^{2}=2,834, p<<0.001\right)$. North America, Oceania and Europe were the most over-represented continents, whereas South America, Africa and Asia were the most under-represented continents (Fig. 2.1C).

\subsubsection{Success rates against criteria}

Of the 603 response cases, stage-based success or failure could not be assessed against any criterion in 90 cases (15.1\%; Table 2.7). This was due to either an inconclusive result or insufficient reporting of information necessary to make an accurate evaluation of success at any of the four stages.

While all evaluable cases $(\mathrm{N}=513)$ reported on whether or not a species used the enhanced habitat patch(es), only $7.8 \%$ could be assessed using the Stage 2 criterion 
A

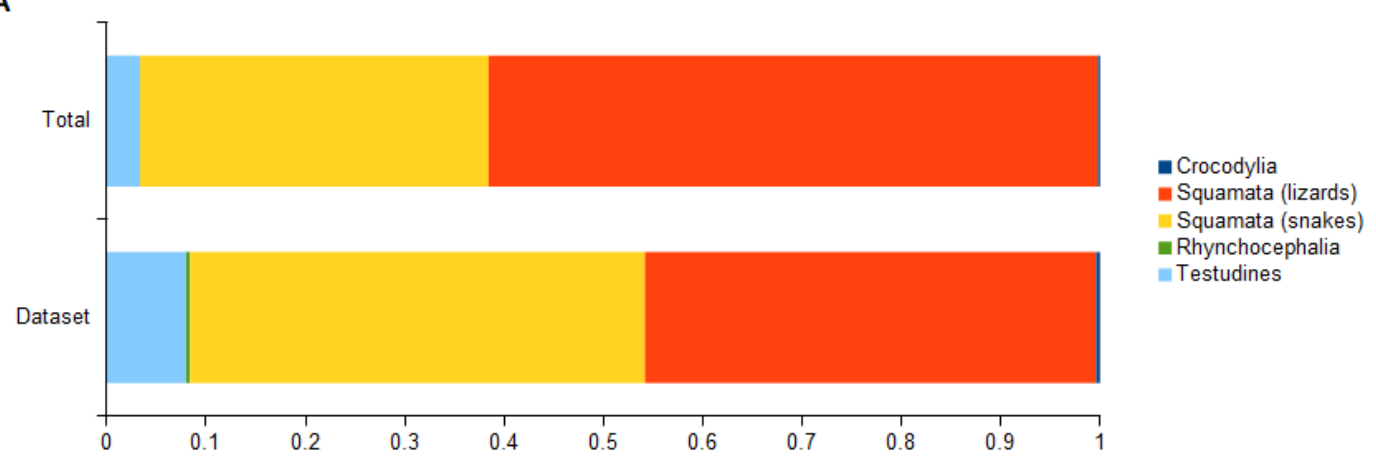

B

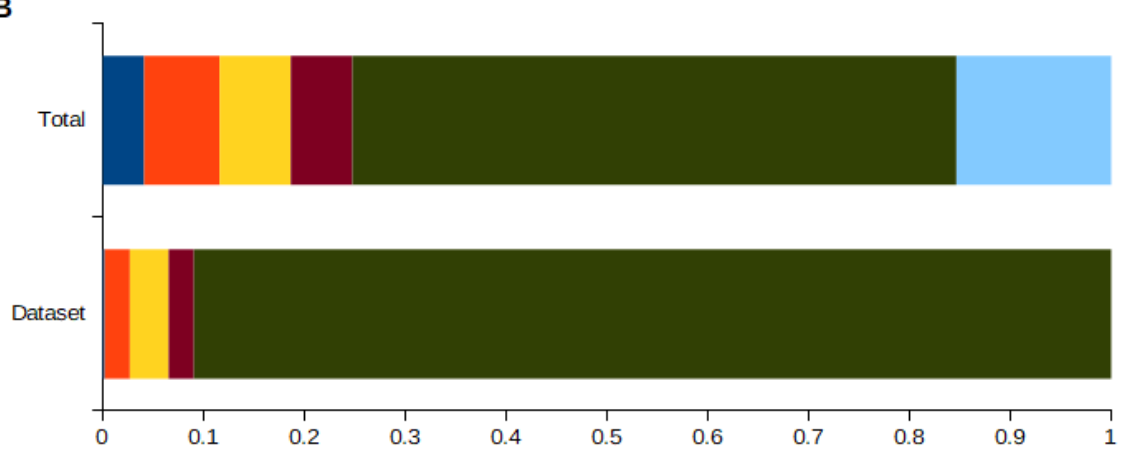

= Data Deficient

- Least Concern or LR/lC

- Near Threatened or LR/nt

$=\mathrm{LR} / \mathrm{cd}$

- Vulnerable

- Endangered

- Critically Endangered

C

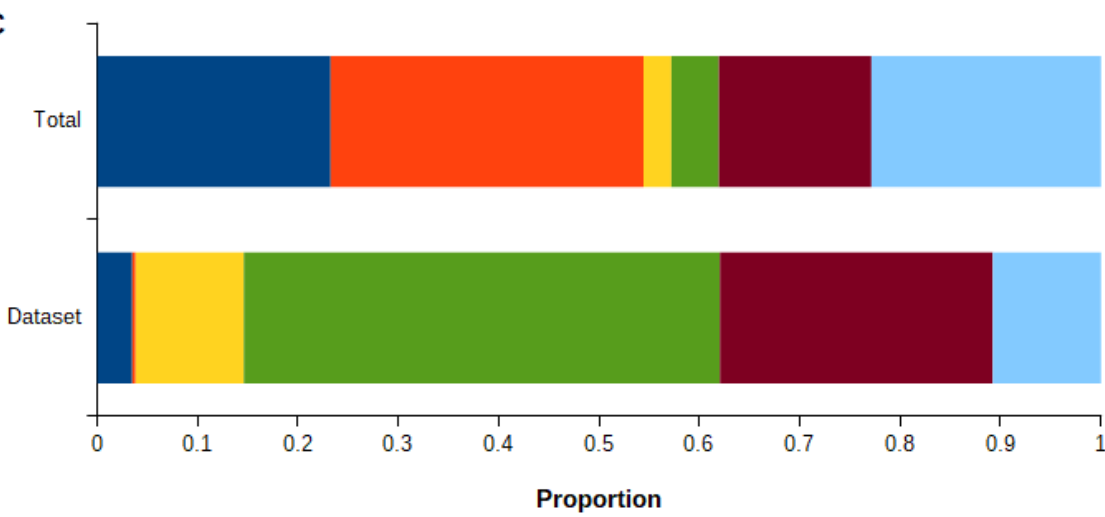

= South America

- Oceania (Australia and the Pacific Islands)

North America (USA and Canada)

Europe

Asia (including Russia)

- Africa (including Indian Ocean islands)

Figure 2.1: Proportion of total enhancement cases in dataset categorised by: A Order (Order Squamata has been further divided into Lizards (including Amphisbanenids) and Snakes), B IUCN Threat Classification (species with no IUCN Threat Classification excluded from analysis), and C Geographic region (region specification follows www.reptile-databse.org./ and regions with no cases in the dataset were excluded from analysis). The top bar ('Total') of each graph represents expected proportions based on: A total number of described species within each Order / higher taxonomic grouping as at September 2018 (Source: www.reptile-database.org), B total number of described species within each IUCN Threat Classification as at September 2018 (Source: www.iucnredlist.org), and C number of described reptile species inhabiting geographic regions as at August 2015 (Source: www.reptile-database.org/db-info/diversity). 
Table 2.7: Number of cases displaying a given stage-based outcome and success score (Success). $1=$ successful at Stage $i, 0=$ not successful at $i,-=$ not evaluable against $i . \mathrm{N}$ $=$ number of cases displaying a given outcome.

\begin{tabular}{cccccc}
\hline \hline Stage 1 & Stage 2 & Stage 3 & Stage 4 & N cases & Success \\
\hline- & - & - & - & 90 & NA \\
\hline 0 & - & - & - & 57 & 0 \\
0 & - & 0 & - & 29 & 0 \\
0 & 0 & - & - & 1 & 0 \\
\hline 1 & - & - & - & 185 & 1 \\
1 & - & 0 & - & 130 & 1 \\
1 & - & 0 & 0 & 2 & 1 \\
1 & - & 0 & 0 & 2 & 1 \\
1 & 0 & - & - & 2 & 1 \\
1 & 0 & 0 & - & 2 & 1 \\
\hline 1 & 1 & - & - & 23 & 2 \\
1 & 1 & 0 & - & 5 & 2 \\
1 & 1 & 0 & 0 & 1 & 2 \\
\hline 1 & - & 1 & - & 61 & 3 \\
1 & 0 & 1 & - & 1 & 3 \\
1 & 1 & 1 & - & 10 & 3 \\
1 & 1 & 1 & 0 & 1 & 3 \\
\hline 1 & - & 0 & 1 & 1 & 4 \\
1 & - & 1 & 1 & 1 & 4 \\
1 & 1 & 1 & 1 & 1 & 4 \\
\hline \hline
\end{tabular}

(evidence of reproduction in enhanced habitat), 40.6\% could be assessed against the Stage 3 criterion (demographic benefit to population occupying enhanced habitat), and 1.2\% examined long-term population trends or population models sufficient to evaluate against the Stage 4 criterion (self-sustaining population) (Fig. 2.2).

Success rates for each criterion were non-uniform when compared against expected success rates derived from the mean success rate across all criteria (61\%) $\left(\chi_{3}^{2}=83.6, p<0.001\right)$. The largest deviations from expected rates were observed in Stage 1 (higher than expected) and Stage 3 (lower than expected). Evidence for use of enhanced habitats by reptiles (Stage 1) and evidence of reproduction (Stage 2) were found in the majority of evaluable cases (Fig. 2.2). However, success rates were lower than $50 \%$ at Stages 3 and 4 (Fig. 2.2). Of the four unsuccessful out of seven total cases $\left(N_{\text {studies }}=2\right)$ evaluated at Stage 4, it was concluded that the population receiving enhancement would require additional conservation management to be self-sustaining (by supplementary translocation (Somers, 2000) or control of invasive fauna (Hoare et al., 2007a)). 


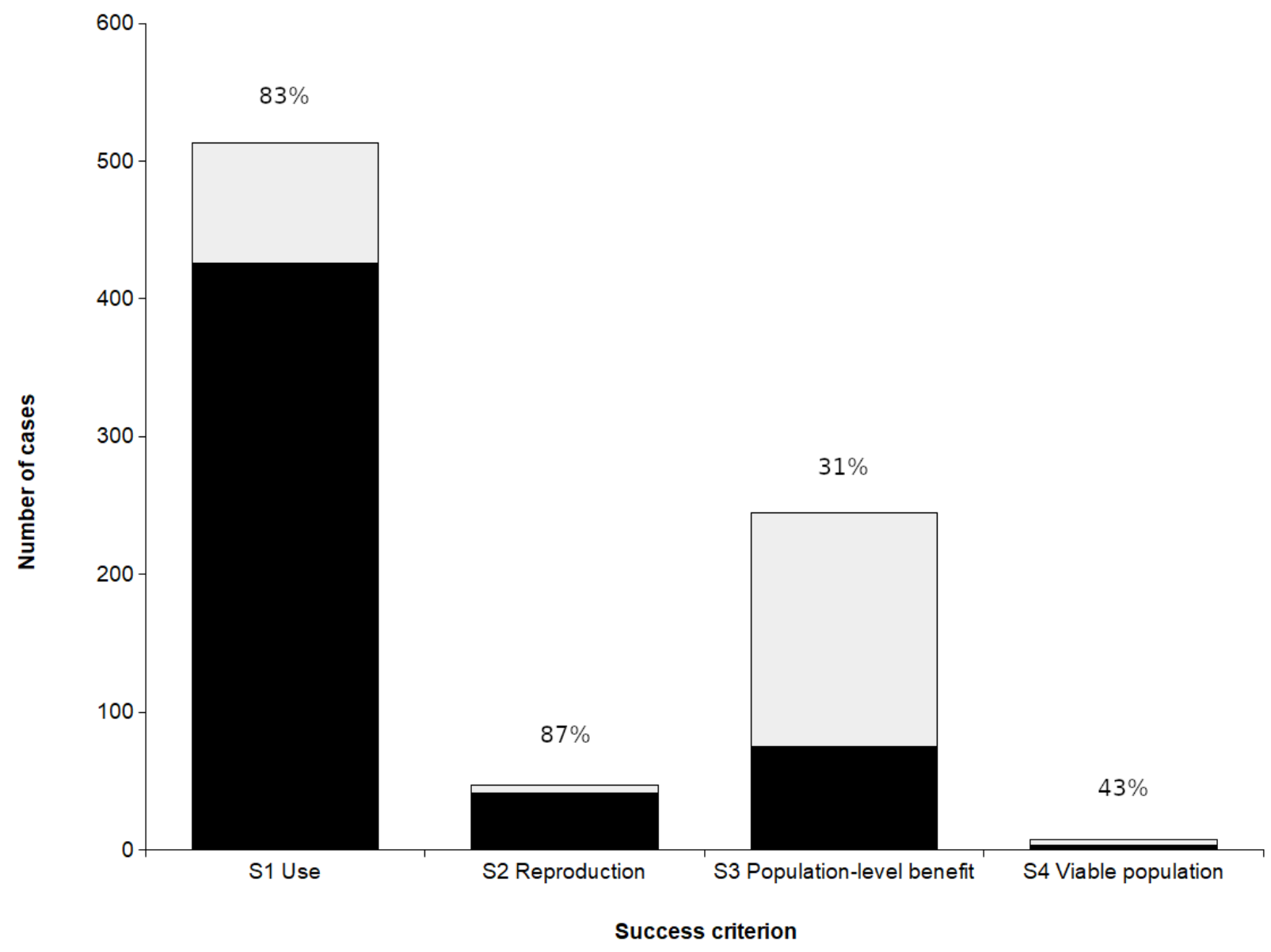

Figure 2.2: Number of assessable cases and success rates of habitat enhancement for reptiles as assessed against progressive stage-bound criteria modified from Miller et al. (2014). Successful cases are indicated by the black part of the bars, and unsuccessful cases by the grey part. Numbers above the bars are the success rates. Each criterion provides a more rigorous indicator of ultimate success (establishment of a self-sustaining population in the enhanced habitat patch) moving from left to right across the $\mathrm{x}$ axis. However, as the weight of evidence provided by each criterion increases, the amount of time and resources required to assess against a criterion also increases. 


\subsubsection{Effect of study design on criterion-weighted outcome evaluation}

Inclusion of temporal or spatial references in the study design for evaluating the effect of enhancement were important predictors of the success score (Table 2.8). The effects of time elapsed between enhancement and the end of post-enhancement monitoring (TimePE) and incorporation of a baseline all positively affected the strength of evidence obtained from a given case, but only the effect of incorporating a baseline was significant (Table 2.9). The negative interaction effects suggest that evaluation against positive or negative reference sites in the short-term could result in a positive bias: making the enhancement seem more likely to be successful in the long-term than reality (Table 2.9). While both of these interaction effects were not significant, the implications become apparent when predicted over the full range of TimePE (Fig. 2.3). Under this model, shorter-term studies (time $<$ the geometric mean of 7.3 years post-enhancement) that evaluated success against spatial reference sites were predicted to demonstrate lower mean success, and the most variable outcomes, at 100 years post-enhancement, the longest-term time scale reported in the data set. In contrast, cases lacking a comparison against a spatial reference were expected to slightly underestimate success at shorter term scales than at longer-term scales.

Table 2.8: Candidate models for examining the effect of study design on success score. All models incorporated a random additive effect of Species and Study. N iterations = 100,000 , burn-in $=10,000$, thinning interval $=10$, sample size $=9,000$. Models are ordered by increasing DIC. The maximal model is indicated by an asterisk.

\begin{tabular}{|c|c|c|}
\hline Fixed effects structure & 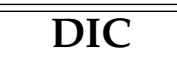 & 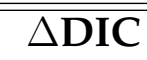 \\
\hline $\begin{array}{l}\text { TimePE }+ \text { Baseline }+ \text { PosR }+ \text { NegR }+ \text { TimePE } \times \text { PosR }+ \text { TimePE } \times \\
\text { NegR }\end{array}$ & -3233.83 & \\
\hline TimePE + Baseline + PosR + NegR + TimePE $\times N e g R$ & -2760.55 & 473.28 \\
\hline $\begin{array}{l}\text { TimePE }+ \text { Baseline }+ \text { PosR }+ \text { NegR }+ \text { TimePE } \times \text { Baseline }+ \text { TimePE } \times \\
P o s R+\text { TimePE } \times N e g R^{*}\end{array}$ & -1856.28 & 1377.55 \\
\hline TimePE + Baseline + NegR & -1778.58 & 1455.25 \\
\hline TimePE + Baseline & -658.74 & 2575.09 \\
\hline TimePE $+N e g R$ & 625.25 & 3859.08 \\
\hline 1 (null model) & 919.36 & 4153.19 \\
\hline Baseline $+N e g R$ & 922.75 & 4156.58 \\
\hline TimePE + Baseline + PosR + NegR + TimePE $\times$ PosR & 924.23 & 4158.06 \\
\hline TimePE + Baseline + Pos $R+N e g R$ & 927.17 & 4161.00 \\
\hline
\end{tabular}

\subsubsection{Effect of species and enhancement attributes on criterion-weighted outcome evaluation}

All $\chi^{2}$ contingency tables demonstrated non-independence between each pairwise comparison of enhancement (Etype, Purpose) and species (IUCN, Htaxa), with all 
Table 2.9: Factor effects on success scores from the best ranked model by the DIC. The intercept represents cases from studies that lacked a baseline, positive reference, and a negative reference. Significant parameters are indicated by an asterisk next to the $p$ value. Covariate interactions are denoted by a multiplication sign $(\times)$. CI $=$ credible interval.

\begin{tabular}{llllll}
\hline Covariate & $\begin{array}{l}\text { Posterior } \\
\text { mean }\end{array}$ & $\mathbf{9 5 \%}$ CI & $\begin{array}{l}\text { Effective } \\
\text { sample } \\
\text { size }\end{array}$ & $N_{\text {observations }}$ & $p_{M C M C}$ \\
\hline (Intercept) & 5.395 & $1.325-10.324$ & 3.2 & 99 & $<0.001^{*}$ \\
TimePE & 0.002 & $-0.009-0.015$ & 732.8 & 505 & 0.633 \\
Baseline & 2.961 & $0.393-6.415$ & 13.9 & 77 & $0.003 *$ \\
PosR & 0.411 & $-2.205-3.140$ & 1,556 & 227 & 0.708 \\
NegR & 0.191 & $-2.231-2.779$ & 1,858 & 316 & 0.875 \\
TimePE $\times$ PosR & -0.008 & $-0.028-0.007$ & 152.2 & 227 & 0.240 \\
TimePE $\times$ NegR & -0.005 & $-0.019-0.007$ & 249.4 & 316 & 0.371 \\
\hline \hline
\end{tabular}

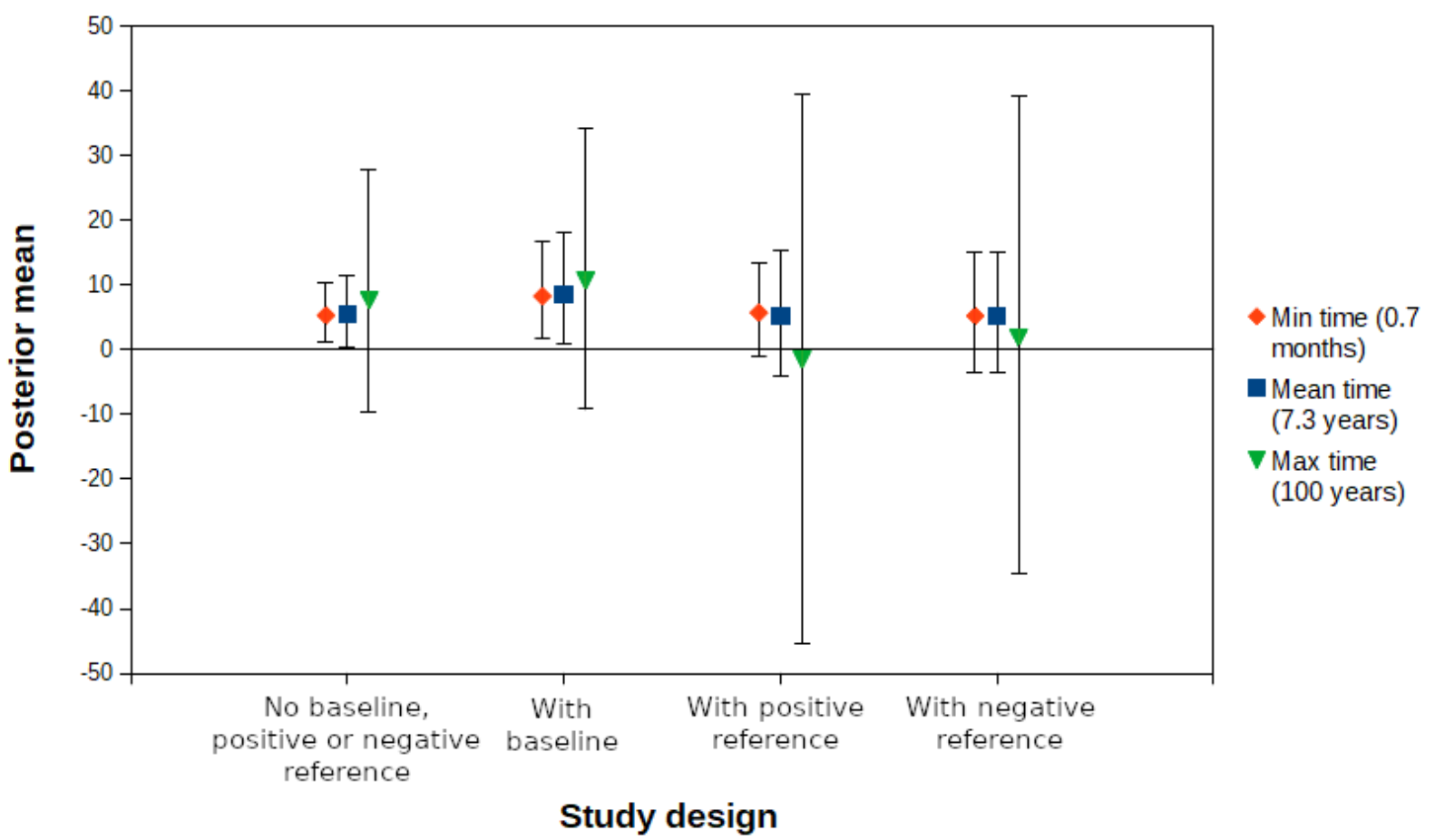

Figure 2.3: Effect sizes of enhancement type on success scores, categorised by the two study design variables thought to affect outcome. The error bars are $95 \%$ credible intervals. 
$p\left(\chi^{2}\right)<0.001$. In addition, Baseline, TimePE, and NegR demonstrated non-independence from most species and enhancement attributes (i.e. $p(F)$ or $p\left(\chi^{2}\right)<0.001$ ), with the exception of $N e g R$ and Htaxa (deviance $=7.754, d f=3, p\left(\chi^{2}\right)=0.051$ ) and $I U C N$ and Baseline (deviance $=7.181, d f=5, p\left(\chi^{2}\right)=0.207$ ). Therefore, a series of single-factor models were run without inclusion of study design effects to examine net differences between groups within each factor. The 95\% credible intervals for all levels of Etype, $I U C N$, and Htaxa overlapped, indicating no significant difference in posterior means (Table 2.10). However, Purpose affected the success score, with enhancement attempts carried out for both ecological restoration or habitat reconciliation being less successful than those carried out for conservation of non-reptilian fauna (Table 2.10). The posterior mean of enhancement attempts carried out specifically for reptile conservation was lower than for non-reptilian fauna and higher than both restoration and reconciliation, but could not be considered significantly different from any of these other levels (Table 2.10). The difference among success scores by Purpose appeared to arise from non-uniformity at Stage $3\left(\chi_{3}^{2}=52.6, p<0.001, N_{\text {cases }}=244\right)$. In particular, the proportion of successful restoration-driven habitat cases at Stage 3 was much lower than Stage 3 success of other enhancement purposes (Fig. 2.4). In contrast, success rates by purpose were uniform at Stage $1\left(\chi_{3}^{2}=4.7, p=0.199, N_{\text {cases }}=486\right)$ and Stage $2\left(\chi_{2}^{2}=0.89, p=0.828, N_{\text {cases }}=44\right)$.

\subsection{Discussion}

Habitat enhancement appears to be a relatively new technique for reptile conservation, with the first studies being published 28 years ago. A significant increase in the number of publications per year on this subject indicates that the outcomes of habitat enhancement techniques on reptiles are being increasingly scrutinised. While the largest proportion of cases were documented for habitat manipulations at the landscape scale or seral stage of the vegetative community, this is because studies examining these types of enhancement included between ten and 12 species responses. In contrast, manipulation of specific habitat or microhabitat features was documented in half of the studies, but tended to report fewer species responses, possibly because of the smaller spatial scale of these enhancements.

Habitat enhancement for reptiles appears to be mostly applied for 'keeping common species common' (Jennings, 2000; Ramesh and McGowan, 2009; Frimpong, 2018). More cases than expected detailed the effects of enhancement on species with a Least Concern threat ranking. This could simply be due to more abundant species being easier to study and more widespread. Alternatively, conservationists may be hesitant to use habitat enhancement for conserving endangered reptiles. However, successful outcomes at some stages have been achieved for species with a high threat classification. For example, the response to an enhancement (construction of stock fencing around turtle-occupied wetland patches in farmland coupled with a controlled low intensity grazing regime) for the 
Table 2.10: Estimated effect sizes of Etype, Purpose, IUCN, and Htaxa on enhancement success scores. These four multi-level factors were not independent of each other, therefore were modelled separately as ordinal Bayesian GLMMs with a probit link. Factor levels are listed in order of increasing divergence of effect size from the level used as the intercept (indicated by an asterisk). All models included random additive effects of Study and Species, used weak priors (i.e. priors were unspecified in R model formulation), and were run for 100,000 iterations with burn-in $=10,000$ and thinning interval $=10 . N_{o b s}=$ number of cases in dataset. $\mathrm{CI}=$ credible interval.

\begin{tabular}{|c|c|c|c|c|}
\hline Factor and levels & $\begin{array}{c}\text { Untransformed } \\
\text { posterior } \\
\text { mean }\end{array}$ & 95\% CI & $\begin{array}{l}\text { Effective } \\
\text { sample } \\
\text { size }\end{array}$ & $N_{\text {obs }}$ \\
\hline \multicolumn{5}{|l|}{ Enhancement type (Etype) } \\
\hline Refugia added* & 15.70 & $5.13-26.24$ & 6.10 & 94 \\
\hline Patch optimisation & 0.24 & $-8.34-9.55$ & $6,271.13$ & 99 \\
\hline Seral stage decreased & 0.42 & $-7.81-8.60$ & $5,578.57$ & 156 \\
\hline Basking or foraging habitat & 2.78 & $-10.45-18.19$ & $2,211.23$ & 19 \\
\hline Dispersal habitat & 4.58 & $-5.24-15.65$ & 452.48 & 51 \\
\hline Seral stage increased & 5.31 & $-4.07-16.13$ & 223.03 & 71 \\
\hline Nesting habitat & 7.55 & $-4.18-20.03$ & 115.66 & 15 \\
\hline \multicolumn{5}{|l|}{ Enhancement purpose (Purpose) } \\
\hline Non-reptile species conservation* & 17.11 & $4.66-33.81$ & 3.473 & 97 \\
\hline Reptile conservation & -0.43 & $-8.05-7.21$ & $6,066.25$ & 108 \\
\hline Ecological restoration & -4.34 & $-14.07-3.04$ & 118.53 & 219 \\
\hline Reconciliation & -8.39 & $-22.63-2.19$ & 51.03 & 81 \\
\hline \multicolumn{5}{|l|}{ Species' IUCN status (IUCN) } \\
\hline Critically Endangered* & 42.83 & $3.72-95.78$ & 13.75 & 1 \\
\hline Near Threatened & -16.45 & $-62.24-20.94$ & 261.38 & 13 \\
\hline Endangered & -19.44 & $-66.20-16.44$ & 157.24 & 12 \\
\hline Not assessed & -23.21 & $-68.79-13.57$ & 82.82 & 67 \\
\hline Least Concern & -24.12 & $-71.24-10.62$ & 72.44 & 396 \\
\hline Vulnerable & -26.24 & $-77.09-7.18$ & 62.78 & 16 \\
\hline \multicolumn{5}{|l|}{ Species' higher taxonomy (Htaxa) } \\
\hline Crocodylia* & 4.43 & $0.29-9.09$ & 55.66 & 3 \\
\hline Lizards & 0.21 & $-3.65-4.37$ & $7,416.75$ & 247 \\
\hline Testudines & 0.726 & $-3.13-4.99$ & $4,571.62$ & 39 \\
\hline Snakes & -0.78 & $-4.73-3.33$ & $3,944.67$ & 216 \\
\hline
\end{tabular}




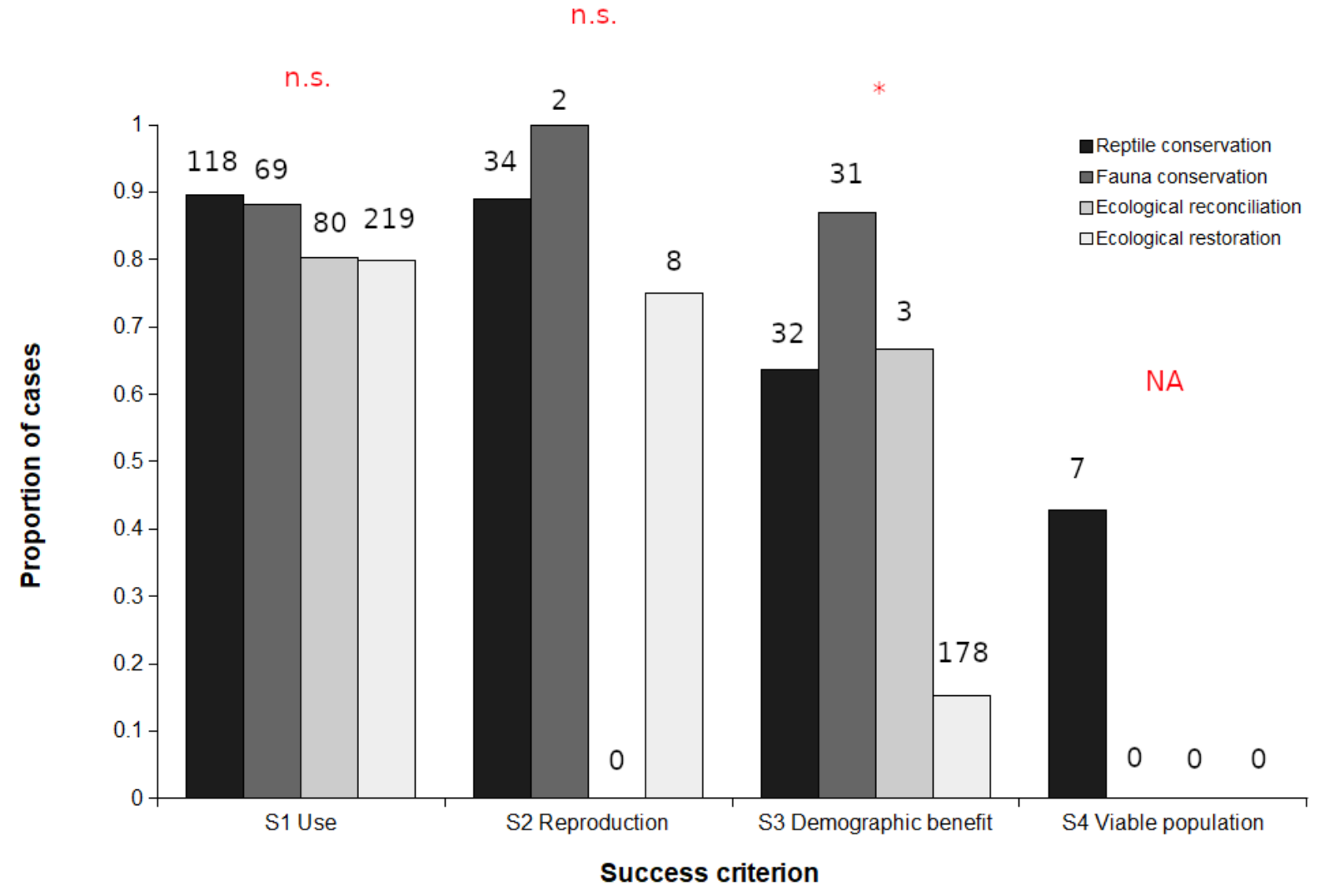

Figure 2.4: Success rates against criteria, categorised by enhancement purpose. Numbers above the bars are the number of cases for which the given criterion was evaluable. Significant differences in success rates between purposes are indicated by a red asterisk above the bars, non-significance by n.s., and NA means that differences in success rates between purposes could not be tested due to insufficient data. 
Critically Endangered turtle Glyptemmys muhlenbergii was evaluated against all four success stages (Somers, 2000). While this study was able to demonstrate use of, reproduction, and population growth (with respect to a pre-enhancement baseline) in the enhanced patches, population viability modelling suggested that the population was not viable at one enhanced site, and too small at the other site to be viable without supplementation with translocated animals (Somers, 2000). Studies of Endangered species have also demonstrated positive outcomes. For example, addition of artificial burrows to pygmy bluetongue skinks' (Tiliqua adelaidensis) habitat resulted in increased abundance relative to baseline and negative control plots (Souter et al., 2004). Several species of endangered North American turtles successfully nested in restored or artificial nesting habitat patches (Paterson, 2011; Paterson et al., 2013; Kiviat et al., 2000; Buhlmann and Osborn, 2011), which resulted in an increased population growth rate in one study (Reid et al., 2016). These studies illustrate that enhancement is capable of producing positive outcomes at Stages 1-3 for threatened species.

Evidence of geographic bias was found, with some regions and all insular environments being under-represented in the dataset. The dearth of studies from islands or archipelagos may be explained by invasive predators being the most urgent threat to their reptile fauna (Böhm et al., 2013). For example, for the Antiguan Racer (Alsophis antiguae), a Critically Endangered snake that was restricted to a single islet in the Caribbean by 1995; eradication of invasive mammals followed by reintroduction to further islets formed the most urgent part of their conservation, whereas habitat restoration by reforestation and grazer removal was planned for the future but has not yet occurred (Daltry et al., 2001, 2017). The under-representation of cases in some continents could have arisen from the search methodology, because English search terms were used and only English-language articles could be evaluated by the authors. It is therefore plausible that future reviews or meta-analyses conducted by a multi-lingual research team may reveal additional information. However, a search of the Chinese-language literature did not identify any further studies (L. Liu, pers. comm.). The apparent under-representation of cases from South America, Africa and Asia may represent a conservation research opportunity; given that these continents contain areas supporting very high reptile species richness or centres of high richness of threatened species (Böhm et al., 2013). The taxonomic bias identified from the literature suggests that more studies of lizards' responses to habitat enhancement are also required for an unbiased global assessment.

There was a lot of variation in the measurements collected as indicators of success/failure, and in the experimental designs being used for outcome evaluation of habitat enhancement for reptile populations. The non-independence of most fixed factors from each other suggests that studies on different taxa, enhancement treatment type and underlying purpose, and species with differing levels of conservation risk are being evaluated differently. This suggests that greater standardisation of methodology for 
evaluating outcomes of habitat enhancement would be helpful in order to better evaluate the net effect on reptiles. The progressive, stage bound criteria that I suggest as a framework could be helpful for framing monitoring requirements of future studies. Some flexibility in the monitoring programme for outcome evaluation is allowed by this framework, which is probably important given that different studies will have different resource limitations. This is because studies are evaluated against a continuum of increasing monitoring requirements and resources ranging from relatively quick and easy measures (Stages 1 and 2) to more time-consuming and resource-intensive measures (Stages 3 and 4). Therefore, studies only adequately resourced to monitor population indices for a short time frame can still be evaluated within an overarching standardised framework as demonstrating a degree of success.

However, even with the flexibility allowed by the assessment criteria applied to the assessing each case reported by the literature, 15\% of cases could not be assessed against any criterion. Of those that could, most were assessable at Stage 1, followed by Stage 3, Stage 2 and Stage 4. It was expected that the number of cases assessable against each stage would decrease due to the increasing rigour and resources required for evaluation as one moves from Stage 1 to Stage 4. However, fewer cases were assessable at Stage 2 than expected by this assumption. Where outcomes for relatively r-selected species were being evaluated, a Stage 3 assessment of demographic effects may been achievable in a relatively short post-enhancement time frame, overshadowing the need to report evidence of reproduction. Alternatively, evidence of reproduction may have gone undetected, for example in species where neonates have a much lower detection probability than adults or require specific methods to be detected (e.g. spur-thighed tortoises in Moulherat et al. (2014)). Some cases could not be assessed against any criterion because the enhancement technique used formed part of a broader conservation strategy being applied to a reptile population and insufficient information was reported to allow the direct effect of enhancement to be evaluated (e.g. artificial burrows used in a translocation of tuatara; Nelson et al. (2002)). Measures of reptile or herpetofaunal community responses such as species richness or assemblage dissimilarity were also often reported in place of individual species responses. This is understandable because many herpetofauna occur at low densities or have low detection probabilities, meaning that one of the key challenges is getting a large enough sample size for each species present, making assessment of community attributes convenient when sufficient species-specific information is lacking (Germano and Bishop, 2009). However, reliance on community attributes as outcome indicators may mask negative effects on rarer species, therefore provision of information on species-specific responses, even at the level of species presence-absence in enhanced habitat, would improve inference of the net effect on reptile populations.

Modelling the outcomes demonstrated by a study as an ordinal strength of evidence variable against the time elapsed since enhancement suggested that studies with limited 
resources would benefit from prioritising either a temporal baseline, or a longer post-enhancement monitoring time frame, rather than seeking to incorporate additional sites as spatial references. This is because the outcomes of cases arising from studies with this experimental design had a positive correlation with the amount of time elapsed post-enhancement. Therefore it is expected that the early results of these studies will be self-reinforcing; with positive results at the early stages more likely to remain positive over a long-term (i.e. 100 year) time frame than studies using a spatial reference for evaluating the outcomes of enhancement for a reptile population. In particular, the effect of using a baseline (i.e. a before-after study design) for outcome evaluation was significant, with studies using this design tending to report higher success outcomes over the range of post-enhancement time frames monitored by studies in this dataset. It is of note that the predicted failure rates of studies using a negative (no enhancement applied) or positive (representing a pristine or high-quality habitat) reference were higher than for studies that only monitored enhancement sites. This may reflect a positive reporting bias, particularly at Stage 1 (use of enhanced habitat), arising from studies that only monitored enhancement sites, because studies including additional non-treatment sites should be better at identifying species present in the landscape that have not colonised the enhanced patches which represent a failure against Stage 1. Alternatively, studies with spatial reference sites could set the expectation of use by reptile species too high if barriers to colonisation may exist outside of the measured habitat patches. This effect may be particularly pronounced in the many species of reptile that are relatively sedentary, or in habitat specialists occupying landscapes where a matrix that facilitates dispersal into all suitable habitat patches is lacking (e.g. Berry et al. (2005) and Gebauer et al. (2013)). Additionally, in species occurring at low densities in the landscape, or with extremely cryptic habits, patch-based monitoring of species presence/absence may fail to detect use of enhanced patches. In these cases, habitat use by a species may be better assessed by tracking the movements of individuals to determine whether they encountered any enhanced patches (e.g. Carter (2012)) or incorporation of species detection probability in assessment of patch occupancy (e.g. MacKenzie et al. (2002); Royle and Dorazio (2008)) might be more accurate than reliance on indices of species presence / absence in enhanced patches.

Despite the biases and limitations of the data set, there was reasonable evidence that reptile species do use enhanced habitats, with a high Stage 1 success rate reported from a large number of cases and a significantly positive net effect of enhancement, albeit with a small effect size. Rates of reproduction in enhanced habitats were also high, but was relatively under-reported in studies meaning lower confidence in the net success rates at this stage. Based on these results, the data suggest that habitat enhancement should be a viable method for increasing the total area occupied by a species. Under the small population scenario, it follows that this effect is capable of reducing extinction risk because species occupying a larger range tend to have more abundant populations (Connor and McCoy, 
1979; Hanski, 1999; MacKenzie and Nichols, 2004). Therefore, I believe that this habitat conservation strategy has an important role to play in reptile species conservation.

However, the non-uniformity of success rates across stages indicates that short-term success is not necessarily a good predictor of longer-term success at higher stages, which was relatively lacking. Success or failure against Stage 3 was reasonably well-reported but indicated a much lower incidence of habitat enhancement being able to result in a benefit to the population. While success rates against stage 4 were relatively low (43\%), this rate was calculated from only seven cases of reported from three studies, meaning that a robust conclusion cannot be reached on the question of how likely an enhancement treatment will result in the proposed ultimate goal of a habitat enhancement applied for reptile conservation; a viable population.

Upon further examination, the low net success rate of enhancement cases assessed against Stage 3 was due to the low rates of success of restoration-driven enhancements at this stage. Restoration-driven habitat enhancement did have a positive impact on reptile population processes in some cases, for example Steen et al. (2013) found that the number of marked individuals of the Teiid lizard Aspidoscelis sexlineatus was significantly higher in restored longleaf pine (Pinus palustris) forest relative to negative reference sites where the natural fire regime continued to be suppressed. However, when the entire reptile community was examined, species favouring open-canopy habitats typical of longleaf pine forests increased in apparent abundance but other species, for example the snakes Diadophis punctatus and Tantilla coronata and the skink Scincella lateralis, decreased in apparent abundance relative to the negative reference sites (Steen, 2013). Similarly, regular burning to maintain tallgrass prairie in the absence of bison browsing and prairie fires resulted in a decrease in numbers of the snakes Lampropeltis triangulum and Diodophis punctatus (Wilgers and Horne, 2006). The net conservation implications of reptile population declines in response to ecological restoration were unclear, given that a negative impact of habitat enhancement in the data set was mostly documented for reptiles with a 'Least Concern' conservation status. However, Knox et al. (2012) documented a negative impact of an otherwise well-intentioned restoration action (livestock exclusion to promote recovery of native vegetation in habitat occupied by invasive predators) on the Near Threatened gecko Naultinus gemmeus. Interestingly, the negative impact of grazer removal intended to allow recovery of native plant species was only identified at shrubland sites dominated by Copromsa shrub species, and not at treeland sites dominated by the tree Kunzea robusta, indicating that the impacts of restoration can be context-specific (Knox et al., 2012). The pooled average success rate against Stage 3 of enhancements carried out for the purposes of reptile conservation, conservation of non-reptilian fauna and reconciliation were much higher, at $70 \%$. This suggests that manipulating habitat for ecological restoration likely involves a trade-off between the abundance of some reptile species and habitat conservation values, reflecting a previous caution by Simberloff (1990) 
that extensive or indiscriminate re-vegetation could endanger resident fauna. It is therefore recommended that population responses of threatened reptiles be monitored in ecological restoration projects to identify unintentional negative effects and allow informed adaptation of the management regime to stem any resulting declines. Ideally, restoration programmes at sites containing threatened reptiles will be guided by an understanding of their habitat preferences.

Therefore, I conclude that there is sufficient evidence that habitat enhancement can play an important role in reptile species conservation by creating a larger area that can be occupied by a species. Habitat enhancement is capable of benefiting reptile populations, but probably requires alignment between enhancement goals and the habitat requirements of the target species. Standardisation of the methodology and indicators measured is required for better assessment of the net effect of enhancement on reptile species conservation. Further studies are also required. In particular there is a need for more studies that monitor the long-term population trends, or are capable of robustly estimating demographic parameters for population viability analysis (PVA), of reptiles inhabiting enhanced habitats (see Beissinger and McCullough (2002) for a thorough treatment of parameter estimation for, and limitations of, PVA). Because a rigorous, and realistic framework is lacking for assessment of habitat restoration and reconciliation for animal species conservation, the analyses presented in this paper will serve as a useful starting point for further evaluation of the suitability of habitat enhancement techniques for conserving reptile, and wildlife, species. 


\section{Chapter 3}

\section{Which habitat characteristics are correlated with species occupancy and richness in insular lizard communities?}

\subsection{Introduction}

Habitat loss due to human activity is considered the greatest threat to global biodiversity, with an estimated $39 \%$ to $50 \%$ of the Earth's ice-free terrestrial surfaces being affected (Tilman et al., 1994; Vitousek et al., 1997; Hanski, 2011). The term 'habitat loss' can manifest as a (1) decreased total area of suitable habitat, (2) deteriorated habitat quality, or (3) increased fragmentation of habitat patches, with all three often together in the same landscape (Hanski, 2011). Organisms experiencing habitat loss are exposed to greater extinction risk through an area's decreased carrying capacity, or by disruption of spatially dependent metapopulation processes such as dispersal (Fahrig, 1997; Hanski, 1999; Fahrig, 2003; Hanski, 2011).

Of the vertebrate taxa, herpetofauna (reptiles and amphibians) are the most strongly affected by habitat loss (White et al., 1997). Herpetofauna are extremely sensitive to habitat changes due to the ecological and physiological constraints of ectothermy. The majority of species are small-bodied, and have small home ranges and limited dispersal abilities therefore cannot easily escape the effects of habitat destruction (Huey, 1982; Woinarski and Ash, 2002; Anadón et al., 2006a; Castellano and Valone, 2006). Unsurprisingly, habitat loss is considered one of the primary threats to the survival of the world's c. 11,000 reptile species (Böhm et al., 2013; Uetz, 2019). The major 'services' provided to reptiles by habitat are: opportunities for thermoregulation, food, and protection from predators (Vitt et al., 1998; Santos et al., 2008). However on oceanic islands, the increased predation pressure from introduced species drive extinction rates beyond those caused by habitat loss (Brooks et al., 2002; Böhm et al., 2013; Doherty et al., 2016). Therefore, it can be difficult to untangle 
the effects of habitat loss on reptiles from those of introduced species in island environments (Towns, 1996; Norbury, 2001; Hoare et al., 2007b; Norbury et al., 2013).

The islands of New Zealand are recognised as one of the world's 25 biodiversity hotspots for endemism, and support at least 106 lizard species (Myers et al., 2000; Brooks et al., 2002; van Winkel et al., 2018). The continental origin of the Zealandia subcontinent coupled with c. 80 my of isolation from Gondwana and substantial submergence have created a fauna that retains some archaic continental lineages (for example, tuatara and Leiopelmatid frogs), but has evolved to closely resemble the fauna of oceanic islands (Daugherty et al., 1993). The endemic lizards originated from two separate trans-oceanic dispersal events of a skink and a Diplodactylid gecko (Chapple et al., 2009; Nielsen et al., 2011). The progeny of these two original lineages adaptively radiated to fill almost every available habitat in the New Zealand environment, but the majority (83\%) are now threatened by the combined effects of habitat loss, invasive species, and (to a lesser degree) illegal harvesting (Towns and Daugherty, 1994; Chapple et al., 2009; Nielsen et al., 2011; Hitchmough et al., 2016a).

Conservation efforts for New Zealand reptiles to date have focused on the control or eradication of invasive species, and translocation of threatened reptiles to predator-free sanctuaries (Towns et al., 2001). This closely parallels approaches for reptile conservation on other oceanic islands (Daltry et al., 2001; Russell et al., 2016; Daltry et al., 2017). However, there is increasing interest in restoring or reconciling habitat for lizards on the New Zealand mainland, with a strong public appetite to create enhanced habitat patches (DOC, 2005, 2009a,b,c,d; Lettink and Knox, 2011).

It is important to understand the habitat requirements of target species if restoration attempts are to be successful for their conservation. For example, in the previous chapter of this thesis, it was found that habitat enhancement for ecosystem restoration produced less successful outcomes for reptiles than enhancement that was targeted for one or more reptile species.

Habitat preferences of a number of New Zealand reptile species have been studied, but our understanding is still incomplete (East et al., 1995; Towns, 1996; Barr, 2009; Baling et al., 2016). One disadvantage of many previous studies has been the reliance on population indices for understanding habitat use (although see Teal (2006) and Wiles (2016)). Indices are potentially confounded if the probability of detecting individuals or species is less than one and varies between habitat types (MacKenzie, 2006; Lettink and Cree, 2007; Zipkin et al., 2010). Many reptile species have very low detection probabilities due to their extreme crypsis, making it difficult to gain an unbiased or precise understanding of habitat preferences (Mazerolle et al., 2007; Steen, 2010; Ward et al., 2017). Another consideration is the effect of invasive predators on habitat use. For example, the presence of Pacific rats (Rattus exulans) has been shown to affect habitat use in two New Zealand lizards (Towns, 1996; Hoare et al., 2007b). This implies that lizard detection probability may vary in 
response to mammalian predators.

\subsubsection{Aims}

I examined terrestrial lizard communities in habitat patches within mammal-free and mammal-invaded sites with four aims:

1. To describe the environments available for terrestrial lizards in mammal-free and mammal-invaded coastal habitats. Due to the overarching focus of this dissertation on habitat enhancement, I was particularly interested in variables that could be manipulated to increase habitat quality, rather than fixed variables such as aspect or slope. To achieve this, I focussed on measuring habitat characteristics hypothesised to reflect habitat quality for terrestrial reptiles via one or more effects on: opportunities for thermoregulation (canopy cover at $1 \mathrm{~m}$ above ground level, occurrence of rock), (2) refuge from predators (vegetative ground cover, occurrence of rock, canopy cover at $0 \mathrm{~m}$ above ground level, and plants with a divaricating or complex growth habit), and (3) food (occurrence of fruiting or flowering plants known to provide food for New Zealand lizards).

2. To characterise the terrestrial lizard communities in coastal environments in the Wellington region of New Zealand in order to test the hypothesis that both habitat characteristics and invasive mammal presence affect the composition of lizard communities. Based on the findings of previous studies on the effects of an invasive rodent species (Rattus exulans) on lizard community structure, and observed patterns in extinction and range contractions, I predicted that terrestrial lizard communities inhabiting mammal-invaded areas would be less species-rich than those in mammal-free areas (Whitaker, 1973; Towns, 1991; Towns and Daugherty, 1994).

3. To calculate the individual detection probabilities of frequently encountered species, and examine how these are influenced by observational processes caused by the sampling process. Here, I hypothesised that individual detection probabilities of lizards surveyed by daytime visual estimation would be affected by the following survey-specific covariates: time of year, time of day, air temperature, and survey effort.

4. Hierarchical modelling was used to test the hypothesis that at least one of the habitat characteristics measured was significantly correlated with lizard species' site occupancy, after accounting for their effects on detection probability. 


\subsection{Methods}

\subsubsection{Study sites}

All study sites were within coastal environments in the Greater Wellington Region on the North Island of New Zealand (Fig. 3.1). Thirty-one $80 \mathrm{~m}^{2}$ spatially independent patches were randomly placed within four study sites (hereafter, 'sites') that were either mammal-free or mammal-invaded (i.e. 7-8 patches per site). Lizard communities and habitat characteristics within these patches were sampled using rectangular quadrats measuring $4 \times 20 \mathrm{~m}$.

The mammal-free sites, Mana Island Scientific Reserve (217 ha) and Matiu / Somes Island Scientific and Historic Reserve (24.8 ha), are offshore islands supporting a mixture of regenerating indigenous forest, scrub and exotic grasslands (Table 3.1). Both islands were extensively altered by European agriculture, but now support a mixture of regenerating indigenous forest, shrubland and exotic grassland due to substantial restoration planting (Miskelly, 2010). Historically, these islands were only invaded by a single rodent species each; mice were eradicated from Mana Island by 1990 and ship rats (Rattus rattus) eradicated from Matiu by 1989 (Towns et al., 2001). An endemic reptilian predator of lizards, tuatara (Sphenodon punctatus), has been reintroduced to Matiu but not Mana Island (Miller et al., 2010).

The two mainland sites, Te Motu Kairangi / Miramar Peninsula (area of study site $=474$ ha) and Turakirae Head Scientific Reserve (124 ha), are on the south coast of the Wellington and have been invaded by the full suite of mammalian predators. The Miramar Peninsula was an island until the 1400s, when a large earthquake uplifted the Rongotai Isthmus that connects it to the mainland today (Best, 1923; Pillans and Huber, 1992). Today Miramar is covered by a mixture of privately-owned suburbia and public land managed by the Wellington City Council. Landcover types include suburban infrastructure, sand and cobble beaches, exotic scrub, native shrubland, coastal cliffs and regenerating indigenous forest (Thompson et al., 2003). Brushtail possums (Trichosurus vulpecula) were eradicated from the Miramar Peninsula in 2006, and several pest trapping initiatives are currently in operation on both private and public land (Balls, 2019). Turakirae Head Scientific Reserve is publicly owned land managed by the New Zealand Department of Conservation, and is leased for grazing. It is mostly covered by grey scrub dominated by small-leaved shrubs (Coprosma propinqua, Olearia solandri and Ozothamnus leptophyllus) and the vine Muehlenbeckia complexa. This is interspersed by rock outcrops, cobbles and gravels, swampy flaxland, manuka scrub, and exotic grassland (Bagnall, 1975). It is subject to light grazing by sheep, horses and feral goats, and had received a negligible amount of pest control before this study (A. Hulme-Moir, pers. comm.).

The full range of species listed in Table 3.1 are likely to have been historically present at 
all sites (along with the regionally extinct robust skink O. alani and speckled skink $O$. infrapunctatum), with a few exceptions (Romijn et al., 2012; van Winkel et al., 2018; Melzer et al., 2019). The historical distribution of glossy brown skinks (O. zelandicum) and goldstripe geckos (W. chrysosiretica) appears to be more restricted to the west coast of the North Island, so these species may be naturally absent from all sites except for Mana Island. Newman's speckled skink (O. newmani) was introduced into the Wellington region through a conservation-driven translocation to Mana Island carried out before the speckled skink species complex was identified (Melzer et al., 2019). 


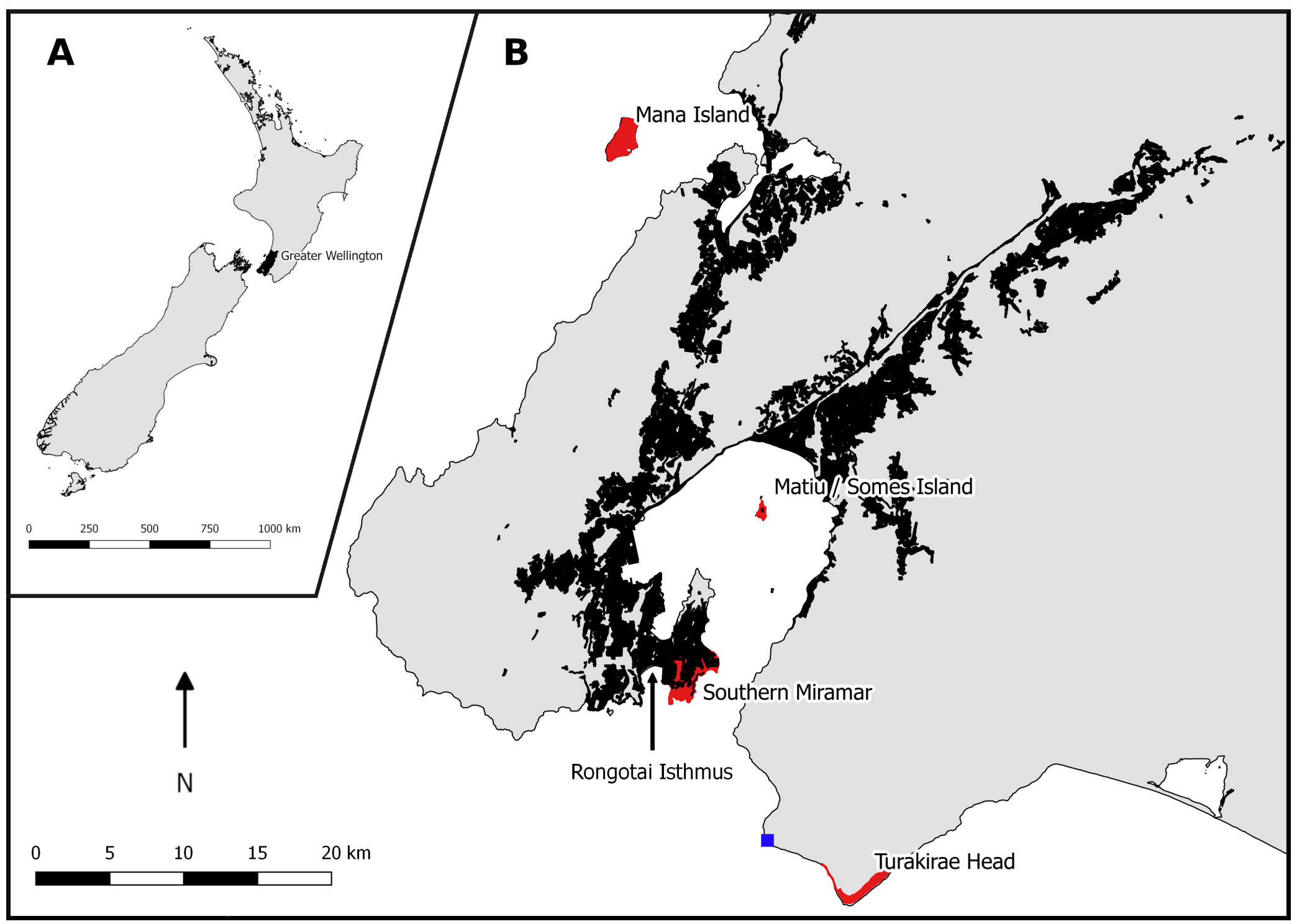

Figure 3.1: A. Location of the greater Wellington region in New Zealand. B. Location of all sites mentioned in this chapter. Study sites are in red. The blue square indicates the location of the Baring Head weather station. Urban and suburban infrastructure is indicated by black shading. 
Table 3.1: Characteristics of study sites at the time of survey (2016-2017). Use of the term 'rats' refers to Rattus rattus and R. norvegicus. 'Mustelids' refers to ferrets Mustela furo, stoats M. erminea and weasels M. nivalis. Lizard species abbreviations are as follows. Geckos (Diplodactylidae): $\mathrm{HD}=$ Hoplodactylus duvaucelii, $\mathrm{MS}=$ Mokopirirakau aff. 'southern North Island', NP = Naultinus punctatus, WC $=$ Woodworthia chrysosiretica, $\mathrm{WM}=W$. maculata. Skinks: $\mathrm{OA}=$ Oligosoma aeneum, $\mathrm{ON}=\mathrm{O}$. newmani, $\mathrm{OK}=\mathrm{O}$. kokowai, $\mathrm{OM}=\mathrm{O}$. macgregori, $\mathrm{OO}=\mathrm{O}$. ornatum, $\mathrm{OP}=0$. polychroma, $\mathrm{OZ}=0$. zelandicum. ${ }^{*}$ indicates that the species has been translocated to the study site. ${ }^{A}$ indicates an arboreal lizard species and ${ }^{S}$ a semi-arboreal species. Species listed with no signifier in superscript are terrestrial. Sources: Bagnall (1975); Whitaker (1982); Newman (1994); Watts and Gibbs (2002); Miskelly (2010); Romijn et al. (2012); van Winkel et al. (2018); Balls (2019); Bell (2019b); Melzer et al. (2019), and A. Hulme-Moir pers. comm.

\begin{tabular}{|c|c|c|c|}
\hline Site & Invasive mammal status & "Habitat overview & Lizard species \\
\hline Mana Island & $\begin{array}{l}\text { Mammal-free offshore island. Mice } \\
\text { (Mus musculus) are thought to have } \\
\text { arrived in } 1834 \text {, and were eradicated } \\
\text { between } 1989 \text { and } 1990 \text {. }\end{array}$ & $\begin{array}{l}\text { Patches of native shrubland in areas with and } \\
\text { without cobbles, rank grassland and regenerating } \\
\text { coastal broadleaf forest. Grazed by cattle (Bos } \\
\text { taurus) and sheep (Ovis ares) between } 1832 \text { and } \\
\text { 1986. Extensive revegetation has been carried out } \\
\text { since the } 1980 \text { 's. }\end{array}$ & $\begin{array}{l}\mathrm{OA}, \mathrm{OM}, \mathrm{OK}^{*}, \\
\mathrm{ON}^{*}, \mathrm{OP}, \mathrm{OZ}^{\prime} \\
\mathrm{WM}^{\prime}, \mathrm{WC}, \mathrm{HD}^{*}, \\
\mathrm{MS}^{* A}, \mathrm{NP}^{* A}\end{array}$ \\
\hline Matiu & $\begin{array}{l}\text { Mammal-free offshore island. Ship rats } \\
\text { (R. rattus) eradicated in } 1989 .\end{array}$ & $\begin{array}{l}\text { Almost all native vegetation was cleared from } \\
\text { Matiu before } 1870 \text {. Extensive revegetation has } \\
\text { been underway since } 1981 \text {. Patches of grass- } \\
\text { and flax/grass/shrub-land and short regenerating } \\
\text { coastal broadleaf forest. Ungrazed (areas currently } \\
\text { grazed by sheep were not surveyed). }\end{array}$ & $\begin{array}{l}\mathrm{OA}, \mathrm{OK}, \mathrm{OO}^{*}, \\
\mathrm{OP}, \quad \mathrm{WM}^{S}, \\
\mathrm{MS}^{* A}, \mathrm{NP}^{* A}\end{array}$ \\
\hline $\begin{array}{l}\text { Southern } \\
\text { Miramar }\end{array}$ & $\begin{array}{l}\text { Mice, rats, hedgehogs (Erinaceus } \\
\text { europaeus) and mustelids controlled } \\
\text { by community trapping on private } \\
\text { and public land. Cats (Felis catus) very } \\
\text { likely present due to close proximity to } \\
\text { residential areas. }\end{array}$ & $\begin{array}{l}\text { Mosaic of patches of short regenerating mahoe } \\
\text { forest, gorse scrub, mixed coastal shrubland, } \\
\text { suburban infrastructure, grassland and cobble } \\
\text { beach. Ungrazed, but grass mown in places, and } \\
\text { rabbits (Oryctolagus cuniculus) present. Possums } \\
\text { (Trichosurus vulpecula) eradicated in } 2006 \text {. }\end{array}$ & $\begin{array}{l}\mathrm{OA}, \mathrm{OP}, \mathrm{WM}^{S} \\
\mathrm{NP}^{A}\end{array}$ \\
\hline Turakirae Head & $\begin{array}{l}\text { Mustelids, cats, hedgehogs, rats, } \\
\text { possums and mice present. Rabbits and } \\
\text { hares (Lepus europaeus) likely present. } \\
\text { No known pest control prior to } 2019 .\end{array}$ & $\begin{array}{l}\text { Mosaic of grey scrub and swampy flaxland } \\
\text { interspersed with rock cobbles and fractured } \\
\text { boulders. Grazed by cattle and sheep since the late } \\
\text { 1840s. Low-intensity grazing by domestic sheep } \\
\text { and horses, and feral goats. }\end{array}$ & $\begin{array}{l}\mathrm{OA}, \mathrm{OK}, \mathrm{OP} \\
\mathrm{WM}^{S}\end{array}$ \\
\hline
\end{tabular}




\subsubsection{Lizard surveys}

Visual encounter surveys (VES) of lizards were considered to be the best option for examining their habitat use, because this method did not require alteration of habitats by the placement of traps or artificial retreats. Eight $20 \times 4 \mathrm{~m}\left(80 \mathrm{~m}^{2}\right)$ quadrats were placed at each site using a randomly generated waypoint and bearing to orient the $20 \mathrm{~m}$ midline (generated in QGIS 2.18 (QGIS Development Team, 2016), and LibreOffice Calc, respectively). The exception was Turakirae Head, where the random points for only seven quadrats proved to be accessible. Quadrats were spaced at least $100 \mathrm{~m}$ apart to minimise the chance of lizards moving between them during sampling (Lettink et al., 2010). Therefore it is probably reasonable to view each of these quadrats as independent habitat patches.

Daytime VES for lizards were carried out at each quadrat between 8:47 and 19:47 NZST by me and an additional trainee surveyor when available between December 2016 and May 2017 (the austral summer/autumn). All quadrats were surveyed on six separate occasions. Surveys were not conducted on days where rainfall exceeded occasional light showers, or during ambient temperatures less than $11^{\circ} \mathrm{C}$ because of the negative effect on both lizard emergence and detection in refugia (Hoare et al., 2009; Hare, 2012; Lettink and Monks, 2016). Surveyors first slowly walked the quadrat midline from start to finish while scanning the ground and vegetation for active lizards with the aid of binoculars (Fig. 3.2). Surveyors then walked back to the start of the quadrat midline while examining all searchable refugia within $2 \mathrm{~m}$ each side of the quadrat with the aid of a torch (Fig. 3.2). The position of each lizard encountered during the survey was marked with a numbered clothes peg to minimise the risk of double-counting the same individual (Fig. 3.2). The time taken to thoroughly search each quadrat depended on the amount of searchable habitat available, and was recorded at the end of survey to enable search effort to be calculated in person-hours. Where possible, the species of each lizard encountered was recorded. Lizards that could not be identified to species level (for example, when only the tail was seen as a lizard ran under cover) were recorded as either an unidentified skink or gecko. After the survey was finished, surveyors recorded the location of each clothes peg used to mark a lizard sighting as the distance along the quadrat midline $(0.0-20.0 \mathrm{~m})$ and the perpendicular distance from the midline (as $-2.00 \mathrm{~m}-0.00 \mathrm{~m}$ for sightings on the left side of the midline and $0.00-2.00 \mathrm{~m}$ for sightings on the right side). This allowed any sightings outside the quadrat boundary (for example, more than $2 \mathrm{~m}$ from the midline) to be later excluded from analysis. Markers were removed after completion of each survey.

The length of time between the first and last survey of each quadrat spanned no longer than 25 days to reduce the chance of fluctuation in net abundance. This had the disadvantage that sites were surveyed within different months (Fig. 3.3). Two steps were taken to assess the resulting level of autocorrelation between site and survey date. All 


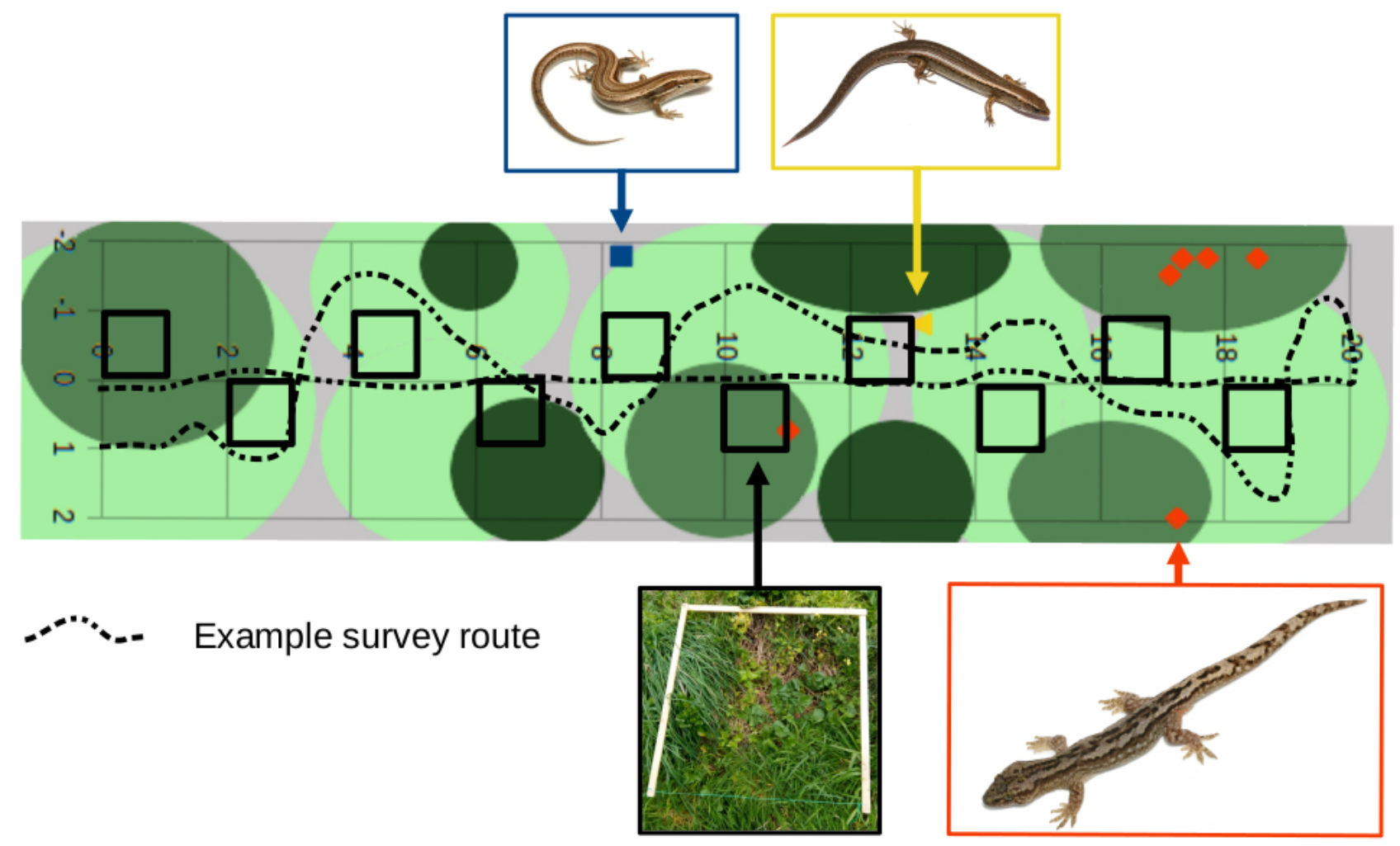

Figure 3.2: Schematic of lizard and habitat sampling at the $80 \mathrm{~m}^{2}$ quadrats. The coloured points and survey route provide an example of visual estimation sampling (VES) for lizards and the encounter data from a single survey. Lizard species pictured are Oligosoma polychroma (top left), O. aeneum (top right), and Woodworthia maculata (bottom right). The black squares show the array of $1 \times 1 \mathrm{~m}$ quadrats for habitat sampling. Lizard photos used with permission from Trent Bell.

Mana Island quadrats were resurveyed in December 2017 to allow comparison of lizard community attributes between visits. The hourly maximum, mean, and minimum temperatures at the time of each survey were accessed from the Baring Head weather station (agent number: 18234, lat: -41.407, long: 174.867, data type: “Max Min Temperature") via the CliFlo database (https://cliflo.niwa.co.nz) curated by the National Institute for Water and Atmosphere (NIWA). This weather station is within $37 \mathrm{~km}$ of all sites (Fig. 3.1). While there are other weather stations in the Wellington region that could have been used for more site-specific weather information (e.g. Mana Island AWS (agent number: 25531), Wellington Airport (3445), Porirua Elsdon Park EWS (41559)), the hourly "Max Min Temperature" data type was not available from these stations during the survey dates.

\subsubsection{Habitat data collection}

Eighteen $80 \mathrm{~m}^{2}$ quadrats $(N($ Mana Island $)=8, N($ Matiu $)=3, N($ Miramar $)=4, N($ Turakirae Head) = 3) were revisited between December 2018 and September 2019 to collect 


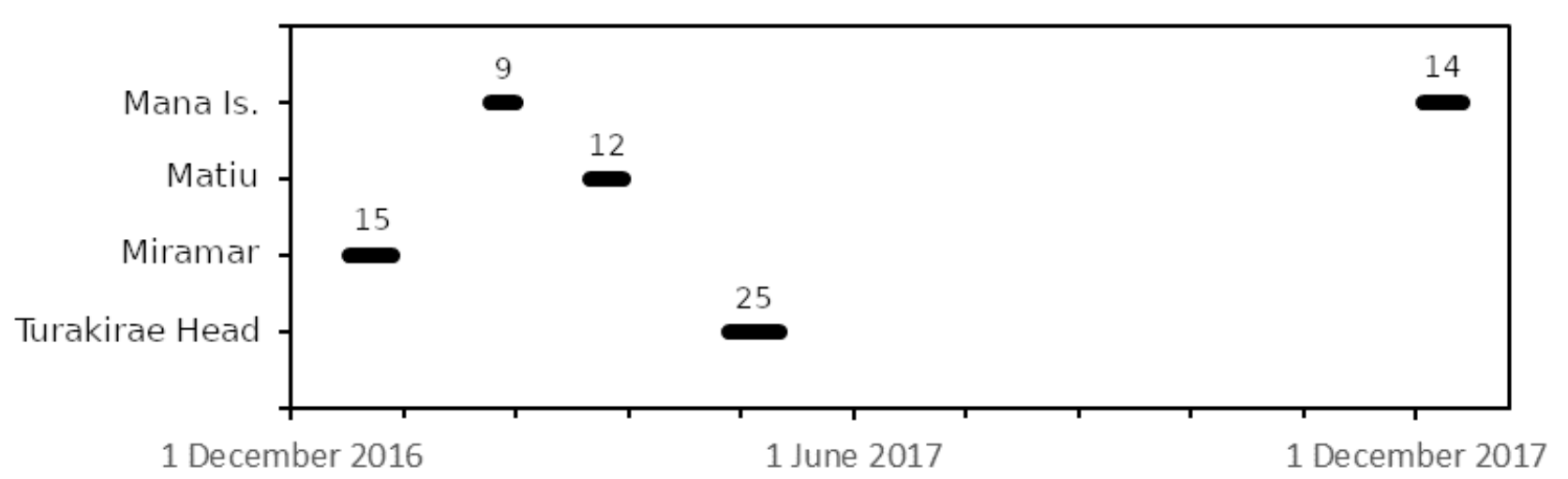

Figure 3.3: Time line of all lizard surveys. The numbers above each bar indicate the length of the survey period in days.

patch-specific habitat data. Habitat samples were taken from ten $1 \mathrm{~m}^{2}$ quadrats laid on alternating sides at $2 \mathrm{~m}$ intervals along the midline of each $80 \mathrm{~m}^{2}$ quadrat (Fig. 3.2). All vascular plant species, presence of rock larger than $20 \mathrm{~mm}$ diameter, and vegetative groundcover estimated to the nearest $10 \%$ were recorded. Where available, previous botanical surveys of each site were used to assist with plant identification (Bagnall, 1975; Watts and Gibbs, 2002; Clapcott and Gill, 2015; Ward, 2016). Canopy cover was measured at the middle of each $1 \mathrm{~m}^{2}$ quadrat at ground level and at $1 \mathrm{~m}$ above ground level as the modified canopy cover (CaCo) index (Tichý, 2016). To do this, the Gap Light Analysis Mobile Application (GLAMA) software was used to analyse canopy photographs taken on a Nokia 3 smartphone (polar camera lens, angle $=60^{\circ}$ ) (Tichý, 2016). This method appears to give consistent canopy cover measurements from photographs taken with a polar or hemispherical lens (Tichý, 2016; Bianchi et al., 2017).

\subsubsection{Statistical analysis}

\section{Habitat and pest mammal covariates}

The habitat data collected from the $80 \mathrm{~m}^{2}$ sample quadrats (alternatively, 'patches') could be separated into two categories: vegetation structure and cover types (Tables 3.2 and 3.3). Three covariates were used to describe vegetation structure: the averages of the ten canopy (at $0 \mathrm{~m}$ and $1 \mathrm{~m}$ above ground level) and groundcover measurements taken per patch (Table 3.2). The presence/absence data for plant species and rocks in each of the ten $1 \mathrm{~m}^{2}$ quadrats per patch were used to construct a set of seven variables describing the relative abundance of cover types hypothesised to be important for lizards (Table 3.3). The pest status of each site was determined from the literature and personal communication with people involved in site management (Whitaker (1982); Miskelly (2010); Balls (2019), A. Hulme-Moir pers. comm., and N. Fitzgerald and S. Hartley unpub. data). This information was translated into a binary variable ( 0 : only rodents historically present and no mammals present since 
1990, 1: all mammalian lizard predators present). Co-linearity among these 11 variables was examined using non-parametric Spearman $\rho$ correlation tests (Table 3.6).

Table 3.2: Patch-specific covariates and hypotheses about how they affect observed lizard species data via an effect on detection probability $(p)$ and/or a population metric (in this case, probability of patch occupancy $\left(\psi_{i}\right)$ or patch-scale abundance $\left.\left(N_{i}\right)\right)$.

\begin{tabular}{lll}
\hline \hline Covariate & Description & Prediction(s) \\
\hline Pests & Binary covariate for presence (1) or & Negative effect on $\psi_{i}$ and /or $N_{i}$ \\
& absence (0) of introduced mammals. & $\begin{array}{l}\text { due to increased predation pressure, } \\
\text { negative effect on } p \text { due to effect on } \\
\end{array}$ \\
& lizard behaviour.
\end{tabular}

\begin{tabular}{ll}
$\begin{array}{l}\text { Vegetation } \\
\text { structure }\end{array}$ & $\begin{array}{l}\text { Average of ten measurements taken } \\
\text { per plot. }\end{array}$ \\
\hline $\mathrm{C} 1$ & $\begin{array}{l}\text { Canopy cover in \% at } 1 \mathrm{~m} \text { above } \\
\text { ground level (modified } \mathrm{CaCo}(1 \mathrm{~m}) \text { ) }\end{array}$ \\
& $\begin{array}{l}\text { measured using the GLAMA } \\
\text { android app (Tichý }(2016)) .\end{array}$ \\
$\mathrm{C} 0$ & Canopy cover in \% measured at \\
& ground level (modified $\mathrm{CaCo}(0 \mathrm{~m}))$.
\end{tabular}

GC Groundcover (defined as vegetation with a height $<1 \mathrm{~m}$ ) within a $1 \mathrm{~m}^{2}$ sampling quadrat estimated to the nearest $5 \%$.

Negative effect on $\psi_{i}$ and/or $N_{i}$ due to decreased solar radiation reaching the ground, no effect on $p$.

Positive effect on $\psi_{i}$ and/or $N_{i}$ due to increased protection from predators, negative effect on $p$ due to increased difficulty of finding lizards in habitats that have a complex structure.

Positive effect on $\psi_{i}$ and/or $N_{i}$ due to increased protection from predators, negative effect on $p$ due to increased difficulty of finding lizards in terrestrial habitat with a complex structure.

\begin{tabular}{|c|c|c|}
\hline $\begin{array}{l}\text { Cover } \\
\text { type }\end{array}$ & $\begin{array}{l}\text { Proportion of ten } 1 \mathrm{~m}^{2} \text { sampling } \\
\text { quadrats per plot with cover type } \\
\text { present. }\end{array}$ & \\
\hline Rock & $\begin{array}{l}\text { Presence of gravel (particle size: } 20 \\
\text { - } 70 \mathrm{~mm} \text { diameter), cobbles }(70-300 \\
\mathrm{mm}) \text {, boulders }(300-1,500 \mathrm{~mm}) \text { or } \\
\text { outcrops }(>1,500 \mathrm{~mm}) .\end{array}$ & $\begin{array}{l}\text { Positive effect on } \psi_{i} \text { and/or } \\
N_{i} \text { due to increased protection } \\
\text { from predators and provision of } \\
\text { thermally suitable refuges, positive } \\
\text { effect on } p \text { due to relative ease of } \\
\text { searching underneath rock refugia } \\
\text { and in rock crevices. }\end{array}$ \\
\hline $\mathrm{PHO}$ & $\begin{array}{l}\text { Flax species Phormium tenax or } P . \\
\text { cookianum. }\end{array}$ & $\begin{array}{l}\text { Positive effect on } \psi_{i} \text { and/or } N_{i} \\
\text { due to increased protection from } \\
\text { predators and provision of nectar } \\
\text { as a food source, negative effect } \\
\text { on } p \text { due to increased difficulty of } \\
\text { finding lizards in habitats that have } \\
\text { a complex structure. }\end{array}$ \\
\hline
\end{tabular}


Table 3.3: Patch-specific covariates and hypotheses continued. Plant species labelled with an $^{E}$ are exotic species.

\begin{tabular}{|c|c|c|}
\hline Covariate & Description & Prediction(s) \\
\hline $\begin{array}{l}\text { Cover } \\
\text { type }\end{array}$ & $\begin{array}{l}\text { Proportion of ten } 1 \mathrm{~m}^{2} \text { sampling } \\
\text { quadrats per plot with cover type } \\
\text { present. }\end{array}$ & \\
\hline DivS & $\begin{array}{l}\text { Divaricating shrubs, including: } \\
\text { Melicytus crassifolius, M. obovatus, } \\
\text { Coprosma propinqua, C. rubra, C. } \\
\text { aereolata. }\end{array}$ & $\begin{array}{l}\text { Positive effect on } \psi_{i} \text { and/or } N_{i} \\
\text { due to increased protection from } \\
\text { predators and provision of fruit } \\
\text { as a food source, negative effect } \\
\text { on } p \text { due to increased difficulty of } \\
\text { finding lizards in habitats that have } \\
\text { a complex structure. }\end{array}$ \\
\hline COPlg & $\begin{array}{l}\text { Larger-leaved Coprosma shrubs, } \\
\text { including: C. propinqua hybrids, C. } \\
\text { repens, C. robusta. }\end{array}$ & $\begin{array}{l}\text { Positive effect on } \psi_{i} \text { and / or } N_{i} \text { due } \\
\text { to provision of fruit as a food source, } \\
\text { no on } p \text { as this shrub type is not } \\
\text { structurally complex. }\end{array}$ \\
\hline GS & 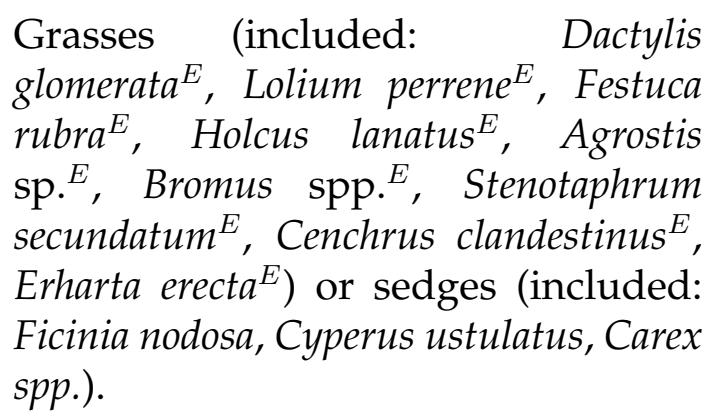 & $\begin{array}{l}\text { Positive effect on } \psi_{i} \text { and/or } N_{i} \\
\text { due to increased protection from } \\
\text { predators, negative effect on } p \text { due } \\
\text { to increased difficulty of finding } \\
\text { lizards in habitats that have a } \\
\text { complex structure. }\end{array}$ \\
\hline MUE & Muehlenbeckia spp. vines. & $\begin{array}{l}\text { Positive effect on } \psi_{i} \text { and/or } N_{i} \\
\text { due to increased protection from } \\
\text { predators and provision of fruit } \\
\text { as a food source, negative effect } \\
\text { on } p \text { due to increased difficulty of } \\
\text { finding lizards in habitats that have } \\
\text { a complex structure. }\end{array}$ \\
\hline Vines & $\begin{array}{l}\text { Perennial trailing plants and lianes } \\
\text { not in Muehlenbeckia genus. Species } \\
\text { included: Tetragonia spp., Calystegia } \\
\text { spp, Convulvulus arvensis }{ }^{E} \text { and } \\
\text { Clematis forsteri. }\end{array}$ & $\begin{array}{l}\text { Positive effect on } \psi_{i} \text { and/or } N_{i} \\
\text { due to increased protection from } \\
\text { predators and provision of fruit } \\
\text { as a food source, negative effect } \\
\text { on } p \text { due to increased difficulty of } \\
\text { finding lizards in habitats that have } \\
\text { a complex structure. }\end{array}$ \\
\hline
\end{tabular}

\section{Lizard community attributes}

Initial exploration of lizard community composition was based on abundance indices for each $80 \mathrm{~m}^{2}$ quadrat. This figure was zero if the species was not observed in a patch during any of the six repeated surveys, otherwise it equalled the average number of individuals observed per survey. Observed species richness was calculated as the cumulative number 
of species encountered per patch over the six repeated surveys, and compared between sites using a quasi-Poisson GLM in R version 3.5.1 (R Core Team, 2018). Sightings that could not be identified to species-level were excluded from this analysis $(N=5)$. Multidimensional scaling (MDS) using Euclidean distances with Wisconsin double standardisation was used to examine how similar the observed lizard species compositions were between patches. This was performed in the vegan $\mathrm{R}$ package (Oksanen et al., 2019). I used a metric distance measure of dissimilarity because I was interested in capturing differences in species abundance as well as occupancy. Pairwise Spearman $\rho$ coefficients were calculated for preliminary examination of correlations between lizard species' relative abundances and patch covariates.

\section{Examination of individual detection probability in common species}

Lizard species detected in at least 10 of the VES quadrats were considered frequently encountered enough to attempt hierarchical modelling for estimation of population (local abundance, $N$ ) or metapopulation (patch occupancy, $\psi$ ) attributes. These species were: $O$. aeneum, O. polychroma and $W$. maculata. The encounter data were expressed as a vector of six repeated counts of sightings made during each survey of a VES plot. For example, an encounter history of 010220 indicated that the species was not encountered during visits one, three, and six to a plot, one individual was encountered during the second visit, and two individuals were encountered during the fourth and fifth visits.

Royle (2004) N mixture models with constant local (i.e. patch-scale) abundance were performed on the repeated count data in PRESENCE 2.12 (Hines, 2006) to calculate individual detection probability $(r)$ and examine sources of heterogeneity caused by the sampling regime. Briefly, $\mathrm{N}$ mixture models estimate individual detection probability $(r)$ from repeated count data by viewing the number of individuals $\left(n_{i t}\right)$ counted at site $i$ during survey $t$ as $n_{\max }$ binomial processes $\left(n_{\max }\right.$ is the maximum number of individuals counted during a single survey). That is, $\operatorname{Binomial}(t, r)$ for $n_{\max }$ independent binary detection histories where $0=$ individual not detected and $1=$ individual detected. Local abundance across sites $\left(N_{i}\right)$ is viewed as a nuisance parameter following either a Poisson distribution with mean and variance $\lambda$, or a negative binomial distribution with mean $\mu$ and extra parameter $\alpha$. Covariates for local abundance following a Poisson or negative binomial distribution can be modelled using a log link. The binomial distributions for $n_{i t}$ and distribution for $N_{i}$ are combined in an integrated likelihood function that can then be used for estimating $r$ and the distribution of $N_{i}$ using maximum likelihood or Bayesian methods. Further information about N mixture models can be found in Royle (2004), Royle et al. (2005), and Royle and Dorazio (2008).

Factors included in these models were based on the following set of hypotheses about their influences on individual detection probability: 
- Presence of invasive mammalian predators causes a behavioural response (such as less time actively foraging, or seeking out refuges that are more difficult for larger animals to access) that decreases individual detection probability of lizards with the VES protocols used.

- There is an optimal temperature range for detecting lizards with the VES protocol used. In other words, individual detection probability displays an inverse parabolic relationship with ambient temperature.

- There is an optimal time of day for detecting lizards with the VES protocol used.

- There is an optimal time of year for detecting lizards with the VES protocol used.

- Higher survey effort in a given survey results in an increased probability of detecting individual lizards.

The data used to assess each of these hypotheses are described in Table 3.4. In the maximal model for each lizard species, abundance was assumed to be constant across patches, but follow a negative binomial distribution where the mean and variance were not equal. Individual detection probability was parametrised in an additive fashion with each of the parameters listed in Table 3.4. The exception here was for O. aeneum, where the effect of Pests was not modelled due to detection probability of this species in the mammal-invaded patches being inestimable because no individuals were observed in mammal-invaded patches. Interactions between factors were not included because the number of parameters required to construct a saturated model of detection probability, or even one with two-way interactions between each pair of parameters, would have exceeded the number of data points. An alternative parametrisation of this model, with constant abundance assumed to follow a Poisson distribution, was constructed for initial comparison with the maximal model. Goodness of fit of the Poisson model was examined (PRESENCE 2.12 does not have functionality to test goodness of fit for negative binomial models), and if the test statistic of the goodness of fit test had a $p<0.05$, the more simple Poisson model was used to construct the rest of the models in the candidate set. Depending on goodness of fit, the Poisson or negative binomial maximal model was compared with a null (constant detection probability) model and one reduced-parameter model for each hypothesis (see Tables in section B.2 in appendix B). A likelihood approach corrected for small sample size (AICc) was used to compare models (Burnham and Anderson, 2002).

In using $\mathrm{N}$ mixture models, I made the assumption that net lizard abundance was constant across the $t=6$ surveys per quadrat (Royle, 2004). While it may be reasonable to assume that no births or deaths occurred during periods spanning 9 - 25 days, movement in and out of quadrats was likely due to the large edge of a $4 \times 20 \mathrm{~m}$ rectangle. Movement on and off quadrats would not affect net abundance if movement was a random process 
Table 3.4: Site- and survey-specific covariates used for analysis of survey- and site-specific effects on individual detection probability $(r)$ in lizard VES plot surveys. Covariates with potentially curvilinear effects (e.g. TOD) were tested in models as both linear and quadratic variables.

\begin{tabular}{|c|c|c|}
\hline $\begin{array}{l}\text { Covariate } \\
\text { name }\end{array}$ & Data type & Description \\
\hline Pests & Binary & $\begin{array}{l}\text { Ranking of pressure from invasive mammals at time of } \\
\text { survey. } 0=\text { mammal-free, } 1=\text { mammals present. }\end{array}$ \\
\hline $\begin{array}{l}\text { Temp, } \\
\text { Temp }\end{array}$ & Continuous & $\begin{array}{l}\text { Mean ambient temperature in }{ }^{\circ} \mathrm{C} \text { during survey, } \\
\text { calculated from hourly } \mathrm{T}_{\text {mean }} \text { measures taken from } \\
\text { Baring Head weather station (agent number }=18234) \\
\text { data in the NIWA CliFlo database, and standardised } \\
\text { about the mean temperature measured across all surveys } \\
\left(15.65^{\circ} \mathrm{C}\right) \text {. }\end{array}$ \\
\hline $\begin{array}{l}\text { TOD, } \\
\text { TOD }^{2}\end{array}$ & Continuous & $\begin{array}{l}\text { Time of survey mid-point, calculated in New Zealand } \\
\text { Standard Time (NZST) as survey end time - survey start } \\
\text { time, and standardised around 12:00 NZST. }\end{array}$ \\
\hline $\begin{array}{l}\text { Date, } \\
\text { Date }^{2}\end{array}$ & Continuous & $\begin{array}{l}\text { Julian date of survey, standardised about the mean } \\
\text { survey date }(24 / 02 / 2017) \text {. }\end{array}$ \\
\hline Seffort & Continuous & $\begin{array}{l}\text { Survey effort on a given occasion in person-minutes (i.e. } \\
\text { search duration in minutes } \times \text { number of surveyors). }\end{array}$ \\
\hline
\end{tabular}

(that is, not tied to any individual characteristic) and if net immigration equalled net emigration.

I also investigated how much species' occupancy would have been underestimated by the six repeated VES surveys by calculating the survey power from null (i.e. constant $r$ ) $\mathrm{N}$ mixture models for each species. If individuals are detected independently, species detection probability $(p)$ is a function of $N_{i}$ and individual detection probability $(r)$ (Royle and Dorazio, 2008):

$$
p_{i}=1-\left(1-r_{i}\right)^{N_{i}}
$$

The power of $t$ repeated surveys to detect the species at patches where it is present can then be calculated as for standard occupancy models (MacKenzie et al., 2017):

$$
\text { Power }=\operatorname{Pr}(\text { detect } \mid \text { present })=1-(1-p)^{t}
$$

Decisions about the best modelling procedure for the dataset going forward were based on two metrics: species or individual detection probabilities ( $p$ or $r$ ) smaller than 0.1 were considered too low to produce reliable population estimates, and the repeated survey design was considered underpowered for detecting species if the conditional probability (i.e. the probability of detecting the species in an occupied quadrat) was $\leq 0.8$ (Royle and Dorazio, 2008; MacKenzie et al., 2017). 


\section{Hierarchical modelling of common lizard species' responses to site variables}

The estimated individual detection probabilities $(r)$ of O. aeneum, O. polychroma and $W$. maculata calculated by the Royle (2004) N mixture models were too low to be reliable for abundance estimation, however species detection probabilities ( $p$ ) exceeded 0.1 (Table 3.12). Therefore single-season occupancy modelling (MacKenzie et al., 2002) was performed in PRESENCE 2.12 on the O. polychroma and W. maculata data (Hines, 2006). Occupancy modelling was not conducted for $O$. aeneum because the surveys were found to be underpowered for this species (Figure 3.5). The repeated count histories were simplified into species detection histories for occupancy modelling. For example, a repeated count history of 010220 became a species detection history of 010110.

There were a large number of potential pairwise combinations of habitat covariates. Therefore the following procedures were followed to simplify construction of the candidate model set. Habitat covariates that were weakly correlated with observed abundance of $W$. maculata or $O$. polychroma were not modelled based on the assumption that they were unimportant for the probabilities of species detection and occupancy (i.e. Spearman's $\rho<|0.25|$; see Table 3.11). Survey-specific variables (Table 3.4) were not included in this analysis because the previous $\mathrm{N}$ mixture modelling exercise suggested that none of these had an important effect on detection probability due to the relationship between $p$ and $r$. Based on this rationale, the maximal models for O. polychroma and W. maculata were specified as the additive models detailed in Table 3.5. Interactions between factors were not considered in the maximal models due to limitations in the sample size. A set of simplified models for $\psi$ were constructed for comparison with the maximal model using all possible reduced-parameter combinations of the variables in the maximal model. A null model for $\psi$ (that is, no effect of any covariates on $\psi$ ) was also included to examine whether any of the modelled covariates for $\psi$ substantially improved model fit. This resulted in four candidate models being trialled for O. polychroma and eight candidate models for W. maculata (Table 3.5). Goodness-of-fit of the maximal models to the data were assessed using a test statistic generated from 1,000 parametric bootstraps (MacKenzie and Bailey, 2004). All models with $\triangle \mathrm{AICc}<2$ were considered to have strong support (Burnham and Anderson, 2002).

\subsection{Results}

\subsubsection{Available habitat for coastal lizards}

Canopy height at the surveyed habitat patches was generally low (average $=2.16 \mathrm{~m}$, range $=0-6.7 \mathrm{~m}$ ). Of the structural cover types that I was interested in, the most frequently occurring were grasses or sedges (present in $80 \%$ of 180 sampling quadrats), followed by large-leaved Coprosma shrubs (61\%), divaricating shrubs (37\%) and Muehlenbeckia species 
Table 3.5: Candidate models for estimating the responses of patch occupancy of the skink Oligosoma polychroma and the gecko Woodworthia maculata to habitat covariates correlated with observed abundance (Spearman's $\rho>|0.25|$, Table 3.11). Parameter notation is as per Tables 3.2 and 3.3. $\psi$ : site occupancy probability, $p$ : species detection probability. The null model is labelled $M_{0}$ and the maximal model $M_{\max }$.

\begin{tabular}{ll}
\hline \hline Model & Parametrisation \\
\hline$M_{0}$ & \\
$M_{1}$ & $\psi(),. p($ DivS + Vines $), p($ DivS + Vines $)$ \\
$M_{2}$ & $\psi($ Vines $), p($ DivS + Vines $)$ \\
$M_{\text {max }}$ & $\psi($ DivS + Vines $), p($ DivS + Vines $)$ \\
\hline W. maculata & \\
\hline$M_{0}$ & $\psi(),. p($ Rock + DivS + MUE $)$ \\
$M_{1}$ & $\psi($ DivS $), p($ Rock + DivS + MUE $)$ \\
$M_{2}$ & $\psi($ MUE $), p($ Rock + DivS + MUE $)$ \\
$M_{3}$ & $\psi($ Rock $), p($ Rock + DivS + MUE $)$ \\
$M_{4}$ & $\psi($ DivS + MUE $), p($ Rock + DivS $+M U E)$ \\
$M_{5}$ & $\psi($ Rock + DivS $), p($ Rock + DivS $+M U E)$ \\
$M_{6}$ & $\psi($ Rock + MUE $), p($ Rock + DivS $+M U E)$ \\
$M_{\max }$ & $\psi($ Rock + DivS + MUE $), p($ Rock + DivS $+M U E)$ \\
\hline \hline
\end{tabular}

(30\%). Rock, flax (Phormium spp.), and non-Muehlenbeckia vines were each recorded in approximately $20 \%$ of quadrats. Large-leaved Coprosma species encountered at sites were mostly C. repens (22\% of quadrats) and C. robusta or C. lucida $(19 \%)$. The divaricating shrub cover type was dominated by Coprosma propinqua (20\%), and Muehlenbeckia vines by $M$. complexa (21\%). Phormium tenax was the only flax species recorded at Turakirae Head and on Mana Island, whereas the smaller P. cookianum was recorded on the Miramar Peninsula and Matiu. The most common vine apart from Muehlenbeckia species was Tetragonia implexicoma (10\% of quadrats). Photographs of common plants with phenotypes that are potentially important for lizards, and further information on the variation in habitat measures among sites are provided in section B.1 of appendix B.

There were significant correlations between several of the habitat variables chosen for analysis (Table 3.6). Mammal presence was negatively correlated with cover by large-leaved Coprosma species, and canopy cover at ground level (C0). C0 and large-leaved Coprosma coverage were positively correlated, indicating that these plants made an important contribution to canopy cover, particularly at heights less than $1 \mathrm{~m}$. An increasing amount of rock in a patch was negatively correlated with canopy cover at $0 \mathrm{~m}$ and $1 \mathrm{~m}$ and cover by large-leaved Coprosma species. In addition, patches with more Muehlenbeckia vines had a lower coverage by grass or sedges, and patches with a higher level of flax (Phormium spp.) had a lower level of vegetative ground cover. Five more pairwise correlations approached significance $(\rho>|0.4|$; Table 3.6). Of these, mammalian pest presence and rock, ground cover and non-Muehlenbeckia vines, rock and divaricating shrubs, and 
Muehlenbeckia and divaricating shrubs were each positively correlated and large-leaved Coprosma species and divaricating shrubs were negatively correlated.

Table 3.6: Spearman $\rho$ correlation coefficients for relationships between plot-specific habitat variables. Statistically significant correlations $(p<0.05)$ are highlighted in bold font. Covariate abbreviations are detailed in Table 3.2.

\begin{tabular}{l|cccccccccc}
\hline \hline & Pests & GC & C1 & C0 & PHO & Rock & DivS & COPlg & GS & MUE \\
\hline GC & 0.16 & & & & & & & & & \\
C1 & -0.26 & -0.23 & & & & & & & & \\
C0 & $\mathbf{- 0 . 7 4}$ & -0.14 & $\mathbf{0 . 5 0}$ & & & & & & & \\
PHO & 0.05 & $\mathbf{- 0 . 5 7}$ & 0.18 & 0.05 & & & & & & \\
Rock & 0.45 & -0.29 & $\mathbf{- 0 . 4 8}$ & $\mathbf{- 0 . 5 7}$ & -0.30 & & & & & \\
DivS & -0.07 & 0.05 & -0.13 & -0.14 & -0.18 & 0.41 & & & & \\
COPlg & $\mathbf{- 0 . 6 3}$ & 0.12 & 0.33 & $\mathbf{0 . 6 2}$ & 0.13 & $\mathbf{- 0 . 7 2}$ & -0.45 & & & \\
GS & -0.08 & 0.36 & -0.03 & 0.11 & 0.29 & -0.10 & 0.11 & 0.28 & & \\
MUE & -0.07 & -0.04 & 0.10 & -0.03 & -0.07 & 0.14 & 0.45 & -0.22 & $\mathbf{- 0 . 5 4}$ & \\
VinesO & 0.11 & 0.41 & -0.04 & 0.03 & -0.02 & -0.29 & -0.28 & 0.15 & -0.18 & 0.14 \\
\hline \hline
\end{tabular}

\subsubsection{Coastal lizard communities and relationships with habitat and presence/absence of invasive mammals}

\section{Description of lizard communities}

A total of seven lizard species were identified from 141 person-hours of search effort spanning 186 daytime VES occasions completed in the 2016/17 summer-autumn (Table 3.8). An additional 88 sightings of four lizard species were made during the resurvey of Mana Island in December 2017. All lizard species detected were naturally resident at sites; no individuals from translocated populations were detected (Tables 3.1 and 3.8). The only species found at all sites were W. maculata and O. polychroma. Local counts of W. maculata could be very high, with up to 16 individuals being counted in a single survey of a site on Mana Island. Up to seven individuals of O. polychroma were counted in a survey on Mana Island and the Miramar Peninsula. Oligosoma aeneum, O. kokowai and W. chrysosiretica were reasonably common at one or both pest-free sites (Table 3.8). Single-survey counts of these species were lower, with up to three (O. kokowai) or four (O. aeneum and W. chrysosiretica) individuals being encountered within a single survey. The most lizards were encountered on Mana Island, followed by Turakirae Head, Matiu, then the Miramar Peninsula (Table 3.8).

Cumulative species richness was not significantly different between the two surveys of Mana Island patches in February 2017 and December 2017 (comparison of Poisson GLMM 'Site-Survey' and 'null' models, with 'Plot' as a random factor: $\chi_{1}^{2}=0.334, p=0.564$ ), suggesting that this metric was not affected by the survey month. However, species richness differed significantly between sites (comparison of quasi-Poisson GLM 
'Site-Survey' and 'null' models: Deviance $=14.922, \mathrm{df}=3, p<0.001$ ). Species richness at the site with the lowest level of pest control, Turakirae Head, was significantly lower than on pest-free Mana Island (Table 3.7). Species richness in Miramar was significantly lower than both pest-free sites (Table 3.7).

Table 3.7: Quasi-Poisson GLM for cumulative species richness by site-survey. Estimates are the $l n$ average number of species per $80 \mathrm{~m}^{2}$ quadrat. The $95 \%$ confidence interval (CI) is constructed from $t_{30}=2.04$. Letters next to the $95 \%$ CIs indicate groupings based on significance. $\mathrm{SE}=$ standard error.

\begin{tabular}{llccccl}
\hline \hline Mammals & Site & Estimate & SE & $t$ & $p$ & $\mathbf{9 5 \%} \mathbf{C I}$ \\
\hline Absent & Intercept (Mana Island) & 1.18 & 0.12 & 10.21 & $<0.001$ & $0.94-1.41 \mathbf{a}$ \\
Absent & Matiu & -0.37 & 0.18 & -2.04 & 0.050 & $0.44-1.18 \mathbf{a}, \mathbf{b}$ \\
Present & Turakirae Head & -0.82 & 0.22 & -3.75 & $<0.001$ & $-0.09-0.80 \mathbf{b}, \mathbf{c}$ \\
Present & Miramar Peninsula & -1.47 & 0.27 & -5.50 & $<0.001$ & $-0.83-0.26 \mathbf{c}$ \\
\hline \hline
\end{tabular}


Table 3.8: Summary of lizard sightings from all VES quadrat surveys. The percentage of $80 \mathrm{~m}^{2}$ quadrats per site where the species was found is reported (naive occupancy). At sites where a species was caught, the number of sightings made across all patch surveys is reported in brackets next to the naive occupancy. Mana Island (MI) and Matiu (MS) were predator-free (PF) offshore islands. Miramar $(\mathrm{MP})$ and Turakirae Head $(\mathrm{TH})$ were within mainland sites with invasive predators present (PI), and some (MP) or very minimal (TH) control of invasive predators.

\begin{tabular}{|c|c|c|c|c|c|c|c|}
\hline & & & \multicolumn{3}{|l|}{ PF sites } & \multicolumn{2}{|l|}{ PI sites } \\
\hline & & & MI & MI & MS & $\mathrm{MP}$ & $\mathrm{TH}$ \\
\hline & & Survey date & Feb 2017 & Dec 2017 & Mar 2017 & $\begin{array}{l}\text { Dec } 2016- \\
\text { Jan } 2017\end{array}$ & $\begin{array}{l}\text { Apr-May } \\
2017\end{array}$ \\
\hline & & $N_{\text {quadrats }}$ & 8 & 8 & 8 & 8 & 7 \\
\hline & & $N_{\text {quadrats }} \times N_{\text {surveys }}$ & 48 & 48 & 48 & 48 & 42 \\
\hline $\begin{array}{l}\text { Scientific name and } \\
\text { abbreviation }\end{array}$ & & Common name & & & & & \\
\hline Woodworthia maculata & WM & Raukawa gecko & $100 \%(88)$ & $86 \%(43)$ & $25 \%(7)$ & $13 \%(1)$ & $86 \%(50)$ \\
\hline Woodworthia chrysosiretica & WC & Goldstripe gecko & $25 \%(15)$ & $38 \%(21)$ & $0 \%$ & $0 \%$ & $0 \%$ \\
\hline Oligosoma aeneum & $\mathrm{OA}$ & Copper skink & $88 \%(15)$ & $75 \%(11)$ & $63 \%(11)$ & $0 \%$ & $0 \%$ \\
\hline Oligosoma polychroma & $\mathrm{OP}$ & Northern grass skink & $75 \%(28)$ & $63 \%(13)$ & $50 \%(6)$ & $63 \%(30)$ & $57 \%(8)$ \\
\hline Oligosoma kokowai & OK & Northern spotted skink & $0 \%$ & $0 \%$ & $50 \%(6)$ & $0 \%$ & $0 \%$ \\
\hline Oligosoma macgregori & $\mathrm{OM}$ & McGregor's skink & $13 \%(1)$ & $0 \%$ & $0 \%$ & $0 \%$ & $0 \%$ \\
\hline Oligosoma zelandicum & $\mathrm{OZ}$ & Glossy brown skink & $13 \%(1)$ & $0 \%$ & $0 \%$ & $0 \%$ & $0 \%$ \\
\hline Oligosoma sp. & OU & Unidentified skink & $13 \%(1)$ & 0 & $38 \%(4)$ & $0 \%$ & $0 \%$ \\
\hline Total N sightings & & & 149 & 88 & 30 & 31 & 58 \\
\hline
\end{tabular}


Relationships between observed lizard community attributes, invasive mammals and habitat

Two MDS dimensions sufficiently described the variation in lizard species abundance between patches (stress $=0.121$ ). Lizard species composition was very similar at both mammal-invaded sites (MP and TH; Fig. 3.4A). Only two species were encountered by VES at these sites: the skink O. polychroma and the gecko W. maculata (Table 3.8). However, lizard species abundances were more homogeneous between patches at Turakirae Head than on Miramar Peninsula, and the centroid of the Turakirae Head patches was more influenced by higher abundances of W. maculata, whereas the centroid of the Miramar patches was more influenced by higher abundance of O. polychroma (Fig. 3.4A). Lizard species assemblages observed at patches in the two mammal-free sites (MI and MS) were quite different, with most of the dissimilarity being attributable to Oligosoma kokowai being encountered frequently on Matiu only, and W. chrysosiretica on Mana Island only (Fig. 3.4A). Relative abundance of O. aeneum was the main element of separation between lizard communities at mammal-invaded and mammal-free sites, with more frequent encounters at mammal-free sites (Table 3.8; Fig. 3.4A).

The presence or absence of mammals had the strongest effect on the observed lizard assemblage in a patch, followed by site (Table 3.9). Lizard species that appeared to be the least negatively affected by the presence of mammals were W. maculata and O. polychroma, whereas the most affected were O. aeneum and O. kokowai (Fig. 3.4). The amount of canopy cover at $1 \mathrm{~m}$ above ground level was the only significant determinant of lizard assemblage, but the effects of increasing coverage of large-leaved Coprosma species and vines not in the Muehlenbeckia genus approached significance (Fig. 3.4 and Table 3.9). Oligosoma aeneum appeared to be more abundant at sites with higher coverage of large-leaved Coprosma species and more canopy closure at $1 \mathrm{~m}$ above ground level (Fig. 3.4). Coverage by non-Muehlenbeckia vines appeared to be positively correlated with $O$. polychroma and negatively with O. kokowai (Fig. 3.4). Relative abundance of W. maculata appeared to be negatively correlated with canopy closure at $1 \mathrm{~m}$ above ground level, whereas this habitat attribute appeared to be positively associated with W. chrysosiretica (Fig. 3.4).

There were no significant correlations in relative abundance of lizard species (Table 3.10). Several significant relationships between species and habitat variables were evident (Table 3.11). All species had a negative correlation with mammal presence, but this effect was only significant for $O$. aeneum. As predicted by the MDS ordination, relative abundance of $O$. aeneum was positively correlated with cover by large-leaved Coprosma species. However, there was a stronger positive correlation between $\mathrm{O}$. aeneum relative abundance and $\mathrm{CaCo}$ at $0 \mathrm{~m}$ than with $\mathrm{CaCo}$ at $1 \mathrm{~m}$, and a negative correlation with rock cover not identified by the ordination. Relative abundance of W. maculata was positively correlated with coverage of divaricates and Muehlenbeckia species. Relative abundance of $W$. chrysosiretica was positively 
correlated with flax cover. Neither O. polychroma nor O. kokowai relative abundance was significantly correlated with any of the habitat variables tested.

Table 3.9: Effects of site-level attributes and patch-level habitat variation on observed lizard species composition.

\begin{tabular}{lcccc}
\hline \hline & MDS1 & MDS2 & $r^{2}$ & $p(>r)$ \\
\hline Site-level attributes & & & & \\
Mammals present & -0.980 & -0.197 & 0.573 & $\mathbf{0 . 0 0 1}$ \\
Site & & & 0.474 & $\mathbf{0 . 0 0 5}$ \\
Mana Island & 0.186 & -0.091 & & \\
Miramar & -0.292 & -0.158 & & \\
Matiu & 0.331 & 0.362 & & \\
Turakirae Head & -0.443 & 0.091 & & \\
\hline Patch-level attributes & & & & \\
Ground cover (GC) & -0.835 & -0.550 & 0.188 & 0.184 \\
Canopy cover Om (C0) & 0.911 & -0.413 & 0.214 & 0.169 \\
Canopy cover above 1m (C1) & 0.941 & -0.337 & 0.379 & $\mathbf{0 . 0 3 7}$ \\
Phormium spp. (PHO) & -0.988 & -0.153 & 0.021 & 0.865 \\
Muehlenbeckia spp. (MUE) & -0.188 & 0.982 & 0.068 & 0.564 \\
Rock & -0.967 & 0.256 & 0.107 & 0.439 \\
Divaricating shrubs (DivS) & -0.971 & -0.239 & 0.069 & 0.597 \\
Large-leaved Coprosma spp. (COPlg) & 0.928 & 0.372 & 0.315 & 0.059 \\
Grasses and sedges (GS) & -0.729 & -0.685 & 0.108 & 0.428 \\
Vines (other than Muehlenbeckia spp.) & -0.386 & -0.922 & 0.292 & 0.069 \\
\hline \hline
\end{tabular}



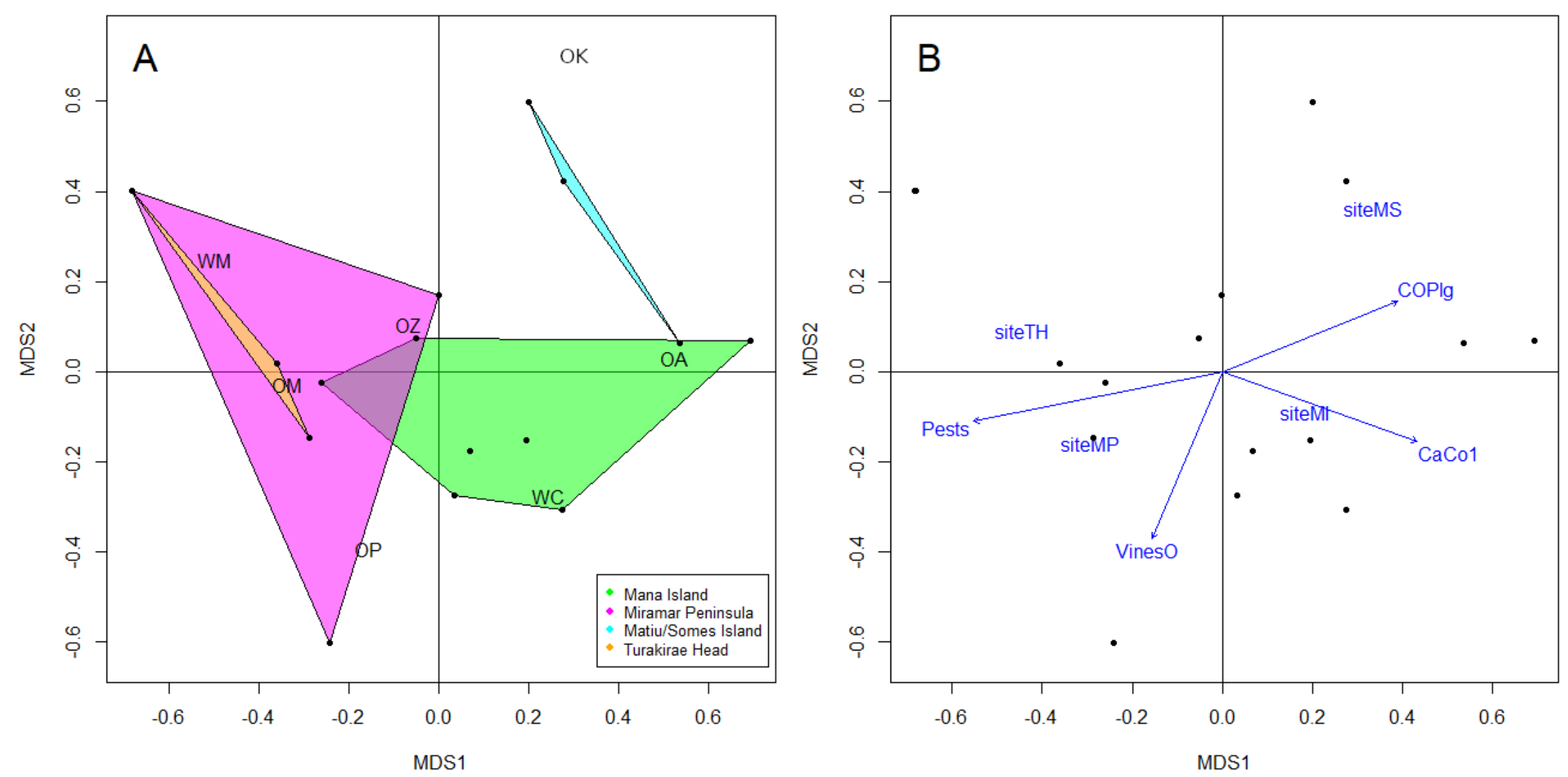

Figure 3.4: Multidimensional scaling of lizard species composition of communities within 18 independently spaced $80 \mathrm{~m}^{2}$ habitat patches where both lizard and habitat data could be collected ( $\mathrm{k}$ dimensions $=2$, stress $=0.121$ ). Multidimensional scaling $(\mathrm{MDS}$ ) represents euclidean distance between the observed number of individuals of each species per patch, averaged across all repeated surveys $(\mathrm{N}=6)$. Points represent each patch scaled by the MDS, note that there are less than 18 points displayed because some were scaled identically. A Similarity in lizard species composition between sites, represented by the degree of overlap in the hull drawn for each site. Separation of sites based on lizard species relative abundance is labelled by the abbreviated species name (see Table 3.8). B The effect of potentially important $(p>0.1$; see Table 3.9) site and patch-level characteristics. The most rapid rate of change of environmental variables is indicated by the direction of the arrows, and the length is proportional to the $r^{2}$. The centroids of each site are indicated by the abbreviated site name: Mana Island = MI, Miramar = MP, Matiu = MS, and Turakirae Head = TH. 
Table 3.10: Spearman $\rho$ correlation coefficients for relationships between the average number of individuals per survey for species encountered more than once. Oligosoma species are skinks and Woodworthia species are geckos. Woodworthia chrysosiretica was only found on Mana Island and O. kokowai on Matiu, therefore the correlation between these two species is not shown. Sample size = 31 quadrats.

\begin{tabular}{l|ccc}
\hline \hline & O. polychroma & W. maculata & O. aeneum \\
\hline Woodworthia maculata & 0.46 & & \\
Oligosoma aeneum & 0.09 & -0.06 & \\
Oligosoma kokowai & -0.14 & -0.45 & 0.33 \\
Woodworthia chrysosiretica & 0.38 & 0.36 & 0.28 \\
\hline \hline
\end{tabular}

Table 3.11: Spearman $\rho$ correlation coefficients for relationships between lizard capture rates and habitat variables. Statistically significant correlations $(p<0.05)$ are highlighted in bold font. Oligosoma species are skinks and Woodworthia species are geckos. Sample size $=18$ quadrats.

\begin{tabular}{l|ccccccccccc}
\hline \hline & Pests & GC & C1 & C0 & PHO & Rock & DivS & COPlg & GS & MUE & Vines \\
\hline Oligosoma polychroma & -0.24 & 0.14 & -0.14 & 0.07 & 0.15 & -0.10 & 0.29 & 0.03 & 0.14 & 0.16 & 0.37 \\
Woodworthia maculata & -0.21 & -0.06 & 0.01 & 0.07 & 0.01 & 0.40 & $\mathbf{0 . 6 6}$ & -0.23 & 0.00 & $\mathbf{0 . 5 2}$ & -0.07 \\
Oligosoma aeneum & $\mathbf{- 0 . 8 2}$ & -0.26 & 0.46 & $\mathbf{0 . 7 6}$ & 0.04 & $\mathbf{- 0 . 6 1}$ & -0.05 & $\mathbf{0 . 6 8}$ & 0.16 & -0.11 & -0.26 \\
Oligosoma kokowai & -0.28 & -0.22 & 0.03 & 0.17 & 0.06 & -0.30 & -0.21 & 0.42 & -0.11 & 0.15 & -0.05 \\
Woodworthia chrysosiretica & -0.28 & -0.17 & 0.23 & 0.19 & $\mathbf{0 . 6 0}$ & -0.30 & -0.07 & 0.30 & -0.01 & 0.10 & 0.02 \\
\hline \hline
\end{tabular}




\subsubsection{Individual and species detection probabilities of frequently encountered lizard species}

$\mathrm{N}$ mixture models with a Poisson distribution for patch-scale abundance $\left(N_{i}\right)$ did not fit the O. polychroma or W. maculata data (OP: $\chi_{17}^{2}=31.99, p=0.015$; WM: $\chi_{23}^{2}=67.15, p<$ 0.001). Instead, a negative binomial distribution for $N_{i}$ was considered more parsimonious $\left(\triangle A I C c>17\right.$ in both cases, see section B.2 in appendix B). $N_{i}$ of 0 . aeneum was adequately described by a Poisson model $\left(\chi_{13}^{2}=9.44, p=0.739\right)$. A constant detection probability model was the most parsimonious for each of these three species (all $\triangle A I C c>20$, see section B.2 in appendix B). However, the effect of mammal presence on detection probability of O. aeneum could not be evaluated because this species was not detected in any mammalinvaded patches.

Individual detection probability was lowest for $O$. polychroma, but did not differ significantly between species (Table 3.12). Species detection probability of O. aeneum was low due to low average abundance across sites, therefore it is very likely that this species was present at more sites than detected. At least 11 repeated surveys would have been required to have a sufficient level of power $(80 \%)$ to detect this species within quadrats where it occurred, suggesting that the surveys were underpowered for this species (Fig. 3.5). For W. maculata and O. polychroma, three or four repeated surveys provided sufficient power and six surveys had $>90 \%$ power (Fig. 3.5 ).

Table 3.12: Individual and species detection probabilities estimated by Royle et al. (2014) models for six repeated counts of lizard species from $80 \mathrm{~m}^{2}$ habitat patches surveyed by VES. Detection probability values less than 0.1 are indicated by an * to signal that the detection probability may be too low to produce precise estimates. $\mathrm{CI}=$ confidence interval.

\begin{tabular}{l|ll|l}
\hline \hline Species & $\hat{r}$ & $95 \% \mathrm{CI}(\hat{r})$ & $\hat{p}$ \\
\hline Oligosoma aeneum & $0.065^{*}$ & $0.015-0.241$ & 0.135 \\
Oligosoma polychroma & $0.012^{*}$ & $0.006-0.027$ & 0.346 \\
Woodworthia maculata & $0.047^{*}$ & $0.012-0.182$ & 0.463 \\
\hline \hline
\end{tabular}




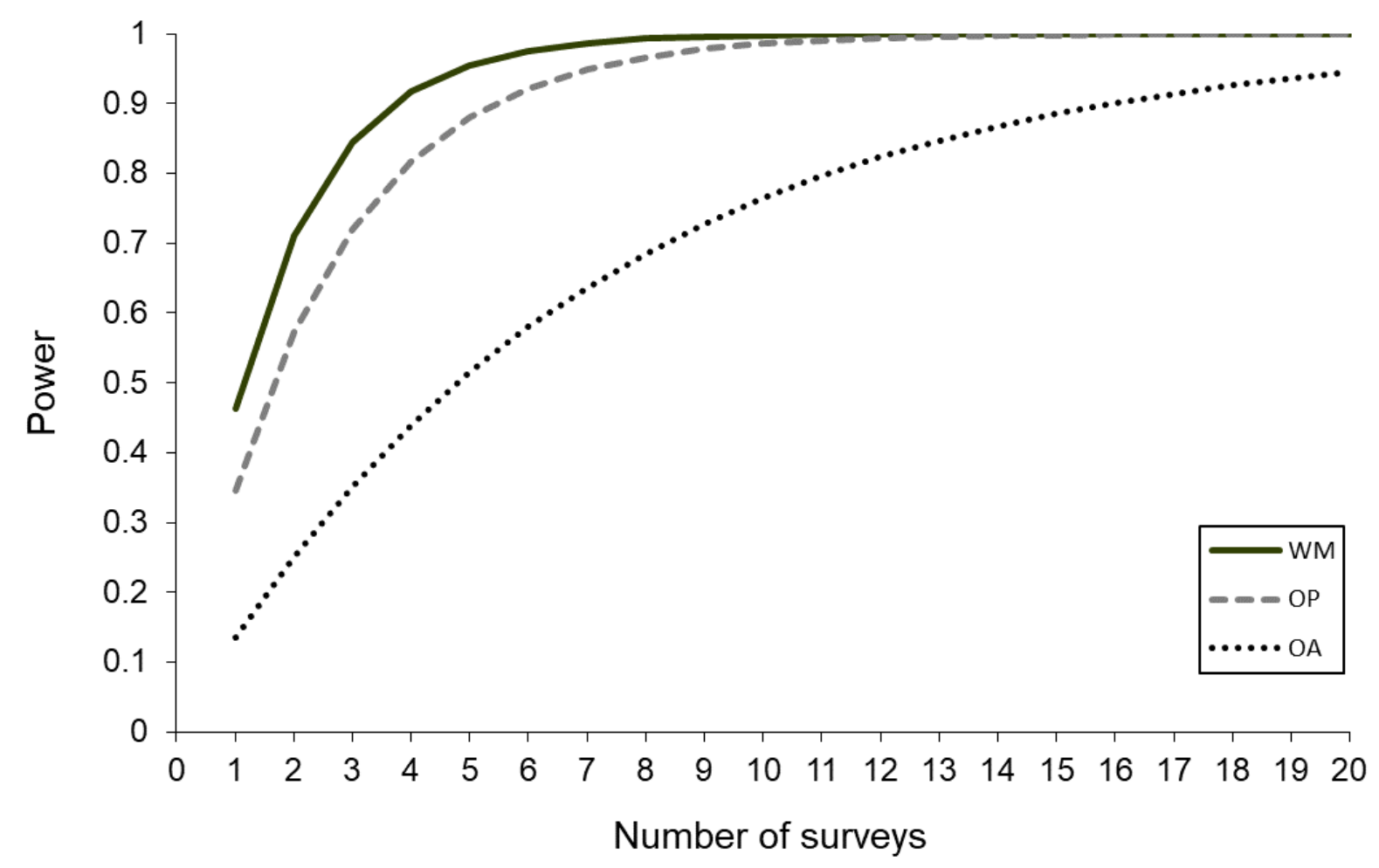

Figure 3.5: The effect of the number of repeated VES surveys on the power of detecting the three most commonly encountered lizard species within $80 \mathrm{~m}^{2}$ habitat patches (quadrats) where they were present. Abbreviations: $\mathrm{OA}=$ copper skink (Oligosoma aeneum), $\mathrm{OP}=$ northern grass skink (O. polychroma), WM = Raukawa gecko (Woodworthia maculata).

\subsubsection{Associations between habitat characteristics, detection probability and patch occupancy of frequently encountered lizard species}

The global candidate models in the analysis for each species (see Table 3.13) had an adequate fit to the data (WM: $S=59.66, p=0.281$; OP: $S=35.92, p=0.989$ ). There was some uncertainty around the best model for O. polychroma, with multiple strongly supported models (that is, with $\triangle \mathrm{AIC}<2$; Table 3.13). However, the maximal model that included effects of coverage by non-Muehlenbeckia vines (Vines) and by divaricating shrubs on occupancy was the best-supported by the AICc (Table 3.13). In this model, site occupancy of $O$. polychroma was positively affected by divaricating shrub and vine coverage, whereas detection probability was negatively affected by both of these variables (Table 3.14).

The only model for W. maculata that received strong support by the AICc was $\psi(\operatorname{Div} S), p($ Rock $+\operatorname{Div} S+M U E)$ (Table 3.13). In this model, coverage by divaricating shrubs had a positive effect on patch occupancy (Table 3.14). Coverage of rock and Muehlenbeckia species had a positive effect on detection probability (Table 3.14). Coverage by divaricating shrubs had a negative effect on detection probability (Table 3.14). 
Logistic curves of the effect of DivS on occupancy suggested that W. maculata would be expected to occupy all sites with more than $50 \%$ cover by divaricating shrubs and that $O$. polychroma occupancy would tend towards $100 \%$ as divaricating shrub and non-Muehlenbeckia vine cover increased towards 100\% (Figs. 3.6 and 3.7). However, the standard errors of the effects of divaricating shrubs and vines on $\psi$ exceeded $50 \%$ of the effect sizes (Table 3.14). So, while the modelling suggested that these habitat variables have an important effect on W. maculata and/or O. polychroma, they were not statistically significant.

Table 3.13: Candidate models for the effect of habitat attributes on occupancy probabilities of the gecko Woodworthia maculata and the skink Oligosoma polychroma. Weight = AICc weight.

\begin{tabular}{|c|c|c|c|c|c|}
\hline Model & $\overline{\mathrm{AICc}}$ & $\triangle \mathrm{AICc}$ & Weight & Likelihood & N par. \\
\hline \multicolumn{6}{|l|}{ Woodworthia maculata } \\
\hline$\psi(\operatorname{Div} S), p($ Rock + DivS + MUE $)$ & 125.89 & 0.00 & 0.6346 & 1.0000 & 4 \\
\hline $\begin{array}{l}\psi(\text { DivS }+M U E), p(\text { Rock }+ \text { DivS }+ \\
M U E)\end{array}$ & 128.25 & 2.36 & 0.1950 & 0.3073 & 5 \\
\hline $\begin{array}{l}\psi(\text { Rock }+ \text { DivS }), p(\text { Rock }+ \text { DivS }+ \\
M U E)\end{array}$ & 129.31 & 3.42 & 0.1148 & 0.1809 & 5 \\
\hline $\begin{array}{l}\psi(\text { Rock }+ \text { DivS }+ \text { MUE }), p(\text { Rock }+ \\
\text { DivS }+M U E)\end{array}$ & 132.38 & 6.49 & 0.0247 & 0.0390 & 6 \\
\hline$\psi(),. p($ Rock + DivS $+M U E)$ & 133.32 & 7.43 & 0.0155 & 0.0244 & 4 \\
\hline$\psi(M U E), p(\operatorname{Rock}+\operatorname{Div} S+M U E)$ & 134.29 & 8.40 & 0.0095 & 0.0150 & 4 \\
\hline$\psi($ Rock $), p($ Rock + Div $S+M U E)$ & 135.80 & 9.91 & 0.0045 & 0.0070 & 4 \\
\hline $\begin{array}{l}\psi(\text { Rock }+ \text { MUE }), p(\text { Rock }+ \text { DivS }+ \\
M U E)\end{array}$ & 138.14 & 12.25 & 0.0014 & 0.0022 & 5 \\
\hline \multicolumn{6}{|l|}{ Oligosoma polychroma } \\
\hline$\psi($ DivS + Vines $), p($ DivS + Vines $)$ & 124.77 & 0.00 & 0.4881 & 1.0000 & 4 \\
\hline$p s i($ Vines $), p($ Div $S+$ Vines $)$ & 126.34 & 1.57 & 0.2227 & 0.4561 & 3 \\
\hline$p s i(\operatorname{Div} S), p($ DivS + Vines $)$ & 126.62 & 1.85 & 0.1936 & 0.3965 & 3 \\
\hline psi(.), $p($ DivS + Vines $)$ & 128.03 & 3.26 & 0.0956 & 0.1959 & 3 \\
\hline
\end{tabular}


Table 3.14: Logit estimates $(\beta)$ of the effect of habitat parameters on Woodworthia maculata and Oligosoma polychroma patch occupancy $(\psi)$ and species detection probability $(p)$. Model selection statistics are in Table 3.13 .

\begin{tabular}{|c|c|c|c|c|}
\hline Parameter & $\overline{\beta \beta}$ & 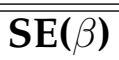 & $\overline{\text { Model }}$ & 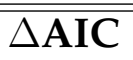 \\
\hline \multicolumn{5}{|c|}{ Woodworthia maculata } \\
\hline$\overline{\operatorname{DivS}}(\psi)$ & 11.111 & 8.989 & $\psi(\operatorname{DivS}), p($ Rock + DivS $+M U E)$ & 0.00 \\
\hline $\operatorname{Rock}(p)$ & 2.448 & 1.646 & $\psi(\operatorname{Div} S), p(\operatorname{Rock}+\operatorname{Div} S+M U E)$ & 0.00 \\
\hline $\operatorname{DIV}(p)$ & -1.502 & 1.036 & $\psi(\operatorname{Div} S), p(\operatorname{Rock}+\operatorname{Div} S+M U E)$ & 0.00 \\
\hline $\operatorname{MUE}(p)$ & 1.057 & 0.857 & $\psi(\operatorname{Div} S), p(\operatorname{Rock}+\operatorname{Div} S+M U E)$ & 0.00 \\
\hline \multicolumn{5}{|c|}{ Oligosoma polychroma } \\
\hline $\operatorname{DivS}(\psi)$ & 3.131 & 2.410 & $\psi($ DivS + Vines $), p($ DivS + Vines $)$ & 0.00 \\
\hline $\operatorname{Vines}(\psi)$ & 5.257 & 4.333 & $\psi($ Div $S+$ Vines $), p($ DivS + Vines $)$ & 0.00 \\
\hline $\operatorname{DIV}(p)$ & -0.888 & 0.477 & $\psi($ DivS + Vines $), p($ DivS + Vines $)$ & 0.00 \\
\hline $\operatorname{Vines}(p)$ & -0.912 & 0.691 & $\psi($ DivS + Vines $), p($ DivS + Vines $)$ & 0.00 \\
\hline
\end{tabular}




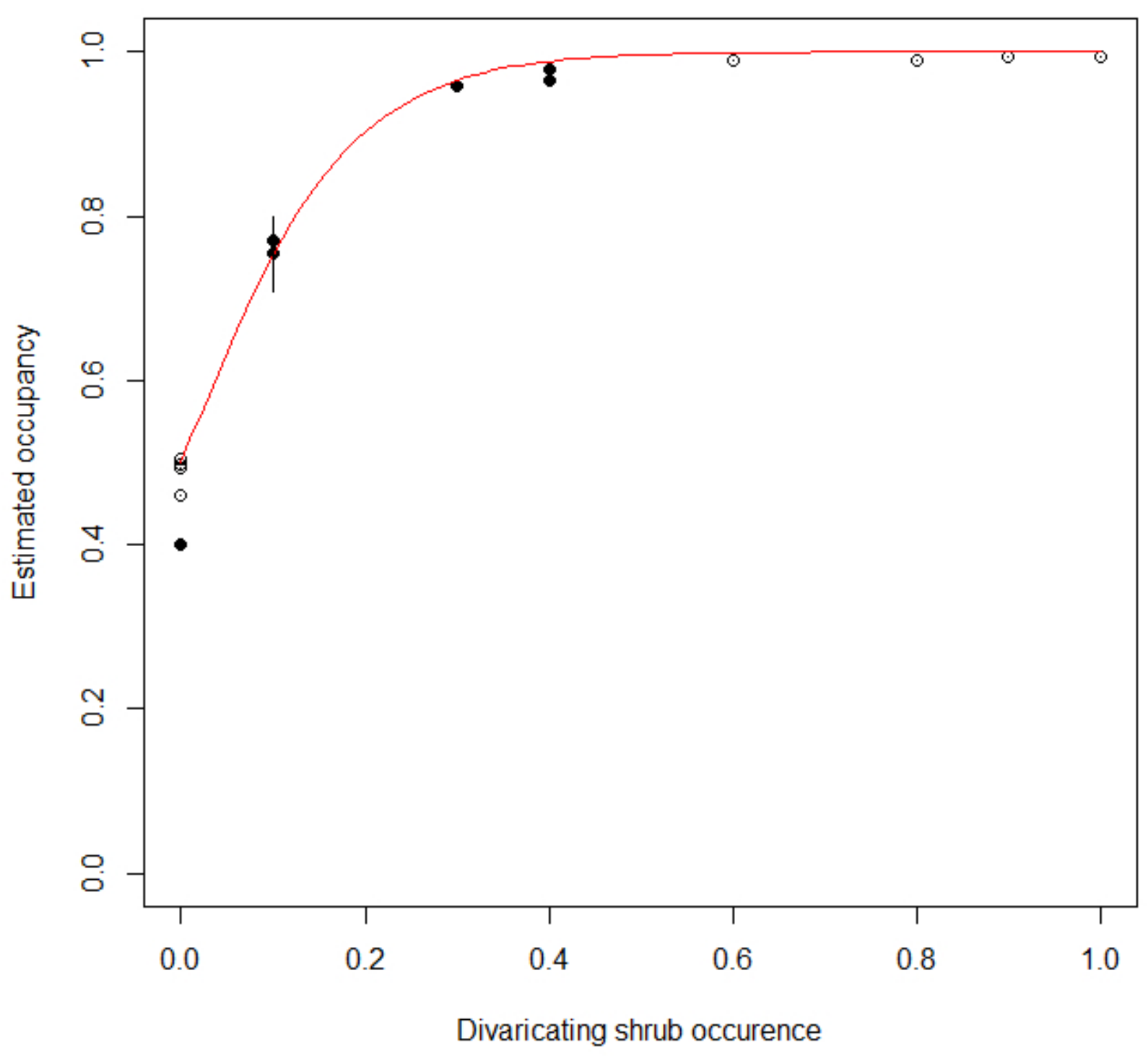

Figure 3.6: Relationship between estimated occupancy of the gecko Woodworthia maculata in $80 \mathrm{~m}^{2}$ patches and estimated coverage of divaricating shrubs (proportion occurrence in ten sampling quadrats per patch). Model-averaged occupancy estimates for each site are also plotted to provide context. Fitted curve is from the model $\psi(D i v S), p($ Rock + DivS + $M U E), \triangle A I C c=0.00$. Mammal-free sites are indicated by black dots. Error bars around occupancy estimates are \pm one standard error. 

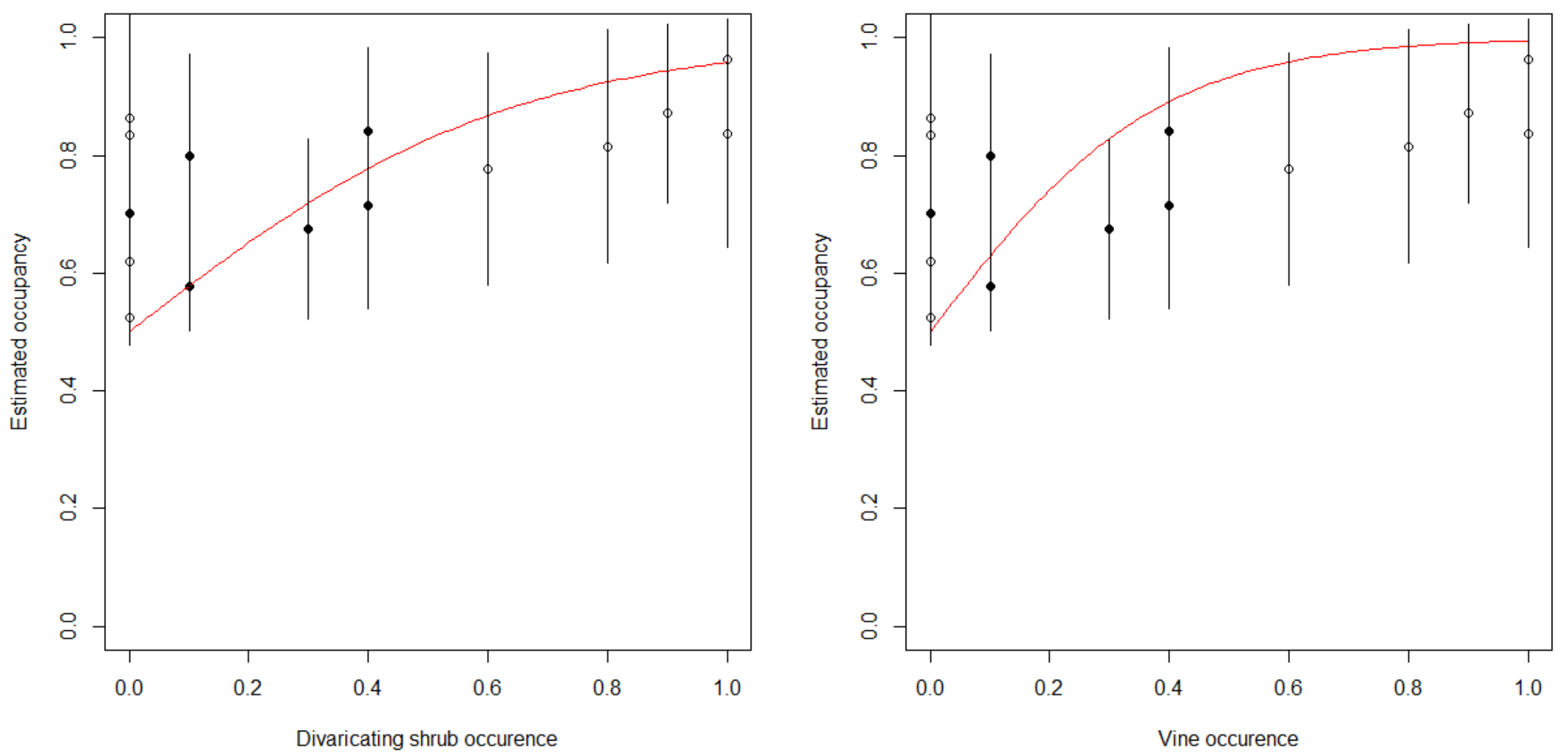

Figure 3.7: Relationships between estimated occupancy of the skink Oligosoma polychroma in $80 \mathrm{~m}^{2}$ quadrats and habitat characteristics. Left-hand panel: relationship with relative abundance of divaricating shrubs. Right-hand panel: relationship with relative abundance of non-Muehlenbeckia vines. In this case, relative abundance was measured as occurrence of a plant type in ten 1 $\mathrm{m}^{2}$ sampling plots per quadrat. Model-averaged occupancy estimates for each site are also plotted to provide context. Fitted curves are from the model $\psi($ Div $S+$ Vines $), p($ Div $S+$ Vines $), \Delta A I C c=0.00$. Mammal-free sites are indicated by solid dots. Error bars around conditional occupancy estimates are \pm one standard error. 


\subsection{Discussion}

I examined terrestrial lizard communities in 18 independently spaced habitat patches within mammal-free and mammal-invaded sites to identify associations with habitat characteristics. Occupancy modelling was then applied to encounter data from frequently encountered lizard species (the gecko Woodworthia maculata and the skink Oligosoma polychroma) to discriminate which habitat characteristics were important determinants of occupancy after accounting for species detection probability.

Presence or absence of invasive mammals was the most important factor affecting the structure of lizard communities and suggested asymmetry in the effect sizes of mammals on different lizard species. Consequently, lizard species richness was significantly lower at mammal-invaded sites. However, some patch-scale habitat features affected terrestrial lizard community structure: canopy cover at $1 \mathrm{~m}$ above ground level, and relative abundance of large-leaved Coprosma species and non-Muehlenbeckia vines. Occupancy probabilities of O. polychroma and W. maculata were positively correlated with increasing cover of divaricating shrubs. O. polychroma was also more likely to occupy patches with increasing cover by non-Muehlenbeckia vines. These results are discussed further in the following sections, along with an evaluation of the repeated VES study design for gathering lizard community data.

\subsubsection{Landscape-scale effects: invasive mammal presence or absence and residual site-level effects}

\section{Invasive mammals}

Two lizard species, Oligosoma polychroma and Woodworthia maculata, were found at both predator-free and predator-invaded sites. Three further species that were frequently encountered at one or both predator-free sites (O. aeneum, O. kokowai and W. chrysosiretica) were not encountered at either mainland site. O. aeneum and O. kokowai were historically present at Turakirae Head, and O. aeneum is still present on the Miramar Peninsula (Whitaker, 1982; Bell, 2019b). While two further skink species were encountered on Mana Island (O. macgregori and O. zelandicum), they were only encountered once during surveys therefore any inference about these species from this study risks being spurious. The lower lizard species richness and shifts in species assemblages in mammal-invaded patches observed in this study reflects the results of lizard community studies on rat-invaded and rat-free offshore islands in northern New Zealand (Whitaker, 1973; Towns, 1991). Overall, the relatively high importance of invasive mammals compared to habitat characteristics identified in this study is consistent with the global trend of island-endemic species being more negatively affected by invasive species than by habitat loss or degradation (Brooks et al., 2002). 
Negative Spearman $\rho$ correlations suggested a negative effect of mammalian predators on all five lizard species frequently encountered in this study. This is mirrored by the findings from other studies that have documented declining abundance in populations of O. aeneum, O. polychroma, O. kokowai and W. maculata co-existing with invasive mammals or an increase in abundance following eradication of one or more mammal species (Newman, 1994; Hoare et al., 2007a; Monks et al., 2014; Dumont, 2015; Gollin, 2016). However, the effect size of mammal presence differed between species; with a significant effect only being identified for $O$. aeneum. This suggests a variable effect of mammal presence on the lizard species studied, which is reflected by other studies on New Zealand's endemic lizards and may explain why some species appear to co-exist with mammals whereas others become extinct (Towns and Daugherty, 1994; Tingley et al., 2013; Woolley et al., 2019). However, the results from this study were correlative and further work would be required to identify whether a causal relationship exists. For most of the species, the relative size of negative impact, and position with respect to mammal presence in the multidimensional scaling analysis, reflected their threat status and results of other studies on the impact of sustained pressure from invasive mammals (Dumont, 2015; Hitchmough et al., 2016a). The exception to this was the strong negative effect of mammal presence on O. aeneum, which was unexpected because this species is currently classified as Not Threatened (Hitchmough et al., 2016a). It is possible that the effect of invasive predator presence varies between locations, or in response to differences among predator species assemblages. Populations of this species near Wellington and on islands off the north-eastern coast of the North Island have declined in the continued presence of a mainland mammalian guild, or increased following the removal of kiore Rattus exulans or both kiore and Norway rats Rattus norvegicus (Hoare et al., 2007a; Monks et al., 2014; Gollin, 2016). In contrast, capture rates of this species were similar on islands off the north-eastern coast of the North Island with and without kiore (Whitaker, 1973).

\section{Residual effects of site}

Despite testing for the effects of several habitat characteristics and presence/absence of invasive mammals, the variable 'site' was a significant determinant of lizard community structure. The literature on the relative importance of landscape-scale and patch-scale characteristics suggests variation between study systems. In some studies, landscape-level attributes were more important determinants of lizard species occupancy or reptile community composition than patch-scale characteristics (Van Heezik and Ludwig, 2012; Bruton et al., 2016). Other studies have identified both landscape and patch-scale habitat characteristics to be important for reptile community structure, or found patch-scale variables to be more important than landscape attributes (Jellinek et al., 2004; Garden et al., 2010). 
While the 'site' covariate in this study is uninformative, in some species it probably reflects biogeographical limits to species dispersal (for example, O. zelandicum and $W$. chrysosiretica appear to be restricted to the west coast of New Zealand (van Winkel et al., 2018)). In species thought to have been historically ubiquitous across the Wellington region and Cook Strait (e.g. O. kokowai; Melzer et al. (2017); Woolley et al. (2019)), current absence from a site likely reflects the legacy of historical extinction coupled with absence of a source population for recolonisation (Van Heezik and Ludwig, 2012). While some lizard species have been reintroduced (or translocated in the case of O. newmani) to Mana Island and Matiu, none of these species were encountered during the VES. This is presumably because these species are either sparsely distributed or have remained clustered around the release site (Griffiths, 1999; Miskelly, 2010; Bell and Herbert, 2017b; Melzer et al., 2019). Most of the translocated populations are of larger-bodied species that have been extirpated from the mainland so it will be interesting to see whether there is a change in lizard community attributes once these species become more abundant and widespread.

\subsubsection{Patch-scale habitat effects on lizard species and communities}

Most of the associations between habitat and lizard community or species' demographic attributes were quite weak or associated with high errors. However, this does not necessarily mean that they are unimportant. In a heterogeneous landscape, it is generally predicted that less than the total number of suitable patches for a species will be occupied (Gyllenberg and Hanski, 1997; Hanski, 1999). This can be viewed as a random process that is expected to increase the variance associated with estimating the effects of habitat characteristics on species' presence or absence at the patch scale. Even so, both structural attributes (canopy cover above $1 \mathrm{~m}$ ) and vegetative composition (large-leaved Coprosma species and vines (mostly Tetragonia species or members of the Convolvulaceae)) were correlated with variation among lizard species assemblages. The relative effects of patch-scale structural habitat elements and vegetative composition on terrestrial reptile communities been explicitly examined before in Queensland, Australia (Garden et al., 2007). In that study, structural elements were more important determinants of species assemblages than vegetative composition, but there are distinct differences in climate (temperate versus tropical), biogeography (insular versus continental) and reptilian taxa (lizards versus lizard, testudines and snakes) between my study system and the one studied by Garden et al. (2007). For the most part, I would expect that the effects of habitat attributes on lizard species assemblages would be most strongly regulated by the habitat preferences of each species within the assemblage, but also influenced by the contexts of climate and relationships with sympatric species. In this section I will discuss how the observed lizard community structures within the sample patches could have been affected by the habitat preferences of species. 


\section{Habitat characteristics affecting community composition: canopy cover, large-leaved Coprosma species, and vines}

The importance of canopy cover at $1 \mathrm{~m}$ above ground level (in this study, representing high canopy cover rather than cover provided by low-growing vegetation) for structuring lizard communities mirrors outcomes from research done in Australia, Europe, and North America on the impacts of canopy cover reduction on reptile assemblages (Greenberg, 2001; Pike et al., 2011a,b; Bonnet et al., 2016). The two species that the multidimensional scaling suggested were more frequently encountered at sites with greater canopy cover $1 \mathrm{~m}$ above ground (O. aeneum and $W$. chrysosiretica) can inhabit forest as well as more open habitats, whereas species with greater distance from increasing canopy cover appear to favour more open habitats (East et al., 1995; Stephens, 2004; Gollin, 2016; van Winkel et al., 2018). Being ectotherms, lizards are dependent on warmth in their immediate environment or directly from the sun to regulate body temperature to within the optimum range (Sunday et al., 2014). In a temperate environment such as the lower North Island, canopy cover is expected to have a stronger influence on the body temperatures of terrestrial lizards than in lower latitudes (Sunday et al., 2014). However, it should be noted that the maximum canopy height recorded in the study quadrats was $6.7 \mathrm{~m}$. Therefore, inference about lizard species' responses to canopy cover based on the results of this study can only be made for habitats with relatively low canopies.

The fruit of both divaricating and larger-leaved Coprosma species are eaten by several lizard species, including W. maculata, O. kokowai and O. polychroma (Spencer et al., 1998; Wotton, 2002; Wotton et al., 2016). Positioning in the multidimensional scaling analysis and a Spearman $\rho$ correlation coefficient of 0.42 suggested a weak positive association between relative abundance of $O$. kokowai with large-leaved Coprosma species. On predator-free North Brother Island, estimated abundance of O. kokowai is highest in patches of taupata (Coprosma repens) scrub (Phillpot, 2000). While fruit consumption in the wild has not been reported for O. aeneum (Porter, 1982, 1987; Wotton et al., 2016), captive animals will consume fruit (banana, D. Wilkinson, pers. comm.; Piper excelsum berries, C. Wedding, pers. comm.). Therefore the positive correlation between large-leaved Coprosma species and O. aeneum relative abundances could signal that these plants are a food source for this species. Or, it could be an artefact of the positive correlation between large-leaved Coprosma species and greater canopy cover at ground level which may provide protection for terrestrial lizards from predators. Large-leaved Coprosma species had a negative effect on detection of $W$. maculata. Because of the link between abundance and species detection probability, it is unclear whether W. maculata are more difficult to detect in daytime searches of large-leaved Coprosma shrubs, or less abundant where these species proliferate (Royle and Nichols, 2003).

The effect of non-Muehlenbeckia vines on the lizard communities studied most likely 
resulted from the positive effect on O. polychroma occupancy. The only similar result I could find in the literature was from a survey of mammal-free Takapourewa / Stephens Island in 1991-1992, where capture rates of O. polychroma were highest in vineland, scrub, and tall grassland (East et al., 1995). The most frequently encountered non-Muehlenbeckia vine species in sample quadrats was Tetragonia implexicoma (Aizoaceae), which can form very dense clumps of low foliage that may provide shelter and protection from predators. This species also produces fleshy berries, although there is no evidence that these are eaten by lizards (Gabites, 2015; Wotton et al., 2016).

\section{Inferred habitat preferences of the study species}

Before delving into a discussion of lizard species' habitat preferences, it should be noted that stronger inference about habitat associations can be made from occupancy modelling results than from relative abundance or presence/absence data. This is because relative abundance and observed presence/absence are the cumulative results of two underlying processes: true abundance and detection probability at the local scale. For example, fewer or no individuals may be encountered in complex habitats because they are harder to find rather than because they are less abundant or have a lower probability of occupancy (MacKenzie, 2006). Generally, inference from the habitat studies on lizards discussed in this section that explicitly account for detection probability (O. kokowai in Phillpot (2000) and Stephens (2004), and O. polychroma in Wiles (2016)) are likely to be more accurate than those based on abundance indices (Patterson, 1992; Newman, 1994; East et al., 1995; Towns and Elliott, 1996; Freeman, 1997; Van Heezik and Ludwig, 2012; Gollin, 2016).

Oligosoma polychroma and W. maculata were more likely to occupy sites with an increasing amount of divaricating shrubs and O. polychroma was more likely to occupy sites with increasing vine cover. As predicted, an increasing amount of divaricating shrub cover reduced the probability of detecting both lizard species, and increasing amounts of vine cover reduced the probability of detecting O. polychroma. Because of the concurrent positive effect of these variables on occupancy, it seems more likely that the negative effects of these variables on species' detection probability is due to individuals being harder to observe in these habitats, rather than less abundant. The positive association between W. maculata occupancy and divaricating shrubs is not surprising, given that Coprosma propinqua was the most abundant species in this vegetative class and is an important food source for this species (Wotton, 2002; Wotton et al., 2016). The complex structure of divaricating shrubs may also provide protection for lizards from larger-bodied predators.

The positive association between $W$. maculata species detection probability and rock could indicate greater abundance in rocky habitat patches, or a higher probability of detecting this species in rock refugia during the daytime (Royle and Nichols, 2003). Both of these scenarios are plausible. While they are predominately nocturnal, W. maculata and 
other saxicolous Woodworthia species use warm rocks for daytime 'indirect' and direct basking for thermoregulation (Werner and Whitaker, 1978; Gibson et al., 2015; van Winkel et al., 2018). Therefore these geckos could be actively selecting rock refugia during the daytime, although radio-tracking or a use versus availability study would be required to confirm whether there is a preference or not. Additionally, W. maculata often occupy refugia in large aggregations that may be easier to detect during VES than single geckos (Hare and Hoare, 2005). Alternatively, previous work in New Zealand has shown that rocks may provide valuable refuges from mammalian predators for lizards (Towns, 1996; Lennon, 2019), therefore rock cover could positively affect local abundance of W. maculata. Because of the very complex structure of Muehlenbeckia species, it was hypothesized that increasing coverage of plants in this genus would have a negative effect on species detection probability. However, a positive association was identified between Muehlenbeckia species and $W$. maculata detection probability. It is possible that this association indicates a positive effect of Muehlenbeckia species on local abundance of $W$. maculata because the fruit of plants in this genus are eaten by this lizard species (Wotton et al., 2016).

The strongly significant positive correlation between encounter rates of W. chrysosiretica and Phormium species was not surprising because this species is known to display a preference for strap-leaved vegetation and is frequently found in Phormium tenax (Flannagan, 2000; Jewell, 2011; Melgren, 2012; van Winkel et al., 2018). However, it was interesting that there was not an important association between O. polychroma occupancy or O. aeneum relative abundance and the amount of cover by grasses or sedges. Populations of O. aeneum and O. polychroma are known to occupy rank grass in the Wellington region, sometimes with O. polychroma reaching very high abundances (Gollin, 2016; Bell et al., 2018; Bell, 2019a). Other studies have found that capture rates or estimated abundances of $O$. polychroma sensu stricto and other members of the O. polychroma species complex are higher in long grass or tussock compared to other habitat types in both mammal-free and invaded environments (Patterson, 1992; Newman, 1994; Phillpot, 2000; Stephens, 2004; Liggins et al., 2008; Van Heezik and Ludwig, 2012; Gollin, 2016). However, other studies suggest that grasslands may not necessarily be high quality habitats for O. polychroma or O. aeneum, or that preferences vary across sites. While a study of the Stephens Island lizard community in 2002-2003 found the highest abundances of O. polychroma in tussock-land, average body condition of individuals inhabiting scrub was higher than that of conspecifics found among tussock (Stephens, 2004). Southern grass skinks (O. aff. polychroma Clade 5) in Canterbury were more abundant in shrubland than dune grassland, although this could have been due to competition with another small open-habitat skink, O. maccani (Freeman, 1997; Liggins et al., 2008). Research conducted on a terrestrial lizard community on the Wellington mainland found no association between vegetative cover and capture rates of O. polychroma or O. aeneum in pitfall traps (Towns and Elliott, 1996). Instead, capture rates of $O$. polychroma were highest where there were few boulders (defined as $>20 \mathrm{~cm}$ in 
diameter). Oligosoma aeneum were most commonly captured where loam, boulders, and stones (6-20 cm in diameter) were abundant (Towns and Elliott, 1996). At Ōrua Pouanui / Baring Head in Wellington, estimated abundance of O. polychroma was significantly higher in scrub than shrubland or grassland and was not influenced by rocks (Wiles, 2016). At the same site, individual detection probability of these skinks in pitfall traps was significantly affected by habitat type, with detection probability being highest in shrubland, lower in grassland, and lowest in scrub (Wiles, 2016). Individuals were also more likely to be detected at sites with more rocks (Wiles, 2016).

\subsubsection{Separation between lizard species in multidimensional space: niche partitioning, antagonism, or an indirect interaction mediated by invasive mammals?}

Early studies on lizard communities were mostly in tropical or subtropical areas (e.g. Rand (1964); Inger and Colwell (1977)) or deserts (e.g. Pianka (1967); Smith (1981)). These studies suggested that the diversity and structure of lizard communities is related to primary productivity, spatial heterogeneity and competition. In temperate regions, differential thermal strategies of lizard species also explains community structure, with large-bodied species being associated with more vegetated and cooler microhabitats and small and slender species with warmer and more open microhabitats (Scheibe, 1987). Previous studies on New Zealand lizard assemblages suggest that co-existence of lizard species is facilitated by niche partitioning based on habitat and diet preferences, but is also influenced by predation and interference or resource competition (Patterson, 1985; Porter, 1987; Patterson, 1992; Towns and Elliott, 1996; Freeman, 1997; Fischer et al., 2019). Thermoregulatory strategy may also play a role in structuring New Zealand lizard communities. For example, most of the large and robust-bodied North Island skinks tend to inhabit forest floor microhabitats whereas most of the small and slender-bodied terrestrial skinks tend to inhabit more open habitats (van Winkel et al., 2018).

Among the five most frequently encountered lizard species in this study, only one species pair is likely to have a considerable niche overlap; the diurnal, heliothermic, open-habitat skinks O. polychroma and O. kokowai (Spencer et al., 1998; van Winkel et al., 2018). MDS separation between all other pairwise species combinations could be attributed to different activity patterns, habitat preferences and/or arboreality (Melgren, 2012; van Winkel et al., 2018). Therefore the large MDS distance between O. polychroma and O. kokowai could indicate an antagonistic relationship between these species. It is unknown whether O. kokowai eats O. polychroma, but the size difference between these species suggests it is possible (Spencer et al., 1998). O. kokowai has been observed chasing O. polychroma on North Brother and Matiu-Somes Islands, but not vice versa (Phillpot (2000); S. Herbert, pers. obs.). However, antagonistic interactions are not always observed between the two species; they have also 
been seen sun-basking together in close proximity (N. Nelson pers. obs.). While differences in body size can be a niche partitioning factor, larger species tend to competitively exclude smaller species if there is overlap in resource use (Wilson, 1975). This type of relationship has previously been postulated between two other New Zealand skinks that have considerable niche overlap: O. ornatum and O. aeneum (Porter, 1987). It appears that where O. kokowai occurs on mammal-free islands (including Matiu), it is the most abundant terrestrial lizard and may suppress O. polychroma abundance (East et al., 1995; Markwell, 1999; Phillpot, 2000; Stephens, 2004). For example, on North Brother and Stephens Islands, densities or capture rates of $O$. polychroma were highest in tussock habitats where O. kokowai occurred at lower densities. In contrast, where these two species co-exist in mammal-invaded habitats around Wellington, capture rates of O. kokowai are extremely low and O. polychroma is most abundant in scrub (Wiles, 2016; Herbert and Bell, 2019). A similar shift in habitat preference has been noted in southern grass skinks (O. aff. polychroma Clade 5) in the Lammerlaw and Rock and Pillar Ranges of the South Island of New Zealand (Patterson, 1985, 1992). Here, southern grass skinks appeared to be excluded from scrub habitats by two similarly-sized skinks: McCann's skink (O. maccani) and the Burgan skink (O. burganae) (Patterson, 1985, 1992). Under experimental conditions, O. maccani and O. burganae chased southern grass skinks out of shrub habitat, but not the reverse (Patterson, 1992). Elsewhere, southern grass skinks are found in scrub (Freeman, 1997). It is therefore possible that O. polychroma populations could benefit indirectly from competitive release at sites where invasive mammals suppress the abundance of $O$. kokowai.

Antagonism with sympatric open-habitat diurnal skinks may explain the variable preference of $O$. polychroma for grassland versus scrub or shrubland environments mentioned previously in this chapter. Phillpot (2000) suggested that tussock provides more complex cover at ground level than shrubland, which may protect the smaller $O$. polychroma from antagonistic interactions with $O$. kokowai. Therefore, it is possible that even though it can inhabit tall grassland, shrubland is the preferred habitat of O. polychroma and related species, but only in the absence of stronger competitors (Patterson, 1992; Freeman, 1997; Wiles, 2016; Bell et al., 2018; Bell, 2019a). Apparent competition mediated by predation from the invasive mammal guild (Holt, 1977; Holt and Bonsall, 2017) is another possibility. A fluctuating predator-prey relationship in catch rates has previously been identified between O. polychroma (Clade 1b) and weasels, hedgehogs and stoats (Dumont, 2015). At the same study site, there was a strong sustained decline in O. kokowai and Newman's speckled skink O. newmani, and a weaker decline in O. polychroma (Dumont, 2015; Melzer et al., 2017, 2019). In contrast with O. polychroma, no cyclical relationship was identified between mammalian species and O. newmani (Dumont, 2015). 


\subsubsection{Assessment of the repeated VES methodology}

Visual estimation surveys (VES) are a frequently used technique for surveying lizards in New Zealand and overseas (e.g. Porter (1987); Towns (1991); Hare and Cree (2005); Lardner et al. (2009); Melgren (2012); Lardner et al. (2019)). However, the lower the detection probability of individuals and species, the more likely that observed presence/absence data will underestimate site occupancy. Individual detection probabilities of three lizard species examined (O. aeneum, O. polychroma and $W$. maculata) were similar and not significantly different, therefore the power of $t$ repeated surveys to detect each species is more likely to be determined by local variation in abundance. A single survey of a small $\left(80 \mathrm{~m}^{2}\right)$ patch had insufficient (i.e. $\left.<80 \%\right)$ power to detect each of these species. Adequate power was achieved for the two abundant and widespread lizard species within 3-4 repeated surveys. However for the rarer species (O. aeneum), it was estimated that 12 repeated surveys would have been required for adequate power. Therefore while it appeared that $O$. aeneum was absent from both mammal-invaded sites, it may simply not have been detected due to low $p$ driven by low abundance. Indeed, O. aeneum was later detected at south Miramar at low relative abundance in a third of the pitfall-and-refuge monitoring grids used in Chapter 5 of this thesis.

One concern with the accuracy of lizard community data generated from the surveys was an autocorrelation between site and the timing of surveys. Accurate inference from single-season occupancy models and $\mathrm{N}$ mixture models relies on completing all surveys of a quadrat within a time frame short enough to reduce the risk of non-constant net abundance or occupancy (MacKenzie et al., 2002; Royle and Nichols, 2003; Royle, 2004). Because of the relatively long distances between sites relative to the distance between patches within a site, I chose to prioritise completion of all repeated surveys at a site within a short time frame over spreading surveys across different sites in a time-independent manner. The consequences of this time-correlated survey design were investigated in two ways: by re-survey of all Mana Island quadrats in a different season, and by examination of the effect of differing weather conditions on detection probability. In the first instance, the difference in lizard community data generated from the two surveys of Mana Island was not significantly different, although the second survey yielded a lower observed species richness. The effects of varying air temperature and date of the 2016/17 surveys on individual detection probability were considered relatively unimportant for model parsimony for the three species modelled, so it is likely that the observed repeated lizard counts accurately reflect differences between sites. Individual detection probability was also robust to differences in the time of day and survey effort, indicating that count indices generated from the standardised VES methods employed were unbiased for O. aeneum, $O$. polychroma and W. maculata.

Due to low individual detection probabilities calculated from the VES data, occupancy 
modelling was expected to produce more robust information about the state of populations in patches than $\mathrm{N}$ mixture modelling. Occupancy modelling has the logistical advantage of patches being likely to be closed to changes in occupancy over longer times frames than abundance, but the disadvantage of occupancy being a coarser scale indicator of population status than abundance. Given that the time frame for completion of repeated surveys can be relaxed somewhat for occupancy survey designs compared to those required for $\mathrm{N}$ mixture modelling, perhaps a better approach for using VES to investigate habitat associations would have been to survey a greater number of smaller habitat patches and to have staggered repeated surveys at sites in a time-independent manner. Alternatively, a mark-recapture protocol at fewer large sites where each individual, rather than each site, forms the unit of replication could have been used.

\subsubsection{Conclusion and recommendations for habitat restoration}

Suppression or eradication of invasive mammal populations is likely to be more important than habitat quality for conservation of O. aeneum, O. kokowai and W. chrysosireticus in coastal environments of the Wellington region. However, two lizard species (O. polychroma and W. maculata) could benefit from planting divaricating shrubs in mammal-invaded environments. Planting native vines in mammal-invaded sites may also benefit $O$. polychroma. Divaricating shrub species found frequently at the sites and thus appropriate for habitat enhancement in coastal areas of Wellington include: Melicytus crassifolius, $M$. obovatus, and Coprosma propinqua. The most frequently occurring non-Muehlenbeckia vine was Tetragonia implexicoma, but Calystegia species and Clematis forsteri could also be used for enhancing habitat for O. polychroma. There was no distinct clustering of lizard species together in the MDS, suggesting niche separation or competition between species. Therefore, the direction of habitat enhancement will ideally be tailored to the target species' preference. If several species are present in an area, building heterogeneity into the enhancement programme may be useful for conserving lizard biodiversity. Because of the positive relationship between species detection probability and local abundance in occupancy models, habitat characteristics positively correlated with detection probability should also be trialled in habitat enhancement programmes to confirm their effect on abundance (Royle and Nichols, 2003). Habitat characteristics were considered important for species detection probability only in W. maculata, which had positive relationships with increasing coverage of divaricating shrubs and rocks. 


\section{Chapter 4}

\section{The intermediate- to long-term effects of invasive mammal presence on an insular lizard fauna}

\subsection{Introduction}

The introduction of invasive predators to new areas around the globe has resulted in declines and extinctions of native fauna, with insular species being particularly affected (Doherty et al., 2016). When a suite of exotic species is introduced into an area, the effects on native species can be difficult to understand due to the multitude of interactions that form between exotic species, which are in turn impacted by anthropogenic pressures such as habitat modification and climate change (Fig. 4.1). The cascading effects of these interactions can also alter pre-existing relationships between native prey species, leading to indirect effects in addition to direct effects (Norbury, 2001; Norbury et al., 2013; Wittmer et al., 2013; Holt and Bonsall, 2017).

In an environment that supports both invasive species and more than one native species of conservation interest, it is important to understand whether all species are impacted equally, or whether asymmetry exists, so that conservation resources can be prioritised accordingly to species and targeted at the ecological interactions responsible for the decline (Wittmer et al., 2013). Long-term population data are often unavailable to make an assessment of extinction risk, therefore static population quantities - population size and/or the area occupied - often need to be used to inform assessment of a species' threat classification (Mace et al., 2008; Townsend et al., 2008). In these cases, based on metapopulation theory, it is assumed that abundant and widespread populations have a low risk of extinction (Hanski, 1999).

The complexity of the interactions between suites of exotic predators and indigenous fauna is illustrated in the endemic lizard fauna of the archipelago of New Zealand, given 


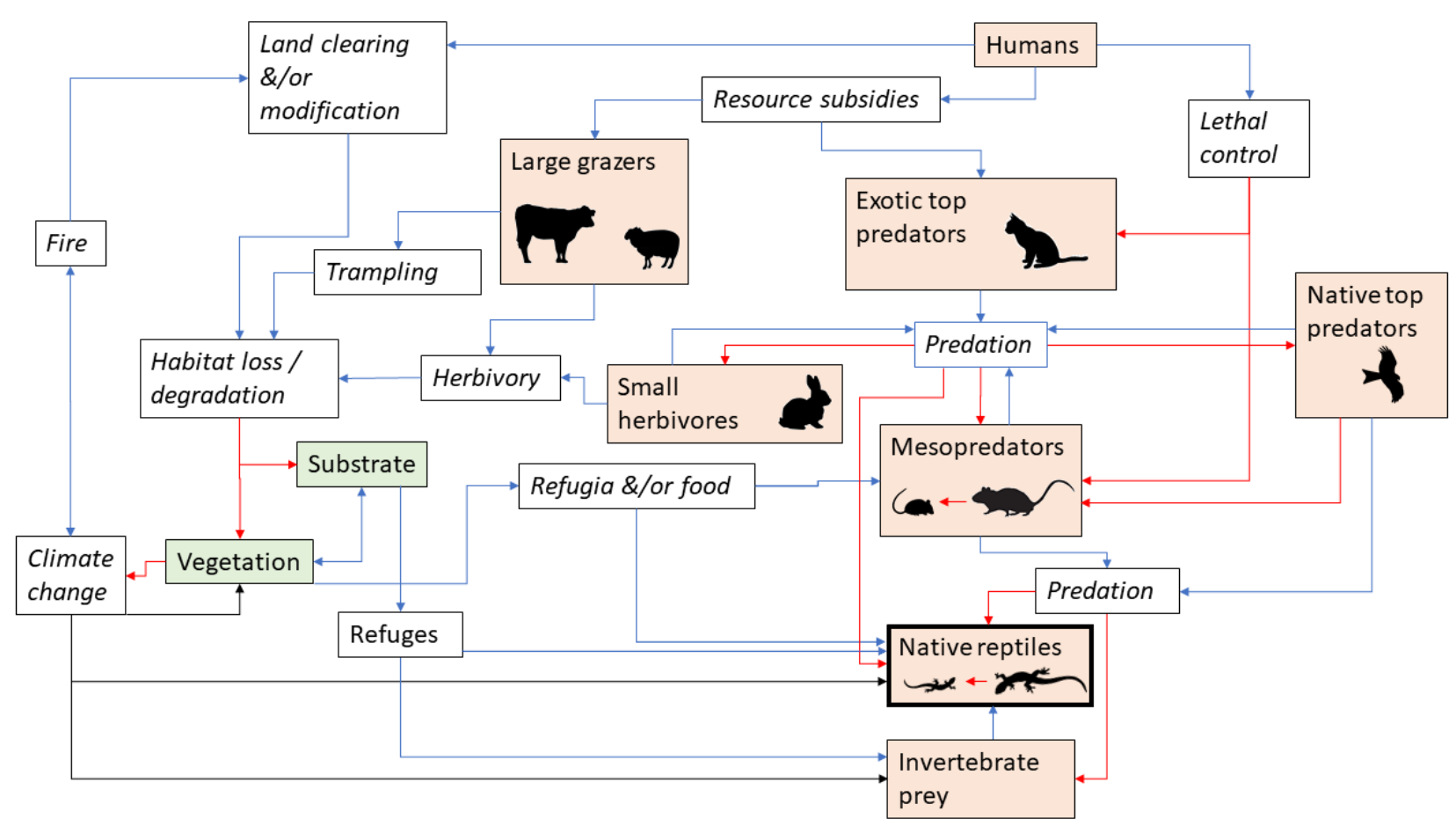

Figure 4.1: Conceptual diagram of the relationship between community- and habitatmediated interactions and their effects on native reptiles within the New Zealand context. Community-mediated threats are those that arise due to the composition of the fauna community, and habitat-mediated threats are those that are mediated by alterations in vegetation and substrate structure. Components of the faunal community are indicated by pale red boxes; habitat components are indicated by green boxes. Interaction types are indicated by italic text. Positive relationships are represented by blue arrows, negative relationships by red arrows, and black arrows represent relationships that can be either negative or positive. Model based on Doherty et al. (2015), with context-specific information from Norbury (2001); Bridgman et al. (2013); Norbury et al. (2013). 
the diversity of the endemic skink (Scincidae; 63 extant species) and gecko (Diplodactylidae; 43 extant species) fauna (Norbury, 2001; Norbury et al., 2013; Chapple, 2016; van Winkel et al., 2018), (Fig. 4.1). Subfossil and biogeographic evidence suggests that before the arrival of humans, and their associated domestic and commensal fauna, New Zealand's mainland lizard communities included a larger component of large-bodied lizard species than they do today (Worthy, 1987, 2016; Towns and Daugherty, 1994). Like the endemic fauna of many islands, the major threats responsible for declines and local extinctions are the impact of invasive mammalian predators and habitat loss or degradation, and it is thought that nocturnal or crepuscular and large-bodied species have suffered the most severe impact (Case and Bolger, 1991; Towns and Daugherty, 1994; Tingley et al., 2013; Hitchmough et al., 2016a; Woolley et al., 2019). The suite of lizard predators introduced to New Zealand includes representatives from the Rodentia (three rat species (Rattus exulans, $R$. rattus and $R$. norvegicus and one mouse Mus musculus), Eulipotyphla (European hedgehogs Erinaceus europaeus occidentalis) and Carnivora (three mustelids (Mustela furo, M. nivalis vulgaris and M. erminea) and domestic cats Felis catus) (Fig. 4.1). It is uncertain whether two other introduced omnivores, pigs Sus scrofus and brushtail possums Trichosurus vulpecula consume lizards (Thoresen, 2012; Doherty et al., 2015). The ability of these invasive predators to drive endemic lizard populations to extinction is clear in several large-bodied lizards that are now restricted to predator-free sanctuaries (for example, New Zealand's largest extant skink, the robust skink Oligosoma alani (van Winkel et al., 2018)). Other New Zealand lizard species currently persist in predator-invaded environments, making their responses to exotic predators less clear. The apparently abundant New Zealand lizard species may be in a state of gradual decline due to predation by invasive mammals. However, it is possible that declines are difficult to detect if a few long-lived individuals persist in an area or due to the generally very cryptic nature of small reptiles (Cree, 1994; Ward et al., 2017). Without information on population trends across different species, accurate prioritisation of conservation resources will be difficult for this fauna.

I investigated lizard communities and populations in the Wellington region of New Zealand to determine which species (if any) are capable of maintaining viable populations in mammal-invaded areas. Firstly, I used a mark-recapture framework to estimate the contemporary (2018-2019) abundances of common lizard species at two mammal-invaded sites. Secondly, data from previous lizard monitoring programmes were acquired from three mammal-invaded sites to examine moderate-to-long term trends in lizard species' relative abundance, estimated abundance, or occupancy. It was hypothesised that the two species frequently observed in the mammal-invaded sites surveyed in Chapter 3 (the skink Oligosoma polychroma and the gecko Woodworthia maculata) would (1) be captured frequently enough in contemporary surveys of mammal-invaded areas to estimate abundance and (2) at least at one of these areas, display no evidence of a decrease in 
abundance or occupancy over time.

\subsection{Methods}

\subsubsection{Study sites and species}

The three study sites used for this chapter were located within mammal-invaded coastal areas of the Greater Wellington region of New Zealand: Pukerua Bay Scientific Reserve, Turakirae Head Scientific Reserve, and Ōrua Pouanui / Baring Head (see Table 1.3 and Fig. 1.4 in Chapter 1). Both Scientific Reserves are Crown-owned and managed by the New Zealand Department of Conservation (DOC). Baring Head is part of the East Harbour Regional Park managed by the Greater Wellington Regional Council (GWRC). Two of these sites, Pukerua Bay and Baring Head, have predator control programmes in operation whereas Turakirae Head had received a negligible amount of control until June 2019 (Table 1.3). All sites were a minimum of $4 \mathrm{~km}$ apart so that spatial independence of the lizard populations was a reasonable assumption, but were located within $60 \mathrm{~km}$ of each other so that there would be some homogeneity in climate and ecology. However, there were some differences in lizard assemblages between sites, reflected by their location within different Ecological Districts (EDs) (McEwen, 1987; Bell and Wiles, 2015). Some of these differences probably reflect the species' biogeography. For example, glossy brown skinks Oligosoma zelandicum are absent from the Tararua ED meaning that this species was unlikely to be present at Turakirae Head or Baring Head (Bell and Wiles, 2015). Other species distributions likely reflect range restrictions due to invasive mammals. For example, the geckos Hoplodactylus duvaucelli, Toropuku stephensi, and W. chrysosiretica, and the skinks O. alani, O. macgregori, and O. whitakeri are restricted to a few (mostly mammal-free) sites within the Cook Strait ED in Wellington (Towns and Daugherty, 1994; van Winkel et al., 2018; Woolley et al., 2019). The lizard species known to occur at each site are listed in Table 1.3 , and relevant life history characteristics of species found during this study are provided in Tables 1.4 and 1.5 in Chapter 1.

\subsubsection{Contemporary (2018-2019) lizard abundance in mammal-invaded environments}

\section{Data collection}

Lizard mark-capture monitoring programmes were installed at two mammal-invaded mainland study sites: Pukerua Bay and Turakirae Head Scientific Reserve (Figs. 4.3 and 4.4). Terrestrial lizards at each site were monitored in two $100 \mathrm{~m}^{2}$ areas that consisted of a $6 \times 6$ grid of monitoring 'stations' spaced approximately $2 \mathrm{~m}$ apart. Each monitoring 
station consisted of a $4 \mathrm{~L}$ plastic pitfall trap (Stowers Plastics, Petone) covered with a double-layered $40 \times 50 \mathrm{~cm}$ Onduline (Composite Insulation, Christchurch) artificial cover object (hereafter, 'ACO') (Fig. 4.2; Lettink and Cree (2007); Hare (2012)). Pitfall traps had four $3 \mathrm{~mm}$ holes drilled in the bottom for drainage and ACOs were weighted down with heavy rocks to prevent them blowing away in the wind. Each station per grid was labelled with an alphanumeric code (A-F and 1-6). When not in use, the pitfall traps were filled with dead wood and stones to avoid trapping lizards.

The $100 \mathrm{~m}^{2}$ monitoring grids were placed in February 2018 using randomised corner points generated in a GIS, with the caveat that they needed to be separated by at least 100 $\mathrm{m}$ to be spatially independent (Lettink et al., 2010; QGIS Development Team, 2016). At both of these sites, the monitoring grids were not placed in the same location as previous monitoring work. A two-hectare area of intensive mouse control using self-resetting A24 traps was implemented at Pukerua Bay in autumn 2018 within and around the historical Whitaker's skink monitoring area, which meant that any future monitoring within this area would poorly reflect historical responses to background levels of pest control across the reserve (A. Hulme-Moir, pers. comm.; Fig. 4.3). Instead, sites were placed at a random distance along the escarpment bottom (on a similar contour to previous monitoring efforts) in the western section of reserve that was at least $100 \mathrm{~m}$ away from the edge of the mouse control area (Fig. 4.3). At Turakirae Head, the contemporary lizard CMR grids were randomly placed within the area of reserve between $500 \mathrm{~m}$ east and west of Cape Turakirae surrounding previous mark-recapture monitoring work by Whitaker (1982), Marshall (1983), and Green (2001) to give a more general idea of lizard abundance across the area that included these historical monitoring grids and previous lizard sightings (Fig. 4.4).

Closed mark-recapture 'seasons' consisting of 5-6 days were completed in May 2018 (3 months after placement) and February 2019 (12 months after placement). The first day was considered to be a capture session (i.e. one "station-day") because lizards were caught in the ACOs and were also found using the debris filling each closed pitfall trap as refuges. Pitfall traps were opened by removing the sticks and stones filling the trap, placing a 20-50 $\mathrm{mm}$ layer of rocks, soil, and/or vegetation plus a wet sponge in the bottom of the pitfall to provide lizards with cover and moisture. Pitfalls were baited with an approximately 1 $\mathrm{cm}^{3}$ piece of tinned pear to attract lizards (Whitaker, 1967). The monitoring stations were checked daily while the pitfall traps were open. The pear bait was replaced every 2-3 days, and a water bottle was used to wet the substrate and sponge at the bottom of each trap as needed to prevent trapped lizards from becoming desiccated. The following variables were collected from each lizard captured: species, snout-vent-length (SVL), and the presence or absence of an umbilical scar in neonate-sized animals. The sex of adult-sized animals was determined by examination of the internal structures of the cloaca or hemipenal eversion (skinks) or by examination of external characteristics of the cloacal region (geckos: presence or absence of a hemipenal bulge and cloacal spurs, and prominence of precloacal pores; 


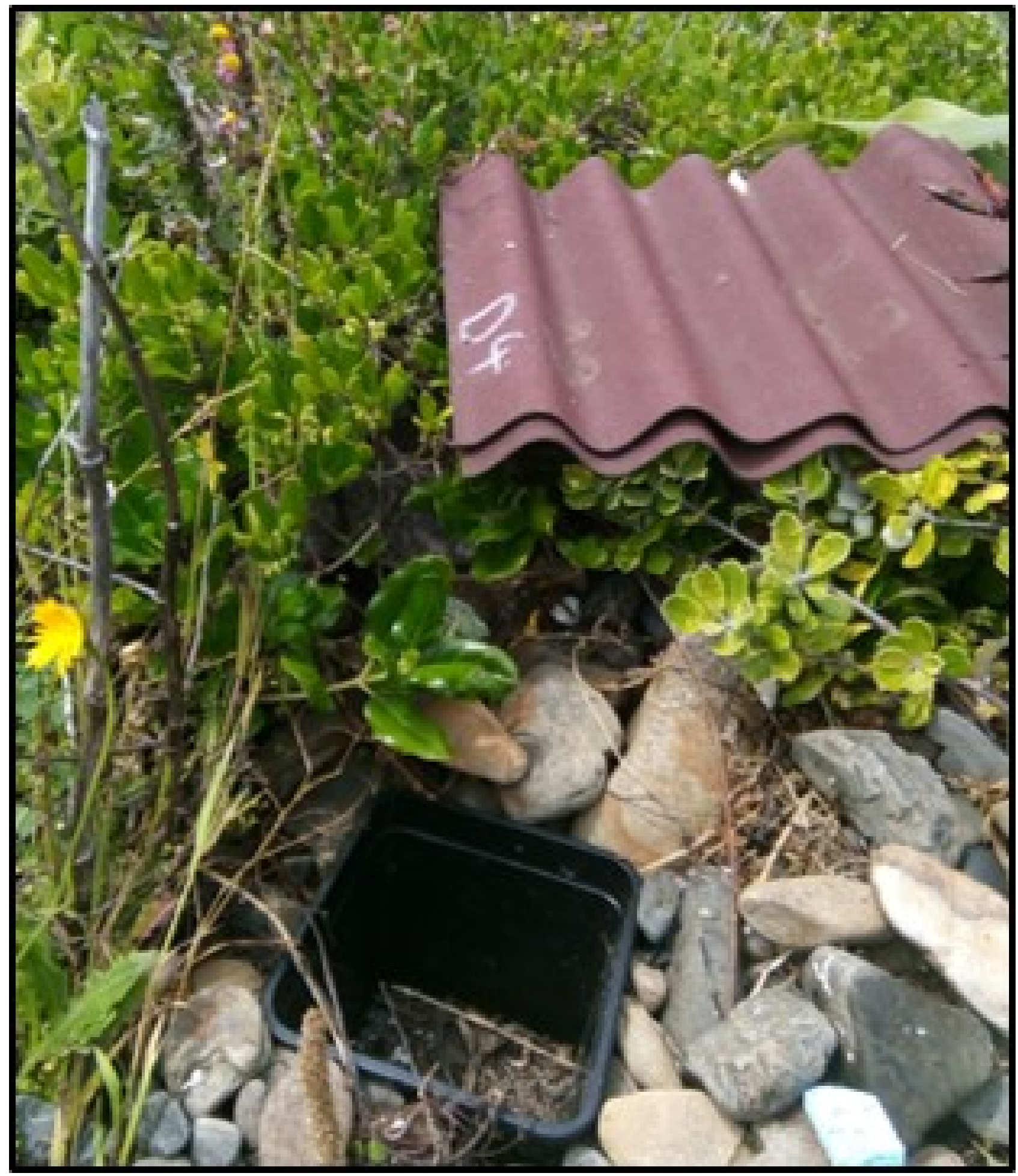

Figure 4.2: Example of a lizard monitoring station consisting of a 4 L pitfall trap covered with an Onduline artificial cover object (ACO). The ACO has been lifted off the pitfall trap in this photo so that both components can be seen. The sponge (blue) added to the bottom of the pitfall traps when set can be seen in the lower right side of the photograph. 
skinks: presence of obvious hemipenal bulges posterior to the cloaca in large males). Skinks were marked with a unique four digit code by clipping two toes on different feet just beneath the base of the claw. Any existing toe loss was integrated into the toe code. Geckos were marked temporarily on the abdomen with a unique number using an Artline 990XF xylenefree permanent marker (Fig. 4.5). These pen marks last for at least 21 days on geckos and are lost when the skin is shed (Herbert et al., 2013a, 2014a). 


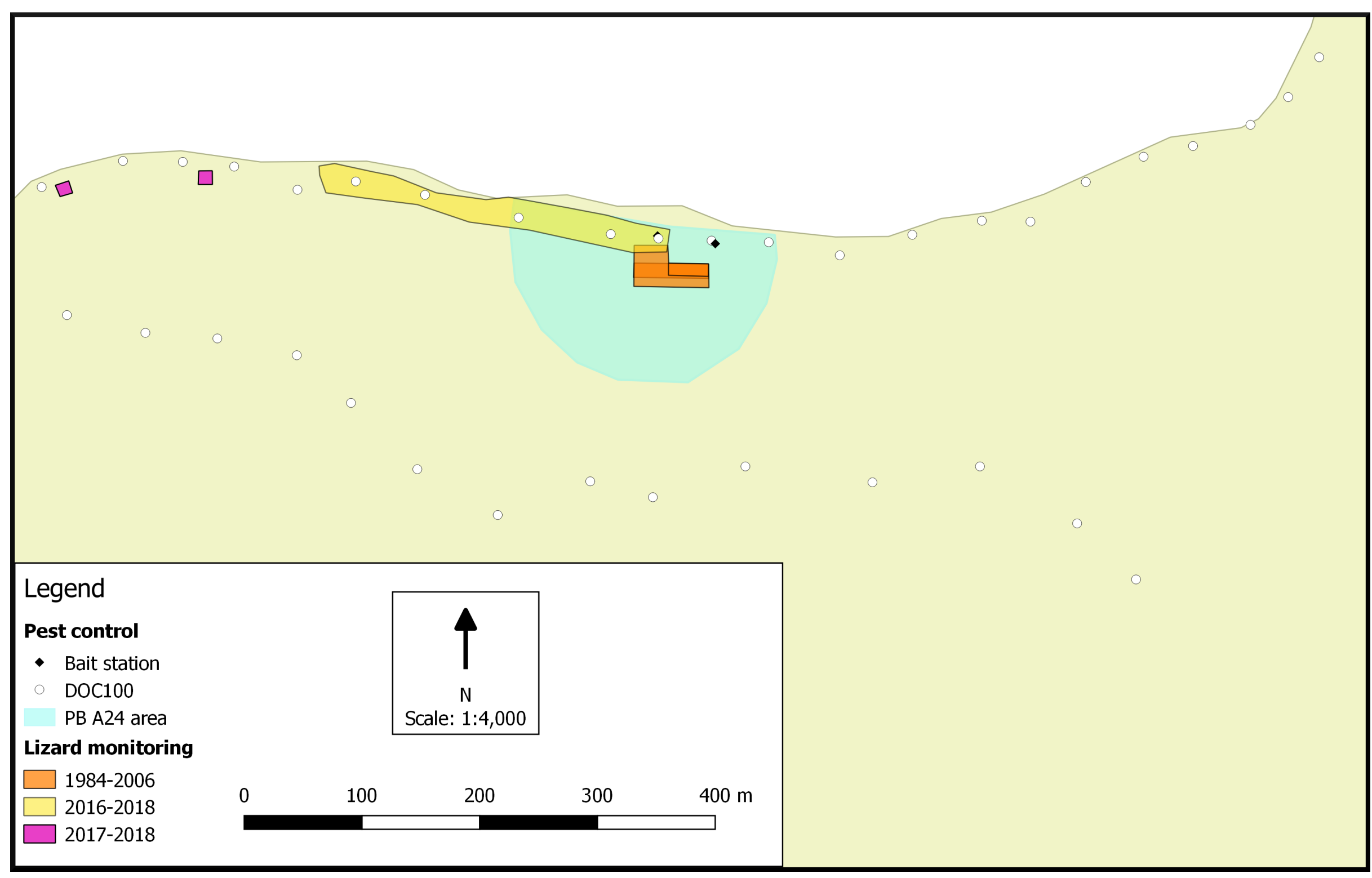

Figure 4.3: Location of contemporary (2018-2019, this study) and long-term (1984-2006 and 2015-2018) lizard monitoring at Pukerua Bay. PB A24 area = mouse control area. 


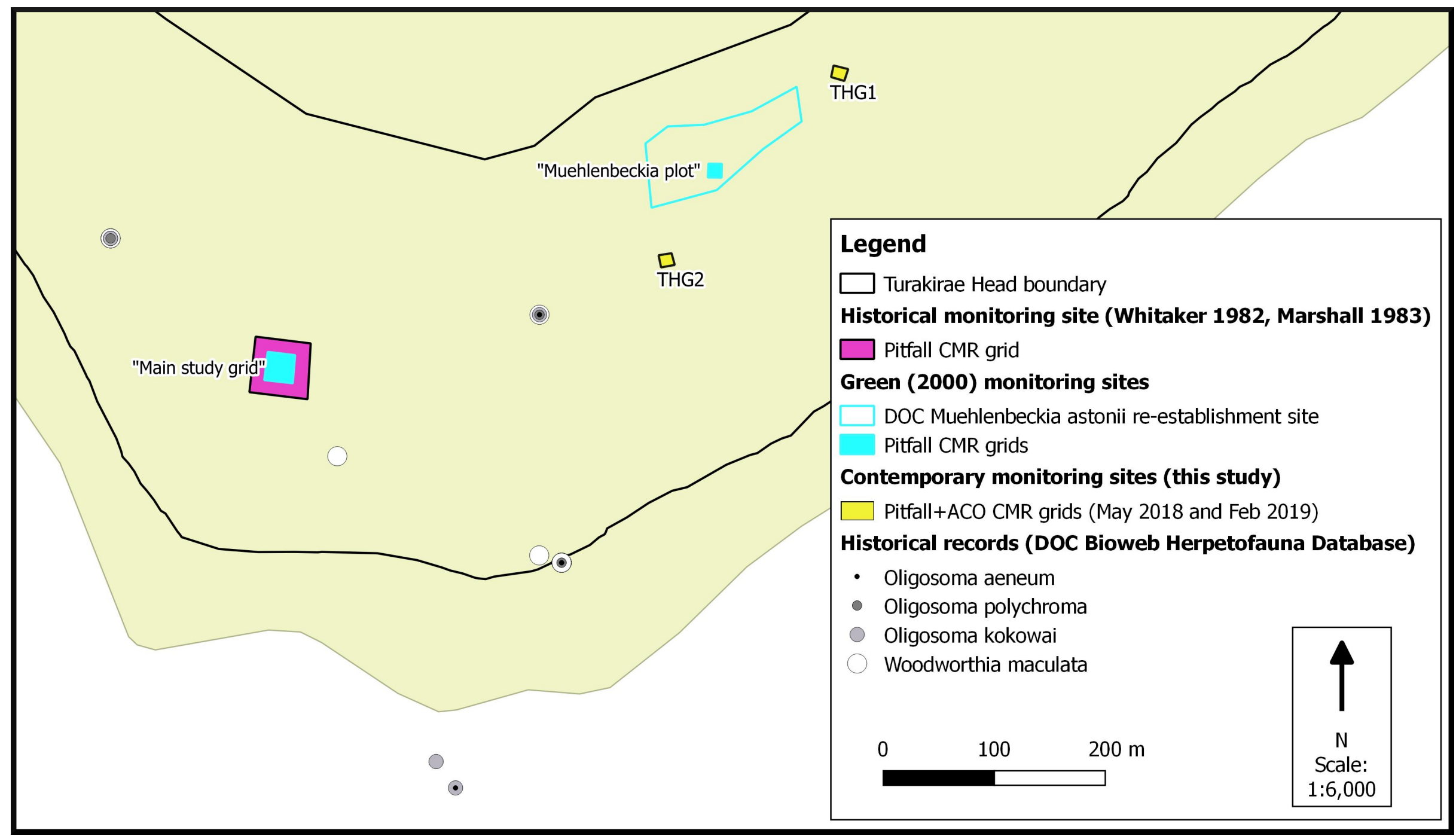

Figure 4.4: Location of contemporary (2017-2019, this study), and historical (1967-1976, 1983, and 2000) lizard monitoring effort at Turakirae Head (Whitaker, 1982; Marshall, 1983; Green, 2001). The location of lizard sightings recorded in the DOC Bioweb Herpetofauna Database (accessed 8 August 2015) are provided for context. CMR = capture-mark-recapture. 


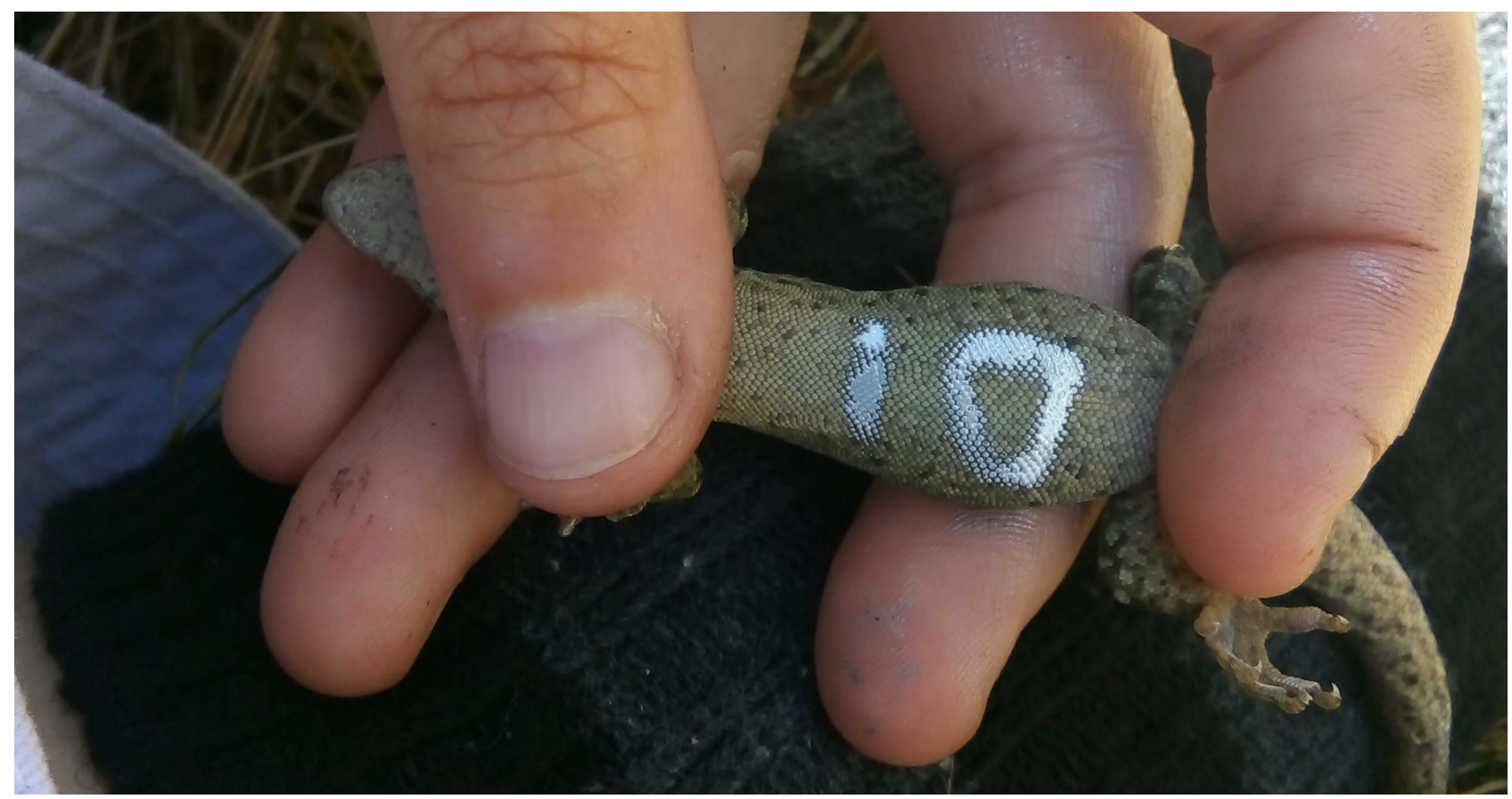

Figure 4.5: An example of the temporary pen marks given to geckos for short-term individual identification. The number ' 10 ', means that this was the tenth individual caught at a site within a single closed capture period.

\section{Analysis}

Abundances of Raukawa geckos Woodworthia maculata and northern grass skinks Oligosoma polychroma in the monitoring grids were estimated using Huggins' closed capture models in MARK 9.0 (Huggins, 1989, 1991; White, 2019). Other lizard species were captured too infrequently for mark-recapture modelling to be feasible. Generally, abundance was estimated for each grid separately, with the exception of O. polychroma at Turakirae Head, where grids were not specified because there were too few captures of this species in each grid. Individual heterogeneity was modelled as the logit of snout-vent length (SVL) and as two finite mixtures (i.e. $\pi=2$; Pledger (2000)). SVL was modelled to account for differences in detection probability between neonate, juvenile, subadult, and adult animals. Finite mixtures were used to account for the possibility of an unmeasured source of individual capture heterogeneity, such as trap happiness and trap shyness, or differences between sexes. Sex was not modelled explicitly because neonate to subadult-aged animals cannot be reliably sexed. Some individuals lacked SVL data because they escaped part-way through the marking and measuring process. Individuals with SVL data lacking were assigned a value that equalled the average of all other conspecifics in the same age class (neonate, juvenile, subadult, or adult) captured at the same site. Because of low capture and recapture rates within some grids, data from all grids at a site were pooled and all real parameters ( $\pi$, capture probability $p$, and recapture probability $c$ ) assumed to be constant across grids. Each of the models trialled, along with their biological rationale for inclusion 
in the candidate model set, are listed in Table 4.1.

Depending on the overdispersion value $(\hat{c})$ of the global model, parsimony was assessed using the AICc (for $\hat{c} \leq 1$ ) or QAICc (for overdispersed models with $\hat{c}>1$; Burnham and Anderson (2002)). The real parameter estimates of each model were checked to identify over-parametrised models. These models produce unreliable estimates that can be identified by either (1) singular parameter estimates that are non-estimable or approach a boundary value or (2) standard errors that are either zero or extremely large (Conn et al., 2006; Jones et al., 2013; White, 2019). For the purposes of model critique, abundance estimates with 'extremely large' standard errors were defined as those with a coefficient of variation $\geq$ 100\%. Therefore, the model ultimately used to estimate $\hat{N}$ was the model with the lowest QAICc that did not display signs of being overparametrised. Model averaging was not used due to the presence of overparametrised models in the candidate model set.

To calculate density estimates from estimated abundance, abundance was divided by the effective trapping area (ETA) of each grid. The ETA was calculated by adding the same sized boundary strips used by Green (2001), based on movements of O. polychroma and $W$. maculata in pitfall grids. That is, the ETA of each grid for W. maculata was calculated as $(10+2.07)^{2}=145.68 \mathrm{~m}^{2}$ and O. polychroma as $(10+2.38)^{2}=153.26 \mathrm{~m}^{2}$.

\subsubsection{Temporal lizard population trends in mammal-invaded environments}

Historical or time series lizard monitoring data were available for Pukerua Bay, Turakirae Head, and Baring Head. The methodologies used to collect these data (for example, different spacing between pitfall traps used to capture lizards), and the types of data collected, differed among these sites. Therefore the inference that could be made about the temporal dynamics of lizard species differed among sites, and I did not attempt to compare the historical or time series data from different sites. It was necessary to use a different approach for analysing the data from each site. Where possible, I prioritised the use of analytical methods that explicitly accounted for detection probability (that is, mark-recapture abundance estimation or occupancy modelling) over indices such as capture-per-unit-effort (CPUE). Habitat and small mammal monitoring data were available for Baring Head, making it possible to examine lizard species' responses to these variables in addition to changes in lizard populations over time at this site.

\section{Pukerua Bay Scientific Reserve}

Long-term (1984-2018) lizard pitfall trap data from Pukerua Bay were made available by the New Zealand Department of Conservation (DOC). The historical data (1984-2006) have been previously published by Towns (1996); Hoare (2006), and Hoare et al. (2007a). More 
Table 4.1: Models included in the candidate set for closed-captures abundance estimation of northern grass skinks (Oligosoma polychroma) and Raukawa geckos (Woodworthia maculata) from $100 \mathrm{~m}^{2}$ monitoring grids. Model notation follows Chao et al. (1992), where $M_{0}$ is the null model and $M_{t b h}$ is the global model including effects of time $(t)$, behaviour $(b)$ and individual heterogeneity $(h) . p=$ capture probability and $c=$ recapture probability.

\begin{tabular}{|c|c|}
\hline Model & Biological rationale \\
\hline$M_{0}$ & $\begin{array}{l}\text { Null model where } p \text { and } c \text { are equal and constant across } \\
\text { individuals and capture occasions. }\end{array}$ \\
\hline$M_{b}$ & $\begin{array}{l}\text { Behaviour model where } p \neq c \text { due to the first capture influencing } \\
\text { the likelihood of recapture. Typical examples include trap- } \\
\text { shyness where an animal learns to avoid traps and thus } p>c \text {, } \\
\text { and trap-happiness where an animal learns to use traps more } \\
\text { frequently after the first capture and thus } p<c \text {. Trap-happiness } \\
\text { is likely driven by a perceived reward from entering a trap (e.g. } \\
\text { live-capture traps that use food as bait), whereas trap-shyness } \\
\text { results from learned avoidance of traps (Willson et al., 2011). }\end{array}$ \\
\hline$M_{h}(\pi=2)$ & $\begin{array}{l}\text { Heterogeneity model with two finite mixtures where } p \text { and } c \\
\text { are influenced by an unspecified individual attribute that is } \\
\text { hypothesised to fall into two groups (Pledger, 2000). An example } \\
\text { is personality, where bold individuals may be more likely to enter } \\
\text { pitfall traps than shy individuals. }\end{array}$ \\
\hline $\begin{array}{l}M_{h} \\
(p(S V L)=c(S V L))\end{array}$ & $\begin{array}{l}\text { Reduced-parameter heterogeneity model where } p \text { and } c \text { are } \\
\text { influenced by a single covariate: an individual's life stage. } \\
\text { Body size as snout-vent length (SVL) can be used as a proxy } \\
\text { measure of age in lizards to discriminate neonate, juvenile, } \\
\text { and adult animals. Juvenile reptiles are often more difficult to } \\
\text { observe or capture than adults in mark-recapture studies due to } \\
\text { smaller body size. Alternatively, behaviour may differ between } \\
\text { immature and adult animals, making one group less likely to be } \\
\text { captured (Ballouard et al., 2013). }\end{array}$ \\
\hline$M_{t}$ & $\begin{array}{l}\text { Time-dependent model where } p=c \text {, but these values vary } \\
\text { between capture occasions. For example, weather conditions } \\
\text { influence use of Onduline ACOs and pitfall traps by lizards } \\
\text { (Lettink and Monks, 2016). }\end{array}$ \\
\hline$M_{b h}(\pi=2)$ & $\begin{array}{l}\text { Behaviour and heterogeneity model with two finite mixtures } \\
\text { where } p \neq c \text { and are influenced by an unspecified individual } \\
\text { attribute. }\end{array}$ \\
\hline$M_{t b}$ & $\begin{array}{l}\text { Time-dependent and behaviour model where } p \neq c \text { and both } \\
\text { variables vary between capture occasions. }\end{array}$ \\
\hline$M_{t h}(\pi=2)$ & $\begin{array}{l}\text { Time-dependent and heterogeneity model with two finite } \\
\text { mixtures where } p=c \text { and both variables vary between capture } \\
\text { occasions. }\end{array}$ \\
\hline$M_{t b h}(\pi=2)$ & $\begin{array}{l}\text { Time-dependent, behaviour, and heterogeneity model with two } \\
\text { finite mixtures where } p \neq c \text { and both variables vary between } \\
\text { capture occasions. }\end{array}$ \\
\hline
\end{tabular}


recent data (2015-2018) from Pukerua Bay are available as series of unpublished reports (Newman, 2015, 2016, 2017, 2018). The lizard pitfall trapping was focused on maximising captures of endangered Whitaker's skinks (Oligosoma whitakeri) rather than lizard community monitoring which resulted in pitfall locations being changed between years, sometimes without accurate location data being recorded (particularly between 2007 and 2014). Known locations of this monitoring programme are detailed in Figure 4.3. A catch-per-unit-effort index (CPUE) for each lizard species between 1984 and 2006 was calculated by Hoare et al. (2007a) as the number of captures per 100 trap-days. I repeated their methodology for calculating CPUE for 2007-2018. Here, a "trap-day" was defined as one pitfall trap being open for a 24-hour period. For example, 20 pitfall traps opened for five days would equal 100 trap-days. Linear regression was performed in $R$ version 3.5.1 ( $R$ Development Team, 2018) to examine the response of each lizard species' CPUE from 1984-2018 to 'Year' as a (model 1) linear and a (model 2) quadratic term to examine the direction and shape of the relationship. Likelihood ratio tests were performed to compare the parsimony of these two alternative models.

\section{Turakirae Head Scientific Reserve}

The results of historical (1967-1976, 1983, and 2000) lizard mark-recapture monitoring programmes at Turakirae Head were available from Whitaker (1982); Marshall (1983) (W. maculata only), and Green (2001) (W. maculata and O. polychroma). I compared the contemporary density estimates of $W$. maculata and O. polychroma calculated from the February 2019 mark-recapture data (see section 4.2.2) with historical density estimates. Significant differences in estimated abundance among the studies conducted at different time periods were identified by examining overlap of the $95 \%$ confidence intervals. CPUEs were calculated for each lizard species from the 2018-2019 mark recapture studies as the number of captures per 100 trap-nights for comparison with historical CPUE data for $O$. polychroma, O. aeneum, and O. kokowai collected by Whitaker (1982).

\section{Ōrua-pouanui / Baring Head}

Lizard and small mammal monitoring data from 2012-2018 were made available by the Greater Wellington Regional Council (GWRC). Previous outputs from this programme have been reported by Herbert and Bell (2012); Herbert et al. (2013b, 2014b); Wiles et al. (2015); Wiles (2016); Bell et al. (2018); Herbert and Bell (2019) and Uys (2019). The small mammal data comes from quarterly monitoring of eight $100 \mathrm{~m}$ transects of ink tracking tunnels placed across the park in a stratified random fashion (Fig. 4.6, Uys (2019)). Rodents were monitored as one-night tracking indices from ink tunnels baited with peanut butter. Mustelids and hedgehogs were monitored as three-night tracking indices from ink tunnels 
baited with rabbit meat. The lizard data consisted of repeated counts of lizards caught in pitfall traps across five seasons (mid-December 2012, 2013, 2014, 2017 and 2018) comprised of seven consecutive trap-days across 210 spatially independent pitfall trap-sites. Pitfall traps were placed at least $25 \mathrm{~m}$ apart according to a stratified random sampling design, with at least 40 traps being placed in each of the five land management units at Baring Head (strata: coastal beach, coastal escarpment, river escarpment, river flats, and terrace farmland, Fig. 4.6). Pitfall trap locations were unchanged between 2012 and 2018, but a small proportion of pitfall traps each year were treated as missing data due to flooding or damage. Habitat data collected by Owen Spearpoint from the GWRC was available for the $2 \mathrm{~m}$ radius surrounding each pitfall trap (see Wiles (2016) for a previous application of these data). Weather covariates (average hourly temperature and relative humidity for the 24 hour-period preceding 08:00 of the day of survey) for 2013-2018 were extracted from CliFlo for the Baring Head weather station (agent number: 18234, latitude: -41.407, longitude: 174.867), and 2012 from the nearest alternative weather station at Wellington Airport (agent number: 3445, latitude: -41.322 , longitude: 174.804), because there were no data from Baring Head for this year.

Correlations between habitat and pest covariates (an ordinal amount of grazing and rock as $0=$ none, 1 = some, 2 = a lot, and an identity matrix describing whether the pitfall was in grassland, shrubland (defined as shrubs comprising $<80 \%$ of canopy) or scrub (shrubs comprising $\geq 80 \%$ of canopy; sensu Atkinson (1985)) were examined using the non-parametric Spearman's $\rho$ statistic. Principal components analysis (PCA) was performed in $\mathrm{R}$ to resolve the highly correlated mammal species tracking data into two principal components describing the 'pest guild' present at each pitfall site.

The repeated count data from the two species captured frequently enough to enable modelling (W. maculata and O. polychroma) were re-expressed as a binary vector, where $0=$ species not detected in a pitfall and $1=$ species detected. These data were initially modelled as multi-season occupancy models in program PRESENCE to estimate rates of site colonisation and extinction, and to examine changes in site occupancy between each year of the monitoring programme (MacKenzie et al., 2003; Hines, 2006).

Site occupancy of $W$. maculata in each season was modelled using a mechanistic framework, as follows. Site occupancy in the first season (2012) was estimated from the presence/absence data. Site occupancy in each subsequent season was modelled as the result of the cumulative effects of local colonisation and extinction rates on occupancy in the first season. Given the six-year time frame, I did not expect local colonisation and extinction rates to vary substantially between seasons, therefore they were constrained to be constant over time. Construction of the maximal model ( $M_{\text {max }}$; Table 4.2) was based on the following rationale:

1. Divaricating species form a large component of the shrubland and scrub areas of Baring Head. Divaricating shrubs were demonstrated to have a positive effect on $W$. 


\section{Legend}

- GWRC lizard monitoring (2012-2019)

Bait station grids

Stock exclusion zone

Baring Head boundary

Land

Pest monitoring lines

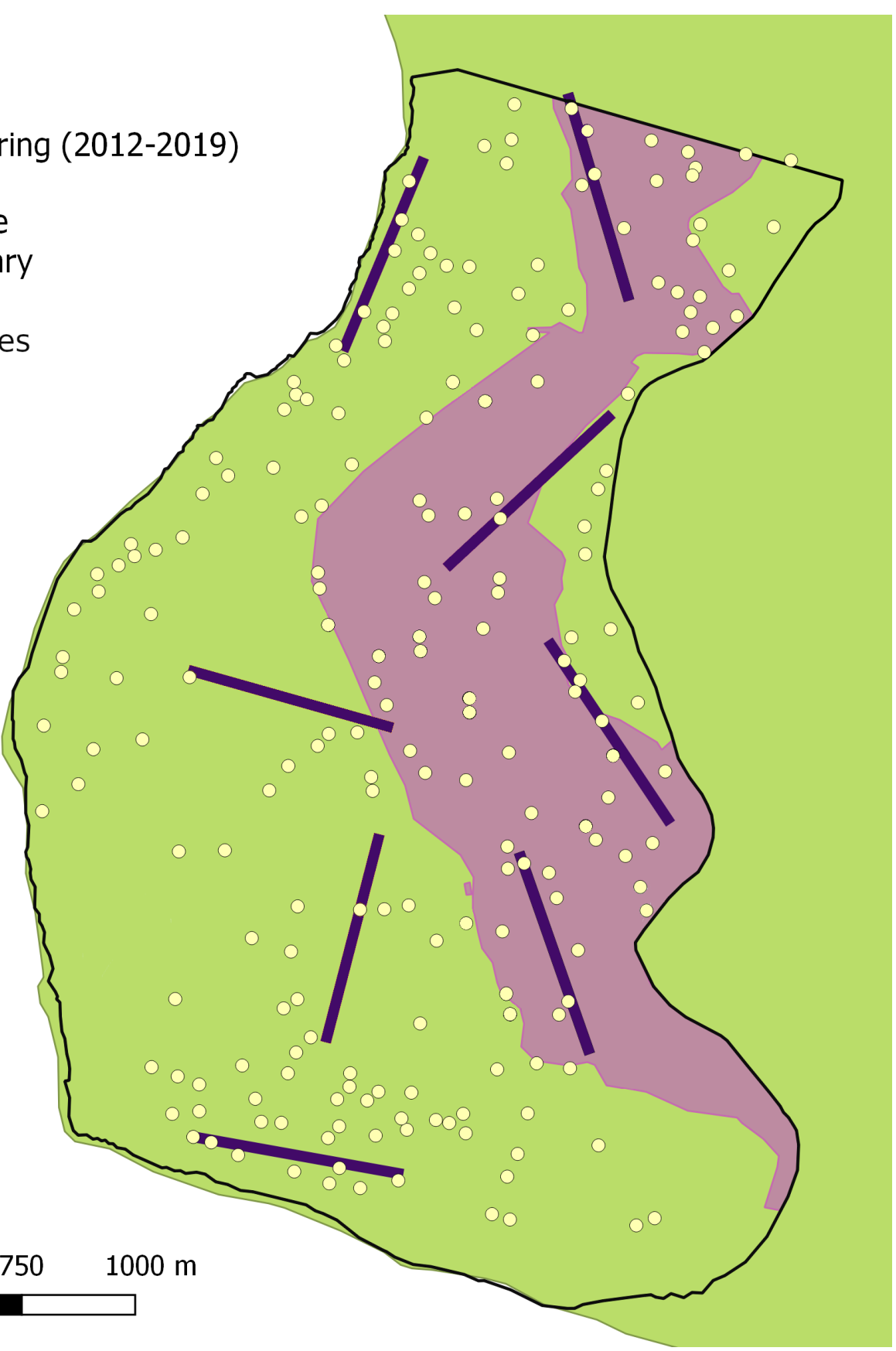

Figure 4.6: Location of the lizard pitfall traps and small mammal ink tracking tunnel transects monitored by the Greater Wellington Regional Council (GWRC) between 2012 and 2018. 
maculata occupancy, and a negative effect on species detection probability in Chapter 3. I therefore hypothesised that initial occupancy and probability of local extinction $(\epsilon)$ would be lowest in scrub, intermediate in shrubland, and highest in grasslands. Species detection probability $(p)$ was expected to be highest in grassland, intermediate in shrubland and lowest in scrub. Shrubland and grassland were included as factors for occupancy, $\epsilon$, and $p$ as orthogonal contrasts against the intercept. Here, the intercept represented pitfalls in scrub habitats.

2. In Chapter 3, the amount of rock cover at a site had a positive effect on species detection probability of $W$. maculata. This could be purely due to a positive effect on individual detection probability. It could also indicate that this species is more abundant in rocky areas due to an underlying population or metapopulation process. Therefore, the effect of rock cover was modelled as a covariate for $\epsilon$ and $p$.

3. The pest mammal guild and grazing regime surrounding each pitfall were hypothesised to affect occupancy of $W$. maculata via an effect on local extinction probability. Therefore, the two principal components that summarised spatial variation in the mammal species assemblage between grazed and ungrazed areas were included as additive effects in the model.

4. Species detection probability $(p)$ is likely to vary between capture occasions. W. maculata can climb out of pitfall traps, so it is expected that detection probability will be governed by similar processes as that of artificial retreats (Hoare et al., 2009). It was hypothesised that $p$ would decrease with increasing ambient temperatures, but increase with increasing amounts of rainfall. These covariates to allow $p$ to vary between capture sessions with respect to rainfall and temperature.

Three further reduced-parameter models $\left(M_{1-3}\right.$; Table 4.2$)$ were constructed to test whether inclusion of spatial covariates for site occupancy and local extinction were important for model fit.

Multi-season occupancy models were found to have a poor fit to the O. polychroma detection data. The underlying reason for this was examined by comparing model fits for the 2018 detection data as a single-season occupancy model that assumes homogeneous detection probability with a Royle/Nichols (RN) heterogeneity model that conceptualises heterogeneity in detection probability $(p)$ as caused by variation in local abundance $(\lambda)$ (MacKenzie et al., 2002; Royle and Nichols, 2003). The RN model formulation had an adequate fit to the data and strong support by the AIC, therefore the 2018 O. polychroma data were modelled separately using this approach for comparison with the previous years' occupancy estimates reported in Herbert and Bell (2018). Construction of the maximal model ( $M_{\max }$; Table 4.3$)$ was based on the following rationale: 
Table 4.2: Candidate model set for site occupancy of Woodworthia maculata at Baring Head, 2012-2018. All models are multi-season occupancy models. The maximal model is named $M_{\text {max }}$. $P C 1$ and $P C 2$ are principal components describing spatial variation in the grazing regime and invasive mammalian species assemblage. temp $=$ temperature, $\operatorname{sh} u b=$ shrubland, grass $=$ grassland.

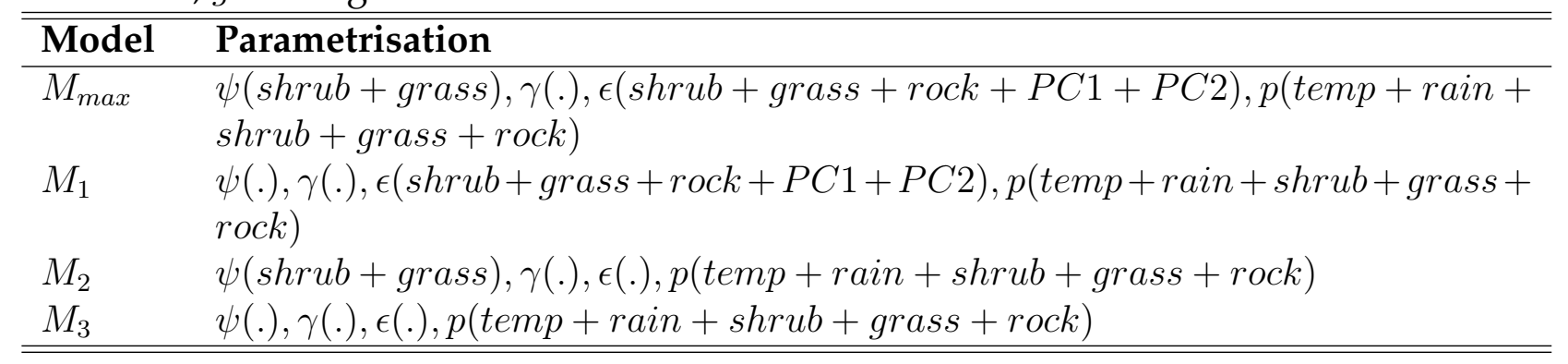

1. Divaricating species form a large component of the shrubland and scrub areas of Baring Head. Divaricating shrubs were demonstrated to have a positive effect on $O$. polychroma occupancy, and a negative effect on species detection probability $p$ in Chapter 3, therefore it was hypothesised that occupancy would be highest in scrub, intermediate in shrubland, and lowest in grasslands. Individual detection probability $r$ was expected to be highest in grassland, intermediate in shrubland and lowest in scrub. Scrub and grassland were included as factors for occupancy and $r$ as orthogonal contrasts against the intercept, which represented pitfalls in shrubland habitats.

2. The number of W. maculata caught in each pitfall per day was included as a covariate for occupancy and $r$. This was to account for the possibility of a competitive interaction with the smaller-bodied O. polychroma, which would result in a negative effect on occupancy. Alternatively, interspecific competition could result in $O$. polychroma avoiding pitfalls on occasions where more $W$. maculata were caught, which would result in a negative effect on $r$.

3. The pest mammal guild and grazing regime surrounding each pitfall were expected to affect occupancy of $O$. polychroma, therefore the two principal components that summarised spatial variation in the mammal species assemblage between grazed and ungrazed areas were included as additive effects in the model.

4. $r$ is likely to vary between capture occasion because capture of a lizard in a pitfall trap depends on weather conditions being conducive for active foraging, and also potentially on the behavioural responses (i.e. trap-happiness or trap-shyness) of individual lizards to previous capture(s). In the maximal model, an identity matrix was used to allow $r$ to vary independently between each capture occasion.

The candidate model set included two reduced-parameter models for $r$, one $\left(M_{1}\right)$ including the effects of ambient temperature and rainfall, because lizard activity is 
Table 4.3: Candidate model set for site occupancy of Oligosoma polychroma at Baring Head, December 2018. All models are single-season Royle/Nichols heterogeneity models with a zero-inflated Poisson distribution. $i$ indicates that variation in individual detection probability was modelled as an identity matrix. The maximal model is named $M_{\max }$. $P C 1$ and $P C 2$ are principal components describing spatial variation in the grazing regime and invasive mammalian species assemblage. temp $=$ temperature, shrub $=$ shrubland, grass $=$ grassland, $W M=$ number of Woodworthia maculata caught on a given occasion in each pitfall.

\begin{tabular}{ll}
\hline \hline Model & Parametrisation \\
\hline$M_{\max }$ & $\lambda(),. \psi(P C 1+P C 2+$ shrub + grass $+W M), r(i+$ shrub + grass $+W M)$ \\
$M_{1}$ & $\lambda(),. \psi(P C 1+P C 2+$ shrub + grass $+W M), r($ temp + rain + shrub + grass $+W M)$ \\
$M_{2}$ & $\lambda(),. \psi(P C 1+P C 2+$ shrub + grass $+W M), r($ shrub + grass $+W M)$ \\
$M_{3}$ & $\lambda(),. \psi(),. r(i+$ shrub + grass $+W M)$ \\
$M_{4}$ & $\lambda(),. \psi(),. r($ temp + rain + shrub + grass $+W M)$ \\
$M_{5}$ & $\lambda(),. \psi(),. r($ shrub + grass $+W M)$ \\
\hline \hline
\end{tabular}

expected to be higher during periods with warm temperatures and lower during periods of rain. The other $\left(M_{2}\right)$ reduced-parameter model assumed that $r$ was constant across all capture occasions. Lastly, a null model for occupancy with each of the three parameter combinations for $r$ were constructed to test whether modelling any of the covariates for occupancy improved model fit.

For the both the O. polychroma and W. maculata datasets, model fit was assessed for the global model in the set using the test statistic from 1,000 parametric bootstraps (MacKenzie and Bailey, 2004). If the maximal model exhibited an acceptable fit to the data (i.e. $p<0.05$ ), the parsimony of each model in the candidate set was examined using the AIC. Otherwise, the QAIC was used.

\subsection{Results}

\subsubsection{Contemporary (2018-2019) lizard species abundance in mammal-invaded environments}

Only two lizard species, Raukawa geckos (Woodworthia maculata) and northern grass skinks (Oligosoma polychroma) were caught at both mammal-invaded study sites (Table 4.4). Two further species, copper skinks (O. aeneum) and glossy brown skinks (O. zelandicum) were caught at Pukerua Bay (Table 4.4). No Whitaker's skinks (O. whitakeri) or northern spotted skinks (O. kokowai) were caught in the mark-recapture grids, despite being present in previous surveys at Pukerua Bay and Turakirae Head, respectively. Only W. maculata and O. polychroma were captured on enough occasions to attempt abundance estimation by mark-recapture methodology (Table 4.4).

The gecko W. maculata was the most frequently captured species in the mark-recapture 
Table 4.4: Summary of lizard captures from the mark-recapture grids at two mammalinvaded sites in Greater Wellington, New Zealand. Effort = the number of station-days. A dash indicates that the species was not captured. Otherwise, the number of captures is given in brackets beside the number of individuals. Species: Woodworthia maculata (WM), Oligosoma polychroma (OP), O. aeneum (OA), O. zelandicum (OZ).

\begin{tabular}{llllllll}
\hline \hline Site & Season & Grid & Effort & WM & OP & OA & OZ \\
\hline Pukerua & May 2018 & PB1 & 216 & $40(50)$ & $13(14)$ & - & - \\
Bay & & PB2 & 180 & $31(36)$ & $11(13)$ & $1(1)$ & - \\
& & Total & 396 & $71(86)$ & $24(27)$ & $1(1)$ & - \\
& \multirow{2}{*}{ Feb 2019 } & PB1 & 216 & $27(28)$ & $5(5)$ & $1(1)$ & $3(3)$ \\
& & PB2 & 216 & $13(13)$ & $40(47)$ & $4(4)$ & $2(2)$ \\
& & Total & 432 & $40(41)$ & $45(52)$ & $5(5)$ & $3(5)$ \\
\hline Turakirae & \multirow{2}{*}{ May 2018 } & THG1 & 180 & $18(18)$ & $10(15)$ & - & - \\
Head & & THG2 & 180 & $108(108)$ & $5(5)$ & - & - \\
& & Total & 360 & $126(126)$ & $15(20)$ & - & - \\
& \multirow{2}{*}{ Feb 2019 } & THG1 & 216 & $69(76)$ & $15(17)$ & - & - \\
& & THG2 & 180 & $253(312)$ & $17(19)$ & - & - \\
& & Total & 396 & $322(528)$ & $32(36)$ & - & - \\
\hline \hline
\end{tabular}

grids at Pukerua Bay (Table 4.4). The catch-per-unit-effort (CPUE) of W. maculata was much higher in May 2018 (21.72 captures per 100 station-days) than in February 2019 (9.49 per 100 station-days). In comparison, CPUE of O. polychroma was higher in February 2019 (12.04 per 100 station-days) than in May 2018 (6.82 per 100 station-days). There were few captures of $O$. aeneum and O. zelandicum, with average CPUEs of 1.21 per 100 station-days for both species across both the May 2018 and February 2019 capture seasons. The W. maculata captures comprised individuals spanning all size classes (SVL range: 21-65 mm), as did the O. polychroma (SVL range: $28-57 \mathrm{~mm}$ ) and O. aeneum captures (SVL range: 24 $53.5 \mathrm{~mm}$ ). Only sub-adult and adult $O$. zelandicum were captured (SVL range: $45-59.5 \mathrm{~mm}$ ).

At Turakirae Head, CPUE of both species captured was higher in February 2019 compared to May 2018 (W. maculata: February 2019 CPUE: 133.3 captures per 100 station-days, May 2018 CPUE = 35 captures / 100 station-days; O. polychroma: February 2019 CPUE $=9.09$ captures per 100 trap-nights, May 2018 CPUE $=5.56$ captures per 100 trap-nights). All size classes of geckos were caught (SVL range: 23 - $63 \mathrm{~mm}$ ). Juvenile, subadult, and adult northern grass skinks (SVL range: $35-67 \mathrm{~mm}$ ) were caught, but not neonates (individuals with SVL $<35 \mathrm{~mm}$ ).

There was a high degree of overdispersion inherent in the global model $\left(M_{t b h}\right)$ for $O$. polychroma abundance at Pukerua Bay, which resulted in the QAICc strongly favouring models with fewer parameters. In both May 2018 and February 2019, strongly supported models were the null $\left(M_{0}\right)$ model, a behavioural response $\left(M_{b}\right)$ model, or an individual heterogeneity $\left(M_{h}\right)$ model with SVL describing heterogeneity (Table 4.5). This indicated some uncertainty in model selection. However, for both monitoring seasons, the estimates 
from the $M_{b}$ and $M_{h}(S V L)$ models appeared to be unreliable due to overparametrisation, as they produced abundance estimates with extremely large standard errors (Table 4.5). That is, the coefficient of variation (CV) for the abundance estimates exceeded 100\%. For the $M_{b}$ models, estimated capture probabilities were extremely low and variable for the February 2019 data $\left(\hat{p}=1.52 \times 10^{5} \pm\right.$ one standard error of $\left.1.93 \times 10^{3}\right)$ and zero with a standard error of zero for the May 2018 data. In the $M_{h}(S V L)$ models, both the intercept (May 2018: $\operatorname{logit}(\beta)=-9.15 \pm 15.83$, February 2019: $\operatorname{logit}(\beta)=-10.56 \pm 12.20$ ) and estimated effects of SVL (May 2018: $\operatorname{logit}(\beta)=0.13 \pm 0.31$, February 2019: $\operatorname{logit}(\beta)=0.16 \pm 0.24$ ) on $\hat{p}$ had overinflated standard errors (i.e $\mathrm{CV} \geq 100 \%$ ). Therefore only the $M_{0}$ models were used to estimate O. polychroma abundance at Pukerua Bay (Table 4.8). Estimated individual capture probabilities of skinks in the null models for May 2018 and February 2019 were low, being $\hat{p}=0.05 \pm 0.06$ and $\hat{p}=0.06 \pm 0.05$, respectively.

Similar to the analysis of O. polychroma abundance, there was also uncertainty around model selection for estimating the abundance of $W$. maculata at Pukerua Bay, with $M_{0}, M_{b}$ and $M_{h}(S V L)$ models receiving strong support from the QAICc (Table 4.6). There was a high degree of overdispersion inherent in the global model, $M_{t b h}$, which resulted in the QAICc strongly favouring models with fewer parameters. All three strongly supported models for the May 2018 data produced abundance estimates that did not have overinflated standard errors (i.e. their CV was $<100 \%$ ), which are listed in Table 4.8. While there was variation among the estimated abundances of $W$. maculata produced by these three models, they were not significantly different (Table 4.8). The same three models $\left(M_{0}, M_{b}\right.$ and $\left.M_{h}(S V L)\right)$ were strongly supported for the February 2019 W. maculata data, but only the $M_{b}$ model produced abundance estimates that did not have overinflated standard errors (Tables 4.6 and 4.8). Estimates of individual detection probability of W. maculata at Pukerua Bay in May 2018 ranged between $0.08 \pm 0.04\left(M_{0}\right.$ and $M_{h}(S V L)$ models) and $0.16 \pm 0.14$ ( $M_{b}$ model). Detection probability was higher in February $2019(0.21 \pm 0.16)$. In the behaviour models, recapture probabilities of W. maculata were generally low (May $2018 \hat{c}=0.07 \pm 0.04$, February 2018 $\hat{c}=0.01 \pm 0.02)$.

At Turakirae Head, the abundances of W. maculata and O. polychroma could only be estimated from the February 2019 dataset, due to no recaptures (geckos) or too few captures (skinks) in May 2018 (Table 4.4). There was evidence for overdispersion in the global $M_{t b h}$ models for both species, but overdispersion was lower in the O. polychroma data (Table 4.7). The best models for W. maculata included a time effect with or without a behavioural effect (Table 4.7). Models incorporating a behavioural effect produced abundance estimates with overinflated standard errors, so abundance estimates were derived from the second-best model $\left(M_{t}\right.$; Tables 4.7 and 4.8). A null model $\left(M_{0}\right)$ was the best model for the $O$. polychroma capture data, followed by an $M_{b}$ model which produced an abundance estimate with an overinflated standard error (Table 4.7). Individual capture probabilities in these models varied between $0.05 \pm 0.02$ and $0.23 \pm 0.09$ for geckos and 
Table 4.5: Models trialled and selection criteria for abundance estimation of northern grass skinks (OP = Oligosoma polychroma) from $100 \mathrm{~m}^{2}$ monitoring grids at Pukerua Bay. Model type used was Huggins' heterogeneity for closed captures with $\pi=2$ finite mixtures, capture probability $p$ and recapture probability $c$. Candidate models in each set listed that are above the horizontal line are those that were strongly supported by the QAICc ( $\triangle$ QAICc $>2$ ). Models marked with an asterisk $\left(^{*}\right)$ produced abundance estimates with extremely large standard errors (that is, a coefficient of variation value $\geq 100 \%$ ), thus were not used to estimate abundance. Model notation follows Chao et al. (1992), where $M_{0}$ is the null model and $M_{t b h}$ is the global model including effects of time $(t)$, behaviour $(b)$ and individual heterogeneity $(h)$. Weight $=$ model weight according to the QAICc.

\begin{tabular}{lccccc}
\hline \hline OP May 2018 & $\hat{c}=5.06$ & & & & \\
Model & QAICc & $\Delta$ QAICc & Weight & Likelihood & N. Par \\
\hline$M_{0}$ & 22.855 & 0.000 & 0.490 & 1.000 & 1 \\
$M_{b}{ }^{*}$ & 24.439 & 1.584 & 0.222 & 0.453 & 2 \\
$M_{h}(p(S V L)=c(S V L))^{*}$ & 24.666 & 1.811 & 0.198 & 0.404 & 2 \\
\hline$M_{h}(\pi=2)$ & 27.011 & 4.156 & 0.061 & 0.125 & 3 \\
$M_{b h}(\pi=2)^{*}$ & 28.659 & 5.804 & 0.027 & 0.055 & 4 \\
$M_{t}$ & 34.173 & 11.318 & 0.002 & 0.004 & 8 \\
$M_{t b}{ }^{*}(\pi=2)^{*}$ & 36.378 & 13.523 & 0.001 & 0.001 & 9 \\
$M_{t h}(\pi=2)^{*}$ & 38.771 & 15.916 & 0.000 & 0.000 & 10 \\
$M_{t b h}(\pi)$ & 40.182 & 17.327 & 0.000 & 0.000 & 11 \\
\hline OP Feb 2019 & $\hat{c}=4.91$ & & & & \\
Model & QAICc & $\Delta$ QAICc & Weight & Likelihood & N. Par \\
\hline$M_{0}$ & 45.639 & 0.000 & 0.392 & 1.000 & 1 \\
$M_{b}^{*}$ & 46.907 & 1.268 & 0.208 & 0.531 & 2 \\
$M_{h}(p(S V L)=c(S V L))^{*}$ & 46.967 & 1.327 & 0.202 & 0.515 & 2 \\
\hline$M_{h}(\pi=2)^{*}$ & 49.628 & 3.989 & 0.053 & 0.136 & 3 \\
$M_{h}(p(S V L)=c(S V L))^{*}$ & 49.960 & 4.321 & 0.045 & 0.115 & 4 \\
$M_{t}$ & 50.040 & 4.401 & 0.043 & 0.111 & 6 \\
$M_{b h}(\pi=2)^{*}$ & 51.013 & 5.374 & 0.027 & 0.068 & 4 \\
$M_{t b}$ & 51.543 & 5.904 & 0.021 & 0.052 & 7 \\
$M_{t h}(\pi=2)$ & 54.273 & 8.633 & 0.005 & 0.013 & 8 \\
$M_{t b h}(\pi=2)$ & 55.656 & 10.016 & 0.003 & 0.007 & 9 \\
\hline \hline
\end{tabular}


Table 4.6: Models trialled and selection criteria for abundance estimation of Raukawa geckos (WM = Woodworthia maculata) in the $100 \mathrm{~m}^{2}$ monitoring grids at Pukerua Bay. Model type used was Huggins' heterogeneity for closed captures with $\pi=2, p$ and $c$ and a logit link. Candidate models in each set listed that are above the horizontal line are those that were strongly supported by the QAICc $(\triangle$ QAICc $>2)$. Models marked with an asterisk $\left(^{*}\right)$ produced abundance estimates with extremely large standard errors (that is, a coefficient of variation value $\geq 100 \%$ ), thus were not used to estimate abundance. Model notation follows Chao et al. (1992), where $M_{0}$ is the null model and $M_{t b h}$ is the global model including effects of time $(t)$, behaviour $(b)$ and individual heterogeneity $(h)$. Weight = model weight according to the QAICc.

\begin{tabular}{lccccc}
\hline \hline WM May 2018 & $\hat{c}=5.33$ & & & & \\
Model & QAICc & $\Delta$ QAICc & Weight & Likelihood & N par. \\
\hline$M_{0}$ & 69.349 & 0.000 & 0.478 & 1.000 & 1 \\
$M_{b}$ & 70.969 & 1.621 & 0.213 & 0.445 & 2 \\
$M_{h}(p(S V L)=c(S V L))$ & 71.301 & 1.953 & 0.180 & 0.377 & 2 \\
\hline$M_{h}(\pi=2)$ & 73.396 & 4.047 & 0.063 & 0.132 & 3 \\
$M_{b h}(p(S V L), c(S V L))$ & 74.609 & 5.260 & 0.034 & 0.072 & 4 \\
$M_{b h}(\pi=2)$ & 75.036 & 5.687 & 0.028 & 0.058 & 4 \\
$M_{t}$ & 80.454 & 11.105 & 0.002 & 0.004 & 9 \\
$M_{t b}$ & 81.530 & 12.182 & 0.001 & 0.002 & 10 \\
$M_{t h}(\pi=2)$ & 84.659 & 15.310 & 0.000 & 0.001 & 11 \\
$M_{t b h}(\pi=2)$ & 85.756 & 16.407 & 0.000 & 0.000 & 12 \\
\hline WM Feb 2019 & $\hat{c}=4.21$ & & & & \\
Model & QAICc & $\Delta$ QAICc & Weight & Likelihood & N par. \\
\hline$M_{0}^{*}$ & 38.728 & 0.000 & 0.402 & 1.000 & 1 \\
$M_{b}$ & 39.363 & 0.636 & 0.293 & 0.728 & 2 \\
$M_{h}(p(S V L)=c(S V L))^{*}$ & 40.741 & 2.013 & 0.147 & 0.366 & 2 \\
\hline$M_{h}(\pi=2)^{*}$ & 42.813 & 4.085 & 0.052 & 0.130 & 3 \\
$M_{b h}(p(S V L), c(S V L))$ & 42.912 & 4.184 & 0.050 & 0.123 & 4 \\
$M_{b h}(\pi=2)$ & 43.483 & 4.755 & 0.037 & 0.093 & 4 \\
$M_{t}^{*}$ & 45.695 & 6.968 & 0.012 & 0.031 & 6 \\
$M_{t b}$ & 47.495 & 8.767 & 0.005 & 0.013 & 7 \\
$M_{t h}(\pi=2)^{*}$ & 49.958 & 11.230 & 0.001 & 0.004 & 8 \\
$M_{t b h}(\pi=2)$ & 51.795 & 13.067 & 0.001 & 0.001 & 9 \\
\hline \hline & & & & & \\
\hline
\end{tabular}


Table 4.7: Models trialled and selection criteria for abundance estimation of common lizards (WM = Raukawa geckos Woodworthia maculata; OP = northern grass skinks O. polychroma) in $100 \mathrm{~m}^{2}$ monitoring grids at Turakirae Head. Model type used was Huggins' heterogeneity for closed captures with $\pi=2$, p and c. Candidate models in each set listed that are above the horizontal line are those that were strongly supported by the QAICc $(\triangle$ QAICc $>2)$. Models marked with an asterisk ${ }^{*}$ ) produced abundance estimates with extremely large standard errors (that is, a coefficient of variation value $\geq 100 \%$ ), thus were not used to estimate abundance. Model notation follows Chao et al. (1992), where $M_{0}$ is the null model and $M_{t b h}$ is the global model including effects of time $(t)$, behaviour $(b)$ and individual heterogeneity $(h)$.

\begin{tabular}{lccccc}
\hline \hline WM Feb 2019 & Fletcher & $\hat{c}=4.05$ & & & \\
Model & QAICc & $\Delta$ QAICc & Weight & Likelihood & N par. \\
\hline$M_{t b}{ }^{*}$ & 411.871 & 0.000 & 0.437 & 1.000 & 7 \\
$M_{t}$ & 412.321 & 0.450 & 0.349 & 0.799 & 6 \\
\hline$M_{t h}(\pi=2)^{*}$ & 414.485 & 2.614 & 0.118 & 0.271 & 8 \\
$M_{t b h}(\pi=2)^{*}$ & 415.905 & 4.034 & 0.058 & 0.133 & 9 \\
$M_{b}{ }^{*}$ & 417.063 & 5.192 & 0.033 & 0.075 & 2 \\
$M_{b h}(\pi=2)^{*}$ & 421.075 & 9.204 & 0.004 & 0.010 & 4 \\
$M_{0}$ & 426.556 & 14.685 & 0.000 & 0.001 & 1 \\
$M_{h}(\pi=2)$ & 429.608 & 17.737 & 0.000 & 0.000 & 3 \\
\hline OP Feb 2019 & Fletcher & $\hat{c}=1.40$ & & & \\
Model & QAICc & $\Delta$ QAICc & Weight & Likelihood & N par. \\
\hline$M_{0}$ & 101.848 & 0.000 & 0.411 & 1.000 & 1 \\
$M_{b}{ }^{*}$ & 102.587 & 0.738 & 0.284 & 0.691 & 2 \\
\hline$M_{t}^{*}$ & 103.966 & 2.118 & 0.142 & 0.347 & 6 \\
$M_{h}(\pi=2)$ & 105.965 & 4.117 & 0.052 & 0.128 & 3 \\
$M_{t b}{ }^{*}$ & 106.032 & 4.184 & 0.051 & 0.124 & 7 \\
$M_{b h}(\pi=2)^{*}$ & 106.752 & 4.904 & 0.035 & 0.086 & 4 \\
$M_{t h}(\pi=2)$ & 108.334 & 6.486 & 0.016 & 0.039 & 8 \\
$M_{t b h}(\pi=2)$ & 109.624 & 7.775 & 0.008 & 0.021 & 9 \\
\hline \hline
\end{tabular}

$0.05 \pm 0.03$ for skinks.

The abundance estimates for O. polychroma were relatively similar across surveys and sites (Fig. 4.7). In contrast, the estimated abundance of W. maculata was significantly higher at Turakirae Head than at Pukerua Bay (Fig. 4.7). Based on the effective trapping area for each species, density estimates of $O$. polychroma were 3,980 (95\% confidence interval: 2,121 - 9,559) individuals / ha at Pukerua Bay (average estimated density from May 2018 and February 2019 surveys) and 4,078 (2,055 - 10,048) individuals / ha at Turakirae Head. For W. maculata, density was estimated at 4,067 (2,917 - 6,882) individuals / ha at Pukerua Bay and 38,372 (31,233 - 48,291) individuals / ha at Turakirae Head. These figures suggest that, on average, geckos were 1.02 times more abundant at Pukerua Bay than northern grass skinks, and 9.41 times more abundant than skinks at Turakirae Head. 
Table 4.8: Estimated abundance $(\hat{N})$ of lizards in $100 \mathrm{~m}^{2}$ monitoring grids at Turakirae Head (TH grids) and Pukerua Bay (PB grids) from models that were not overparametrised and were strongly support by the QAICc. While the $M_{0}$ model for Woodworthia maculata at Turakirae Head was poorly supported by the QAICc, estimates from this model are included here because it represents the closest equivalent model to the abundance estimation process used in 1976 for this site (Whitaker, 1982). CI = confidence interval.

\begin{tabular}{|c|c|c|c|c|c|}
\hline Grid & $\hat{N}$ & $\mathrm{SE}(\hat{N})$ & $95 \% \mathrm{CI}(\hat{N})$ & Model & $\triangle \mathrm{QAICc}$ \\
\hline \multicolumn{6}{|c|}{ Woodworthia maculata } \\
\hline \multicolumn{6}{|l|}{ Pukerua Bay } \\
\hline \multicolumn{6}{|l|}{ May 2018} \\
\hline PB1 & 104 & 23.95 & $72-170$ & $M_{0}$ & 0.00 \\
\hline PB2 & 81 & 19.33 & $55-135$ & $M_{0}$ & 0.00 \\
\hline PB1 & 61 & 14.53 & $46-112$ & $M_{b}$ & 1.62 \\
\hline PB2 & 47 & 11.50 & $36-88$ & $M_{b}$ & 1.62 \\
\hline PB1 & 106 & 25.42 & $72-177$ & $M_{h}(S V L)$ & 1.95 \\
\hline PB2 & 82 & 20.40 & $55-140$ & $M_{h}(S V L)$ & 1.95 \\
\hline \multicolumn{6}{|l|}{ Feb 2019} \\
\hline PB1 & 35 & 7.26 & $29-63$ & $M_{b}$ & 0.64 \\
\hline PB2 & 17 & 3.87 & $14-33$ & $M_{b}$ & 0.64 \\
\hline \multicolumn{6}{|l|}{ Turakirae Head } \\
\hline \multicolumn{6}{|l|}{ Feb 2019} \\
\hline THG1 & 784 & 86.76 & $639-983$ & $M_{t}$ & 0.45 \\
\hline THG2 & 334 & 38.67 & $271-424$ & $M_{t}$ & 0.45 \\
\hline THG1 & 773 & 84.68 & $632-967$ & $M_{0}$ & 14.69 \\
\hline THG2 & 369 & 43.59 & $297-470$ & $M_{0}$ & 14.69 \\
\hline \multicolumn{6}{|c|}{ Oligosoma polychroma } \\
\hline \multicolumn{6}{|l|}{ Pukerua Bay } \\
\hline \multicolumn{6}{|l|}{ May 2018} \\
\hline PB1 & 47 & 25.22 & $23-137$ & $M_{0}$ & 0.00 \\
\hline PB2 & 47 & 26.13 & $21-140$ & $M_{0}$ & 0.00 \\
\hline \multicolumn{6}{|l|}{ Feb 2019} \\
\hline PB1 & 17 & 7.98 & $8-44$ & $M_{0}$ & 0.00 \\
\hline PB2 & 133 & 44.10 & $78-265$ & $M_{0}$ & 0.00 \\
\hline \multicolumn{6}{|l|}{ Turakirae Head } \\
\hline \multicolumn{6}{|l|}{ Feb 2019} \\
\hline THG1 + THG2 & 125 & 55.90 & $63-308$ & $M_{0}$ & 0.00 \\
\hline
\end{tabular}



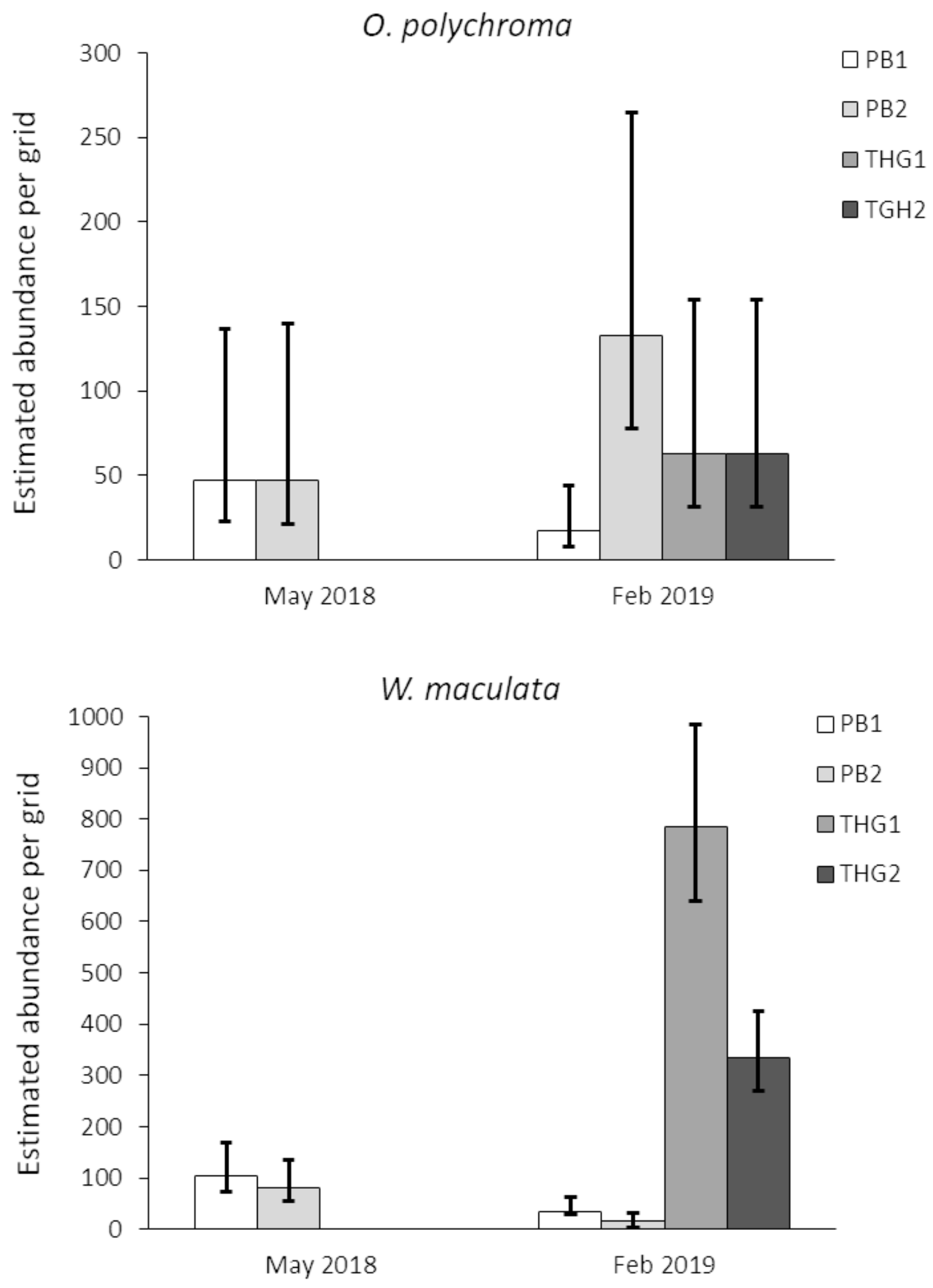

Figure 4.7: Abundance estimates from the most supported models reported in Table 4.8 for northern grass skinks (O. polychroma) and Raukawa geckos (W. maculata) in $100 \mathrm{~m}^{2}$ markrecapture grids at two mammal-invaded sites on the Wellington mainland, New Zealand $(\mathrm{PB}=$ Pukerua Bay, $\mathrm{TH}=$ Turakirae Head $)$. 
Table 4.9: Summary of lizard captures in pitfall traps at Pukerua Bay between 2007 and 2018. The number of individuals captured is given beside the number of captures in brackets. Species: Raukawa gecko (WM), northern grass skink (OP), copper skink (OA), glossy brown skink (OZ), and Whitaker's skink (OW).

\begin{tabular}{llcccccc}
\hline \hline Year & $\begin{array}{l}\text { Trap } \\
\text { nights }\end{array}$ & OA & OW & WM & OP & OZ & Total \\
\hline 2007 & 1,643 & 2 & 0 & 117 & 212 & 51 & 382 \\
2008 & 1,681 & 3 & 1 & 202 & 241 & 40 & 487 \\
Nov 2009 - Apr 2010 & 14,529 & 274 & 5 & 563 & 3,030 & 962 & 4,834 \\
Nov 2010 - Mar 2011 & 8,417 & 204 & 1 & 1,603 & 4,185 & 403 & 6,396 \\
Nov 2011- Mar 2012 & 7,026 & 602 & 0 & 1,987 & 3,168 & 542 & 6,299 \\
2012-2013 & 0 & - & - & - & - & - & - \\
Dec 2013-Mar 2014 & 4,707 & 447 & 0 & 2,463 & 2,080 & 362 & 5,352 \\
2015 & 2,525 & 51 & 0 & 976 & 524 & 81 & 1,632 \\
2016 & 2,394 & 54 & 0 & 216 & 950 & 122 & 1,342 \\
2017 & 3,052 & 54 & 0 & 255 & 737 & 57 & 1,103 \\
2018 & 3,740 & 47 & 0 & 188 & 812 & 52 & 1,099 \\
\hline \hline
\end{tabular}

\subsubsection{Lizard population trends in mammal-invaded environments}

\section{Pukerua Bay: 35 year (1984-2018) trends in lizard species' catch per unit effort (CPUE)}

Records of 30,619 lizard captures from from 57,311 pitfall trap-nights (one trap night represents one 24-hour period that a pitfall trap was open) were available for analysis. The dataset represents a near-annual monitoring programme spanning from 1984 to 2018 (34 years), with the exception of 1989-90, 1998-99, 2003 and 2012/13 which were excluded from analyses due to a single capture occasion (1989-90, 1998-99 and 2003; Hoare et al. (2007a)), or due to data having been lost (2012/13). Details of captures and trapping effort between 1984 and 2006 are available in Hoare et al. (2007a). A summary of captures from 2007 to 2018 is given in Table 4.9 .

Year had a significant effect on the catch per unit effort (CPUE, the number of captures per 100 trap-days) of copper skinks (O. aeneum), Whitaker's skinks (O. whitakeri) and Raukawa geckos (W. maculata) in pitfalls at Pukerua Bay (Table 4.10). Captures of W. maculata increased linearly over time (likelihood ratio test (LRT) between linear models with and without year as a quadratic term: $\left.F_{1}=0.900, p=0.352\right)$ at the average rate of 0.691 (standard error $(\mathrm{SE})=0.186)$ geckos captured per 100 trap-days (Fig. 4.8). Captures of $O$. whitakeri decreased linearly (LRT: $F_{1}=0.021, p=0.885$ ) with time at an average rate of 0.065 $(\mathrm{SE}=0.025)$ captures per year (Fig. 4.8). In contrast, O. aeneum CPUE had a curvilinear relationship with time (LRT: $F_{1}=5.120, p=0.032$ ). The fitted quadratic curve $\left(C P U E_{O A}=0.021 \times Y_{\text {ear }}^{2}-0.850 \times Y e a r+0.0009\right)$ suggested that O. aeneum CPUE decreased between 1984 and 2006, then began to increase after 2006 (Fig. 4.8). However, the quadratic trend may have been caused by a temporary increase in CPUE between 2010 and 
Table 4.10: Effects of year and survey on catch-per-unit effort (number of captures per 100 tra-nights) of lizard species between 1984 and 2018 at Pukerua Bay. Species are listed in order of increasing body size, with the largest species $O$. whitakeri at the bottom of the table. Significant $p$ values are indicated in bold front. DF = degrees of freedom.

\begin{tabular}{cccccc}
\hline \hline Factor & DF & Sum of squares & Mean square & $F$ & $p$ \\
\hline Copper skink & (OA) & Oligosoma aeneum & & & \\
\hline Year & 1 & 184.96 & 184.96 & 7.136 & $\mathbf{0 . 0 1 3}$ \\
Residuals & 26 & 673.94 & 25.921 & & \\
\hline Glossy brown skink & $\mathbf{( O Z )}$ & Oligosoma zelandicum & & & \\
\hline Year & 1 & 6.39 & 6.391 & 0.662 & 0.423 \\
Residuals & 26 & 250.84 & 9.648 & & \\
\hline Northern grass skink & $\mathbf{( O P )}$ & Oligosoma polychroma & & & \\
\hline Year & 1 & 73.5 & 73.491 & 0.305 & 0.585 \\
Residuals & 26 & $6,261.5$ & 240.827 & & \\
\hline Raukawa gecko & $\mathbf{( W M )}$ & Woodworthia maculata & & & \\
\hline Year & 1 & $1,470.0$ & $1,470.03$ & 13.794 & $<\mathbf{0 . 0 0 1}$ \\
Residuals & 26 & $2,770.8$ & 106.57 & & \\
\hline Whitaker's skink & $\mathbf{( O W )}$ & Oligosoma whitakeri & & & \\
\hline Year & 1 & 12.879 & 12.8787 & 6.8563 & $\mathbf{0 . 0 1 5}$ \\
Residuals & 26 & 48.838 & 1.8784 & & \\
\hline \hline
\end{tabular}

2014, where O. aeneum CPUE values were higher than expected by the fitted quadratic curve (Fig. 4.8). In contrast, CPUE values of O. aeneum were lower than expected by the quadratic curve between 2015 and 2018 (Fig. 4.8). 
$\mathrm{OA}$

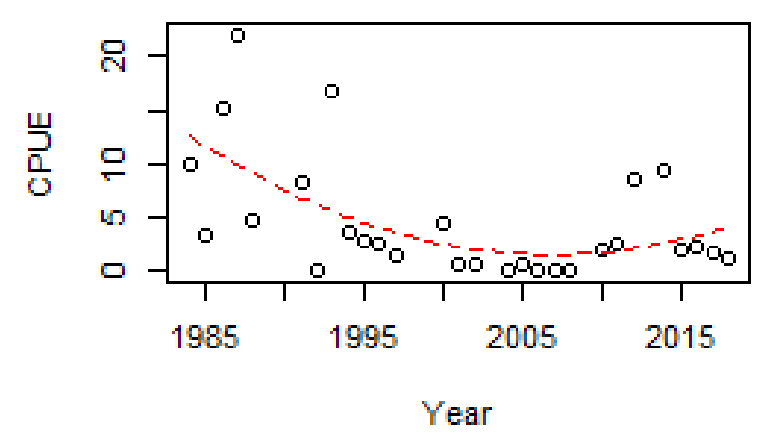

OP

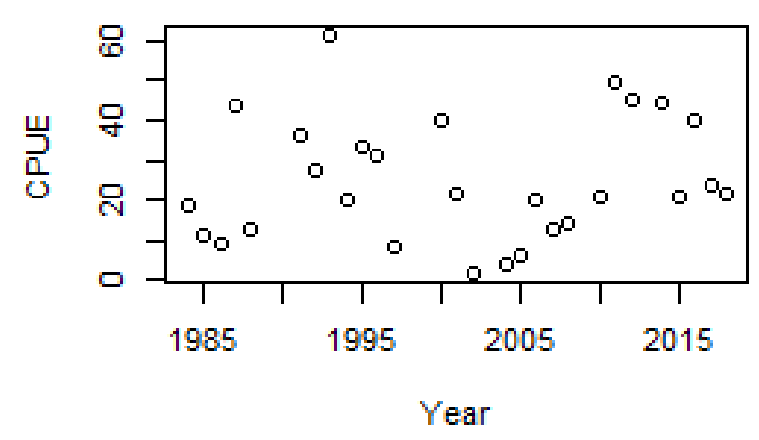

ow

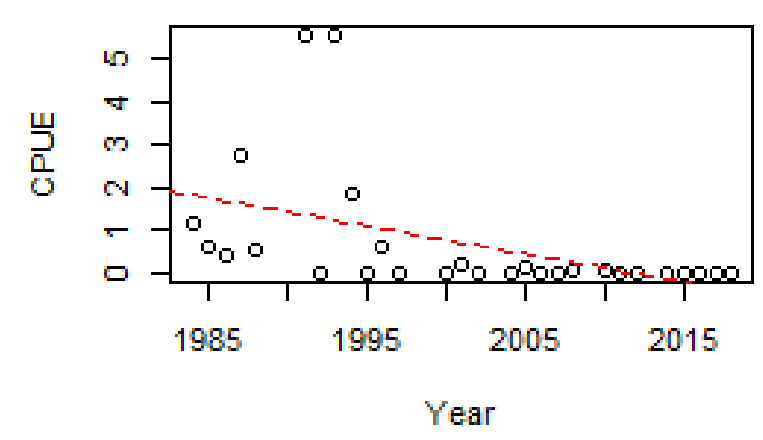

$\mathrm{OZ}$

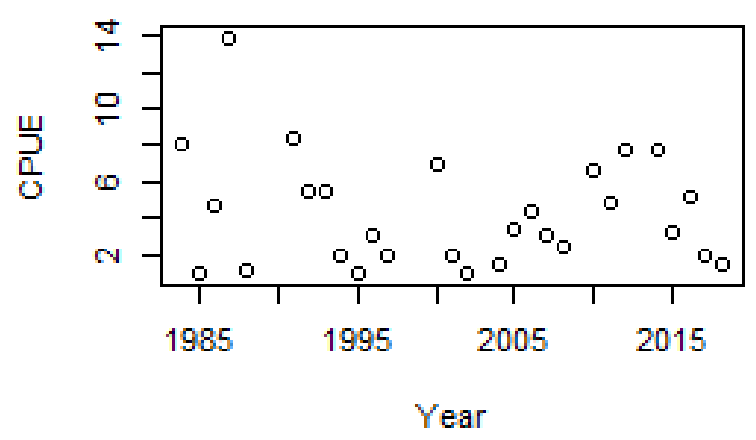

WM

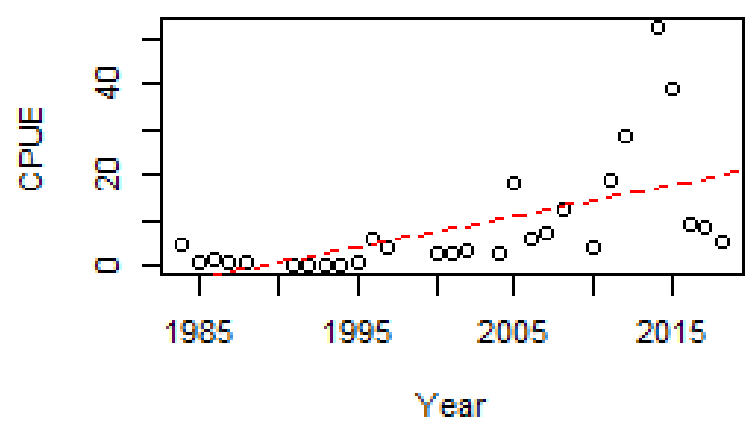

Figure 4.8: Catch per unit effort (CPUE; as the number of captures per 100 trap-nights) of all lizard species currently or historically found at Pukerua Bay. Captures from 1984-2008 are from the same $336 \mathrm{~m}^{2}$ site; captures from 2008-2018 are from a different monitoring area adjacent to the $336 \mathrm{~m}^{2}$ site (Fig. 4.3). The dashed red lines indicate statistically significant responses to time, as per linear modelling. 
Turakirae Head: historical (1970-2001) versus contemporary (2018-2019) lizard CPUE and abundance

Catch per unit effort (CPUE) of Raukawa geckos was substantially higher in this study than in previous studies (Table 4.11). For northern grass skinks, CPUE in this study was intermediate between historical values (Table 4.11). Two additional lizard species captured between 1970 and 1976 by Whitaker (1982) were not encountered during this study, nor by Green (2001) (Table 4.11). Assuming a constant copper skink capture rate of 0.027 per trap-day (sensu Whitaker (1982)) between monitoring programmes, this species would probably not have been detected in 2000 (0.50 captures expected from 1,834 trap-days) or in 2018-2019 (0.21 captures expected from 756 trap-days). However, with a constant trap-rate of 0.206 (sensu Whitaker (1982)) between years, northern spotted skinks should have been detected by Green (2001) (3.77 captures expected) and potentially in this study (1.55 captures expected).

Table 4.11: CPUE of lizard species in monitoring programmes at Turakirae Head, 1970-2019. Sources: 1970-1976 from Whitaker (1982), 2000-2001 from Green (2001) and 2018-2019 from this study. Species: Raukawa gecko (WM), northern grass skink (OP), northern spotted skink (OK), copper skink (OA). CPUE 100 : number of captures per 100 trap-days.

\begin{tabular}{lllll}
\hline \hline Year(s) & $\begin{array}{l}\text { Effort } \\
\text { (N trap-days) }\end{array}$ & Area covered by grid(s) $\mathbf{( m}^{2} \mathbf{)}$ & Species & CPUE $_{100}$ \\
& 7,293 & 1,725 & WM & 37.04 \\
& & & OP & 8.04 \\
& & & OK & 0.206 \\
& & & OA & 0.027 \\
\hline $2000-01$ & 1,834 & 625 & WM & 5.62 \\
& & & OP & 4.8 \\
& & \multirow{2}{*}{200} & OK & 0 \\
& & & OA & 0 \\
\hline $2018-19$ & 756 & & WM & 84.15 \\
& & OP & 7.33 \\
& & & OK & 0 \\
& & & OA & 0 \\
\hline \hline
\end{tabular}

Compared to all estimates reported by Green (2001), the contemporary abundance estimate for Raukawa geckos in February 2019 was significantly higher (Fig. 4.9). $M_{0}$ models trialled on the Raukawa gecko data in CAPTURE and as Huggins' closed captures in order to be more comparable to abundance estimation for the 1967-1976 period by Whitaker (1982) also produced a significantly higher estimated abundance of Raukawa geckos compared to the estimates by Green (2001) (Table C.1 in Appendix C). In comparison, there was no significant difference between northern grass skink density in 2000 and 2019 (Fig. 4.9) using either Huggins' closed capture models (this study) or Otis et al. (1978) models in CAPTURE (Green, 2001). 


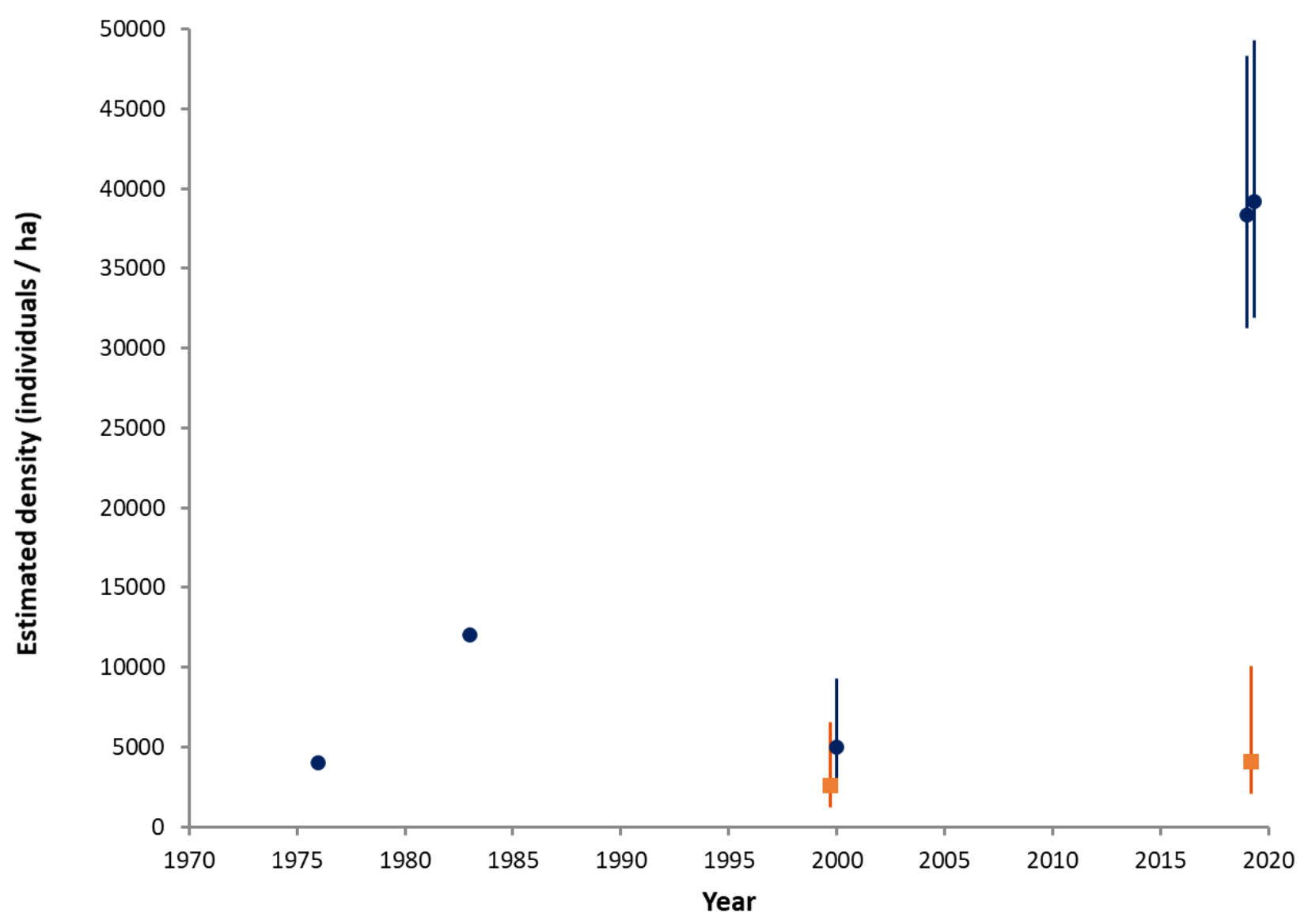

Figure 4.9: Estimated density of Raukawa geckos (blue circles) and northern grass skinks (orange squares) at Turakirae Head over 49 years (1976-2019). Error bars represent the 95\% confidence interval for estimates by Green (2001) and this study, or the range of estimates derived using different approaches by Whitaker (1982). The 1976 estimate is from Whitaker (1982), 1983 from Marshall (1983), 2000 from Green (2001), and 2019 from this study. Jitter along the $\mathrm{x}$ axis has been applied to estimates from the same year for ease of interpretation. Further details of each estimate are provided in Table C.1 in Appendix C.

Ōrua-pouanui / Baring Head (East Harbour Regional Park): six-year (2012-2018) trend in lizard species' CPUE or site occupancy

Lizard data from 210 independently spaced pitfalls, checked a total of 35 times ( $\mathrm{N}$ trap-days $=7,350$ ) across five seasons spanning 2012-2018 were available for analysis of spatial and temporal trends in occupancy of $W$. maculata (between 16 and 94 captures per year) and $O$. polychroma (between 95 and 464 captures per year). Only 1-4 O. aeneum and 0-4 O. kokowai captures were made per year, too few to attempt occupancy modelling for these species.

A number of strong correlations (i.e. Spearman's $\rho>0.6$ ) were apparent between most pest species tracking rates and grazing intensity (Table 4.12). Therefore, a principal components analysis (PCA) was applied to discriminate between site conditions: (PC1) sites where grazing intensity is positively correlated with rat (both Rattus rattus and $R$. norvegicus), hedgehog and mustelid (Mustela furo, M. nivalis and M. erminea) activity and 
Table 4.12: Spearman's $\rho$ correlations between Baring Head pitfall covariates. Values with a high degree of correlation (i.e. $|(\rho)|>0.6$ ) are shown in bold font). Correlations between scrub, shrubland and grassland are not provided because these habitat covariates were mutually exclusive (for example, a pitfall could not be categorised as being in both grassland and shrubland). Abbreviations: ShrubL = shrubland, GrassL = grassland.

\begin{tabular}{ccccccccc}
\hline \hline & Scrub & ShrubL & GrassL & Rock & Mice & Rats & Hedgehogs & Mustelids \\
\hline Rock & 0.023 & 0.129 & -0.160 & & & & & \\
Mice & 0.255 & 0.030 & -0.255 & 0.061 & & & & \\
Rats & 0.007 & 0.196 & -0.218 & 0.275 & $\mathbf{- 0 . 6 4 1}$ & & & \\
Hedgehogs & -0.103 & 0.044 & 0.042 & -0.009 & $\mathbf{- 0 . 9 0 0}$ & $\mathbf{0 . 6 4 1}$ & & \\
Mustelids & -0.107 & 0.047 & 0.042 & -0.002 & $\mathbf{- 0 . 9 0 0}$ & $\mathbf{0 . 6 4 1}$ & $\mathbf{0 . 9 9 9}$ & \\
Grazing & -0.264 & -0.107 & 0.347 & -0.088 & $\mathbf{- 0 . 6 9 2}$ & 0.323 & $\mathbf{0 . 6 0 9}$ & $\mathbf{0 . 6 0 8}$ \\
\hline \hline
\end{tabular}

low mouse activity; and (PC2) sites where grazing intensity is negatively correlated with pest tracking rates (probably representing trapped or otherwise unsuitable sites for mammals within the grazer exclusion zone). Taken together, these two principal components accounted for $84.76 \%$ of the total variation (PC1: $65.57 \%$, PC2: $19.20 \%$ ).

The maximal multi-season occupancy model for Raukawa geckos (W. maculata) (Table 4.13) in the candidate set had an adequate fit to the data (test statistic from 1,000 parametric bootstraps $=3,138, p=0.356$ ). Compared to sites in scrub, sites in shrubland had a significantly lower probability of being occupied by this species (Table 4.16). While the estimate of occupancy probability was much lower in grassland sites compared to scrub sites, it was not significant because the associated standard error was extremely large, leading to some doubt about the accuracy of this estimate (Table 4.16). The presence of rock significantly reduced local extinction risk (Table 4.16). However, none of the other habitat variables or predator-grazing principal components significantly affected local extinction risk (Table 4.16). Temperature and rainfall both had a significant negative effect on this species' detection probability (Table 4.16).

Multi-season occupancy models for O. polychroma had a very poor fit to the data (test statistic from 100 parametric bootstraps $=166,537,396,933, \mathrm{p}<0.001, \hat{c}=49.98$ ). Investigation of the relationship between site occupancy and abundance via a series of simple singleseason models fitted to the 2018 season occupancy data suggested that O. polychroma were better explained by a Poisson Royle/Nichols $(\mathrm{RN})$ heterogeneity model $\left(\chi^{2}=26.69, \mathrm{df}=21\right.$, $\mathrm{p}=0.181, \hat{c}=1.271)$ than a single-season occupancy model (test statistic from 100 parametric bootstraps $=493.89, \mathrm{p}=0.040, \hat{c}=1.635)$. A zero-inflated Poisson model, however, had the lowest AIC of these models (Table 4.14).

For the 2018 O. polychroma data, the most complex model trialled had the highest parsimony ( $\triangle \mathrm{AIC}$ of all other models $\geq 7.99$; Table 4.15 . The analysis suggested that the pest guild (PC2), grazing effects on the pest guild (PC1) and habitat significantly influenced occupancy of O. polychroma at Baring Head (Table 4.16). The strongest effects on site 


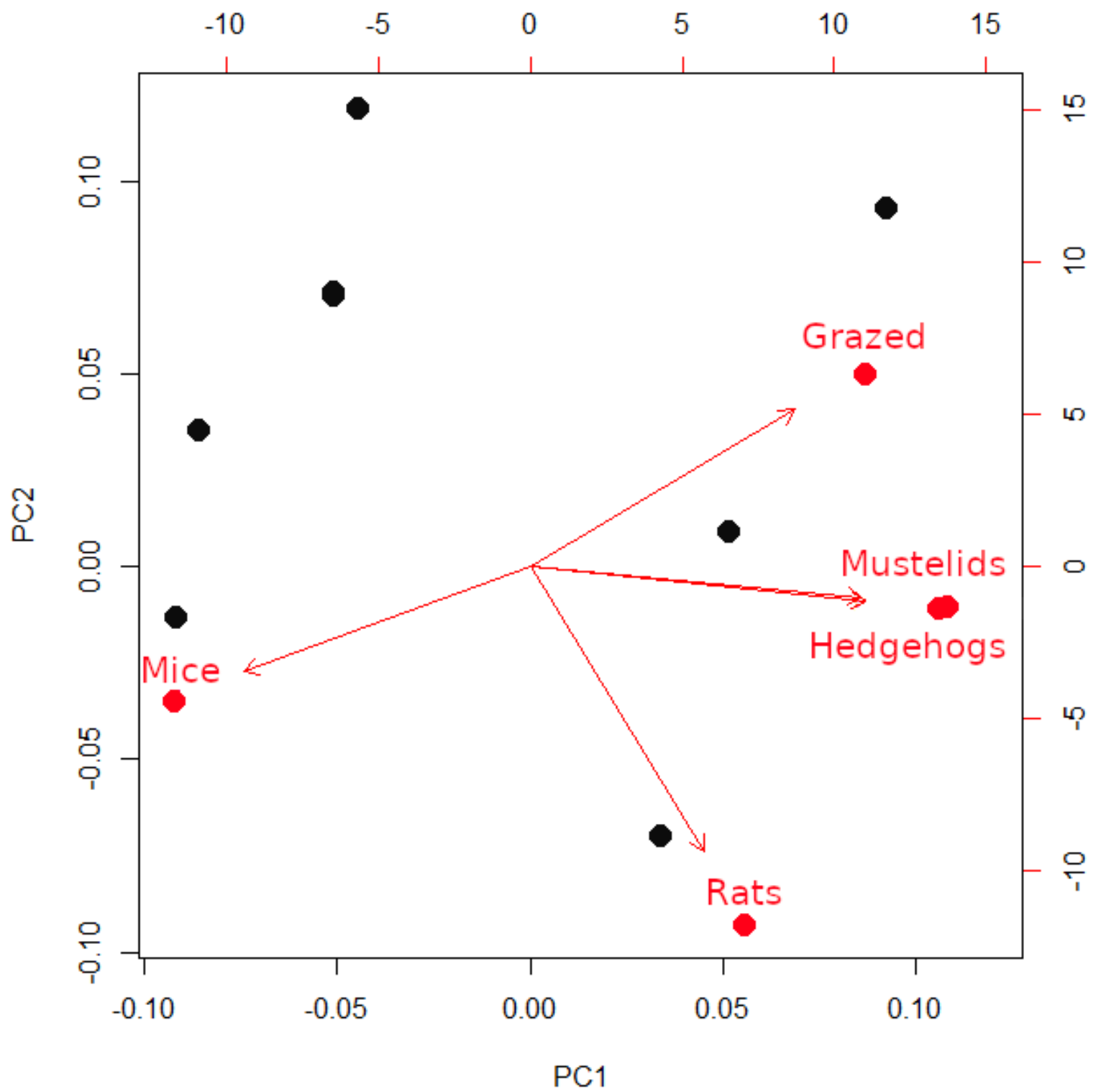

Figure 4.10: Principal components for pest activity measured in tracking tunnels and intensity of stock (sheep Ovis aries and cattle Bos taurus) grazing, 2017-2018. Black markers indicate individual pitfalls; there are fewer points than the number of pitfalls $(\mathrm{N}=210)$ due to overlap in the PC scaling of multiple pitfalls. Red markers indicate the centroid of each factor, the labels of which have been offset for visibility. 
Table 4.13: Candidate models and model selection statistics for multi-season W. maculata (2012-2018) monitoring data at Baring Head. Parameter notation: $\psi=$ probability of site occupancy, $\gamma=$ probability of site colonisation, $\epsilon=$ probability of site extinction, $p=$ species detection probability. Abbreviations: $P C 1$ and $P C 2$ are principal components describing spatial variation in the grazing regime and invasive mammalian species assemblage. temp $=$ temperature, $R H=$ relative humidity, $s h r u b=$ shrubland, grass $=$ grassland .

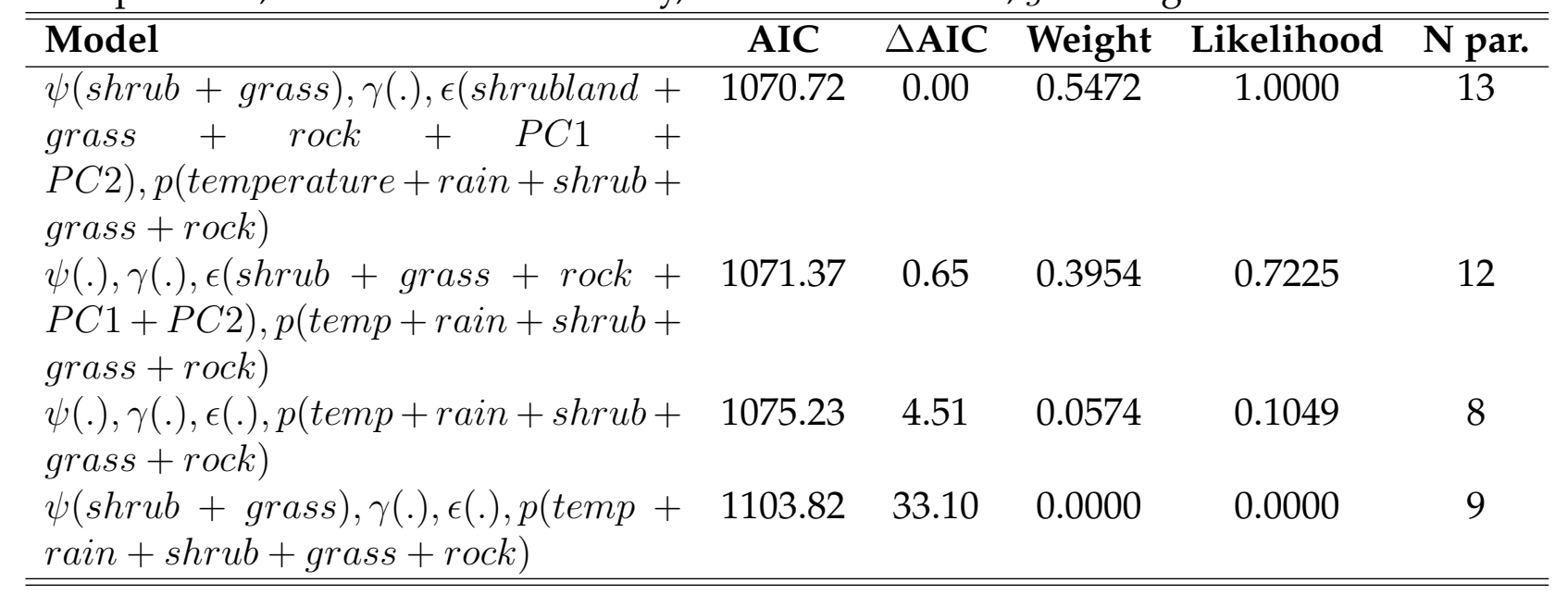

Table 4.14: List of single season occupancy models with different parametrisation of the relationship between abundance $(\lambda)$, occupancy $(\psi)$ and individual $(r)$ or species $(p)$ detection probability in the 2018 season O. polychroma monitoring data at Baring Head. The notation "identity" means that an identity matrix was used for describing between-check variation in detection probability. Weight = AIC weight.

\begin{tabular}{lccccc}
\hline \hline Model & AIC & $\Delta$ AIC & Weight & Likelihood & N par. \\
\hline$\lambda(),. \psi(),. r($ identity) & 1103.1 & 0.00 & 0.828 & 1.000 & 9 \\
(zero-inflated Poisson RN model) & & & & & \\
$\lambda(),. r($ identity) (Poisson RN model) & 1106.2 & 3.14 & 0.172 & 0.208 & 8 \\
$\psi(),. p($ identity) & 1131.1 & 28.00 & 0.000 & 0.000 & 8 \\
(single season occupancy model) & & & & & \\
\hline \hline
\end{tabular}

occupancy by O. polychroma were the predator-grazing principal components, with PC1 having a positive effect on this species' probability of site occupancy, and PC2 having a negative effect on occupancy. Compared to shrubland habitats, occupancy was significantly lower in grassland habitats. Individual detection probability was higher in scrub habitats, and lower in grassland habitats, than in shrubland (Table 4.16). While the number of $W$. maculata was positively correlated with individual detection probability of $O$. polychroma, there was no significant effect on O. polychroma site occupancy (Table 4.16).

In 2018 , average estimated abundance $(\lambda)$ of $O$. polychroma per pitfall trap was 2.668 (95\% CI: 1.484 - 4.797), and estimated abundance across the effective trapping area of all pitfalls was 560 skinks (95\% CI: 311 - 1007). The average estimated site occupancy for this species was $48.11 \%$ (95\% CI: 0.446 - 0.517). Site occupancy of O. polychroma and W. maculata at Baring Head appears to have increased significantly between 2012 and 2018 (Figs. 4.11). Of the two 
Table 4.15: Candidate models and model selection statistics for single-season (2018) $O$. polychroma monitoring data at Baring Head. Parameter notation: $\lambda=$ mean abundance per site, $\psi=$ probability of site occupancy, $r=$ individual detection probability. Abbreviations: $\mathrm{RN}=$ Royle / Nichols heterogeneity model formulation; $W M=$ number of $W$. maculata caught at a site on a given trap occasion; $i$ means that an identity matrix was used for describing between-check variation in detection probability, Weight = AIC weight.

\begin{tabular}{lccccc}
\hline \hline Model & AIC & $\Delta$ AIC & Weight & Likelihood & N par. \\
\hline$\lambda(),. \psi(P C 1+P C 2+$ scrub + grass + & 1053.2 & 0.00 & 0.982 & 1.000 & 16 \\
$W M), r(i+$ scrub + grass $+W M)$ & & & & & \\
$\lambda(),. \psi(P C 1+P C 2+$ scrub + grass + & 1061.2 & 7.99 & 0.018 & 0.018 & 11 \\
$W M), r($ temperature + rain + scrub + & & & & & \\
grass $+W M)$ & & & & & \\
$\lambda(),. \psi(),. r(i+$ scrub + grass $+W M)$ & 1094.2 & 41.0 & 0.000 & 0.000 & 12 \\
$\lambda(),. \psi(),. r($ temperature + rain + & 1102.3 & 49.3 & 0.000 & 0.000 & 7 \\
scrub+grass $+W M)$ & & & & \\
$\lambda(),. \psi(P C 1+P C 2+$ scrub + grass + & 1123.7 & 70.5 & 0.000 & 0.000 & 9 \\
$W M), r($ scrub + grass $+W M)$ & & & & & \\
$\lambda(),. \psi(),. r($ scrub + grass $+W M)$ & 1157.7 & 104.6 & 0.000 & 0.000 & 5 \\
\hline \hline
\end{tabular}

species, O. polychroma is estimated to occupy more sites than W. maculata. The magnitude of the increase in site occupancy of W. maculata between 2012 and 2018 was lower than that of O. polychroma. 
Table 4.16: Untransformed estimates of co-efficients for model parameters (i.e. $\beta$ values) with non-null covariate structures in the most highly parametrised models with strong support by the AIC $(\triangle A I C<2) . \epsilon=$ probability of species extinction from a site, $\psi$ probability of occupancy of a site, $p=$ species detection probability, $r=$ individual detection probability. Statistically significant effects (assessed from standard errors using a normal approximation with $\alpha=0.05$ ) are highlighted in bold font.

\begin{tabular}{|c|c|c|}
\hline \multirow[t]{2}{*}{$\begin{array}{l}\text { Woodworthia maculata multi-season (2012-2018) } \\
\text { occupancy } \\
\text { Model } \triangle A I C=0.00 \\
\text { Covariate }\end{array}$} & \multirow[b]{2}{*}{ Estimate } & \multirow[b]{2}{*}{ SE(estimate) } \\
\hline & & \\
\hline$\psi($ Shrubland $)$ & -1.9037 & 0.4330 \\
\hline$\psi($ Grassland $)$ & -21.968 & 70891 \\
\hline$\epsilon($ Shrubland $)$ & -4.5611 & 4.3033 \\
\hline$\epsilon($ Grassland $)$ & -0.3199 & 1.3795 \\
\hline$\epsilon($ Rock $)$ & -2.6409 & 1.1056 \\
\hline$\epsilon(P C 1)$ & 0.9473 & 1.6685 \\
\hline$\epsilon(P C 2)$ & 0.7165 & 0.6121 \\
\hline$p($ Temperature $)$ & -0.1167 & 0.0160 \\
\hline$p($ Rain $)$ & -0.2478 & 0.0734 \\
\hline$p($ Rock $)$ & 0.4015 & 0.2337 \\
\hline$p($ Shrubland $)$ & 0.0938 & 0.2435 \\
\hline$p($ Grassland $)$ & 0.0018 & 0.4291 \\
\hline \multicolumn{3}{|l|}{ Oligosoma polychroma single-season } \\
\hline \multicolumn{3}{|l|}{ Royle/Nichols heterogeneity } \\
\hline \multicolumn{3}{|l|}{ Model $\triangle A I C=0.00$} \\
\hline Covariate & Estimate & SE(estimate) \\
\hline$\psi(P C 1)$ & 7.6313 & 2.5483 \\
\hline$\psi(P C 2)$ & -9.4871 & 3.1040 \\
\hline$\psi($ Scrub $)$ & 0.1681 & 0.4833 \\
\hline$\psi($ Grassland $)$ & $-\mathbf{1 . 8 8 4 0}$ & 0.4759 \\
\hline$\psi(W M)$ & -0.0001 & 0.0004 \\
\hline$r(S c r u b)$ & 0.1151 & 0.0003 \\
\hline$r($ Grassland $)$ & -0.1148 & 0.0003 \\
\hline$r(W M)$ & 0.6145 & 0.2403 \\
\hline
\end{tabular}



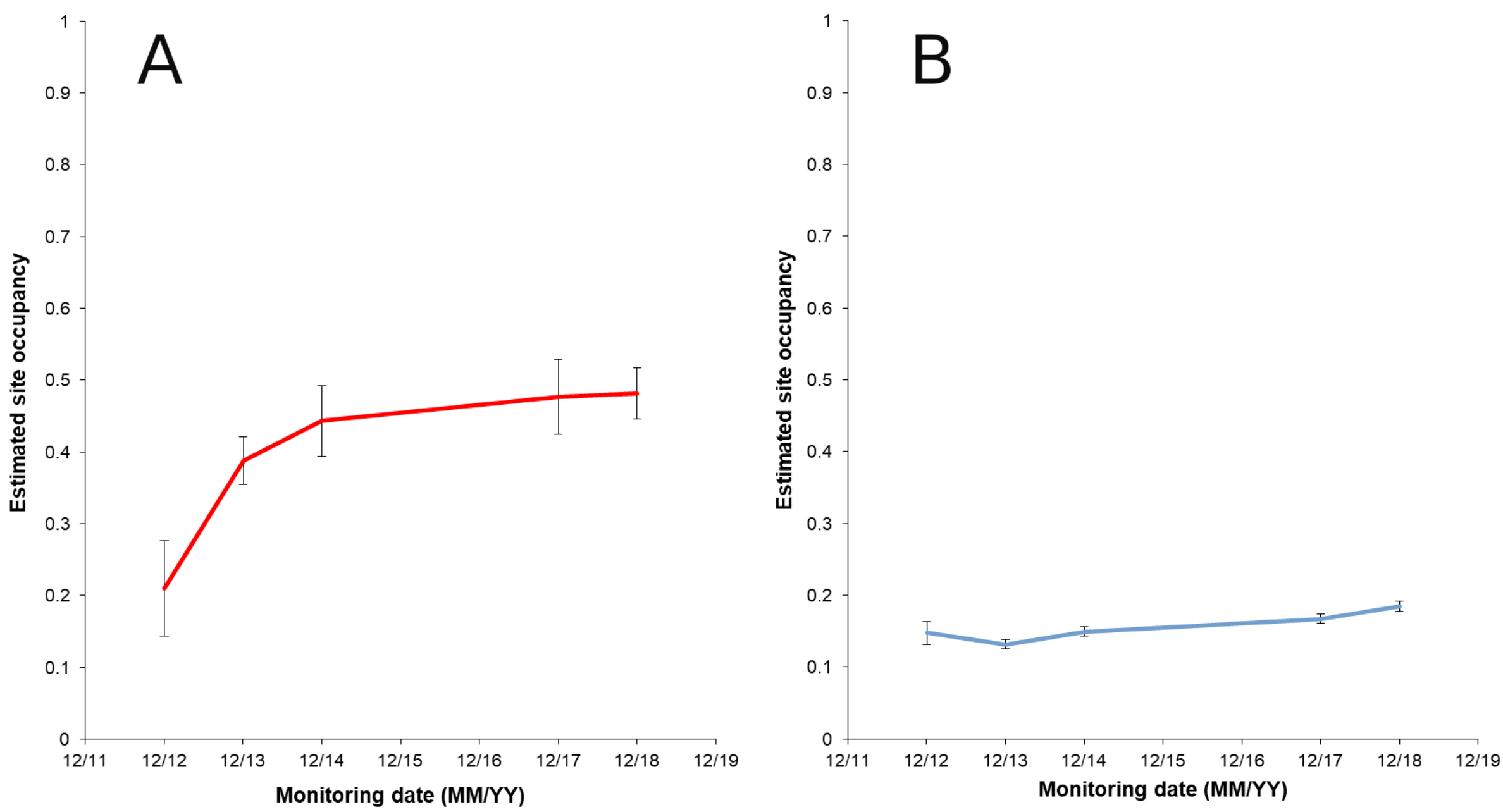

Figure 4.11: Temporal trends in estimated occupancy of A northern grass skinks (Oligosoma polychroma) and B Raukawa geckos (Woodworthia maculata) at Baring Head, 2012-2018. Occupancy estimates for northern grass skinks between 2012 and 2017 are from single-season modelling performed previously by Herbert et al. (2013b, 2014b); Wiles et al. (2015) and Herbert and Bell (2018), whereas the occupancy estimate for 2018 is from this study and updates previous modelling work by Herbert and Bell (2019). Occupancy estimates of Raukawa geckos are from multi-season occupancy modelling performed in this study. Error bars are the $95 \%$ confidence intervals. $\mathrm{N}$ sites $=210$. 


\subsection{Discussion}

\subsubsection{Effect of invasive mammal species on lizard species}

Two lines of evidence were examined to understand the effect of invasive mammals on lizard species in the Wellington region of New Zealand: (1) contemporary presence/absence of lizard species in mark-recapture surveys, and abundance of common species, at two mammal-invaded sites; and (2) population trends of lizard species at three mammal-invaded sites spanning six to 49 years. There was evidence (summarised in Table 4.17) indicating that metapopulations of the two most frequently encountered species on the mainland (O. polychroma and $W$. maculata) can persist for long time frames and reach high abundances at mammal-invaded sites. No significant positive or negative trend was detected in the CPUE of a third species, O. zelandicum, at Pukerua Bay over 34 years of monitoring. However, the evidence for this species being capable of co-existence with invasive mammals is not as robust because it inhabited only one of the study sites, and capture rates were comparatively low.

However, out of the six lizard species where there was enough evidence to make an assessment, three species were considered to be vulnerable to the presence of invasive mammals: O. aeneum, O. kokowai, and O. whitakeri. This outcome was unsurprising for $O$. kokowai and O. whitakeri because these species are considered to be At Risk or Threatened with extinction (Hitchmough et al., 2016a). The inflection point of the quadratic trend in CPUE for O. aeneum at Pukerua Bay is particularly interesting; the fitted average CPUE decreased between 1984 and 2006, then began to increase slightly between 2006 and 2018. However, the quadratic trend may have been an artefact of a temporary increase in CPUE between 2010 and 2014, where O. aeneum CPUE values were higher than expected by the fitted quadratic curve. The temporary increase in CPUE of O. aeneum could indicate a time-lagged effect from the instalment of DOC 200 and 250 traps at Pukerua Bay beginning in 2004, and the start of a rodent control programme in 2005 which continued until 2012 (A. Hulme-Moir, B. Tandy, and C. Giddy pers. comm.). The rodent control programme appeared to be successful for suppressing rats but not mice, with rat ink tracking tunnel rates being between $0-7 \%$ and mouse tracking tunnel rates being between $80-87 \%$ in 2010 (Stone, 2010). In contrast, negligible control of mammalian predators occurred at Baring Head before 2014 and at Turakirae Head before June 2019 (Uys (2019); A. Hulme-Moir pers. comm.). Mammal abundance has not been monitored at Turakirae Head, but could be similar to the neighbouring Baring Head before predator control began in 2014. At Baring Head, mustelid ink tunnel tracking rates have remained low $(<10 \%)$ between 2012-2019, rat tracking rates were moderate $(<20 \%)$, and mouse and hedgehog tracking rates were high in some seasons (up to $70 \%$ and $80 \%$, respectively; Uys (2019) and GWRC unpub. data). Rodent control was intensified around the core O. kokowai habitat in 2018, but the 
Table 4.17: Summary of spatial and temporal population responses of lizard species to the presence of invasive mammals. Catch per unit effort (CPUE) information for copper skinks and northern spotted skinks at Baring Head are from Herbert and Bell (2019). $\hat{\psi}=$ estimated probability of occupancy, $\hat{N}=$ estimated abundance. 'Absent' indicates that the species has never been detected at a site.

\begin{tabular}{|c|c|c|c|}
\hline Species & Baring Head & Pukerua Bay & Turakirae Head \\
\hline $\begin{array}{l}\text { Copper skinks } \\
\text { (Oligosoma } \\
\text { aeneum) }\end{array}$ & Low CPUE. & $\begin{array}{l}\text { Curvilinear relationship } \\
\text { with time suggests } \\
\text { decreasing CPUE between } \\
1984 \text { and 2006, followed by } \\
\text { an apparent slight recovery } \\
\text { between } 2007 \text { and } 2018 \text {. } \\
\text { However, recovery cannot } \\
\text { be confirmed due to higher } \\
\text { than expected average } \\
\text { CPUE only between } 2010 \\
\text { and 2014, and lower than } \\
\text { expected average CPUE } \\
\text { between } 2015 \text { and } 2018 \text {. }\end{array}$ & $\begin{array}{l}\text { Not encountered since } \\
1982 .\end{array}$ \\
\hline $\begin{array}{l}\text { Northern } \\
\text { spotted skinks } \\
\text { (O. kokowai) }\end{array}$ & Low CPUE. & Absent. & $\begin{array}{l}\text { Not encountered since } \\
1984 .\end{array}$ \\
\hline $\begin{array}{l}\text { Northern } \\
\text { grass skinks } \\
\text { (O.polychroma) }\end{array}$ & $\begin{array}{l}\text { Significant } \\
\text { increase } \\
\text { in occupancy } \\
\text { over six years. }\end{array}$ & $\begin{array}{l}\text { 2018/19 estimated density: } \\
3,980 \text { individuals per ha, } \\
\text { stable CPUE over } 34 \text { years. }\end{array}$ & $\begin{array}{l}2019 \text { density estimate: } \\
4,078 \text { individuals per } \\
\text { ha, no evidence of } \\
\text { decline in estimated } \\
\text { abundance over } 19 \\
\text { years, CPUE stable } \\
\text { over } 49 \text { years. }\end{array}$ \\
\hline $\begin{array}{l}\text { Whitaker's } \\
\text { skinks } \\
\text { (O. whitakeri) }\end{array}$ & Absent. & $\begin{array}{l}\text { CPUE decreased to zero } \\
\text { over } 34 \text { years. Species not } \\
\text { encountered since } 2004 \text {. }\end{array}$ & Absent. \\
\hline $\begin{array}{l}\text { Glossy } \\
\text { brown skinks } \\
\text { (O. zelandicum) }\end{array}$ & Absent. & $\begin{array}{l}\text { No significant trend in } \\
\text { CPUE over } 34 \text { years. }\end{array}$ & Absent. \\
\hline $\begin{array}{l}\text { Raukawa } \\
\text { geckos } \\
\text { (Woodworthia } \\
\text { maculata) }\end{array}$ & $\begin{array}{l}\text { Significant } \\
\text { increase } \\
\text { in occupancy } \\
\text { over six years. }\end{array}$ & $\begin{array}{l}\text { 2018/19 estimated density: } \\
4,067 \text { individuals per ha, } \\
\text { increasing CPUE over } 34 \\
\text { years. }\end{array}$ & $\begin{array}{l}2019 \text { density estimate: } \\
38,372 \text { individuals per } \\
\text { ha, no evidence of a } \\
\text { sustained decline in } \\
\text { estimated abundance } \\
\text { over } 49 \text { years. }\end{array}$ \\
\hline
\end{tabular}


effect of this on localised rodent abundance has not been examined yet (P. Warren and R. Masters, pers. comm.).

\subsubsection{Mechanisms for persistence of common lizard species in mammal- invaded environments}

Because of the robust occupancy data available for lizards, invasive mammals and habitat at Baring Head, some inference could be made about mechanisms promoting persistence of these two species. The local extinction risk of Raukawa geckos at the pitfall site scale was significantly reduced by an increasing amount of rock surrounding a pitfall trap. As hypothesised based on the results of Chapter 3, Raukawa geckos appeared to prefer scrub over shrubland and grassland. However, the contrast between estimated occupancy rates of Raukawa geckos in scrub versus grassland habitat was not significant owing to the extremely large standard error around estimated occupancy of this species in grassland. Northern grass skinks appeared to prefer scrub and shrubland over grassland. Site occupancy of northern grass skinks also appeared to respond positively to grazing effects on the pest guild (PC1) and negatively to rats and mice in ungrazed areas (PC2).

At Baring Head, many of the grassland areas are intensively to moderately grazed. There was a strong negative correlation between grazing intensity and mouse tracking rates, and strong positive correlations between grazing intensity and hedgehog and mustelid tracking rates. In several studies on New Zealand lizards, removal of grazing stock has been associated with concurrent increases in rodent numbers and lizard population declines or sustained suppression of abundance (Newman, 1994; Hoare et al., 2007a; Knox et al., 2012; Norbury et al., 2013). While a reduction in grazing pressure increases the amount of vegetative cover and biomass of fruit borne on native shrubs for lizards, increased seeding in pasture grasses following release from grazing pressure can sustain high abundances of mice and rats that function as mesopredators of lizards in New Zealand ecosystems (Norbury, 2001; Norbury et al., 2013, 2014b; Wotton et al., 2016). At Baring Head, shrubland is dominated by a mixture of pasture grasses, rocky screes, and the native divaricating shrub Coprosma propinqua. While O. polychroma and W. maculata are capable of climbing woody vegetation to at least 1 metre in height, they are predominantly terrestrial and appear to be less abundant in habitats with tall and closed canopies (East et al., 1995). The positive association between Raukawa gecko abundance and rocks is similar to results from other studies in New Zealand that suggested rocks provide refuges for lizards from larger-bodied predators (Towns, 1996; Lennon, 2019). 


\subsubsection{Potential consequences of mammal invasion for lizard communities}

The analyses of lizard communities in this study and in Chapter 3 of this thesis suggest that lizard species richness in mammal-invaded environments is lower than mammal-free environments, due to the absence or suppressed abundance of certain species. However mammal-free sites in coastal Wellington are limited to offshore islands, whereas all of the mammal-invaded sites studied were on the mainland. There is evidence that many New Zealand lizards are negatively impacted by invasive mammals (e.g. Towns (1991); Towns and Daugherty (1994); Hoare et al. (2007a,b) and Norbury et al. (2014b)). Therefore, in making spatial comparisons between these sites, an island versus mainland effect independent of the presence of exotic mammals cannot be discounted. Globally, oceanic seabird islands are very high productivity sites that tend to support very high reptile abundances, for example an estimated $37-41 \mathrm{~kg} / \mathrm{ha}$ on Takapourewa / Stephens Island in the Cook Strait of New Zealand (representing an estimated density of 6,666 lizards/ha), and reaching $96 \mathrm{~kg} / \mathrm{ha}$ on Cousin Island in the Seychelles (Cheke, 1984; Markwell, 1999; Bullock et al., 2002). A rough calculation based on estimated lizard densities and average weights of individuals captured at Turakirae Head in this study (geckos: 2.98 g, skinks: $3.75 \mathrm{~g}$, S. Herbert unpub. data) results in a total lizard biomass of $65 \mathrm{~kg} / \mathrm{ha}$. This suggests that a high lizard biomass can persist in pest-invaded environments of New Zealand, even when some species in the natural assemblage have become locally extinct or declined to a non-detectable abundance.

\section{Community-mediated effects of invasive mammals on lizard species}

Potential consequences of unequal vulnerability to predation within a species assemblage include the alteration of indirect or direct competition dynamics (Holt and Lawton, 1994; Bolnick et al., 2010). Very little is known about interactions between sympatric lizard species in New Zealand, although resource competition, competitive exclusion, and saurivory have been observed (Patterson, 1992; Bell et al., 2012; Evans et al., 2015; van Winkel et al., 2018; Fischer et al., 2019). Competitive interactions between conspecific lizards tend to favour larger individuals, so it is possible that in a case of substantial niche overlap, larger species would have a competitive advantage (Downes and Shine, 1998; Melgren, 2012; Evans et al., 2015). Therefore it is possible that poorer competitors could benefit from the suppression of species more susceptible to predation due to ecological release (Bolnick et al., 2010; Doherty et al., 2015). Even in the absence of direct competition between two species with a shared predator, a stable abundance of one species may facilitate the decline of another by supporting a high predator abundance (Holt, 1977). Relatively 'r-selected' species with high reproductive outputs, shorter times to maturity and short life span are generally expected to be more robust to high predation pressure Holt and Bonsall (2017). 
The spatial and temporal patterns observed in the lizard communities in this study suggest that, in the continued presence of pests, lizard communities on the Wellington mainland may become increasingly homogenized until only one (O. polychroma) to three (O. polychroma, O. zelandicum, and W. maculata) species remain. This conclusion is supported by the significantly lower lizard species richness observed at mammal-invaded sites compared to mammal-free sites in Chapter 3 of this thesis. It is therefore recommended that future conservation research on O. aeneum, O. kokowai, and O. whitakeri focus on identifying what would represent an adequate pest control or eradication strategy for protecting these populations on the mammal-invaded New Zealand mainland. 


\section{Chapter 5}

\section{Short-term responses of lizard species assemblages to habitat enhancement in a pest-invaded mainland environment}

\subsection{Introduction}

Habitat loss is a key threatening process to vertebrates around the world, particularly the herpetofauna due to their increased dependence on the environment for body temperature regulation (White et al., 1997). Because of often considerable lag times between habitat loss and extinction for many fauna, the consequences of the current level of habitat loss has not yet been realised (Tilman et al., 1994; Hanski and Ovaskainen, 2002; Kuussaari et al., 2009; Jackson and Sax, 2010).

Reservation, the process of securing legal protection for natural habitats, is an established technique for preventing further habitat loss for endangered fauna (e.g. Noon and McKelvey (1996); Anthony et al. (2006)). However, it has been estimated that the degree of habitat loss that has already occurred is too great to prevent further wildlife extinctions (Rosenzweig, 2003). Habitat restoration and reconciliation are promising strategies for reclaiming lost or degraded habitat for wildlife (Dobson et al., 1997; Rosenzweig, 2003). The difference between these two strategies is that restoration seeks to restore an environment to an 'original' state, whereas reconciliation seeks to create a habitat that is inhabitable by wildlife but does not necessarily reflect a natural state (Rosenzweig, 2003; Mcdonald et al., 2016). Examples of habitat reconciliation for wildlife include green roofs and wildlife-friendly landscaping (Francis and Lorimer, 2011; Linares and Eterovick, 2013; Rosenzweig, 2016). Together, these three strategies; reservation, restoration and reconciliation; have the potential to complement each other as wildlife conservation strategies in mixed-use landscapes. I use the term 'enhancement' to encompass both restoration and reconciliation because both strategies can potentially improve wildlife 
habitats.

Habitat enhancement has been trialled on a number of reptilian fauna around the world, but more studies are required to address biases in the literature according to taxonomy, geography, and conservation status (see Chapter 2). There is also a need to initiate more long-term studies that can assess ultimate success or failure of enhancement to protect reptilian fauna; that is, establishment of self-sustaining reptile populations in enhanced patches with emigration rates exceeding or equalling immigration (paralleling the ultimate goal of conservation translocations, e.g. Miller et al. (2014)). Meeting this criterion would indicate that an enhancement programme contributes positively to the persistence of reptile metapopulations across connected landscapes (Hanski, 1999).

Insular lizards were one of the understudied groups identified in a previous meta-analysis of the effects of enhancement on reptiles in the global literature (Chapter 2). Habitat enhancement in insular environments is often complicated by naive prey and novel predator scenarios that have resulted from the introduction of invasive fauna (Hoare, 2006; Norbury et al., 2013). On islands, the deleterious effects of predation by, and competition with, exotic fauna tends to outweigh the negative effects of habitat loss for native fauna (Brooks et al., 2002). Furthermore, habitat enhancement in invaded environments is potentially complicated by the concurrent effects on all members of the faunal community and the relationships between them (Norbury et al., 2013). For example, habitat restoration attempts on the New Zealand archipelago have sometimes generated negative outcomes for threatened native fauna via an unexpected effect on the activity or abundance of invasive mammals (Hoare et al., 2007a; Ratz, 2000; Knox et al., 2012). Thus, fauna conservation efforts in insular environments have tended to focus on eradicating or controlling exotic fauna, and translocating threatened native species to pest-free areas (Daltry et al., 2001; Towns et al., 2001; Russell et al., 2015, 2016).

Habitat enhancement has been tried previously for endemic New Zealand lizards, but it has not been used broadly and outcomes have been variable (Hoare et al., 2007a; Lettink et al., 2010; Knox et al., 2012; Bell and Herbert, 2016, 2017a). Research conducted in Chapters 3 and 4 and other studies suggest that the occupancy or abundance of some lizard species is related to certain vegetative characteristics and that rocks could provide protection from larger-bodied mammalian predators (Patterson, 1992; Towns, 1996; Phillpot, 2000; Stephens, 2004; Gollin, 2016; Wiles, 2016; Lennon, 2019). Several fruiting and flowering native plants also provide food for lizards, or support important invertebrate food sources (Whitaker, 1987; Evans et al., 2015; Wotton et al., 2016). Therefore it is reasonable to assume that manipulating habitat quality for one or more target lizard species could be useful for their conservation. With high initial resources required for effective predator control and the ongoing resources needed to maintain pest-free status or adequate suppression, creation of self-sustaining high-quality habitats is an attractive complementary strategy for conserving New Zealand's endemic lizard fauna (Norbury 
et al., 2014a). Therefore in this chapter, I established a before-after-control-impact (BACI; Stewart-Oaten et al. (1986)) experiment to test the outcomes of habitat enhancement on a coastal lizard community inhabiting a mammal-invaded area of the lower North Island of the New Zealand archipelago. In this setting, it was hypothesised that enhancement would only produce successful outcomes in populations of lizard species capable of long-term persistence with invasive mammals. Based on the findings of Chapters 3 and 4 of this thesis, species that would benefit from enhancement were predicted to be the skink Oligosoma polychroma and the semi-terrestrial gecko Woodworthia maculata.

\subsection{Methods}

\subsubsection{Study site}

The Miramar Peninsula (Te Motu Kairangi in Māori language) was once an island in the Wellington Harbour (Te Whanganui a Tara) of the lower North Island of New Zealand (see Fig. 1.4 in Chapter 1). It became connected to the mainland in the $1400 \mathrm{~s}$ by a large earthquake that uplifted what is now the Rongotai Isthmus and Lyall Bay (Best, 1923; Pillans and Huber, 1992). Historically, Miramar would have been covered in coastal-lowland podocarp-broadleaf forest and swampland, bordered by native scrub assemblages typical of the coastal cliffs and rocky shores of the Palliser-Wellington coast (for example, a mixture of flax (Phormium cookianum), shrubs (Coprosma repens, C. propinqua, Myoporum laetum, and Olearia paniculata), and various native climbers, grasses and herbs Gabites (2015)). Nowadays, the habitat is comprised of a mosaic of regenerating māhoe (Melicytus ramiflorus) forest, gorse (Ulex europaeus) scrub, mixed native coastal shrubland, suburban infrastructure, grassland and cobble beaches.

Lizard species known from Miramar include the terrestrial skinks Oligosoma aeneum and O. polychroma, semi-terrestrial gecko Woodworthia maculata, and arboreal gecko Naultinus punctatus (Bell, 2019b). Other lizard species such as ornate skinks O. ornatum, northern spotted skinks O. kokowai, and ngahere geckos Mokopirirakau aff. granulatus 'southern North Island' were probably historically present but have not been recorded recently in Miramar (Romijn et al., 2012; Bell, 2019b).

Invasive rats (Rattus norvegicus and R. rattus), mice (Mus musculus) and hedgehogs (Erinaceus europaeus) are all present on the Miramar Peninsula, thus could potentially affect enhancement outcomes on endemic lizards (Balls (2019); Table 5.1). Brushtail possums (Trichosurus vulpecula) were historically present, but were eradicated in 2006. There was a substantial amount of pest control occurring across private and public land when this study commenced in 2017 (Balls, 2019).

Kill traps used for the control of rodents, hedgehogs and mustelids were in operation 
across the Miramar Peninsula at densities of 0.2-8.0 traps per hectare (ha) between November 2017 to January 2019 (Balls, 2019). Trap density at the study sites was 0.2-1 per ha on Hue-Te-Taka, and 0.4-1 per ha at Wahine Park and the Rangitatau Reserve escarpment (Balls, 2019). Prior to commencement of the Pest Free Miramar Project (www.pfw.org.nz/miramar-2019) in July 2019, rat and weasel (Mustela nivalis) abundance in Southern Miramar were predicted to be relatively high, mouse and hedgehog abundance low, and stoat abundance moderate compared with the surrounding Wellington City (Balls, 2019). Cats (Felis catus) were not detected by Balls (2019), but are very likely present due to the close proximity of these sites to suburban development (Aguilar and Farnworth, 2013; Woolley and Hartley, 2019). An intensive predator control programme by the Predator Free Wellington organisation began in July 2019, with the goal of eradicating stoats, weasels and rats from the Miramar by December 2019.

Table 5.1: Summary of mammalian predator relative abundance across South Miramar. The percentage is calculated as the number of detections divided by the number of functional ink tracking tunnels (TTs) or chew cards (CCs), with disturbed tunnels or cards scored as -0.5 , and missing cards or tunnels scored as -1 . Possums are thought to be absent and were not detected during these surveys. Data are from the People, Cities and Nature project (N. Fitzgerald and S. Hartley, unpubl. data).

\begin{tabular}{lllllll}
\hline \hline Month & Method & Mice & Rats & Hedgehogs & Mustelids & Cats \\
\hline Dec 2017 & 1-day TT & $8 \%$ & $4 \%$ & $24 \%$ & $0 \%$ & $0 \%$ \\
& 1-day CC & $7 \%$ & $0 \%$ & $0 \%$ & $0 \%$ & $0 \%$ \\
& 7-day TT & $53 \%$ & $24 \%$ & $37 \%$ & $0 \%$ & $0 \%$ \\
& 7-day CC & $14 \%$ & $41 \%$ & $0 \%$ & $0 \%$ & $0 \%$ \\
\hline May 2018 & 1-day TT & $17 \%$ & $10 \%$ & $24 \%$ & $0 \%$ & $0 \%$ \\
& 1-day CC & $10 \%$ & $20 \%$ & $0 \%$ & $0 \%$ & $0 \%$ \\
& 7-day TT & $17 \%$ & $10 \%$ & $24 \%$ & $0 \%$ & $0 \%$ \\
& 7-day CC & $10 \%$ & $20 \%$ & $0 \%$ & $0 \%$ & $0 \%$ \\
\hline \hline
\end{tabular}

\subsubsection{Lizard monitoring}

Twelve approximately $10 \times 10 \mathrm{~m}$ plots consisting of $6 \times 6$ grids of lizard monitoring stations were established between June and October 2017 (the austral winter-spring). These plots were established in three public parks administered by the Wellington City Council: (1) Hue-Te-Taka (HT), (2) Rangitatau Reserve Escarpment (RE), and (3) Wahine Park (WP), with four grids per park. Each grid was placed using a randomly generated GPS waypoint constrained to be at least $100 \mathrm{~m}$ apart in QGIS to site the top left corner (QGIS Development Team, 2016). Two grids per site were randomly allocated to receive the 'enhancement' treatment.

In other studies on reptile communities, use of multiple trap types tended to capture a broader range of species (Greenberg et al., 1994; Pulsford et al., 2017). Therefore in this 
study, each lizard monitoring station was comprised of two lizard detection techniques: pitfall traps and Onduline artificial cover objects (ACOs)(Lettink and Cree, 2007; Hare, 2012; Lettink and Monks, 2016). Pitfall traps were constructed from a 4 L plastic liver pail (Stowers Plastics, Lower Hutt, New Zealand), and covered an ACO constructed from two $40 \times 50 \mathrm{~cm}$ layers of Onduline (Composite Insulation, Christchurch, New Zealand). Pitfalls had four 3.5 $\mathrm{mm}$ holes drilled in the bottom for drainage, and were filled with a mixture of rocks, soil, sticks and leaves when closed so that any lizard entering the trap could easily get back out. The Onduline layers were spaced $0.5-2 \mathrm{~cm}$ apart to allow lizards of different sizes to inhabit the spaces between or under both layers. Each station within a grid was given a unique identifier, using letters A-F for grid rows and 1-6 for grid columns (e.g. C3). At publicly accessible sites (HT1-4, WP1-4, RE1-2), one to two Onduline ACOs per grid were covered with a laminated paper sign to deter people from disturbing the monitoring equipment.

Pre-enhancement monitoring was carried out during three primary periods in late spring/early summer (November - December 2017), late summer (January - February 2018) and in autumn (March - April 2018). Each primary period consisted of eight to ten checks done on separate days, across a maximum of 14 days. Pitfalls were checked daily when open, and closed down when not being checked to ensure compliance with animal ethics standards. Post-enhancement monitoring was carried out in November - December 2018 (2-3 months after enhancement planting) and October - November 2019 (13-14 months after enhancement planting, and 9-10 months after adding rock piles). Due to the number of lizard captures, a maximum of six grids could be checked within a day. Therefore one control and one enhancement grid were checked per site within each of two rounds. To avoid auto-correlation with weather conditions, the order in which grids were checked was varied each day.

All lizards captured were measured (body length as snout-vent length (SVL) to the nearest $0.5 \mathrm{~mm}$. For lizards with a combined bag plus lizard weight less then $10 \mathrm{~g}$ (i.e. most skinks and juvenile geckos), weight was measured by a $10 \mathrm{~g}$ Pesola scale to the nearest 0.05 g. Lizards with a combined weight of more than $10 \mathrm{~g}$ (i.e. most adult geckos) were weighed to the nearest $0.25 \mathrm{~g}$ using a $30 \mathrm{~g}$ Pesola scale. Individuals were identified to species level, and the monitoring station number was recorded. Geckos were temporarily marked with a unique number on the underside of the abdomen with a xylene-free permanent marker. Skinks were permanently marked with a unique toe clip. Toe coding does not appear to affect capture probabilities (Jones and Bell, 2010). Two toes on different feet were clipped and existing toe loss was incorporated into the toeclip pattern. Three-toe codes were used in later surveys at sites after all two-toe codes had been used. The same set of codes were used for all grids within a site to account for the possibility of skinks moving between grids between primary survey periods. Adult animals were sexed by examination of the external features of the cloacal area (geckos), or by examination of internal and external cloacal features and/or eversion of hemipenes (skinks). Lizards were released within $0.5 \mathrm{~m}$ of the 
point of capture immediately after measurements had been taken. Measurements were taken from individuals only once (usually during the first capture occasion) to minimise handling-related stress.

\subsubsection{Habitat enhancement}

Habitat enhancement was carried out between July 2018 and January 2019. The main round of planting occurred in the austral winter between July and August 2018 to ensure optimal conditions for plant establishment. Between 88 and 102 ecosourced native plants from Berhampore Nursery were planted per site, with more plants allocated to sites with lower vegetative cover (an average density of 0.96 plants per $\mathrm{m}^{2}$ ). Different conditions at each grid required a different mixture of plant species from a list consisting of the shrubs Coprosma repens, C. propinqua, C. acerosa, Veronica [=Hebe] stricta, vines Muehlenbeckia complexa and Disphyma australe, flax Phormium cookianum, and the tussock-forming grass Poa cita (A. Benbrook, pers. comm.). Supplementary planting with P. cookianum, P. cita, and the divaricating shrub Plagianthus divaricata from Orongorongo Nursery was carried out at the Wahine Park grids to infill gaps between September and December 2018. Further details of the planting programme are given along with plant survival rates in Table 5.6 in the results.

Rock piles consisting of 20-40 mm crushed greywacke were added to the enhancement grids in the austral summer between December 2018 and January 2019 so that lizards would have high enough body temperatures to move, thus avoid being crushed by the rocks as they were laid down. An example of enhancement is provided in Figure 5.1 and maps of all enhanced grids are in Appendix D. The Predator-Free Wellington mustelid and rat eradication programme also commenced across the whole Miramar Peninsula in July 2019 and had the potential to affect lizard populations within all monitoring grids.

\subsubsection{Assessment of enhancement success / failure}

To determine success or failure of the enhancement programme, outcomes for each lizard species encountered were assessed against a four-stage evaluation framework adapted from Miller et al. (2014) and Chapter 2 of this thesis, as follows:

1. Species detected within enhanced habitat patch(es), with same or increased body condition relative to pre-enhancement and negative control sites.

2. Detection of reproduction (pregnant females or neonates) in enhanced habitat(s)

3. A demographic benefit to lizard populations occupying enhanced habitat(s): increased abundance, survival and/or reproductive output relative to baseline and control sites. 

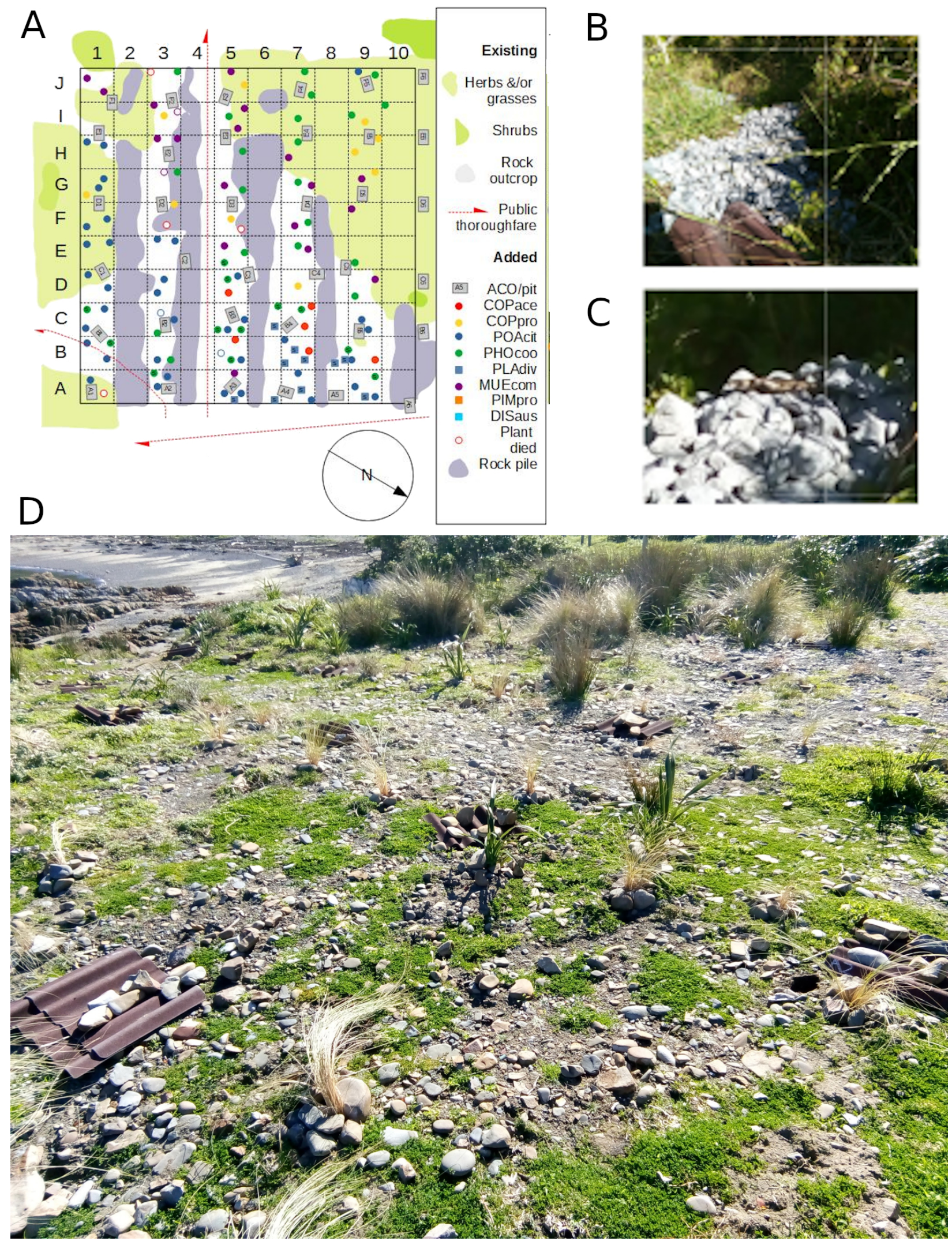

Figure 5.1: A. Map of grid WP4 showing existing cover, enhancement planting, and rock piles. B. Constructed rock pile, grid MM2. C. Close-up of B showing size of adult skink (O. polychroma, SVL $=50-70 \mathrm{~mm}$ ) in relation to the rocks. D. Grid WP4 in August 2018 after completion of planting, looking from monitoring station A1 (see 5.1A.) 
4. Self-sustaining population established in enhanced habitat(s)

Although body condition was not included as a measure supporting stage 1 in Chapter 2 of this thesis, an increase in body size, weight or body condition is used as a measure of translocation success in lizards (Miller et al., 2014). However, unlike previous assessments of translocation success (Miller et al., 2014; Bell and Herbert, 2017b), I considered both maintenance and increase of body condition to indicate suitability of the enhanced habitat for the species. Success at stage four was not assessed because the post-enhancement monitoring period was too short to determine whether populations of the study species were self-sustaining or not (Barwick, 1959; Whitaker, 1982; Miller et al., 2014; van Winkel et al., 2018).

\subsubsection{Statistical analysis}

Unless otherwise stated, all statistical analyses were completed in $\mathrm{R}$ version 3.5.1 (R Core Team, 2018). Generalised linear mixed effects modelling (GLMM) was performed using the lme4 R package (Bates et al., 2015). Figures were edited in GIMP version 2.10.

\section{Stage 1: Response of patch use and body condition to enhancement}

Patch use was defined as a binary variable describing whether a species was detected $(=1)$ or undetected $(=0)$ within a grid during a given monitoring season. The difference in patch use before and after treatment was assessed separately for each species using a binomial GLMM with a fixed factor structure of Treatment $\times$ Be fore/After $(B A)$ and a random effects structure of (Season|Site/Grid).

A series of Gaussian GLMMs were constructed based on six alternative scenarios for the response of body condition of individual lizards to enhancement treatment and period (pre- and post-enhancement), and evaluated using the Akaike's Information Criterion (AIC; Burnham and Anderson (2002)). In each model, the natural logarithm of lizard body weight was regressed against body size (SVL). Observations from pregnant females were excluded from this analysis to avoid a seasonal effect on body condition $(\mathrm{N}$ O. polychroma $=$ 124 of 743 observations, N O. aeneum $=30$ of 120 observations, N W. maculata $=26$ of 203 observations excluded). A model with a linear SVL effect was considered to be the null model, whereas the global model had a fixed effects structure of $S V L \times$ Treatment $\times B A$ (Table 5.2). The random effects structure for these models was (Season|Site/Grid). The more correct structure (Season $\mid$ Site/Grid/ID) could not be used due to the majority of individuals only being caught in one season. O. aeneum was only found at the escarpment site (RE grids), so only Grid was used as a random factor in models for this species. Pearson residuals were examined graphically to determine whether model assumptions were met. 
Table 5.2: Fixed factor structure of the candidate model set for modelling the response of body condition of individual copper skinks (Oligosoma aeneum), northern grass skinks (O. polychroma), and Raukawa geckos (Woodworthia maculata) to enhancement. The maximal model is labelled $M_{\max }$ and the null model is labelled $M_{0}$. Treatment $=$ enhancement or control plots. $B A=$ before / after enhancement.

\begin{tabular}{|c|c|c|}
\hline Model & Fixed factor structure & Hypothesis \\
\hline$M_{\max }$ & $S V L \times$ Treatment $\times B A$ & $\begin{array}{l}\text { Both the slope and intercept of individual body } \\
\text { condition (as weight regressed against SVL) of } \\
\text { lizards is affected by habitat enhancement. }\end{array}$ \\
\hline$M_{1}$ & $S V L+$ Treatment $\times B A$ & $\begin{array}{l}\text { Only the intercept of individual body condition } \\
\text { of lizards is affected by habitat enhancement. }\end{array}$ \\
\hline$M_{2}$ & $S V L+$ Treatment $+B A$ & $\begin{array}{l}\text { Habitat enhancement does not affect individual } \\
\text { body condition. There are pre-existing } \\
\text { differences between control and enhancement } \\
\text { plots, and the change in body condition between } \\
\text { the pre- and post-enhancement time periods is } \\
\text { unaffected by treatment. }\end{array}$ \\
\hline$M_{3}$ & $S V L+$ Treatment & $\begin{array}{l}\text { Habitat enhancement does not affect individual } \\
\text { body condition. Rather, there are pre-existing } \\
\text { differences between control and enhancement } \\
\text { plots. }\end{array}$ \\
\hline$M_{4}$ & $S V L+B A$ & $\begin{array}{l}\text { Habitat enhancement does not affect individual } \\
\text { body condition, but body condition of lizards } \\
\text { differs between pre- and post-enhancement } \\
\text { periods. }\end{array}$ \\
\hline$M_{0}$ & $S V L$ & $\begin{array}{l}\text { Habitat enhancement does not affect individual } \\
\text { body condition. Individual body condition is } \\
\text { similar across all plots and between pre- and } \\
\text { post-enhancement periods. }\end{array}$ \\
\hline
\end{tabular}




\section{Stage 2: Reproduction}

Each grid was given a binary code for each primary monitoring period to indicate whether there was evidence of reproduction for each species. Presence of either at least one pregnant female or neonate-sized individual was taken as evidence of reproduction (Whitaker, 1982; Porter, 1987; Spencer et al., 1998). A series of Binomial GLMMs were constructed based on five alternative scenarios about the response of reproduction to enhancement treatment and period (Table 5.3). Model parsimony was evaluated using the Akaike's Information Criterion (AIC; Burnham and Anderson (2002)). Pearson residuals were examined graphically to determine whether model assumptions were met.

Table 5.3: Fixed factor structure of the candidate model set for modelling the response of body condition of individual copper skinks (Oligosoma aeneum), northern grass skinks (O. polychroma), and Raukawa geckos (Woodworthia maculata) to enhancement. The maximal model is labelled $M_{\max }$ and the null model is labelled $M_{0}$. Treatment $=$ enhancement or control plots. $B A=$ before / after enhancement.

\begin{tabular}{|c|c|c|}
\hline Model & Fixed factor structure & Hypothesis \\
\hline$M_{\max }$ & Treatment $\times B A$ & $\begin{array}{l}\text { Whether or not reproduction occurs in a habitat } \\
\text { patch is affected by habitat enhancement. }\end{array}$ \\
\hline$M_{1}$ & Treatment $+B A$ & $\begin{array}{l}\text { Enhancement does not affect whether or not } \\
\text { reproduction occurs in a habitat patch. However, } \\
\text { there are pre-existing differences between control } \\
\text { and enhancement plots, and the change in } \\
\text { evidence for reproduction between the pre- and } \\
\text { post-enhancement time periods is unaffected by } \\
\text { treatment. }\end{array}$ \\
\hline$M_{2}$ & Treatment & $\begin{array}{l}\text { Enhancement does not affect whether or not } \\
\text { reproduction occurs in a habitat patch. Rather, } \\
\text { there are pre-existing differences between control } \\
\text { and enhancement plots. }\end{array}$ \\
\hline$M_{3}$ & $B A$ & $\begin{array}{l}\text { Enhancement does not affect whether or not } \\
\text { reproduction occurs, but evidence of reproduction } \\
\text { differs between pre- and post-enhancement } \\
\text { periods. }\end{array}$ \\
\hline$M_{0}$ & 1 & $\begin{array}{l}\text { Habitat enhancement does not affect whether or } \\
\text { not reproduction occurs. Evidence of reproduction } \\
\text { is similar across all plots and between pre- and } \\
\text { post-enhancement periods. }\end{array}$ \\
\hline
\end{tabular}

\section{Stage 3: Skink (Oligosoma aeneum and O. polychroma) demography}

The effects of enhancement on apparent survival (deaths + emigration), probability of entry into the population (apparent births $=$ births + immigration) and abundance on permanently marked species (O. aeneum and O. polychroma) were examined using POPAN models in MARK 9.0 (Schwarz and Arnason, 1996; White, 2019). To create the open capture 
histories required for these models, the full capture history for each individual was collapsed into a five-digit binary history describing whether or not it was captured at least once within each of the five primary survey periods. For example, an individual with a full capture history of 00100000100000000000000100000000000000010010010 would be simplified to 10101. A logit link was used for survival $(\phi)$ and individual detection probability $(p)$ to allow inclusion of individual covariates, a multinomial logit link for probability of entry into each grid $\left(p_{\text {ent }}\right)$, and a log link for abundance $(N)$.

I used the Fletcher $\hat{c}$ to evaluate how well the most saturated model in the candidate set fitted the data. Values of Fletcher $\hat{c}>1.0$ indicated lack of fit (i.e. overdispersion). Models were evaluated by parsimony using either the Akaike Information Criterion corrected for small sample size (AICc), or a quasi-likelihood approach (QAICc) where the saturated model was overdispersed (Burnham and Anderson, 2002). Where there was substantial uncertainty in model selection (i.e. where there was more than one model with $\Delta A I C<2$ ), model averaged estimates were taken from models with $\triangle A I C<2$. Annual apparent survival was calculated from monthly rates as $\left(\phi_{\text {monthly }}\right)^{12}$.

For habitat enhancement to be considered as having an effect on a lizard species, models with an interaction between time and grid would need to be supported by the AICc. This interaction effect could be specified in full or in a simplified form. The full interaction for $\phi$ and $p_{\text {ent }}, g \times t$, allowed these parameters to vary independently between plots and time periods. A simplified interaction, $E \times t$, allowed parameters to differ between enhanced and control plots only. The simplification site $\times t$, which allowed parameters to differ between RE, MP and WP plots, was also used for analysis of the $O$. polychroma data. A further simplification, $E \times A$, allowed parameters to differ before and after enhancement, but not between each survey period. Therefore, the maximal model for each of these species was $\psi(S V L+g \times t), p(g \times t), p_{\text {ent }}(g \times t), N(g \times t)$. An alternative parametrisation of the maximal model $\left(\psi(g \times t), p(g \times t), p_{\text {ent }}(g \times t), N(g \times t)\right)$ was then constructed for comparison with the maximal model to test the importance of a body size (SVL) effect on survival. The decision whether or not to include an $S V L$ term in the rest of the candidate models was made by comparing the AICc values of these two models. The resultant candidate models sets are detailed in Tables 5.4 and 5.5. 
Table 5.4: Candidate POPAN model set for examining population responses of northern grass skinks (O. polychroma) to habitat enhancement. The maximal model is labelled $M_{\text {max }}$, hypothesis-driven reduced models $M_{1-15}$, and the null model is labelled $M_{0}$. Parametrisation for abundance and in each candidate model is $N(g \times t)$ to allow abundance to vary independently between plots and sampling periods. Abbreviations used: $\phi=$ apparent survival, $p=$ individual capture probability in sampling period; $p_{\text {ent }}=$ probability of entry into sampling plots by birth or immigration, $g=\operatorname{plot}(\mathrm{n}=12), E=$ enhancement "treatment" plots $(\mathrm{n}=6)$, site $=$ Wahine Park, Hue-te-Taka, or Rangitatau Reserve Escarpment $(\mathrm{n}=3) ; t=$ sampling period $(\mathrm{n}=5), A=$ post-enhancement sampling periods $(\mathrm{n}=2)$, $S V L=$ individual body size as snout-vent length in $\mathrm{mm}$.

\begin{tabular}{|c|c|c|c|c|}
\hline Model & $\phi$ & $p$ & $p_{\text {ent }}$ & Rationale \\
\hline$M_{\max }$ & $S V L+g \times t$ & $g \times t$ & $g \times t$ & $\begin{array}{l}\text { Maximal model where body size influences survival, and } \phi, p \text { and } p_{\text {ent }} \text { vary } \\
\text { independently among plots and seasons. Included for goodness-of-fit testing. }\end{array}$ \\
\hline \multirow[t]{2}{*}{$M_{\max A}$} & $g \times t$ & $g \times t$ & $g \times t$ & $\begin{array}{l}\text { Alternative parametrisation of the maximal model to test the importance of a body } \\
\text { size effect on survival. }\end{array}$ \\
\hline & & & & Alternative hypothesis 1: habitat enhancement affects survival and $p_{\text {ent }}$. \\
\hline \multirow[t]{2}{*}{$M_{1}$} & $S V L+E \times A$ & constant & $E \times t$ & \\
\hline & & & & Alternative hypothesis 2: habitat enhancement affects survival, but not $p_{\text {ent }}$. \\
\hline$M_{2}$ & $S V L+E \times t$ & $g \times t$ & $g \times t$ & \\
\hline$M_{3}$ & $S V L+E \times t$ & $t$ & $g \times t$ & \\
\hline$M_{4}$ & $S V L+E \times A$ & $g \times t$ & $g \times t$ & \\
\hline$M_{5}$ & $S V L+E \times A$ & site $\times t$ & $g \times t$ & \\
\hline$M_{6}$ & $S V L+E \times A$ & $E \times t$ & $g \times t$ & \\
\hline$M_{7}$ & $S V L+E \times A$ & $E+t$ & $g \times t$ & \\
\hline$M_{8}$ & $S V L+E \times A$ & $t$ & $g \times t$ & \\
\hline$M_{9}$ & $S V L+E \times A$ & constant & $g \times t$ & \\
\hline$M_{10}$ & $S V L+E \times A$ & constant & site $\times t$ & \\
\hline \multirow[t]{2}{*}{$M_{11}$} & $S V L+E \times A$ & constant & site $+t$ & \\
\hline & & & & Null hypothesis: habitat enhancement does not affect survival or $p_{\text {ent }}$. \\
\hline$M_{12}$ & $S V L+$ site $\times t$ & $g \times t$ & $g \times t$ & \\
\hline$M_{13}$ & $S V L+E+A$ & $g \times t$ & $g \times t$ & \\
\hline$M_{14}$ & $S V L+E+A$ & constant & site $\times t$ & \\
\hline$M_{15}$ & $S V L+E+A$ & constant & $g \times t$ & \\
\hline$M_{0}$ & constant & constant & constant & \\
\hline
\end{tabular}


Table 5.5: Candidate POPAN model set for examining population responses of copper skinks (O. aeneum) to habitat enhancement. The maximal model is labelled $M_{\text {max }}$, hypothesis-driven reduced models $M_{1-13}$, and the null model is labelled $M_{0}$. Parametrisation for abundance and in each candidate model is $N(g \times t)$ to allow abundance to vary independently between plots and sampling periods. Abbreviations used: $\phi=$ apparent survival, $p=$ individual capture probability in sampling period; $p_{\text {ent }}=$ probability of entry into sampling plots by birth or immigration, $g=\operatorname{plot}(\mathrm{n}=4), E=$ enhancement "treatment" plots $(\mathrm{n}=2), t=\operatorname{sampling}$ period $(\mathrm{n}=5), A=$ post-enhancement sampling periods $(\mathrm{n}=2), S V L=$ individual body size as snout-vent length in $\mathrm{mm}$.

\begin{tabular}{|c|c|c|c|c|}
\hline Model & $\overline{\phi \phi}$ & $\overline{p p}$ & $p_{\text {ent }}$ & Rationale \\
\hline$M_{\max }$ & $S V L+g \times t$ & $g \times t$ & $g \times t$ & $\begin{array}{l}\text { Maximal model where body size influences survival, and } \phi, p \text { and } p_{\text {ent }} \text { vary } \\
\text { independently among plots and seasons. Included for goodness-of-fit testing. }\end{array}$ \\
\hline \multirow[t]{2}{*}{$M_{\max A}$} & $g \times t$ & $g \times t$ & $g \times t$ & $\begin{array}{l}\text { Alternative parametrisation of the maximal model to test the importance of a body } \\
\text { size effect on survival. }\end{array}$ \\
\hline & & & & Alternative hypothesis 1: habitat enhancement affects survival and $p_{\text {ent }}$. \\
\hline$M_{1}$ & $E \times t$ & $E \times t$ & $E \times t$ & \\
\hline$M_{2}$ & $E \times t$ & $E+t$ & $E \times t$ & \\
\hline$M_{3}$ & $E \times A$ & $E+t$ & $E \times t$ & \\
\hline$M_{4}$ & $E \times A$ & $E+t$ & $E \times A$ & \\
\hline \multirow[t]{2}{*}{$M_{5}$} & $E \times A$ & $t$ & $E \times t$ & \\
\hline & & & & Alternative hypothesis 2: habitat enhancement affects survival, but not $p_{\text {ent }}$. \\
\hline$M_{6}$ & $E \times A$ & $t$ & $E+t$ & \\
\hline$M_{7}$ & $E \times A$ & $t$ & $t$ & \\
\hline \multirow[t]{2}{*}{$M_{8}$} & $E \times A$ & $t$ & constant & \\
\hline & & & & Null hypothesis: habitat enhancement does not affect survival or $p_{\text {ent }}$. \\
\hline$M_{9}$ & $E+A$ & $t$ & $t$ & \\
\hline$M_{10}$ & $A$ & $t$ & $t$ & \\
\hline$M_{11}$ & $A$ & $t$ & constant & \\
\hline$M_{12}$ & $A$ & constant & $t$ & \\
\hline$M_{13}$ & constant & $t$ & constant & \\
\hline$M_{0}$ & constant & constant & constant & \\
\hline
\end{tabular}




\subsection{Results}

\subsubsection{Enhancement planting survival}

Flax (Phormium cookianum), silver tussock (Poa cita), and taupata (Coprosma repens) had consistently high survival rates across grids (Table 5.6). Average survival rates ( \pm 1 SD) across grids in which these species were planted were $93.4 \% \pm 5.5 \%, 88.8 \% \pm 5.5 \%$, and $86.3 \% \pm 5.5 \%$, respectively. The average survival rate of mingimingi (C. propinqua) was also high, but more variable between sites $(85 \% \pm 23.8 \%)$. The survival rates of the other species planted in the initial planting phase were relatively low; ranging from $64.2 \% \pm 21.8 \%$ (pohuehue Muehlenbeckia complexa) to $15.3 \% \pm 17.9 \%$ (New Zealand ice plant Disphyma australe) (Table 5.6). None of the Plagianthus divaricata survived, but this may have been due to planting in the supplementary, and sub-optimal, spring-summer period (Table 5.6).

\subsubsection{Lizard captures}

The most common species across the 12 experimental plots was O. polychroma, followed by W. maculata (Tables 5.7 and 5.8). O. aeneum was the least common species, and appeared to be restricted to the escarpment (RE) grids (Table 5.9). Demography of the lizards captured (body size as snout-vent length (SVL) and pregnant females) is summarised in Figure 5.2. Neonate (young-of the year), juvenile and pregnant $O$. polychroma and W. maculata were encountered. However, while pregnant and juvenile $O$. aeneum were encountered, neonate animals were not.

Fencing off the control plot WP1 to prevent Wellington City Council contractors from destroying the lizard monitoring stations during mowing produced a noticeable succession from short grassland to tall exotic herbs and grass. The change in mowing regime appeared to affect the maximum body size and reproductive status of O. polychroma and W. maculata, but not occupancy of any species (Fig. 5.2). Therefore, WP1 was considered as a separate treatment throughout the analysis, with the exception of grid occupancy by species. 
Table 5.6: Planting lists and survival rates for each grid. All plant species are native to New Zealand. Initial planting was done between July and August 2018, and supplementary planting (Suppl.) between September and December 2018.

\begin{tabular}{|c|c|c|c|c|c|}
\hline \multirow[t]{2}{*}{ Plant species } & \multicolumn{2}{|c|}{ Number planted } & \multirow[t]{2}{*}{ Class } & \multirow[t]{2}{*}{ Description } & \multirow[t]{2}{*}{ Survived } \\
\hline & Initial & Suppl. & & & \\
\hline \multicolumn{6}{|l|}{ WP3 } \\
\hline Disphyma australe & 11 & - & VinesO & Trailing, succulent herb & $36 \%$ \\
\hline Muehlenbeckia complexa & 23 & - & MUE & Fruiting liane & $65 \%$ \\
\hline Phormium cookianum & 10 & - & $\mathrm{PHO}$ & Nectar-bearing flax & $100 \%$ \\
\hline Pimelea prostrata & 10 & & - & Prostrate shrub & $100 \%$ \\
\hline Plagianthus divaricata & - & 18 & DIV & Divaricate & $0 \%$ \\
\hline Poa cita & 48 & 20 & GoS & Sedge & $88 \%$ \\
\hline Total & 102 & 38 & & & \\
\hline \multicolumn{6}{|l|}{ WP4 } \\
\hline Coprosma acerosa & 10 & - & DIV & Fruiting divaricate & $60 \%$ \\
\hline Coprosma propinqua & 10 & - & DIV & Fruiting divaricate & $50 \%$ \\
\hline Muehlenbeckia complexa & 20 & - & MUE & Fruiting liane & $90 \%$ \\
\hline Phormium cookianum & 20 & 12 & $\mathrm{PHO}$ & Nectar-bearing flax & $100 \%$ \\
\hline Plagianthus divaricata & - & 9 & DIV & Divaricate & $0 \%$ \\
\hline Poa cita & 40 & - & GoS & Sedge & $95 \%$ \\
\hline Total & 100 & 21 & & & \\
\hline \multicolumn{6}{|l|}{ RE2 } \\
\hline Coprosma propinqua & 8 & & DIV & Fruiting divaricate & $100 \%$ \\
\hline Coprosma repens & 20 & - & COPlg & Fruiting / nectar shrub & $80 \%$ \\
\hline Veronica [Hebe] stricta & 10 & - & - & Nectar-bearing shrub & $50 \%$ \\
\hline Muehlenbeckia complexa & 20 & - & MUE & Fruiting liane & $65 \%$ \\
\hline Phormium cookianum & 30 & - & $\mathrm{PHO}$ & Nectar-bearing flax & $77 \%$ \\
\hline Total & 88 & 0 & & & \\
\hline \multicolumn{6}{|l|}{ RE3 } \\
\hline Coprosma propinqua & 20 & - & DIV & Fruiting divaricate & $90 \%$ \\
\hline Coprosma repens & 20 & - & COPlg & Fruiting shrub & $90 \%$ \\
\hline Muehlenbeckia complexa & 20 & - & MUE & Fruiting divaricate & $35 \%$ \\
\hline Phormium cookianum & 30 & - & $\mathrm{PHO}$ & Nectar-bearing flax & $90 \%$ \\
\hline Total & 90 & 0 & & & \\
\hline \multicolumn{6}{|l|}{ HT1 } \\
\hline Disphyma australe & 20 & - & VinesO & Trailing, succulent herb & $5 \%$ \\
\hline Muehlenbeckia complexa & 30 & - & MUE & Fruiting divaricate & $83 \%$ \\
\hline Poa cita & 50 & - & GoS & Sedge & $100 \%$ \\
\hline Total & 100 & 0 & & & \\
\hline \multicolumn{6}{|l|}{ HT4 } \\
\hline Coprosma repens & 9 & - & COPlg & Fruiting shrub & $89 \%$ \\
\hline Disphyma australe & 19 & - & VinesO & Trailing, succulent herb & $5 \%$ \\
\hline Muehlenbeckia complexa & 17 & - & MUE & Fruiting liane & $47 \%$ \\
\hline Phormium cookianum & 9 & - & $\mathrm{PHO}$ & Nectar-bearing flax & $100 \%$ \\
\hline Poa cita & 39 & - & GoS & Sedge & $72 \%$ \\
\hline Total & 93 & 0 & & & \\
\hline
\end{tabular}


Table 5.7: Number of individual O. polychroma $(\mathrm{Mt}+1)$ captured per grid per season. $\mathrm{Y}=$ evidence of reproduction, $\mathrm{N}=$ no evidence of reproduction. Evidence of reproduction refers to capture of at least one pregnant female or neonate (SVL $<35 \mathrm{~mm}$; Spencer et al. (1998)) within a season.

\begin{tabular}{|c|c|c|c|c|c|c|}
\hline \multirow[t]{2}{*}{ Treatment } & \multirow[t]{2}{*}{ Grid } & \multicolumn{3}{|c|}{ Baseline } & \multirow{2}{*}{$\begin{array}{l}\text { After } \\
\text { planting } \\
\text { S4 }\end{array}$} & \multirow{2}{*}{$\begin{array}{l}\text { After planting }+ \\
\text { rocks added } \\
\text { S5 }\end{array}$} \\
\hline & & S1 & S2 & S3 & & \\
\hline Control (fenced) & WP1 & $2 \mathrm{~N}$ & $6 \mathrm{~N}$ & $11 \mathrm{Y}$ & $17 \mathrm{Y}$ & $23 \mathrm{Y}$ \\
\hline \multirow[t]{5}{*}{ Control } & WP2 & $11 \mathrm{Y}$ & $5 \mathrm{Y}$ & $4 \mathrm{~N}$ & $16 \mathrm{Y}$ & $20 Y$ \\
\hline & RE1 & $24 Y$ & $14 \mathrm{Y}$ & $7 \mathrm{~N}$ & $28 \mathrm{Y}$ & $17 \mathrm{Y}$ \\
\hline & RE4 & $39 \mathrm{Y}$ & $59 \mathrm{Y}$ & $52 \mathrm{Y}$ & $23 \mathrm{Y}$ & $24 \mathrm{Y}$ \\
\hline & HT2 & $17 \mathrm{Y}$ & $8 \mathrm{~N}$ & $6 \mathrm{Y}$ & $6 \mathrm{Y}$ & $14 \mathrm{Y}$ \\
\hline & HT3 & $8 \mathrm{~N}$ & $3 \mathrm{~N}$ & $6 \mathrm{~N}$ & $7 \mathrm{Y}$ & $10 \mathrm{~N}$ \\
\hline$\%$ occupied & & 100 & 100 & 100 & 100 & 100 \\
\hline $\begin{array}{l}\text { \% grids reproduction } \\
\text { evident }\end{array}$ & & 67 & 50 & 33 & 100 & 83 \\
\hline \multirow[t]{6}{*}{ Enhanced } & WP3 & $4 \mathrm{Y}$ & $2 Y$ & $2 \mathrm{~N}$ & $6 \mathrm{~N}$ & $12 \mathrm{~N}$ \\
\hline & WP4 & $8 \mathrm{Y}$ & $9 \mathrm{~N}$ & $6 \mathrm{~N}$ & $15 \mathrm{Y}$ & $15 \mathrm{Y}$ \\
\hline & RE2 & $32 \mathrm{Y}$ & $18 \mathrm{~N}$ & $43 \mathrm{~N}$ & $18 \mathrm{Y}$ & $25 \mathrm{Y}$ \\
\hline & RE3 & $34 \mathrm{Y}$ & $27 \mathrm{Y}$ & $23 \mathrm{Y}$ & $21 \mathrm{Y}$ & $31 \mathrm{Y}$ \\
\hline & HT1 & $4 \mathrm{Y}$ & $0 \mathrm{~N}$ & $4 \mathrm{~N}$ & $3 \mathrm{~N}$ & $4 \mathrm{Y}$ \\
\hline & HT4 & $14 \mathrm{Y}$ & $7 \mathrm{~N}$ & $3 \mathrm{~N}$ & $8 \mathrm{Y}$ & $7 Y$ \\
\hline \% occupied & & 100 & 83 & 100 & 100 & 100 \\
\hline $\begin{array}{l}\text { \% grids reproduction } \\
\text { evident }\end{array}$ & & 100 & 33 & 17 & 67 & 83 \\
\hline
\end{tabular}


Table 5.8: Number of individual W. maculata $(\mathrm{Mt}+1)$ captured per grid per season. $\mathrm{Y}=$ evidence of reproduction, $\mathrm{N}=$ no evidence of reproduction. Evidence of reproduction refers to capture of at least one pregnant female or neonate (SVL $<35 \mathrm{~mm}$; Whitaker (1982)) within a season.

\begin{tabular}{|c|c|c|c|c|c|c|}
\hline \multirow[t]{2}{*}{ Treatment } & \multirow[t]{2}{*}{ Grid } & \multicolumn{3}{|c|}{ Baseline } & \multirow{2}{*}{$\begin{array}{l}\text { After } \\
\text { planting } \\
\text { S4 }\end{array}$} & \multirow{2}{*}{$\begin{array}{l}\text { After planting + } \\
\text { rocks added } \\
\text { S5 }\end{array}$} \\
\hline & & S1 & S2 & S3 & & \\
\hline Control (fenced) & WP1 & $0 \mathrm{~N}$ & $1 \mathrm{~N}$ & $2 \mathrm{~N}$ & $4 \mathrm{Y}$ & $3 \mathrm{~N}$ \\
\hline \multirow[t]{5}{*}{ Control } & WP2 & $18 \mathrm{~N}$ & $14 \mathrm{Y}$ & $19 \mathrm{Y}$ & $28 \mathrm{Y}$ & $21 \mathrm{Y}$ \\
\hline & RE1 & $0 \mathrm{~N}$ & $0 \mathrm{~N}$ & $0 \mathrm{~N}$ & $0 \mathrm{~N}$ & $0 \mathrm{~N}$ \\
\hline & RE4 & $0 \mathrm{~N}$ & $0 \mathrm{~N}$ & $0 \mathrm{~N}$ & $0 \mathrm{~N}$ & $0 \mathrm{~N}$ \\
\hline & HT2 & $0 \mathrm{~N}$ & $6 \mathrm{~N}$ & $7 \mathrm{Y}$ & $5 \mathrm{Y}$ & $11 \mathrm{Y}$ \\
\hline & HT3 & $0 \mathrm{~N}$ & $1 \mathrm{~N}$ & $7 Y$ & $4 \mathrm{~N}$ & $4 \mathrm{~N}$ \\
\hline \% occupied & & 17 & 67 & 67 & 67 & 67 \\
\hline $\begin{array}{l}\% \text { grids reproduction } \\
\text { evident }\end{array}$ & & 0 & 17 & 50 & 50 & 33 \\
\hline \multirow[t]{6}{*}{ Enhanced } & WP3 & $1 \mathrm{~N}$ & $1 Y$ & $4 \mathrm{Y}$ & $27 \mathrm{Y}$ & $15 \mathrm{Y}$ \\
\hline & WP4 & $0 \mathrm{~N}$ & $1 \mathrm{~N}$ & $0 \mathrm{~N}$ & $0 \mathrm{~N}$ & $6 Y$ \\
\hline & RE2 & $0 \mathrm{~N}$ & $1 \mathrm{~N}$ & $1 \mathrm{~N}$ & $0 \mathrm{~N}$ & $2 \mathrm{~N}$ \\
\hline & RE3 & $0 \mathrm{~N}$ & $1 \mathrm{~N}$ & $1 \mathrm{~N}$ & $3 Y$ & $10 \mathrm{Y}$ \\
\hline & HT1 & $0 \mathrm{~N}$ & $0 \mathrm{~N}$ & $3 Y$ & $1 \mathrm{~N}$ & $4 \mathrm{~N}$ \\
\hline & HT4 & $2 Y$ & $0 \mathrm{~N}$ & $3 \mathrm{~N}$ & $1 \mathrm{~N}$ & $1 \mathrm{~N}$ \\
\hline$\%$ occupied & & 33 & 67 & 83 & 67 & 100 \\
\hline $\begin{array}{l}\% \text { grids reproduction } \\
\text { evident }\end{array}$ & & 17 & 17 & 33 & 33 & 50 \\
\hline
\end{tabular}


Table 5.9: Number of individual O. aeneum $(\mathrm{Mt}+1)$ captured per grid per season. $\mathrm{Y}=$ evidence of reproduction, $\mathrm{N}=$ no evidence of reproduction. Evidence of reproduction refers to capture of at least one pregnant female or neonate (SVL $<35 \mathrm{~mm}$; Barwick (1959); Bell et al. (2018)) within a season.

\begin{tabular}{|c|c|c|c|c|c|c|}
\hline \multirow[t]{2}{*}{ Treatment } & \multirow[t]{2}{*}{ Grid } & \multicolumn{3}{|c|}{ Baseline } & \multirow{2}{*}{$\begin{array}{l}\text { After } \\
\text { planting } \\
\text { S4 }\end{array}$} & \multirow{2}{*}{$\begin{array}{l}\text { After planting }+ \\
\text { rocks added } \\
\text { S5 }\end{array}$} \\
\hline & & S1 & S2 & S3 & & \\
\hline Control (fenced) & WP1 & $0 \mathrm{~N}$ & $0 \mathrm{~N}$ & $0 \mathrm{~N}$ & $0 \mathrm{~N}$ & $0 \mathrm{~N}$ \\
\hline \multirow[t]{5}{*}{ Control } & WP2 & $0 \mathrm{~N}$ & $0 \mathrm{~N}$ & $0 \mathrm{~N}$ & $0 \mathrm{~N}$ & $0 \mathrm{~N}$ \\
\hline & RE1 & $19 \mathrm{Y}$ & $1 \mathrm{~N}$ & $0 \mathrm{~N}$ & $15 \mathrm{Y}$ & $11 \mathrm{Y}$ \\
\hline & RE4 & $0 \mathrm{~N}$ & $0 \mathrm{~N}$ & $0 \mathrm{~N}$ & $6 \mathrm{Y}$ & $13 \mathrm{Y}$ \\
\hline & HT2 & $0 \mathrm{~N}$ & $0 \mathrm{~N}$ & $0 \mathrm{~N}$ & $0 \mathrm{~N}$ & $0 \mathrm{~N}$ \\
\hline & HT3 & $0 \mathrm{~N}$ & $0 \mathrm{~N}$ & $0 \mathrm{~N}$ & $0 \mathrm{~N}$ & $0 \mathrm{~N}$ \\
\hline$\%$ occupied & & 17 & 17 & 0 & 33 & 33 \\
\hline $\begin{array}{l}\% \text { grids reproduction } \\
\text { evident }\end{array}$ & & 17 & 0 & 0 & 33 & 33 \\
\hline \multirow[t]{6}{*}{ Enhanced } & WP3 & $0 \mathrm{~N}$ & $0 \mathrm{~N}$ & $0 \mathrm{~N}$ & $0 \mathrm{~N}$ & $0 \mathrm{~N}$ \\
\hline & WP4 & $0 \mathrm{~N}$ & $0 \mathrm{~N}$ & $0 \mathrm{~N}$ & $0 \mathrm{~N}$ & $0 \mathrm{~N}$ \\
\hline & RE2 & $19 Y$ & $6 Y$ & $4 \mathrm{~N}$ & $21 \mathrm{Y}$ & $21 \mathrm{Y}$ \\
\hline & RE3 & $0 \mathrm{~N}$ & $0 \mathrm{~N}$ & $0 \mathrm{~N}$ & $1 \mathrm{~N}$ & $1 \mathrm{~N}$ \\
\hline & HT1 & $0 \mathrm{~N}$ & $0 \mathrm{~N}$ & $0 \mathrm{~N}$ & $0 \mathrm{~N}$ & $0 \mathrm{~N}$ \\
\hline & HT4 & $0 \mathrm{~N}$ & $0 \mathrm{~N}$ & $0 \mathrm{~N}$ & $0 \mathrm{~N}$ & $0 \mathrm{~N}$ \\
\hline \% occupied & & 17 & 17 & 17 & 33 & 33 \\
\hline $\begin{array}{l}\text { \% grids reproduction } \\
\text { evident }\end{array}$ & & 17 & 17 & 0 & 17 & 17 \\
\hline
\end{tabular}



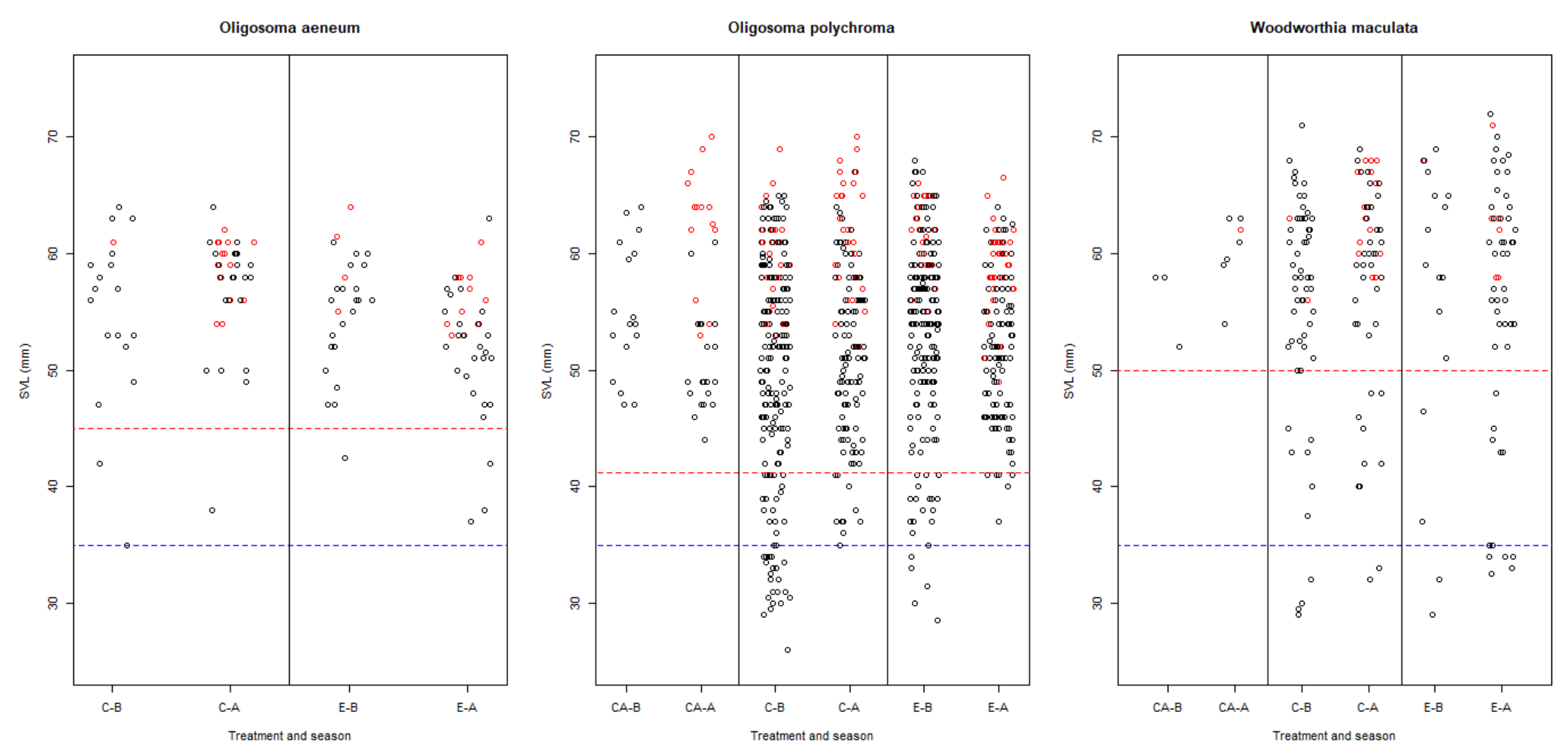

Figure 5.2: Body size as snout-vent length (SVL) of individuals captured before and after enhancement commenced in July 2018. Pregnant females are indicated by red points. Points have been jittered along the x-axis to improve visibility. The blue dashed line is the maximum size of neonates (young-of-the-year) and the red dashed line is the maximum size of juveniles (immature animals), after Barwick (1959); Whitaker (1982); Spencer et al. (1998); and Bell et al. (2018). Treatment: C = control, E = enhancement, CA = control grid WP1 in which habitat change occurred due to cessation of mowing. Oligosoma aeneum was not found at WP1, therefore treatment is only split into control and enhanced in the figure for this species. Season: B = before enhancement (3 survey sessions: November 2017-April 2018), A = after enhancement (2 survey sessions: November-December 2018 (after planting) and October-November 2019 (after planting and addition of rocks). 


\subsubsection{Stage 1 assessment: responses of habitat use and body condition to enhancement}

Patch occupancy of lizard species was the same between treatments after the enhancements had been applied, with the exception of $W$. maculata, which occupied all enhanced grids after the addition of plants and rocks compared to $63 \%$ of the control grids (Tables 5.7, 5.8, and 5.9). However, there was no significant difference in patch occupancy of any lizard species between treatments either before (binomial GLMM: all $|z|<0.38, p>0.70$ ) or after (all $|z|<0.45, p>0.65$ ) enhancement. Grid occupancy by O. aeneum post-enhancement was higher than pre-enhancement occupancy across all RE grids (estimate $=53.33, \mathrm{SE}=21.56$, $\mathrm{z}=2.47, \mathrm{p}=0.01$ ). There was no significant difference in grid occupancy of $O$. polychroma and $W$. maculata pre- versus post-enhancement (all $|z|<0.55, p>0.58$ ). Models with an interaction effect between 'Treatment' and 'Before/After (BA)' were not supported by the AIC, indicating that enhancement did not have a significant effect on body condition in any of the lizard species (Table 5.10).

\subsubsection{Stage 2 assessment: reproduction}

The proportion of grids in which reproduction was evident (indicated by the presence of at least one neonate or pregnant female) in W. maculata and O. aeneum post-enhancement was the same or higher than pre-enhancement (Tables 5.8 and 5.9). In O. polychroma, the proportion of control grids with evidence of reproduction exceeded the maximum pre-enhancement, but evidence of reproduction was found in fewer treatment grids post-enhancement than pre-enhancement (Table 5.7).

Binomial GLMMs for the presence or absence of evidence for reproduction with either 'BA' or 'Treatment + BA' were strongly supported for O. polychroma and O. aeneum (Table 5.11). The additive effect of control vs enhancement was not statistically significant for either skink species $(O$. aeneum: estimate (enhancement) $=-0.88, \mathrm{SE}=5.05, \mathrm{z}=-0.18, \mathrm{p}=$ 0.86; O. polychroma: estimate(enhancement) $=-0.02, \mathrm{SE}=0.84, \mathrm{z}=-0.02, \mathrm{p}=0.99$ ). In the models with 'BA' as the only fixed factor, the number of grids per session with evidence of reproduction detected was higher in the 'after enhancement' survey seasons, but the difference was not significant at $\alpha=0.05$ (O. aeneum: estimate(Before) $=-9.51, \mathrm{SE}=5.59, \mathrm{z}=$ -1.70, $\mathrm{p}=0.09 ;$ O. polychroma: estimate (Before) $=-3.52, \mathrm{SE}=2.34, \mathrm{z}=-1.50, \mathrm{p}=0.13$ ). Models with 'BA' or 'Treatment' as fixed factors and the null model were strongly supported for $W$. maculata (Table 5.11). However, the effects of BA (estimate(Before) $=0.28, \mathrm{SE}=1.61, \mathrm{z}=$ $0.17, \mathrm{p}=0.86$ ) and Treatment (estimate(Enhancement treatment) $=0.08, \mathrm{SE}=1.17, \mathrm{z}=0.07$, $\mathrm{p}=0.94)$ were not significant. Therefore, there was no evidence of enhancement affecting lizard reproduction. 
Table 5.10: Models trialled (Gaussian GLMM) and selection criteria for BACI analysis of body condition of lizards in enhancement and control grids. Measurements taken from pregnant females were excluded from this analysis. The response variable for all models is $\ln$ (Weight). Abbreviations: $\mathrm{df}=$ degrees of freedom, $\mathrm{SVL}=$ snout-vent length of lizards, $\mathrm{BA}$ $=$ Before or After enhancement started in June 2018 .

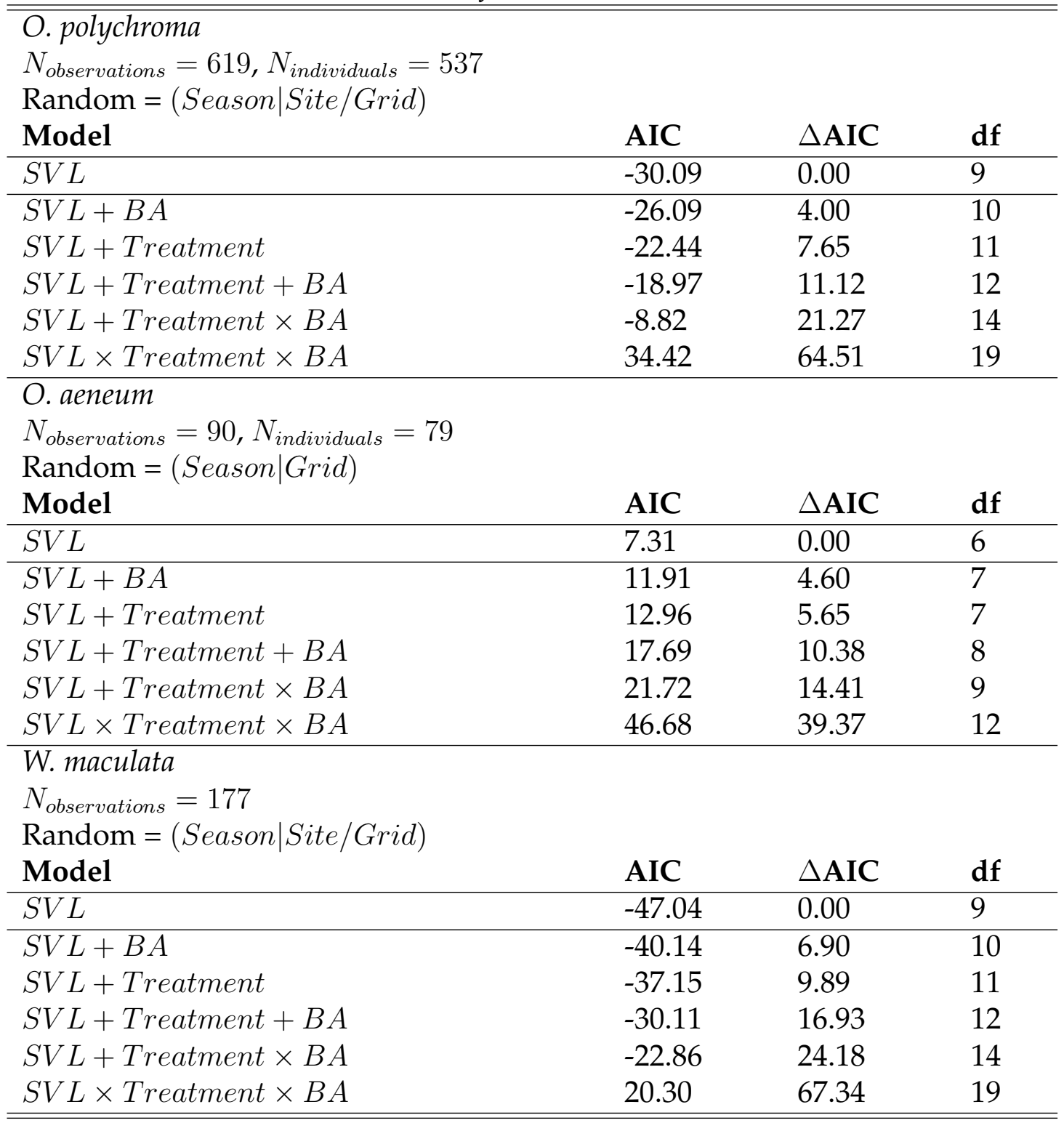


Table 5.11: Models trialled (Binomial GLMM) and selection criteria for BACI analysis of evidence for reproduction in enhancement and control grids. The response variable for all models is $0=$ no pregnant females or neonates detected or $1=$ pregnant females or neonates detected. Abbreviations: $\mathrm{df}=$ degrees of freedom, $\mathrm{SVL}=$ snout-vent length of lizards, BA $=$ Before or After enhancement started in June 2018. $N_{\text {repeatedobservations }}=60, N_{\text {grids }}=$ 12. Model structure of random variables was simplified from an original structure of (Season|Site/Grid) for O. polychroma andW. maculata, and (Season|Grid) for O. aeneum due to problems with models with a more complex random structure being nearly unidentifiable or failing to converge.

\begin{tabular}{llll}
\hline $\begin{array}{l}\text { Oligosoma polychroma } \\
\text { Random }=(\text { Season } \mid \text { Grid })\end{array}$ & & & \\
Model & AIC & $\Delta$ AIC & df \\
\hline$B A$ & 81.98 & 0.00 & 5 \\
Treatment $+B A$ & 83.98 & 2.00 & 6 \\
\hline Treatment $\times$ BA & 85.92 & 3.94 & 7 \\
1 & 87.62 & 5.64 & 4 \\
Treatment & 89.54 & 7.56 & 5 \\
\hline Oligosoma aeneum & & & \\
Random $=(1 \mid$ Grid $)$ & & & \\
Model & AIC & $\Delta \mathbf{A I C}$ & $\mathbf{d f}$ \\
\hline BA & 30.65 & 0.00 & 3 \\
Treatment + BA & 32.62 & 1.97 & 4 \\
\hline Treatment $\times$ BA & 33.92 & 3.27 & 5 \\
1 & 39.35 & 8.70 & 2 \\
Treatment & 41.27 & 10.62 & 3 \\
\hline Woodworthia maculata & & & \\
Random $=($ Season $\mid$ Grid $)$ & & & \\
Model & AIC & $\Delta \mathbf{A I C}$ & $\mathbf{d f}$ \\
\hline 1 & 67.44 & 0.00 & 4 \\
BA & 69.41 & 1.97 & 5 \\
Treatment & 69.44 & 2.00 & 5 \\
\hline Treatment + BA & 71.41 & 3.97 & 6 \\
Treatment $\times$ BA & 73.31 & 5.87 & 7 \\
\hline \hline
\end{tabular}

\subsubsection{Stage 3 assessment: population responses to enhancement}

\section{Northern grass skink Oligosoma polychroma}

Two models were strongly supported by the AICc (Table 5.12). Both of these models included an interaction effect between treatment and before/after enhancement $\left(\mathrm{E}^{*} \mathrm{~A}\right)$ on survival. Model-averaged individual detection probability from these models was $0.219 \pm$ one standard error (SE) of 0.053. Monthly pre-enhancement survival rates in both control and enhancement grids (0.858 \pm SE of 0.077 , and $0.728 \pm 0.077$, respectively) were lower than post-enhancement survival (control: $0.906 \pm 0.020$, enhancement: $0.933 \pm 0.024$ ). However, the magnitude of increase in O. polychroma survival was higher in enhancement 
grids, and the difference between pre- and post-enhancement survival was only significant in enhancement grids (Fig. 5.3). These monthly survival rates translate into annual pre-enhancement apparent survival rates of $15.8 \%$ (95\% confidence interval $(\mathrm{CI})=$ $0.45-56.7 \%)$ in control grids and $2.22 \%(\mathrm{CI}=0.09-14.5 \%)$ in enhancement grids. Annual post-enhancement survival rates were 30.6\% (CI $=15.8-47.1 \%)$ in control grids and $43.3 \%$ $(\mathrm{CI}=17.8-67.1 \%)$ in enhancement grids. The most strongly supported candidate models included effects of time and site on the probability of individuals entering the population by birth or immigration $\left(p_{\text {ent }}\right)$, but there was uncertainty around whether this was an additive or interactive effect (Table 5.12). Estimates averaged from the two strongly supported models were not different at 3 decimal places, suggesting a weak interaction effect. The average $p_{\text {ent }}$ at each site increased over time, but with varying rates (Fig. 5.4). The strongest increase over time was in the Wahine Park grids, and the weakest in the Rangitatau grids, but neither of these resulted in significantly different $p_{\text {ent }}$ values among time periods (Fig. 5.4). Despite the relatively moderate rate of increase in $p_{\text {ent }}$ at Hue Te Taka, there was a significant difference between the first and final periods (Fig. 5.4). The differences in apparent survival between treatments and $p_{\text {ent }}$ between sites resulted in different trajectories in O. polychroma abundance among the six unique site and treatment combinations (Fig. 5.5). However, none of the within-grid changes in abundance were significantly different between any two time periods (Table 5.13). 
Table 5.12: POPAN models trialled and selection criteria for northern grass skink (Oligosoma polychroma) mark-recapture data. $\phi=$ apparent survival probability (deaths + emigration), $p$ $=$ individual detection probability, $p_{\text {ent }}=$ probability of entry (births + immigration), $\mathrm{SVL}=$ body size as snout-vent length in $\mathrm{mm}, \mathrm{E}=$ enhancement treatment applied to grid, $\mathrm{A}=\mathrm{after}$ enhancement, $\mathrm{t}=$ independent fluctuation between time periods, site $=$ whether the grid was placed in RE, MP or WP, $g$ = grid, Weight = AICc weight, Pars. = number of parameters. The horizontal line separates supported models $(\triangle \mathrm{AICc} \leq 6.00)$ from models with lower levels of support.

\begin{tabular}{lccccc}
\hline \hline Model & AICc & $\Delta$ AICc & Weight & Likelihood & Pars. \\
\hline$\phi(S V L+E * A) p(.) p_{\text {ent }}($ site $* t) N(g * t)$ & 1017.2 & 0.0000 & 0.4542 & 1.0000 & 30 \\
$\phi(S V L+E * A) p(.) p_{\text {ent }}($ site $+t) N(g * t)$ & 1017.5 & 0.2913 & 0.3926 & 0.8645 & 24 \\
$\phi(S V L+E+A) p(.) p_{\text {ent }}($ site $* t) N(g * t)$ & 1019.4 & 2.1865 & 0.1522 & 0.3351 & 29 \\
\hline$\phi(S V L+E+A) p(.) p_{\text {ent }}(g * t) N(g * t)$ & 1030.9 & 13.654 & 0.0005 & 0.0011 & 65 \\
$\phi(S V L+E * A) p(.) p_{\text {ent }}(g * t) N(g * t)$ & 1031.4 & 14.123 & 0.0004 & 0.0009 & 66 \\
$\phi(S V L+E * A) p(t) p_{\text {ent }}(g * t) N(g * t)$ & 1035.9 & 18.626 & 0.0000 & 0.0001 & 70 \\
$\phi(S V L+E * A) p(E+t) p_{\text {ent }}(g * t) N(g * t)$ & 1037.9 & 20.701 & 0.0000 & 0.0000 & 71 \\
$\phi(S V L+E * A) p(E * t) p_{\text {ent }}(g * t) N(g * t)$ & 1042.9 & 25.665 & 0.0000 & 0.0000 & 75 \\
$\phi(S V L+E * A) p(.) p_{\text {ent }}(E * t) N(g * t)$ & 1043.8 & 26.583 & 0.0000 & 0.0000 & 26 \\
$\phi(S V L+E * A) p(\operatorname{site} * t) p_{\text {ent }}(g * t) N(g * t)$ & 1049.8 & 32.525 & 0.0000 & 0.0000 & 80 \\
$\phi() p.(.) p_{\text {ent }}() N.(g * t)$ & 1078.0 & 60.779 & 0.0000 & 0.0000 & 15 \\
$\phi(S V L+E * A) p(g * t) p_{\text {ent }}(g * t) N(g * t)$ & 1133.1 & 115.87 & 0.0000 & 0.0000 & 125 \\
$\phi(S V L+E+A) p(g * t) p_{\text {ent }}(g * t) N(g * t)$ & 1136.2 & 118.92 & 0.0000 & 0.0000 & 124 \\
$\phi(S V L+E * t) p(g * t) p_{\text {ent }}(g * t) N(g * t)$ & 1137.1 & 119.89 & 0.0000 & 0.0000 & 128 \\
$\phi(S V L+\operatorname{site} * t) p(g * t) p_{\text {ent }}(g * t) N(g * t)$ & 1147.3 & 130.10 & 0.0000 & 0.0000 & 133 \\
$\phi(S V L+g * t) p(g * t) p_{\text {ent }}(g * t) N(g * t)$ & 1210.8 & 193.61 & 0.0000 & 0.0000 & 169 \\
\hline \hline
\end{tabular}




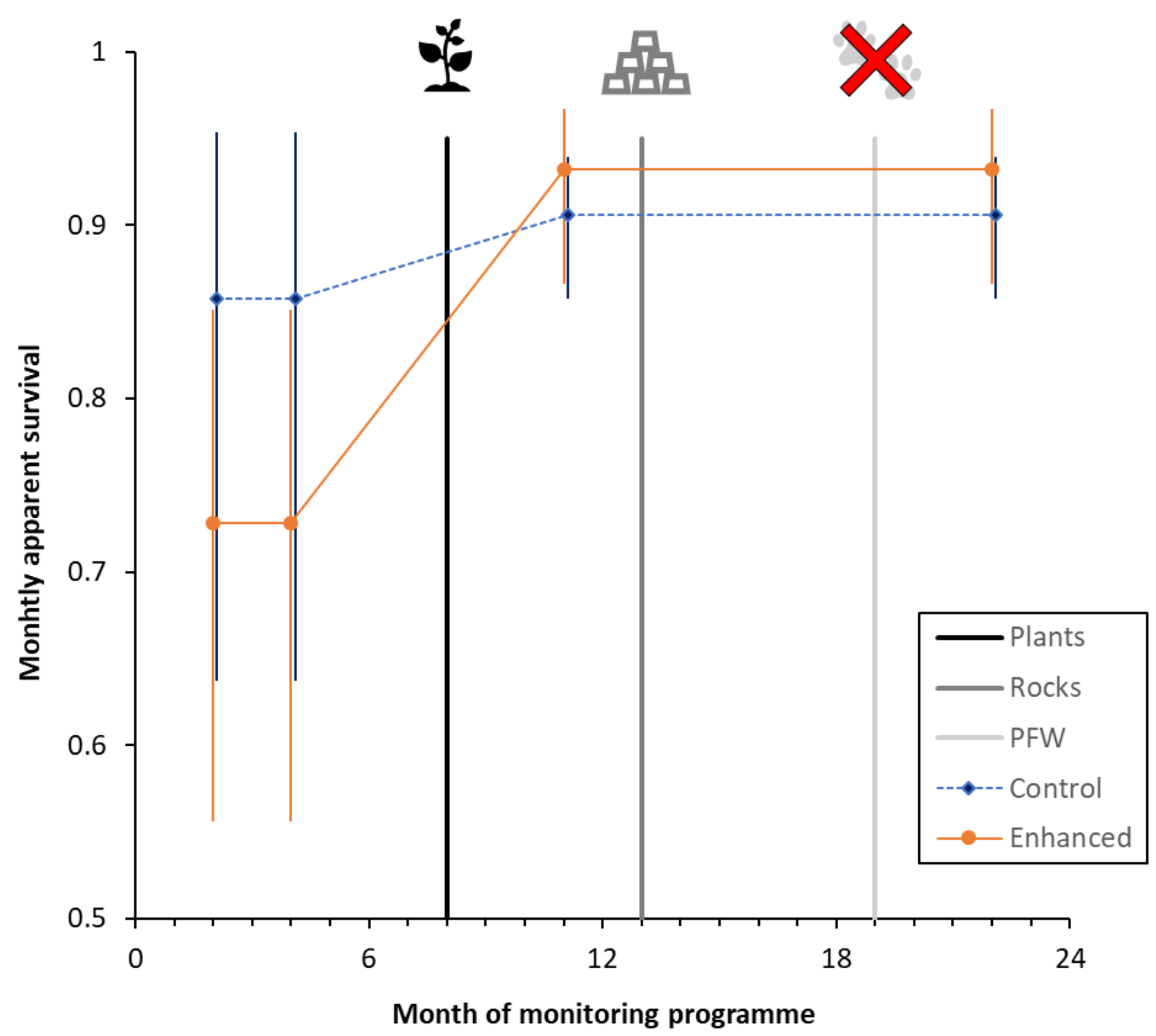

Figure 5.3: Estimated apparent survival of northern grass skinks (O. polychroma) between each monitoring session in control and enhanced grids. Intervals are, from left to right: (1) Nov/Dec 2017 - Jan/Feb 2018 (2 months), (2) Jan/Feb 2018 - Mar/Apr 2018 (2 months), (3) Mar/Apr 2018 - Nov/Dec 2018 (7 months), Nov/Dec 2018 - Oct/Nov 2019 (11 months). Error bars are $\pm 95 \%$ confidence intervals. Management interventions are indicated by vertical lines. Black: Completion of planting at enhancement grids in August 2018. Grey: Completion of rock pile construction at enhancement grids in January 2019. Light grey: Start of Predator Free Wellington rat and mustelid eradication programme across Miramar in July 2019. Points have been jittered along the $x$ axis. 
Hue Te Taka

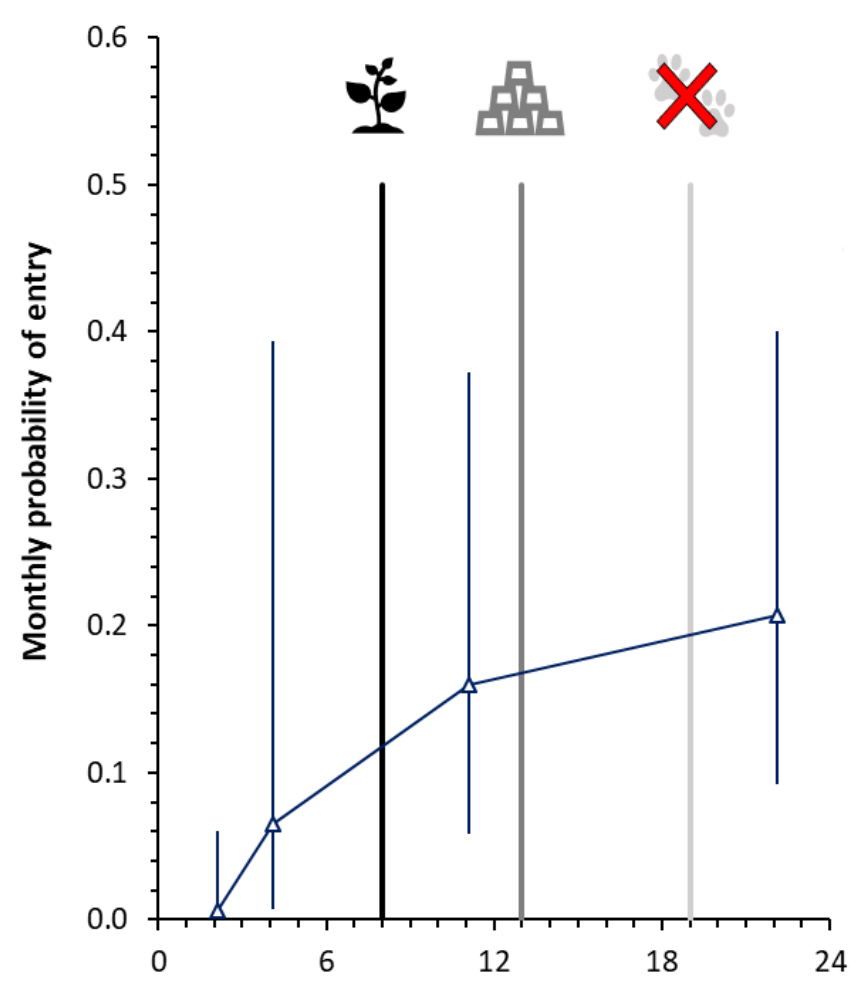

Rangitatau Reserve Escarpment

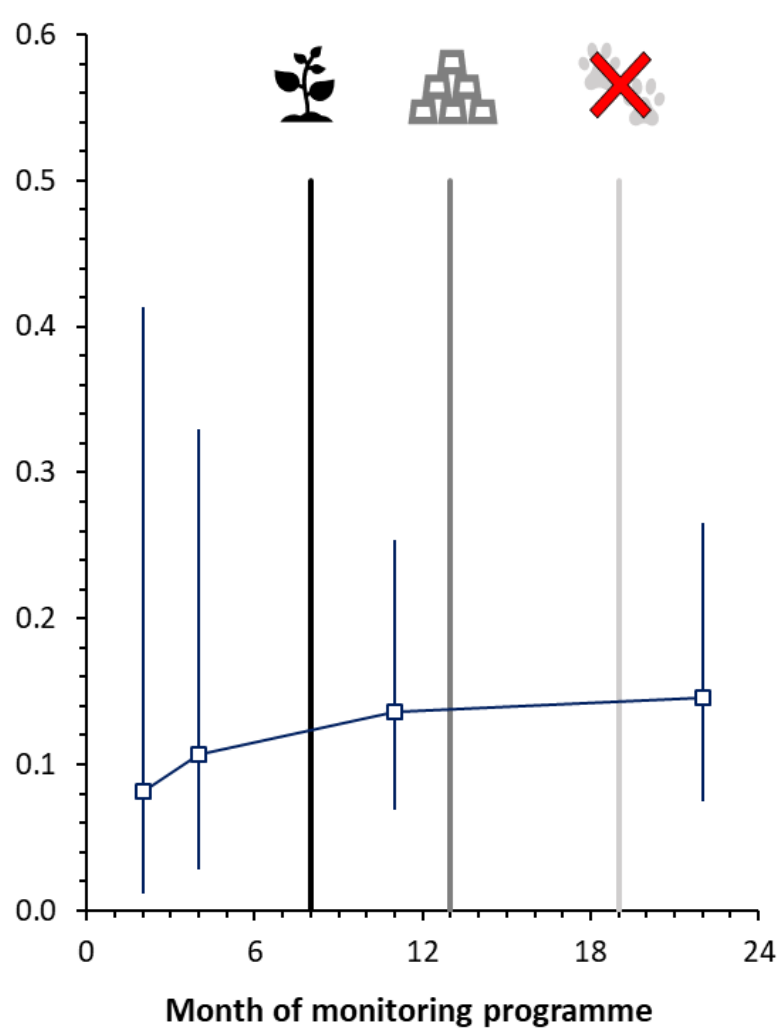

Wahine Park

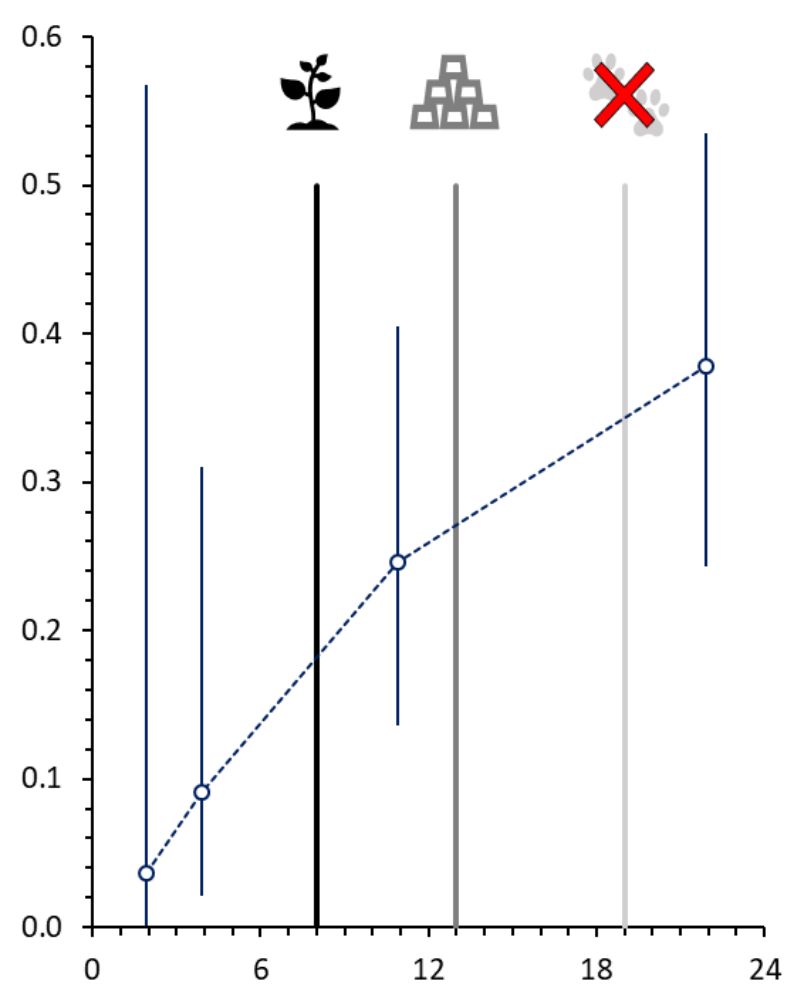

Figure 5.4: Average monthly probabilities of entry of northern grass skinks (O. polychroma) into monitoring grids at each study site. Intervals are, from left to right: (1) Nov/Dec 2017 - Jan/Feb 2018 (2 months), (2) Jan/Feb 2018 - Mar/Apr 2018 (2 months), (3) Mar/Apr 2018 - Nov/Dec 2018 (7 months), Nov/Dec 2018 - Oct/Nov 2019 (11 months). Management interventions are indicated by vertical lines. Black: Completion of planting at enhancement grids in August 2018. Grey: Completion of rock pile construction at enhancement grids in January 2019. Light grey: Start of Predator Free Wellington rat and mustelid eradication programme across Miramar in July 2019. Error bars are the 95\% confidence interval. 
Hue Te Taka

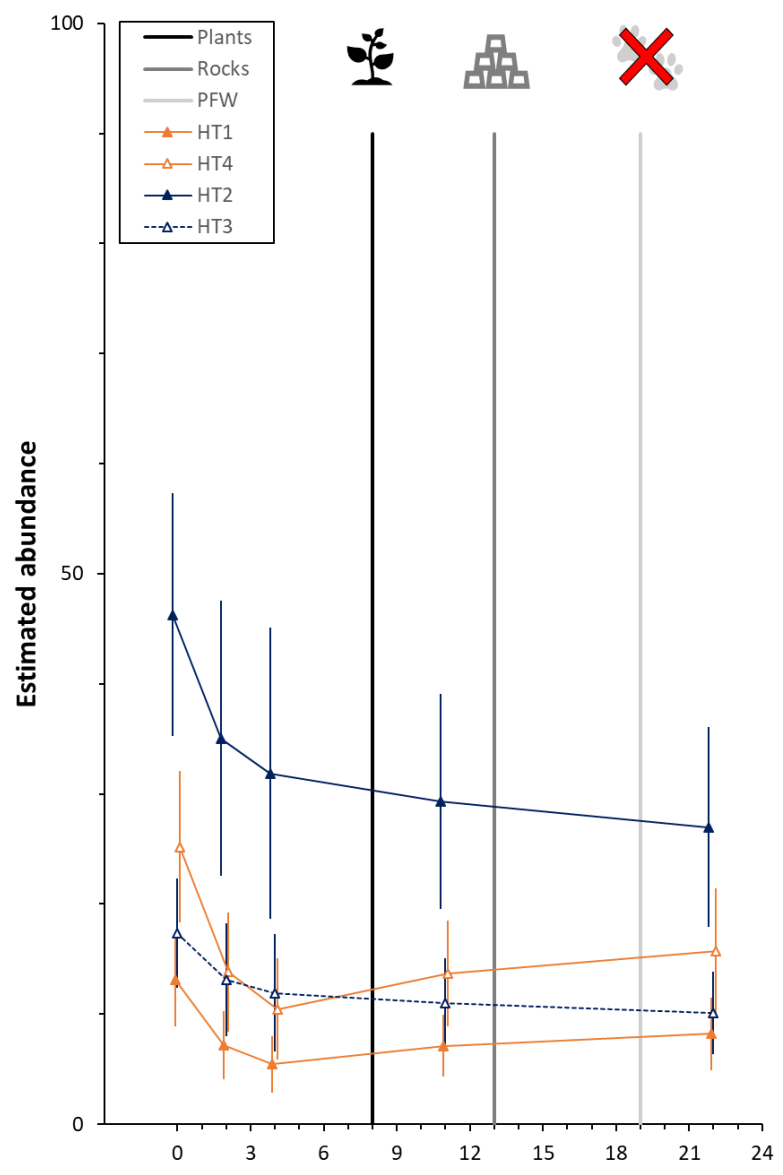

Rangitatau River Escarpment

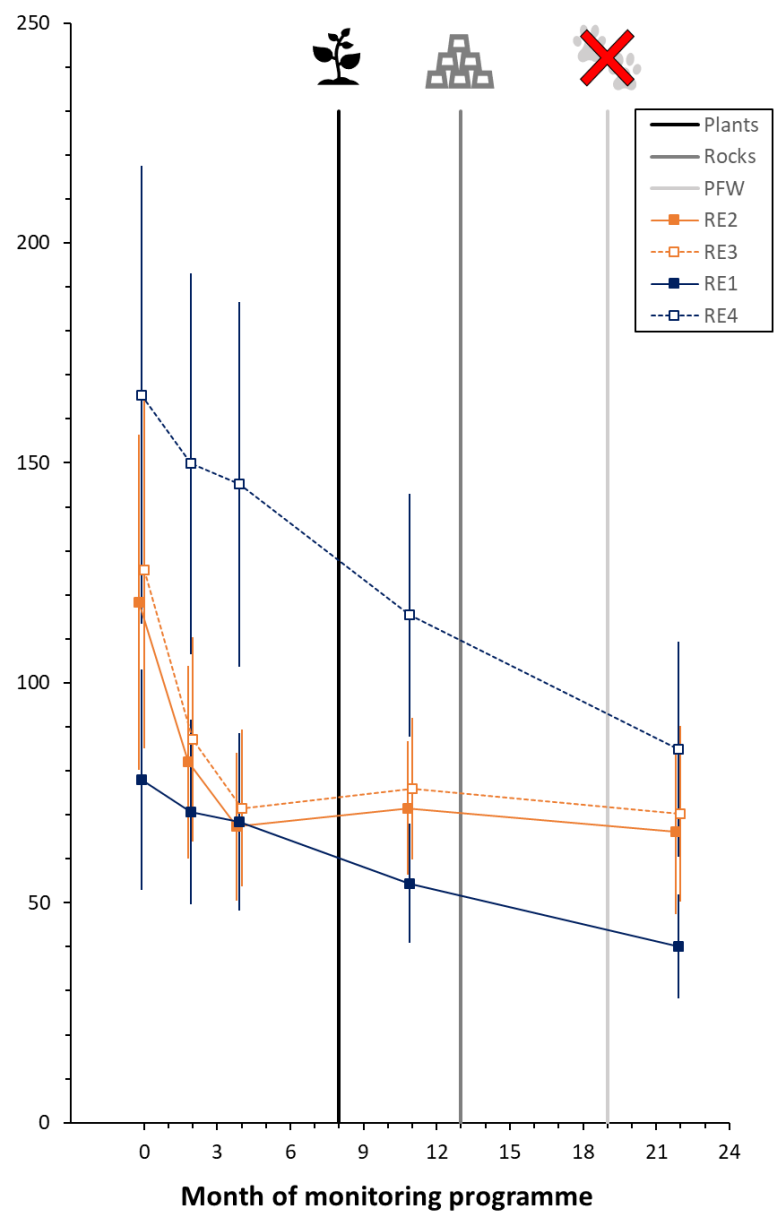

Wahine Park

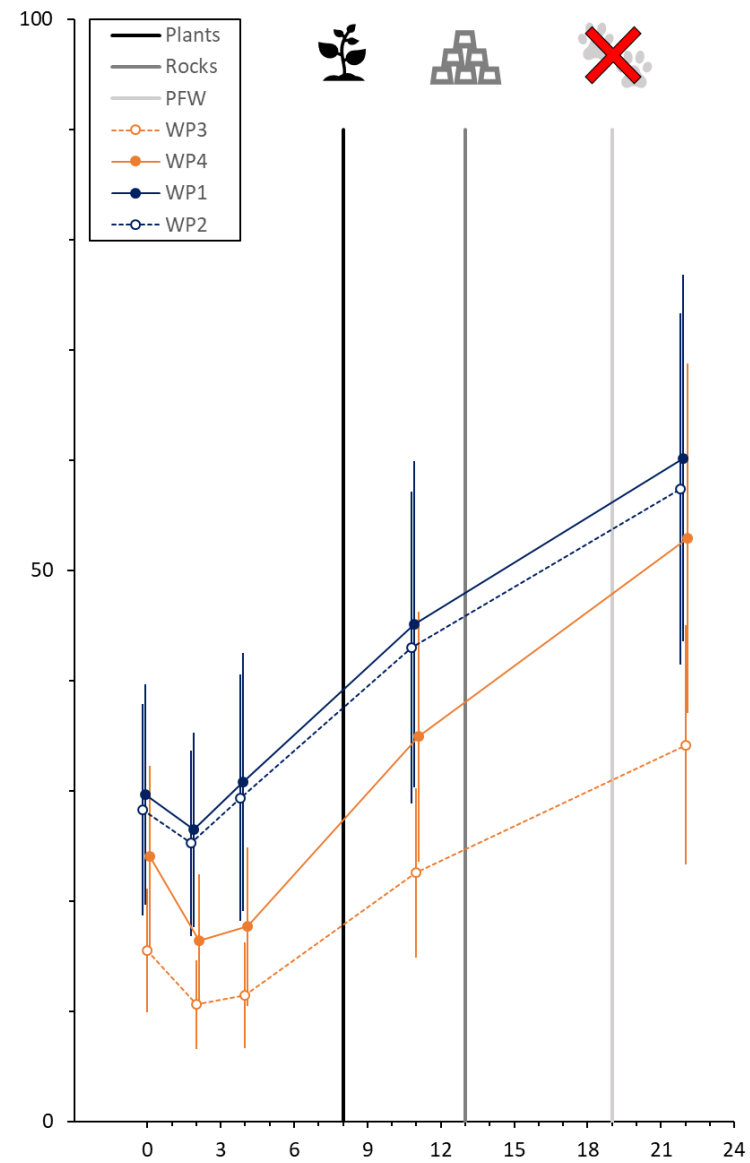

Figure 5.5: Estimated abundance of northern grass skinks (O. polychroma) in each grid by monitoring session (November 2017 November 2019). Control grids are in navy blue and enhanced grids in orange. The grids are divided into three graphs by study site (L-R): Hue-Te-Taka (HT), Rangitatau Reserve escarpment (RE) and Wahine Park (WP). Note the different scale on the y axis in the graph displaying abudnance in the RE grids. Error bars are \pm one standard error. Management interventions are indicated by vertical lines. Black: Completion of planting at enhancement grids in August 2018. Grey: Completion of rock pile construction at enhancement grids in January 2019. Light grey: Start of Predator Free Wellington rat and mustelid eradication programme across Miramar in July 2019. Points have been jittered along the $x$ axis. 
Table 5.13: Estimated abundance $(\hat{N})$ of northern grass skinks (O. polychroma) in grids for each monitoring session (November 2017 - November 2019). Site abbreviations: WP = Wahine Park, RE = Rangitatau Reserve Escarpment, HT = Hue-Te-Taka.

\begin{tabular}{|c|c|c|c|c|c|c|c|}
\hline Control & & & & "Enhancement & & & \\
\hline Grid & Month & $\hat{N}$ & $95 \% \mathrm{CI}$ & Grid & Month & $\hat{N}$ & $95 \% \mathrm{CI}$ \\
\hline \multirow[t]{5}{*}{ WP1 } & 0 & 30 & $10-49$ & WP3 & 0 & 15 & $5-26$ \\
\hline & 2 & 26 & $9-44$ & & 2 & 11 & $3-18$ \\
\hline & 4 & 31 & $8-54$ & & 4 & 11 & $2-21$ \\
\hline & 11 & 45 & $16-74$ & & 11 & 23 & $7-38$ \\
\hline & 22 & 60 & $28-93$ & & 22 & 34 & $13-55$ \\
\hline \multirow[t]{5}{*}{ WP2 } & 0 & 28 & $10-47$ & WP4 & 0 & 24 & $8-40$ \\
\hline & 2 & 25 & $9-42$ & & 2 & 16 & $5-28$ \\
\hline & 4 & 29 & $7-51$ & & 4 & 18 & $4-32$ \\
\hline & 11 & 43 & $15-71$ & & 11 & 35 & $13-57$ \\
\hline & 22 & 57 & $26-89$ & & 22 & 53 & $22-84$ \\
\hline \multirow[t]{5}{*}{ RE1 } & 0 & 78 & $29-127$ & RE2 & 0 & 118 & $44-193$ \\
\hline & 2 & 71 & $29-112$ & & 2 & 82 & $39-125$ \\
\hline & 4 & 68 & $29-108$ & & 4 & 67 & $34-100$ \\
\hline & 11 & 54 & $28-81$ & & 11 & 72 & $42-101$ \\
\hline & 22 & 40 & $17-63$ & & 22 & 66 & $29-103$ \\
\hline \multirow[t]{5}{*}{ RE4 } & 0 & 165 & $64-267$ & RE3 & 0 & 126 & $46-205$ \\
\hline & 2 & 150 & $65-235$ & & 2 & 87 & $42-133$ \\
\hline & 4 & 145 & $64-227$ & & 4 & 72 & $37-106$ \\
\hline & 11 & 115 & $61-170$ & & 11 & 76 & $44-107$ \\
\hline & 22 & 85 & $37-133$ & & 22 & 70 & $31-109$ \\
\hline \multirow[t]{5}{*}{ HT2 } & 0 & 46 & $25-68$ & HT1 & 0 & 13 & $5-21$ \\
\hline & 2 & 35 & $11-59$ & & 2 & 7 & $1-13$ \\
\hline & 4 & 32 & $6-58$ & & 4 & 5 & $0-10$ \\
\hline & 11 & 29 & $10-48$ & & 11 & 7 & $2-13$ \\
\hline & 22 & 27 & $9-45$ & & 22 & 8 & $2-15$ \\
\hline \multirow[t]{5}{*}{ HT3 } & 0 & 17 & $8-27$ & HT4 & 0 & 25 & $12-39$ \\
\hline & 2 & 13 & $3-23$ & & 2 & 14 & $3-24$ \\
\hline & 4 & 12 & $1-22$ & & 4 & 10 & $1-19$ \\
\hline & 11 & 11 & $3-19$ & & 11 & 14 & $4-23$ \\
\hline & 22 & 10 & $3-18$ & & 22 & 16 & $5-27$ \\
\hline
\end{tabular}

\section{Copper skink Oligosoma aeneum}

Inference about populations of $O$. aeneum was restricted to the RE grids, as this was the only site in which this species was detected. Models for O. aeneum that included a full $\left(g^{*} t\right)$ or simplified $\left(E^{*} t\right.$ or $\left.E^{*} A\right)$ interaction effect for survival or $p_{\text {ent }}$ were not supported by the AICc (Table 5.14). Only one model was strongly supported (Table 5.14). This model suggested that monthly apparent survival rates had increased from an average of 0.918 ( \pm one standard error (SE) of $0.526 \times 10^{-6}$ ) between November 2017 and April 2018, to 1.000 $( \pm 0.000)$ between May 2018 and November 2019. This corresponds to an increase in annual 
Table 5.14: POPAN models trialled and selection criteria for copper skink (Oligosoma aeneum) mark-recapture data. $\phi=$ apparent survival probability (deaths + emigration), $\mathrm{p}$ $=$ individual detection probability, $p_{\text {ent }}=$ probability of entry (births + immigration), $\mathrm{SVL}=$ body size as snout-vent length in $\mathrm{mm}, \mathrm{E}=$ enhancement treatment applied to grid, $\mathrm{A}=$ after enhancement, $\mathrm{t}=$ independent fluctuation between time periods, $\mathrm{g}=$ grid, Weight $=$ AICc weight, Pars. = number of parameters. The horizontal line separates strongly supported models $(\triangle \mathrm{AICc} \leq 2.00)$ from models with lower levels of support.

\begin{tabular}{lccccc}
\hline \hline Model & AICc & $\Delta$ AICc & Weight & Likelihood & Pars. \\
\hline$\phi(A), p(t), p_{\text {ent }}(t), N(g * t)$ & 254.44 & 0.0000 & 0.6335 & 1.0000 & 15 \\
\hline$\phi() p.(t) p_{\text {ent }}() N.(g * t)$ & 256.58 & 2.1432 & 0.2169 & 0.3425 & 11 \\
$\phi(A) p(t) p_{\text {ent }}() N.(g * t)$ & 258.75 & 4.3046 & 0.0736 & 0.1162 & 12 \\
$\phi(E+A) p(t) p_{\text {ent }}(t) N(g * t)$ & 259.31 & 4.8724 & 0.0554 & 0.0875 & 16 \\
$\phi(E * A) p(t) p_{\text {ent }}(t) N(g * t)$ & 262.68 & 8.2410 & 0.0103 & 0.0162 & 17 \\
$\phi(E * A) p(t) p_{\text {ent }}() N.(g * t)$ & 263.42 & 8.9806 & 0.0071 & 0.0112 & 14 \\
$\phi(E * A) p(t) p_{\text {ent }}(E+t) N(g * t)$ & 265.29 & 10.849 & 0.0028 & 0.0044 & 18 \\
$\phi(E * A) p(t) p_{\text {ent }}(E * t) N(g * t)$ & 270.85 & 16.409 & 0.0002 & 0.0003 & 21 \\
$\phi(E * A) p(E+t) p_{\text {ent }}(E * A) N(g * t)$ & 271.03 & 16.585 & 0.0002 & 0.0003 & 18 \\
$\phi(E * A) p(E+t) p$ ent $(E * t) N(g * t)$ & 274.08 & 19.639 & 0.0000 & 0.0000 & 22 \\
$\phi(A) p(.) p_{\text {ent }}(t) N(g * t)$ & 282.34 & 27.874 & 0.0000 & 0.0000 & 11 \\
$\phi(E * t) p(E+t) p_{\text {ent }}(E * t) N(g * t)$ & 285.10 & 30.658 & 0.0000 & 0.0000 & 26 \\
$\phi(E * t) p(E * t) p_{\text {ent }}(E * t) N(g * t)$ & 299.41 & 44.967 & 0.0000 & 0.0000 & 30 \\
$\phi() p.(.) p_{\text {ent }}() N.(g * t)$ & 319.05 & 64.606 & 0.0000 & 0.0000 & 7 \\
$\phi(g * t) p(g * t) p_{\text {ent }}(g * t) N(g * t)$ & 378.10 & 123.66 & 0.0000 & 0.0000 & 56 \\
$\phi(S V L+E * t) p(E * t) p_{\text {ent }}(E * t) N(g * t)$ & 35,563 & 35,308 & 0.0000 & 0.0000 & 31 \\
$\phi(S V L+g * t) p(g * t) p_{\text {ent }}(g * t) N(g * t)$ & 35,633 & 35,379 & 0.0000 & 0.0000 & 57 \\
\hline \hline
\end{tabular}

survival from 0.360 to $>0.9999994$.

Detection probability of marked individuals was highest in the spring/early summer (October-December) primary monitoring periods, ranging from $0.100 \pm 0.590 \times 10^{-6}$ to $0.201 \pm$ $0.121 \times 10^{-5}$. Detection probability was low in the January-February and March-April 2018 monitoring periods $\left(0.051 \pm 0.358 \times 10^{-6}\right.$ to $0.028 \pm 0.224 \times 10^{-6}$, respectively)

The number of apparent births (immigration + births) varied between time intervals (Fig. 5.6). Birth or immigration occurred at all grids in time intervals 1, 2 and 4 indicating that individuals entered the grids within these time periods (Fig. 5.6). Apparent births were zero in period 3 which covered the late autumn to spring between April - November 2018. There was no indication that enhanced grids had higher numbers of apparent births than control grids following completion of enhancement (interval 5), although there was significant variation in the number of apparent births between grids (Fig. 5.6).

The cumulative effect of apparent survival and apparent births resulted in an increase in abundance across all grids during the monitoring period, albeit of differing magnitudes (Fig. 5.7). As for apparent births, there was no indication that enhanced grids had higher abundance of $O$. aeneum than control grids after completion of enhancement (Fig. 5.7). 


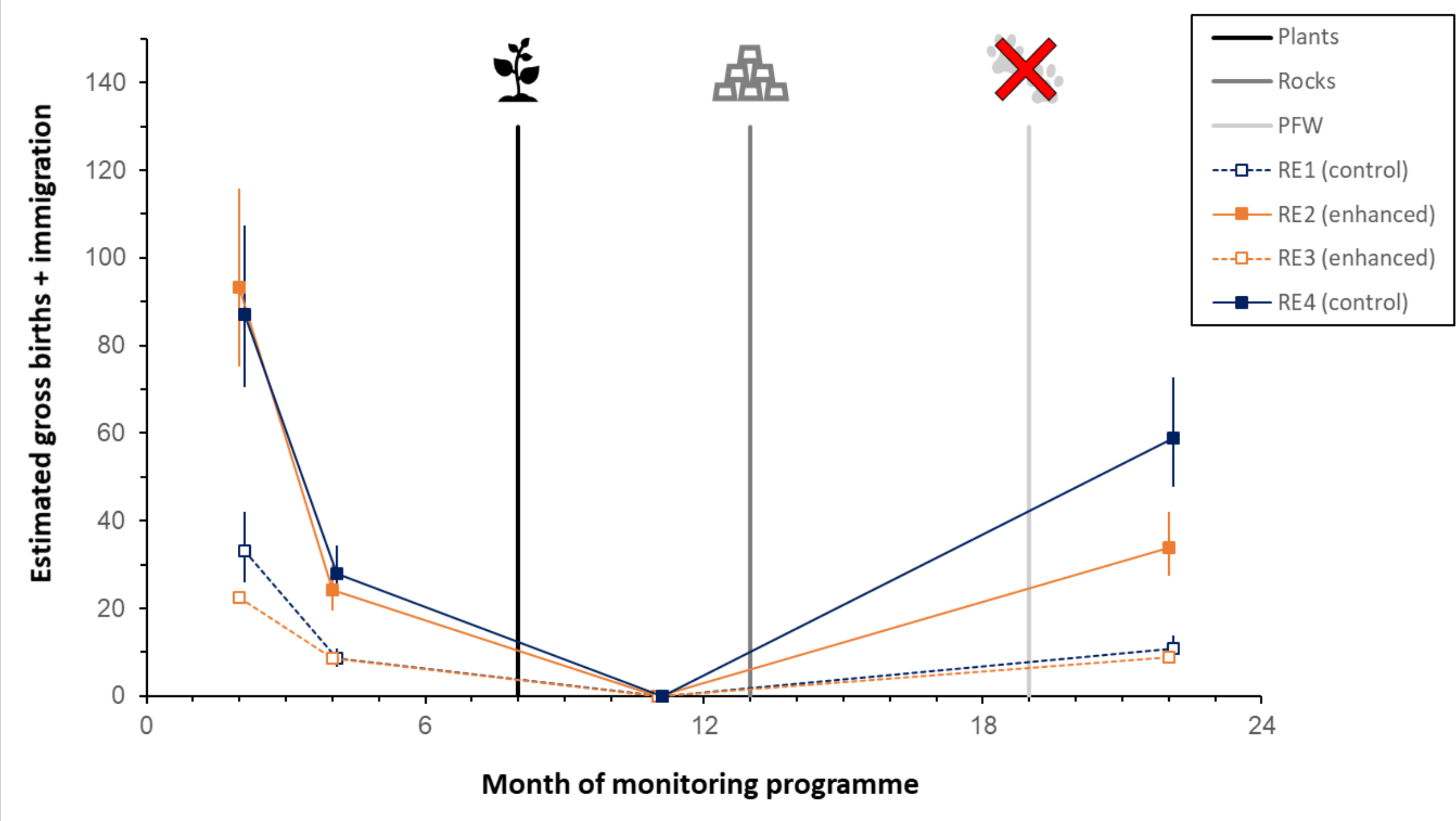

Figure 5.6: Estimated gross number of births + immigration of copper skinks (O. aeneum) between each monitoring session in control and enhanced grids. Intervals are, from left to right: (1) Nov/Dec 2017 - Jan/Feb 2018 (2 months), (2) Jan/Feb 2018 - Mar/Apr 2018 (2 months), (3) Mar/Apr 2018 - Nov/Dec 2018 (7 months), Nov/Dec 2018 - Oct/Nov 2019 (11 months). Error bars are \pm 95\% confidence intervals. 


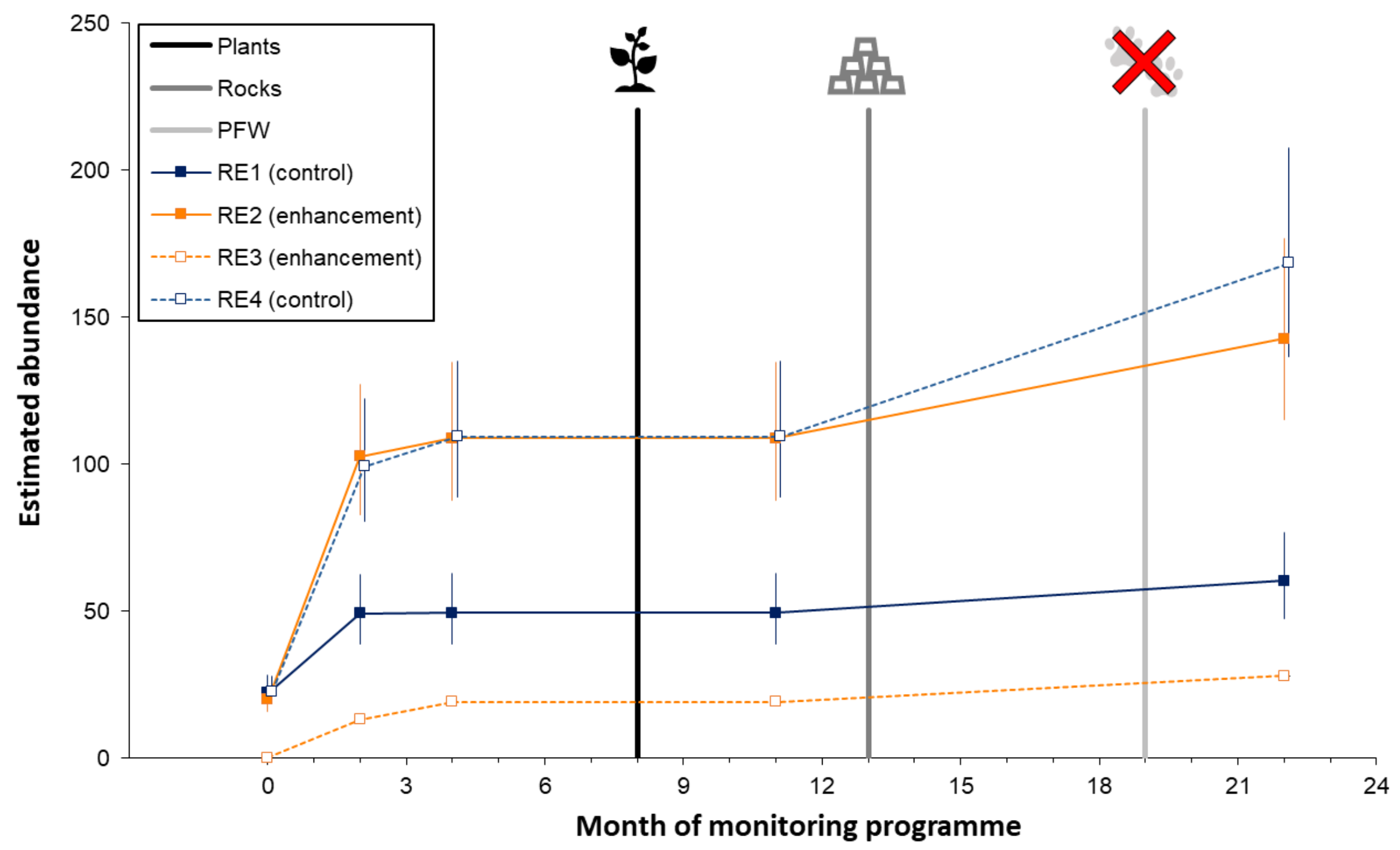

जิ

Figure 5.7: Estimated abundance of copper skinks (O. aeneum) in each monitoring session (November 2017 - November 2019 ) in control and enhanced grids. Error bars are $\pm 95 \%$ confidence intervals. 


\subsection{Discussion}

In the short-term (nine months following rock pile construction and 14 months post-planting), the enhancements could be considered successful at stages 1 and 2 (Table 5.15). All lizard species maintained occupancy, body condition and reproduction in control and enhancement grids in the post-enhancement period relative to the pre-enhancement period. These results suggest that the enhancement techniques used are unlikely to cause any harm to resident lizard species. Therefore, the methods used for enhancement in this study could be suitable for creating new areas of habitat that can be occupied by a reproductive population of $O$. aeneum, O. polychroma and W. maculata.

Habitat enhancement appeared to benefit apparent survival rates of O. polychroma but there was no evidence of an effect of enhancement on O. aeneum. Increases in the apparent survival and grid occupancy, and potentially in abundance, of $O$. aeneum in the post-enhancement period relative to the pre-enhancement period suggest that background levels of pest control across the Miramar Peninsula may be more beneficial for this species than habitat enhancement. This result appears to be consistent with the findings from chapters 3 and 4 of this thesis, where O. polychroma, but not O. aeneum, was found to be capable of persisting in mammal-invaded environments. In comparison, a similar experiment by Lettink et al. (2010) found that the survival rate of the skink Oligosoma maccani increased only in response to predator exclusion and not to addition of artificial refugia. However, the plantings were still reasonably small after 14 months and post-enhancement monitoring for nine months after enhancement completion may not be an adequate time frame in which to realise population increases in fauna that have relatively low intrinsic rates of population growth (Cree, 1994; Towns and Ferreira, 2001; Miller et al., 2014; Bell and Herbert, 2017b). It is therefore recommended that the experiment be continued on the Miramar Peninsula to monitor the effects of habitat enhancement and selective mammal species eradication within this invaded landscape over a longer time frame.

\subsubsection{Apparent survival rates of Oligosoma aeneum and O. polychroma in a mammal-invaded landscape}

The open population mark-recapture data collected from skinks in this experiment represents a valuable addition to our understanding of the population dynamics of New Zealand's lizards, which are generally not well-characterised. There are no prior studies that estimate survival rates of wild Oligosoma polychroma sensu stricto (Liggins et al., 2008). However, some information on the vital rates of $O$. aeneum populations are available for comparison. The low estimated annual survival probability of O. aeneum in this study (36\%) was similar to that in a population studied between 1971 and 1973 in a suburban 
Table 5.15: Summary of the evidence for or against stage-based success criteria developed in Chapter 2 of this thesis. $\mathrm{Y}=$ successful against criterion, $\mathrm{N}=$ not successful against criterion, $(+)=$ increase,$(-)=$ decrease,$(\mathrm{NC})=$ no change, $\mathrm{NA}=$ insufficient evidence for assessment against criterion. Lizard species abbreviations: OA = copper skink Oligosoma aeneum, OP = Northern grass skink O. polychroma, and WM = Raukawa gecko Woodworthia maculata.

\begin{tabular}{lllll}
\hline \hline Stage & Criteria & $\begin{array}{l}\text { Lizard } \\
\text { OA }\end{array}$ & $\begin{array}{l}\text { species } \\
\text { OP }\end{array}$ & WM \\
\hline 1 & $\begin{array}{l}\text { Species uses enhanced habitat and has same or better } \\
\text { body condition in enhanced habitat }\end{array}$ & $\mathrm{Y}(\mathrm{NC})$ & $\mathrm{Y}(\mathrm{NC})$ & $\mathrm{Y}(\mathrm{NC})$ \\
2 & $\begin{array}{l}\text { Evidence of reproduction in enhanced habitats } \\
\text { Benefit to populations inhabiting enhanced habitats } \\
\text { (increased survival }(\phi), \text { abundance }(N) \text { and } / \text { or births } \\
\text { relative to control and baseline) } \\
\text { Self-sustaining population established in enhanced } \\
\text { habitats with emigration greater than or equal to } \\
\text { immigration }\end{array}$ & $\mathrm{NA}(\mathrm{NC})$ & $\mathrm{Y}(\mathrm{NC})$ & $\mathrm{Y}(\mathrm{NC})$ \\
& $\mathrm{NA}(\phi+)$ & $\mathrm{NA}$ \\
& & & $\mathrm{NA}$ \\
\hline \hline
\end{tabular}

garden in Lower Hutt $(38 \% \pm 15.7 \%$; Bell et al. (2018)). A similar monthly survival rate (91\% versus 92\% in this study) was reported in a population in Auckland studied between 1980 and 1981 (Porter, 1987). These studies suggest that the survival rate of O. aeneum on the pest-invaded New Zealand mainland is low, which corresponds with declines observed in this species in mammal-invaded areas (Newman, 1994; Hoare et al., 2007a).

\subsubsection{The utility of habitat enhancement for lizard conservation and mitigation}

Habitat enhancement is encouraged for lizard conservation in New Zealand and is being used to mitigate adverse effects of land use change or development on lizards (Romijn, 2007; Check and Bowie, 2009; DOC, 2009a,b,c,d; Davies et al., 2010a,b; Herbert et al., 2015; Bell and Herbert, 2017a; Lennon, 2019). Conservation- and mitigation- motivated habitat enhancement for reptiles is also widespread in Europe, North America, and Australia (Chapter 2). On a global scale, reptiles frequently use and reproduce in enhanced habitat patches, suggesting that enhancement could be useful for facilitating range expansion of reptiles into previously uninhabitable areas (Chapter 2). However, there was scant evidence to suggest that reptile populations inhabiting enhanced habitat patches are viable, or that reptile populations gain any kind of demographic benefit from enhancement (Chapter 2). Furthermore, the majority of habitat enhancement projects identified in Chapter 2 were located in continental environments. It may not be reasonable to assume similar outcomes in insular environments, particularly in areas where reptiles are subject to increased predation pressure from invasive fauna (Böhm et al., 2013). However, in the 
short-term, the results of my habitat enhancement experiment appear to be consistent with global patterns; in that all three reptile species studied continued to use and reproduce in enhanced habitats, but that enhancement only benefited one of these species. Therefore, I recommend that the following caveats are considered in future applications of habitat enhancement for mitigation or conservation of New Zealand lizards:

- Habitat enhancement could be useful as a remediation measure for replacing lizard habitats destroyed or damaged by land development or land use change. Remediation is defined as per Arlidge et al. (2018).

- Lizard habitat destruction could be offset by using enhancement to replace an equivalent area of lost habitat that is within the known range, and dispersal capabilities, of lizard species affected by development. Offset is defined as per Arlidge et al. (2018).

- This study could not examine whether individuals or species colonise previously uninhabited patches after enhancement. Therefore, empirical research should be conducted to test the hypothesis that lizards will colonise enhanced habitats.

- Habitat enhancement is unlikely to be appropriate for mitigating or reversing reductions in abundance, survival, or recruitment in species that are vulnerable to invasive mammals. For these species, enhancement is therefore not considered to be an appropriate technique to remediate or offset lizard mortalities caused by land use change or development unless a predator control or eradication programme is concurrently implemented. Neither is habitat enhancement considered to be appropriate for the conservation of vulnerable lizard species in the absence of predator control or eradication.

- Habitat enhancement may be appropriate for improving survival rates in lizard species that are capable of co-existence with mammalian predators. It may therefore be an appropriate technique for remediation or offset of mortalities in mammal-resistant lizard species, and for conservation of these species in mammal-invaded areas.

- Because the effects of habitat enhancement have not been evaluated for the majority of New Zealand's lizard species, it is recommended that outcome monitoring be a requirement of habitat enhancement programmes targeted at lizards. 


\section{Chapter 6}

\section{General discussion}

\subsection{Introduction}

In the general introduction of this thesis (Chapter 1), I proposed a model for complementary use of reservation, restoration and reconciliation of habitat patches within a landscape to conserve wildlife metapopulations that are negatively affected by habitat loss (Fig. 1.3). While their end-goals differ, restoration and reconciliation both involve manipulating habitat characteristics in a way that is expected to improve habitability by wildlife (Rosenzweig, 2003; Mcdonald et al., 2016). Therefore, I collectively refer to these strategies as 'habitat enhancement' throughout this thesis. Restoration and reconciliation are attractive prospects for wildlife conservation because they can potentially be employed to reverse habitat loss (Rosenzweig, 2003; Mcdonald et al., 2016).

However, the situation for threatened insular fauna differs in that the declines expected from habitat loss alone are outstripped by the disproportionately large negative effects of introduced predators (Brooks et al., 2002; Salo et al., 2007; Böhm et al., 2013; Smith et al., 2017). Furthermore, habitat manipulation can have unexpected consequences for native fauna in predator-invaded landscapes (Alterio et al., 1998; Ratz, 2000; Didham et al., 2007; Norbury et al., 2013). For example, in New Zealand, the removal of grazing stock to allow regeneration of native vegetation often results in an increased rodent abundance that negatively impacts lizards (Newman, 1994; Knox et al., 2012). Therefore, it is important that habitat enhancement strategies are rigorously evaluated before being adopted as a conservation tool for a fauna.

Reptiles are very sensitive to habitat loss, particularly due to the ecological and physiological constraints of ectothermy, coupled with their typically low capacities for dispersal and small home range sizes (Huey, 1982; White et al., 1997). The 106+ endemic skink and Diplodactylid gecko species inhabiting the New Zealand archipelago appear to be no different, with habitat loss and invasive species being considered the key threats to their persistence (Chapple, 2016; Hitchmough et al., 2016b; van Winkel et al., 2018). Timely 
conservation action will be important for the survival of this fauna. While there are only three known species extinctions, $83 \%$ of extant species are currently threatened or at risk of extinction (Hitchmough et al., 2016a; Melzer et al., 2019).

I selected the endemic lizard fauna of the Wellington region of the lower North Island of New Zealand as a model system to test the viability of habitat enhancement as a conservation strategy for an insular fauna. The study system was further restricted to terrestrial and semi-arboreal lizard species inhabiting coastal environments. This was done in order to reduce the level of complexity to a manageable level.

\subsubsection{Research aims and questions}

The overarching aim of this thesis was to determine whether habitat enhancement is a viable strategy for conserving New Zealand's endemic lizards. Because the mechanics of the two key threats to this fauna (habitat loss and invasive species) are not fully understood, it was important to also ask questions that would improve understanding of these issues.

Therefore, the overarching aim was addressed by asking four main questions:

1. What habitat enhancement strategies are available for reptiles, and have they produced successful conservation outcomes?

2. How do habitat characteristics affect populations and communities of endemic New Zealand lizards?

3. How does the presence of invasive mammals affect populations and communities of endemic New Zealand lizards over intermediate to long-term time frames?

4. Can a habitat enhancement strategy based on knowledge of New Zealand endemic lizard species' habitat preferences produce positive conservation outcomes in the presence of invasive mammals?

Each of these questions was addressed in a separate chapter. The main outcomes of these four chapters are summarized in the following section.

\subsection{Chapter overviews}

Chapter 2: Habitat restoration and reconciliation for reptile species conservation: a global meta-analysis

Review of the global literature identified 75 studies documenting 577 responses of 251 reptile species to habitat enhancement. A wide variety of enhancement techniques were documented. The approaches used could be categorised by the ecological scale at which it 
was targeted (following Shoemaker et al. (2009)): landscape-scale $\left(N_{\text {studies }}=14\right)$, seral stage of the vegetative community $\left(N_{\text {studies }}=27\right)$, or a specific habitat characteristic $\left(N_{\text {studies }}=35\right)$. The 75 studies used a broad range of measurements to indicate enhancement success or failure for the target species. No standard framework was available for assessing wildlife conservation outcomes from habitat enhancement projects so I adapted a four-stage evaluation framework for translocations by (Miller et al. (2014)). In brief, the adapted criteria were:

- Stage 1: use of enhanced habitat

- Stage 2: evidence of reproduction in enhanced habitat

- Stage 3: population growth in enhanced habitat indicated by improvement of one or more demographic parameters

- Stage 4: self-sustaining or source population established in enhanced habitat

Reptiles frequently used enhanced habitats, but there was scant evidence that enhancement promoted population growth or viability. That is, in the 577 cases I reviewed, the majority $(84 \%)$ had provided evidence for or against the shortest-term success criterion (Stage 1). In contrast, $8 \%$ of cases were evaluable against Stage 2, 42\% against Stage 3, and $1 \%$ against Stage 4 . Success at Stages 1 and 2 were achieved in $85 \%$ and $84 \%$ of evaluable cases, respectively. Fewer cases were successful at Stage $3(30 \%)$, and Stage $4(43 \%)$. Amongst cases, accurate indication of long-term success (Stage $3+$ ) by short-term criteria (Stages 1-2) were affected by study design (inclusion of spatial controls, a temporal baseline, or sustained long-term monitoring). Furthermore, while short-term success was not affected by the purpose driving an enhancement program, enhancements carried out primarily for ecological restoration were less successful at Stage 3.

The results suggested that enhancement could be useful for creating areas that can be inhabited, and reproduced in, by reptiles. However, habitat enhancement did not produce population growth in most cases. More long-term studies that collect robust population data are required to address whether habitat enhancement can secure reptiles from extinction.

\section{Chapter 3: Which habitat characteristics are correlated with species richness and abundance in insular lizard communities?}

I sought to identify habitat characteristics that affected lizard communities. To achieve this, I surveyed terrestrial lizards and habitat at 30 randomly placed $80 \mathrm{~m}^{2}$ quadrats across two mammal-free and two mammal-invaded sites around the Wellington coast. All quadrats within each site were visually surveyed for lizards on six occasions, allowing a matrix of repeated count data to be collected for every lizard species encountered $\left(N_{\text {rows }}=30\right.$ quadrats $\times N_{\text {columns }}=6$ surveys). 
Despite measuring several habitat characteristics in quadrats and accounting for unmeasured variation at the site-level, presence or absence of invasive mammals had the most significant impact on observed lizard species assemblages. Species richness was significantly lower at mammal-invaded sites. However, some habitat characteristics affected lizard community structure: canopy cover at $1 \mathrm{~m}$ above ground level, and relative abundance of large-leaved Coprosma species and non-Muehlenbeckia vines.

Estimation of the detection probabilities of species and individual lizards by Royle (2004) N-mixture modelling found that individual detection probabilities of the three most frequently encountered lizards (copper skinks Oligosoma aeneum, northern grass skinks $O$. polychroma and Raukawa geckos W. maculata) were too low to robustly investigate the effects of habitat on abundance. Power analysis of species detection probabilities suggested that the six surveys had adequate power to detect occupancy by O. polychroma and $W$. maculata in quadrats where they were present, but were underpowered for O. aeneum.

Probabilities of quadrat occupancy by Oligosoma polychroma and Woodworthia maculata were positively correlated with increasing abundance of divaricating shrubs. O. polychroma was also more likely to occupy quadrats with more vines (excluding Muehlenbeckia species). In conclusion, these results suggested that characteristics of the vegetative community could be manipulated to increase patch occupancy by two endemic lizard species.

\section{Chapter 4: The intermediate- to long-term effects of invasive mammal presence on an insular lizard fauna}

This study examined terrestrial lizard communities in three mammal-invaded coastal sites on the Wellington mainland: Baring Head, Pukerua Bay, and Turakirae Head. A mark-recapture study was implemented between 2017 and 2019 to determine the current density of lizard species at each site. Lizard surveys had been carried out previously or were ongoing at each site, allowing me to examine how estimated abundance, occupancy, or catch-per-unit-effort (CPUE) measures had changed over periods spanning between six and 49 years.

Only two species, northern grass skinks Oligosoma polychroma and Raukawa geckos Woodworthia maculata, were captured on enough mark-recapture occasions for density estimation. Density estimates of O. polychroma ranged between 3,980 and 4,078 animals / ha. Density of W. maculata ranged between 4,067 and 38,372 animals / ha. Other species known to occur, at least historically, at each site were either not detected (O. aeneum and $O$. kokowai at Baring Head and Turakirae Head, and O. whitakeri at Pukerua Bay) or comprised only a small proportion of the total lizard captures (O. aeneum and O. zelandicum at Pukerua Bay).

There was no evidence for declining abundance, occupancy, or CPUE of O. polychroma or W. maculata at any site over time periods ranging between six and 49 years. Occupancy 
of 210 effective trapping areas surrounding pitfall traps by O. polychroma and W. maculata increased over a six year timeframe at Baring Head. Taken together, these results suggest that only two species can persist in abundance in coastal areas of the Wellington region in the sustained presence of invasive mammals. In the absence of an intensive pest control programme, or successful eradication, it seems unlikely that the other lizard species studied will be capable of long-term persistence.

Habitat information collected by the Greater Wellington Regional Council at the Baring Head pitfall sites made it possible to further examine how spatial habitat variation affects lizard occupancy. Increasing rock cover significantly reduced the local extinction probability of W. maculata. Occupancy of O. polychroma was higher in scrub and shrubland than in grassland, whereas occupancy of $W$. maculata was highest in scrub. These results suggest that conversion of grass and shrubland to scrub may also be beneficial for O. polychroma. However, in the absence of mammalian predator control, the removal of grazing stock may have a negative effect on $O$. polychroma which could complicate revegetation efforts for lizard habitat enhancement.

\section{Chapter 5: Short-term responses of lizard species to habitat enhancement in a pest-invaded mainland environment}

A before-after-control-impact (BACI) habitat enhancement experiment was implemented at $12100 \mathrm{~m}^{2}$ experimental plots on the mammal-invaded Miramar Peninsula in spring 2017. Habitat enhancement consisted of two stages: planting a selection of native plant species thought to benefit one or more lizard species in winter 2018, and the addition of rock piles based on recommendations by Lennon (2019) in summer 2018-19. The responses of resident lizards (O. aeneum, O. polychroma, and W. maculata) to enhancement was monitored using a mark-recapture design until November 2019, representing 14 months post-planting and nine months following rock pile construction. A slightly modified version of the first three stages of the success criteria developed in Chapter 2 were used to assess the short-term outcomes of the enhancement programme: (1) grid occupancy by lizard species and body condition, (2) evidence of reproduction, and (3) change in population parameters.

There was no significant difference in post-enhancement occupancy of any lizard species in the experimental plots at the control $(\mathrm{N}=6)$ versus enhancement $(\mathrm{N}=6)$ grids. However, significantly more plots were occupied in the after-enhancement period by $O$. aeneum. Lizard body condition did not differ significantly between control and enhancement grids, nor between the pre-enhancement and post-enhancement periods. There was also no significant difference in the proportion of control versus enhancement plots in which reproduction was evident, nor between the pre-enhancement and post-enhancement periods for any lizard species.

O. aeneum was only detected in the four plots placed in Rangitatu reserve. The 
best-supported POPAN model for $O$. aeneum according to the $A I C_{c}$ included a time effect on detection probability and the probability of entry into the population $\left(p_{\text {ent }}\right)$, and a different apparent survival rate $(\phi)$ across all plots during the pre-enhancement (annual $\hat{\phi}_{\text {before }}=0.360$ ) and post-enhancement periods (annual $\hat{\phi}_{\text {after }}>0.9999994$ ). The abundance of this species increased between 2017 and 2019 in one of the two Rangitatau escarpment control plots and one of the two enhancement plots. In contrast, apparent survival rates of O. polychroma significantly increased in response to habitat enhancement, but did not result in increased abundance of this species.

All lizard species maintained occupancy, body condition and reproduction in control and enhancement plots in the post-enhancement period, relative to the pre-enhancement period. Therefore, by 9-14 months post-enhancement, the enhancement programme could be considered successful at stages 1 and 2. The absence of short-term negative effects suggests that the enhancement methods used would be suitable for creating new habitat patches that can be occupied by reproductive populations of O. aeneum, O. polychroma, and W. maculata.

However, habitat enhancement only visibly benefited one of the lizard species studied, in terms of short-term indicators or longer-term measures (survival, birth rates, or abundance). Increases in apparent survival, plot occupancy, and abundance of O. aeneum in the post-enhancement period relative to pre-enhancement may have reflected the increasing level of invasive mammal trapping on the Miramar Peninsula. Furthermore, the Predator Free Miramar mustelid and rat eradication programme began operation across the Peninsula in July 2019, three months before the final lizard monitoring season. This outcome mirrors results from a similar experiment by Lettink et al. (2010), where the survival rate of the skink Oligosoma maccani did not increase in response to enhancement (addition of artificial refugia). In that study, survival increased only in response to predator exclusion. However, the plantings were still reasonably small after 14 months and a 9-14 month post-enhancement period may not have been an adequately long time frame in which to realise population increases (Towns and Ferreira, 2001; Miller et al., 2014; Bell and Herbert, 2017b). It is therefore recommended that the experiment be continued on the Miramar Peninsula. The implementation of Predator Free Miramar provides an additional opportunity to monitor the effects of eradicating a sub-set of mammal species and habitat enhancement relative to baseline data.

\subsection{Conclusion: is habitat enhancement a viable strategy for conserving New Zealand's endemic lizards?}

The following criteria are postulated for evaluating the viability of habitat enhancement for conservation of an endemic lizard species in New Zealand: 
1. At least one habitat characteristic has a positive effect on occupancy or abundance.

2. Successful habitat enhancement would need to be demonstrated at Stage 2 or higher. For this to be a reasonable test, habitat enhancement is defined as increasing the characteristics demonstrated to have a positive effect in (1).

3. The species would need to be capable of long-term coexistence with mammals in order for enhancement to be viable in both mammal-invaded and mammal-free landscapes. Otherwise, pest control would be considered essential alongside enhancement.

If one or more of these criteria are not met, it would indicate that the species' conservation in mammal-invaded landscapes should focus on intensifying pest control. If all three of these criteria are met, the enhancement methods used could be applied for mitigating extinction risk at least until predator control can be implemented. Enhancement success demonstrated to stage 2 could be used to increase the total habitable area, thus mitigating species extinction risk under the small population or changing environment scenarios (Connor and McCoy, 1979; Goodman, 1987a; Hanski, 1999). Success demonstrated at stages 3 or 4 could be used for mitigating extinction risk at the population level. In connected metapopulations, enhancements that are successful at stages 3 or 4 could be used to create source populations (Holt, 1992; Hanski, 1999).

The results presented in this thesis suggest that enhancement is a viable strategy for creating habitable areas for O. polychroma and W. maculata in invaded landscapes, and could be used to improve survival in populations of O. polychroma. These two species appear to be capable of persisting in mammal-invaded landscapes and site occupancy was correlated with one or more manipulable habitat characteristics. In particular, addition of divaricating shrubs to a site or reversion to scrub could be used to increase the probability of occupancy by both species. Addition of rocks could decrease the probability of local extinction of $W$. maculata. Addition of vines (native vines in this category were in the Calystegia and Tetragonia genera) to a site may also improve the probability of occupancy by O. polychroma.

Most of the other coastal lizard species native to Wellington appear to be sensitive to sustained mammal presence, even with the low-to-moderate levels of control in operation at Pukerua Bay and Baring Head. Habitat enhancement without intensive mammal control or eradication is thus not expected to benefit these species. Nor is enhancement expected to be capable of restoring coastal lizard communities. Without predator control, it is, at best, a reconciliation measure that could allow co-existence of a species-depauperate endemic lizard community with mammals. However, habitat enhancement could be useful in mammal-free sanctuaries to offset potentially antagonistic relationships between some pairs of lizard species (Patterson, 1985, 1992; Phillpot, 2000; Stephens, 2004; Evans et al., 2015; Fischer et al., 2019). 


\subsection{Conservation management recommendations}

\subsubsection{Combine invasive fauna control and habitat management using a species-specific approach}

It is recommended that invasive fauna control and habitat management are applied to New Zealand lizards using a species-specific approach. Recommendations that can be made for species on the basis of the results in this thesis are provided in Table 6.1.

The use of indicator species to infer the health of lizard communities is attractive in terms of optimising research effort and appears to work in some situations (e.g. Monks et al. (2014)). However, the results presented in Chapters 3 and 4 of this thesis highlighted differences between species in their responses to invasive predators and habitat characteristics. This conclusion parallels findings from other studies on the relevance of indicator species to conservation of communities and ecosystems: evaluation of the composition of species assemblages is perhaps a more accurate approach than measuring single-species responses (Karr, 1981; Bonn et al., 2002; Smith and Rissler, 2010; Carignan and Villard, 2002; Pander and Geist, 2013; Fea et al., 2020). 
Table 6.1: Species-specific recommendations for management of the study species in the Wellington region. Blank = not important, $\mathrm{B}=$ possible benefit, I = important, ? = effect unknown. + = increase, $-=$ reduce. ${ }^{*}=$ only if co-exists with Oligosoma kokowai at a mammal-free site, ${ }^{* *}=$ note that these species appear to be excluded from habitats with a tall, closed canopy, so canopy closure probably refers to closure at $1-2 \mathrm{~m}$ above ground level.

\begin{tabular}{|c|c|c|c|c|c|c|c|c|c|c|}
\hline Species & $\begin{array}{l}\begin{array}{l}\text { Mammal GC } \\
\text { control }\end{array} \\
\text { con }\end{array}$ & $\begin{array}{l}\mathrm{CC} \\
1 \mathrm{~m}\end{array}$ & $\begin{array}{l}\mathrm{CC} \\
0 \mathrm{~m}\end{array}$ & PHO & Rock & DivS & COPlg GS & "MUE & Vines & Source(s) \\
\hline $\begin{array}{l}\text { Oligosoma } \\
\text { aeneum }\end{array}$ & I+ & $\mathrm{B}+* *$ & $\mathrm{~B}+$ & & $\begin{array}{l}\mathrm{B}+ \\
(6-20+ \\
\mathrm{cm})\end{array}$ & & $\mathrm{B}+$ & & & 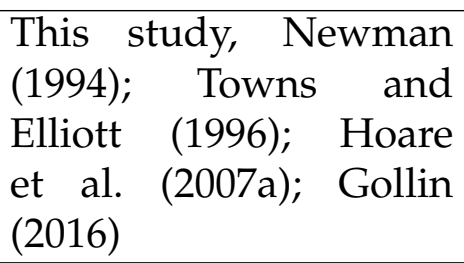 \\
\hline O. kokowai & $\mathrm{I}+$ & $\mathrm{B}+* *$ & & & & & $\mathrm{~B}+$ & & & $\begin{array}{l}\text { This study, Phillpot } \\
\text { (2000); Stephens (2004) }\end{array}$ \\
\hline O. macgregori & I+ & $?$ & $?$ & $?$ & ? & $?$ & $?$ & $?$ & $?$ & $\begin{array}{l}\text { (Newman, 1994; Towns } \\
\text { and Daugherty, 1994) }\end{array}$ \\
\hline O. polychroma & $\mathrm{B}+$ & & & & $\mathrm{B}+$ & $\begin{array}{l}\text { I }(\geq \\
60 \%)\end{array}$ & $\mathrm{B}+{ }^{*}$ & & $\begin{array}{l}\text { I }(\geq \\
50 \%)\end{array}$ & $\begin{array}{l}\text { This study, Newman } \\
\text { (1994); Phillpot (2000); } \\
\text { Stephens (2004); Wiles } \\
\text { (2016) }\end{array}$ \\
\hline O. whitakeri & I+ & $?$ & $?$ & $?$ & $\begin{array}{l}\mathrm{B}+ \\
(6-20 \\
\mathrm{cm})\end{array}$ & $?$ & $?$ & B- & $?$ & $\begin{array}{l}\text { Towns (1991); Towns } \\
\text { and Elliott (1996); Hoare } \\
\text { et al. (2007a), this study }\end{array}$ \\
\hline O. zelandicum & $\mathrm{B}+$ & $?$ & $?$ & $?$ & $?$ & $?$ & $?$ & $?$ & $?$ & $\begin{array}{l}\text { This study, Hoare et al. } \\
\text { (2007a) }\end{array}$ \\
\hline $\begin{array}{l}\text { Woodworthia } \\
\text { chrysosiretica }\end{array}$ & I+ & $\mathrm{B}+$ & & I+ & & & & & & This study \\
\hline W. maculata & $\mathrm{B}+$ & & & & I+ & $\begin{array}{l}\text { I } \quad(\geq \\
30 \%)\end{array}$ & B- & $\mathrm{B}+$ & & $\begin{array}{l}\text { This study, Newman } \\
\text { (1994) }\end{array}$ \\
\hline
\end{tabular}




\subsubsection{Reserve, restore and reconcile: towards landscape-scale management of New Zealand's lizards}

Previous studies have shown that some New Zealand lizard species display metapopulation dynamics (Berry et al., 2005; Gebauer et al., 2013; Nelson-Tunley et al., 2016). Therefore it is reasonable to assume, unless demonstrated otherwise, that conserving metapopulation processes across landscapes is an important consideration for their conservation management.

A landscape-scale lizard conservation strategy in New Zealand would likely require both pest control and habitat management to be successful. For the full suite of species to be conserved, reservation is expected to require mammal eradication or intensive long-term suppression, as has been demonstrated in several mainland sanctuaries and offshore islands (Towns et al., 2001; Nelson et al., 2016; Innes et al., 2019). At present it is not well-understood in New Zealand how strongly each mammal species contributes to the extinction risk of lizard populations, nor is the ideal level of suppression required to produce conservation outcomes in lizards known (Hitchmough et al., 2016b). Given the findings of this thesis, further investigation into effective pest control for conservation of New Zealand's endemic lizards is strongly supported. Restoration is likely to be most effective for lizards if the habitat enhancements are targeted to the needs of resident lizards species, and performed in concert with pest control. Reconciliation is likely to take the form of habitat enhancement targeted at the more common species like O. polychroma and $W$. maculata with or without predator control. Alternatively, pest control without habitat enhancement may be effective for habitat reconciliation for species with higher sensitivity to the presence of invasive predators.

As a final word of caution, restoration and reconciliation should not be viewed as a panacea for halting habitat loss, nor used an excuse for not protecting relatively intact habitats (Menz et al., 2013). As highlighted in Chapter 2 and other studies, these are still developing disciplines dealing with complex systems, in which achievement of desired ultimate outcomes is uncertain and unintended consequences may occur (Hoare et al., 2007a; Knox et al., 2012; Suding, 2011; Maron et al., 2012; Menz et al., 2013; Norbury et al., 2013).

\subsection{Study limitations and suggestions for future research}

\subsubsection{Identifying lizard associations with habitat}

In Chapter 3 of this thesis, the time taken to visually survey $80 \mathrm{~m}^{2}$ quadrats for lizards precluded being able to collect data for a larger sample size within a single 6-month season. Survey effort in terms of person-hours varied between quadrats because areas with more 
complex vegetation took longer to survey. The reliance of visual surveying on periods of dry weather also meant that six repeated surveys often extended for a period much long than six days. Additionally, my initial focus on estimating lizard species abundance using Royle (2004) N-mixture models from repeated count data meant that all surveys of a quadrat had to be conducted within three weeks for closure to change in abundance to be a reasonable assumption (Dail and Madsen, 2011). This had the trade-off that each of the four sites were surveyed in different months which had the potential to introduce auto-correlation between sites and weather variables into the dataset.

The N-mixture method was initially selected for the advantage of being able to detect relationships between habitat characteristics and lizards at the relatively fine-scale of local abundance (Ficetola et al., 2018). However, individual detection probability of lizards was too low to produce reliable abundance estimates. Therefore, the coarser scale of site occupancy was used to examine species-specific relationships with habitat characteristics because species detection probabilities were adequate. In hindsight, the study would have been better designed if I had focused on collection of species presence-absence data at a greater number of smaller quadrats. Occupancy can be assumed to be closed over longer time-frames than abundance, therefore under an occupancy design I could have staggered the repeated surveys of each quadrat over a longer time frame. Doing so would have allowed single-season data to be collected from each site in a staggered manner (e.g. in a series of visits to each site over one six-month season, rather than during a single visit), and either the inclusion of more sites or quadrats in the survey. It is also likely that there are other habitat characteristics that I didn't measure or test. In particular, ascertaining the sizes of rocks and crevices preferred by different lizard species would have been useful, based on the potential ability of environmental refugia to exclude invasive mammals (Towns, 1996; Lennon, 2019). Advances in digital capture and modelling of hard-surface geometries are expected to improve the speed and accuracy of collecting data on rock refugia (González-Aguilera et al., 2009; Lerma et al., 2010; Silcock et al., 2018; Lennon, 2019).

Despite the limitations discussed, the repeated visual encounter survey method was still able to detect some important relationships between two terrestrial lizard species and habitat characteristics. Further research on habitat preferences of New Zealand lizards is likely to be fruitful for better understanding of habitat management. Repetition of this experiment on terrestrial lizard communities across pest-invaded and pest-free site with an occupancy design would also be useful. 


\subsubsection{Evaluation of conservation management against ultimate outcomes is important, but precluded by the difficulty of getting accurate and precise demographic information from reptiles in short time-frames}

To evaluate whether a conservation management strategy is ultimately effective, one needs to assess whether extinction risk has been minimised. In the staged evaluation criteria developed for habitat enhancement in Chapter 2, ultimate success was conceptualised as: a self-sustaining or source population occupies the enhanced area. Fulfilment of this criterion could be fulfilled in two ways: (1) demonstrate a sustained population growth rate of $r \geq 0$ over a multi-generational time frame, or (2) population viability assessment predicts a negligible risk of extinction.

Population modelling has the advantage of being able to evaluate viability in a shorter time frame than monitoring population trends in real-time, particularly in long-lived species. However to achieve this with any level of certainty, it is critical to accurately specify dynamic demographic parameters and the population model structure (Caswell, 2001; Beissinger and McCullough, 2002; Chaudhary and Oli, 2020). Many reptiles have low detection probabilities due to small body size, cryptic habits and camouflage which can preclude precise or accurate estimation of demographic parameters without substantial investment in an intensive survey effort (Steen, 2010; Griffiths et al., 2015; Ward et al., 2017). Difficulty collecting adequate population information is a commonly cited barrier for evaluating conservation status or efficacy of management programmes for herpetofauna (Mazerolle et al., 2007; Germano and Bishop, 2009; Steen, 2010; Bland and Böhm, 2016). The power analysis in Chapter 3 indicated that three to 11 repeated surveys would be required for accurate detection (conditional on site occupancy) of the three most commonly encountered terrestrial lizard species within a single season. Power analyses conducted in other studies of terrestrial New Zealand lizards has suggested that six to eight surveys are necessary for occupancy or abundance estimation (Herbert and Bell, 2012; Herbert et al., 2013a). These results imply that single surveys for lizards are highly likely to underestimate occupancy and population parameters; therefore repeated surveys are strongly recommended. Even better would be to conduct power analysis to inform the number of surveys required either in the study design phase or as part of data analysis to evaluate the quality of information gained (Bailey et al., 2007; Guillera-Arroita and Lahoz-Monfort, 2012; Sewell et al., 2012).

Potential solutions for overcoming the difficulties inherent in evaluating the effects of conservation interventions on small, cryptic lizards may include: (1) further optimising survey methodology to increase detection probability, (2) exploring a wider range of statistical frameworks for estimating meaningful demographic parameters, and (3) conducting long-term studies of lizard populations and communities to see how accurately potential short-term indicators (e.g. body condition, age structure and sex ratios, site 
occupancy, abundance, community structure) predict long-term outcomes (e.g. population or metapopulation viability and stability of species assemblages). Substantial progress has been made in areas (1) and (2) in New Zealand and overseas, but further work is required for creation of an evaluation toolbox for informing lizard conservation management (Thompson, 2004; Mazerolle et al., 2007; Hoare et al., 2009; Sewell et al., 2012; Griffiths et al., 2015; Lettink and Monks, 2016). In particular, further research into how accurately static population measures (e.g. single-season abundance estimates; Hanski (1999); Robert et al. (2015)) and short-term fitness indicators (e.g. body condition; Dudek et al. (2015)) can predict long-term viability of lizard populations would enable more widespread adoption of systematic stage-based approaches for evaluating outcomes of conservation intervention for both case studies and meta-analyses.

Therefore, it is recommended to establish more long-term studies on New Zealand lizards that enable short-term demographic estimates to be evaluated against population trends. An efficient means to do this could be to re-survey historical monitoring sites to document long-term changes to lizard populations and communities or continue existing multi-year monitoring programmes. For the research conducted in Chapters 4 and 5, I set up lizard mark-recapture monitoring programmes at four sites in the Wellington region: Baring Head, Pukerua Bay, south Miramar, and Turakirae Head. The data collected for this thesis would form a robust basis for continued population monitoring work of up to three species in the Wellington region to examine their responses to changes in pest control and habitat enhancement.

\subsubsection{The challenge of evaluating restoration outcomes when we don't know what a 'natural' lizard community looks like}

The substantial deforestation of, and faunal introductions into, New Zealand means that very few lizard communities today occupy unaltered habitats in uninvaded landscapes (McGlone, 1989). With the exception of some offshore islands, this precludes our ability to know what a 'natural' lizard community for a given region and habitat would look like or how it would function (Towns et al., 2016). This lack of knowledge makes it difficult to develop restoration goals for lizard communities in New Zealand. It may, however, be possible to infer pre-European lizard community structures by combining the lines of evidence available to us: the subfossil record, biogeographic and taxonomic studies, historical records and indigenous knowledge of habitat change and lizard distributions, and further study of lizard life histories, ecologies, and community structures across gradients of mammal invasion and habitat modification (Worthy, 1987; McGlone, 1989; Towns and Daugherty, 1994; Park, 1995; Lee et al., 2009; Hare et al., 2016; Worthy, 2016; Cisternas et al., 2019; Melzer et al., 2019; Woolley et al., 2019).

Based on the results from this thesis and previous studies, apparent features of a 
"healthy" lizard species assemblage are in the Greater Wellington region appear to be: (1) high abundance (see Tables 6.2 and 6.3), (2) lizard species richness exceeding two species per 80-100 $\mathrm{m}^{2}$, (3) presence at a detectable abundance of species sensitive to mammals such as copper skinks Oligosoma aeneum and medium to large-bodied (SVL $>80 \mathrm{~mm}$ ) species (Newman, 1994; East et al., 1995; Markwell, 1999; Phillpot, 2000; Stephens, 2004; Gollin, 2016). Until our understanding of lizard communities improves, these criteria could be used to define restoration goals for terrestrial lizard communities in grassland to treeland environments of the Wellington / Cook Strait regions. However, as the canopy becomes higher and more closed, the species assemblage is expected to shift to dominance of arboreal lizard species - a fauna that we know even less about than terrestrial lizards. 
Table 6.2: Density estimates reported in the literature for species in this study for the Wellington / Cook Strait region. Table adapted from Wilson et al. (2017) and C. Woolley, unpub. data. CMR: capture-mark-recapture. SECR: spatially explicit capture-recapture. $\mathrm{M}_{t+1}$ : minimum number of known individuals. CPUE: catch per unit effort index of abundance.

\begin{tabular}{|c|c|c|c|c|c|c|}
\hline Species & Location & Habitat & $\begin{array}{l}\text { Predator } \\
\text { control }\end{array}$ & $\begin{array}{l}\text { Density } \\
\text { (lizards / ha) }\end{array}$ & Method & Source \\
\hline O. aeneum & Pukerua Bay & $\begin{array}{l}\text { Previously grazed } \\
\text { regenerating coastal } \\
\text { shrubland and scree }\end{array}$ & None & 2,494 & $\mathrm{M}_{t+1}$ & $\begin{array}{l}\text { Towns and Elliott } \\
(1996)\end{array}$ \\
\hline O. aeneum & Lower Hutt & Backyard & None & $196-2,662$ & CMR & Bell et al. (2018) \\
\hline O. kokowai & $\begin{array}{l}\text { Takapourewa / } \\
\text { Stephens Island }\end{array}$ & $\begin{array}{l}\text { Forest, grassland, } \\
\text { vineland, shrubland }\end{array}$ & $\begin{array}{l}\text { Predator- } \\
\text { free }\end{array}$ & 3,333 & CPUE & Markwell (1999) \\
\hline O. polychroma & $\begin{array}{l}\text { Takapourewa / } \\
\text { Stephens Island }\end{array}$ & $\begin{array}{l}\text { Forest, grassland, } \\
\text { vineland, shrubland }\end{array}$ & $\begin{array}{l}\text { Predator- } \\
\text { free }\end{array}$ & 252 & CPUE & Markwell (1999) \\
\hline O. polychroma & Wellington & Cemetery & None & 2,200 & CPUE & Barwick (1959) \\
\hline O. polychroma & Turakirae Head & Grazed coastal shrubland & None & 2,565 & $\begin{array}{l}\text { Closed mark- } \\
\text { recapture }\end{array}$ & Green (2001) \\
\hline O. polychroma & Pukerua Bay & $\begin{array}{l}\text { Previously } \quad \text { grazed } \\
\text { regenerating coastal } \\
\text { shrubland and scree }\end{array}$ & $\begin{array}{l}\text { Rats and } \\
\text { mustelids } \\
\text { trapped }\end{array}$ & 3,980 & $\begin{array}{l}\text { Huggins } \\
\text { closed CMR }\end{array}$ & Chapter 4 , this thesis \\
\hline O. polychroma & Turakirae Head & Grazed coastal shrubland & None & 4,078 & $\begin{array}{l}\text { Huggins } \\
\text { closed CMR }\end{array}$ & Chapter 4 , this thesis \\
\hline O. polychroma & Pukerua Bay & $\begin{array}{l}\text { Previously } \quad \text { grazed } \\
\text { regenerating coastal } \\
\text { shrubland and scree }\end{array}$ & None & 4,900 & $\mathrm{M}_{t+1}$ & $\begin{array}{l}\text { Towns and Elliott } \\
\text { (1996) }\end{array}$ \\
\hline O. polychroma & $\begin{array}{l}\text { Wellington and } \\
\text { Nelson }\end{array}$ & $\begin{array}{l}\text { Bush reserves, amenity } \\
\text { areas, and backyards in } \\
\text { urban environments }\end{array}$ & None & $71-8,255$ & $\begin{array}{l}\text { Closed- } \\
\text { population } \\
\text { SECR }\end{array}$ & $\begin{array}{l}\text { C. Woolley, unpub. } \\
\text { data }\end{array}$ \\
\hline O. zelandicum & $\begin{array}{l}\text { Takapourewa / } \\
\text { Stephens Island }\end{array}$ & $\begin{array}{l}\text { Forest, grassland, } \\
\text { vineland, shrubland }\end{array}$ & $\begin{array}{l}\text { Predator- } \\
\text { free }\end{array}$ & 126 & CPUE & Markwell (1999) \\
\hline O. zelandicum & Pukerua Bay & $\begin{array}{l}\text { Previously grazed } \\
\text { regenerating coastal } \\
\text { shrubland and scree }\end{array}$ & None & 1,477 & $\mathrm{M}_{t+1}$ & $\begin{array}{l}\text { Towns and Elliott } \\
\text { (1996) }\end{array}$ \\
\hline
\end{tabular}


Table 6.3: Density estimates reported in the literature for species in this study for the Wellington / Cook Strait region. Table adapted from Wilson et al. (2017) and C. Woolley, unpub. data. CMR: capture-mark-recapture. SECR: spatially explicit capture-recapture. $\mathrm{M}_{t+1}$ : minimum number of known individuals. CPUE: catch per unit effort index of abundance.

\begin{tabular}{|c|c|c|c|c|c|c|}
\hline Species & Location & Habitat & $\begin{array}{l}\text { Predator } \\
\text { control }\end{array}$ & $\begin{array}{l}\text { Density } \\
\text { (lizards / ha) }\end{array}$ & Method & Source \\
\hline W. maculata & Pukerua Bay & $\begin{array}{l}\text { Previously grazed } \\
\text { regenerating coastal } \\
\text { shrubland and scree }\end{array}$ & None & 738 & $\mathrm{M}_{t+1}$ & $\begin{array}{l}\text { Towns and Elliott } \\
(1996)\end{array}$ \\
\hline W. maculata & $\begin{array}{l}\text { Takapourewa / } \\
\text { Stephens Island }\end{array}$ & $\begin{array}{l}\text { Forest, grassland, } \\
\text { vineland, shrubland }\end{array}$ & $\begin{array}{l}\text { Predator- } \\
\text { free }\end{array}$ & 943 & CPUE & Markwell (1999) \\
\hline W. maculata & Turakirae Head & Grazed coastal shrubland & None & 4,100 & $\begin{array}{l}\mathrm{M}_{0} \quad \text { closed } \\
\mathrm{CMR}\end{array}$ & Whitaker (1982) \\
\hline W. maculata & Turakirae Head & Grazed coastal shrubland & None & 4,970 & closed CMR & Green (2001) \\
\hline W. maculata & Pukerua Bay & $\begin{array}{l}\text { Previously grazed } \\
\text { regenerating coastal } \\
\text { shrubland and scree }\end{array}$ & None & 4,067 & $\begin{array}{l}\text { Huggins } \\
\text { closed CMR }\end{array}$ & Chapter 4 , this thesis \\
\hline W. maculata & Turakirae Head & Grazed coastal shrubland & None & 38,372 & $\begin{array}{l}\text { Huggins } \\
\text { closed CMR }\end{array}$ & Chapter 4 , this thesis \\
\hline
\end{tabular}




\section{Bibliography}

Aguilar, G. D. and M. J. Farnworth

2013. Distribution characteristics of unmanaged cat colonies over a 20 year period in Auckland, New Zealand. Applied Geography, 37:160-167.

Alterio, N., H. Moller, and H. Ratz

1998. Movements and habitat use of feral house cats Felis catus, stoats Mustela erminea and ferrets Mustela furo, in grassland surrounding yellow-eyed penguin Megadyptes antipodes breeding areas in spring. Biological Conservation, 83(2):187-194.

Amo, L., P. López, and J. Martín

2007. Habitat deterioration affects body condition of lizards: A behavioral approach with Iberolacerta cyreni lizards inhabiting ski resorts. Biological Conservation, 135(1):77-85.

Anadón, J., A. Giménez, I. Perez, M. Martinez, and M. Esteve

2006a. Habitat selection by the spur-thighed tortoise Testudo graeca in a multisuccessional landscape: implications for habitat management. Biodiversity \& Conservation, 15(7):22872299.

Anadón, J. D., A. Giménez, M. Martínez, J. Martínez, I. Pérez, and M. A. Esteve 2006b. Factors determining the distribution of the spur-thighed tortoise Testudo graeca in south-east spain: a hierarchical approach. Ecography, 29(3):339-346.

Anastasiadis, J. M. and A. H. Whitaker

1987. Longevity of free-living Hoplodactylus maculatus (Reptilia: Gekkonidae). New Zealand Journal of Ecology, 10:141-142.

Anthony, R. G., E. D. Forsman, A. B. Franklin, D. R. Anderson, K. P. Burnham, G. C. White, C. J. Schwarz, J. D. Nichols, J. E. Hines, G. S. Olson, S. H. Ackers, L. S. Andrews, B. L. Biswell, P. C. Carlson, L. V. Diller, K. M. Dugger, K. E. Fehring, T. L. Fleming, R. P. Gerhardt, S. A. Gremel, R. J. Gutiérrez, P. J. Happe, D. R. Herter, J. M. Higley, R. B. Horn, L. L. Irwin, P. J. Loschl, J. A. Reid, and S. G. Sovern

2006. Status and trends in demography of northern spotted owls, 1985-2003. Wildlife Monographs, 163:1-48. 
Aresco, M. J.

2005. Mitigation measures to reduce highway mortality of turtles and other herpetofauna at a North Florida lake. The Journal of Wildlife Management, 69(2):549-560.

Arlidge, W. N. S., J. W. Bull, P. F. E. Addison, G. D. Burgass, M J, T. M. Gorham, C. Jacob, N. Shumway, S. P. Sinclair, W. C. Watson, J E M, and E. J. Milner-Gulland 2018. A global mitigation hierarchy for nature conservation. BioScience, 68(5):336-347.

Atkinson, I. A. E.

1985. Derivation of vegetation mapping units for an ecological survey of Tongariro National Park, North Island, New Zealand. New Zealand Journal of Botany, 23:361-378.

Bagnall, R. G.

1975. Vegetation of the raised beaches at Cape Turakirae, Wellington, New Zealand. New Zealand Journal of Botany, 13(3):367-424.

Bailey, L. L., J. E. Hines, J. D. Nichols, and D. I. MacKenzie 2007. Sampling design trade-offs in occupancy studies with imperfect detection: examples and software. Ecological Applications, 17(1):281-290.

Bailey, M. A., J. N. Holmes, K. A. Buhlmann, and J. C. Mitchell

2006. Habitat management guidelines for amphibians and reptiles of the southeastern United States. Montgomery, Alabama: Partners in Amphibian and Reptile Conservation Technical Publication HMG-2.

Baling, M., D. Stuart-Fox, D. H. Brunton, and J. Dale

2016. Habitat suitability for conservation translocation: the importance of considering camouflage in cryptic species. Biological Conservation, 203:298-305.

Ballouard, J.-M., S. Caron, T. Lafon, L. Servant, B. Devaux, and X. Bonnet

2013. Fibrocement slabs as useful tools to monitor juvenile reptiles: a study in a tortoise species. Amphibia-Reptilia, 34:1-10.

Balls, C. S.

2019. Understanding the distribution of introduced mammalian predators in urban environments using monitoring tools and community trapping. Master's thesis, Victoria University of Wellington, New Zealand.

Bannock, C. A.

1998. Implications of past and future vegetation change for the lizard fauna of Motunau Island. Master's thesis, Lincoln University, Lincoln, New Zealand.

Barr, B. P.

2009. Spatial ecology, habitat use, and the impacts of rats on chevron skinks (Oligosoma 
homalonotum) on Great Barrier Island. Master's thesis, Massey University, Albany, New Zealand.

Barwick, R. E.

1959. The life history of the common New Zealand skink Leiolopisma zelandica (Gray, 1843). Transactions of the Royal Society of New Zealand, 86(3/4):331-380.

Bates, D., M. Mächler, B. M. Bolker, and S. C. Walker 2015. Fitting linear mixed-effects models using lme4. Journal of Statistical Software, 67(1).

Beissinger, S. R. and D. R. McCullough

2002. Population Viability Analysis. Chicago, USA: University of Chicago Press.

Bell, B. D., K. M. Hare, and S. A. Pledger

2018. Lizards in the suburbs: a single-garden study of a small endemic New Zealand skink (Oligosoma aeneum). New Zealand Journal of Zoology, 45(4):341-358.

Bell, T.

2014. Standardized common names for New Zealand reptiles. BioGecko, 2:2-8.

Bell, T.

2019a. Lizard salvage compliance report: 32 Adventure Drive, Whitby. Technical report, EcoGecko Consultants Ltd., Wellington, New Zealand.

Bell, $\mathrm{T}$.

2019b. Wellington City Council lizard surveys: 2016 - 2018. Technical report, EcoGecko Consultants Ltd., Wellington, New Zealand.

Bell, T. and S. Herbert

2017a. Lizard abundance in rock stack habitat: Coronation Project Year Three. Technical report, EcoGecko Consultants Ltd., Wellington, New Zealand.

Bell, T. and A. Wiles

2015. Describing lizard and frog distribution and species assemblages using the ecological districts framework. BioGecko, 3:19-34.

Bell, T., C. Wilson, and S. Herbert

2012. Determining a conservation threat classification for the Nevis skink, Oligosoma toka. BioGecko, 1:16-28.

Bell, T. P. and S. M. Herbert

2016. Lizard abundance in rock stack habitat: Coronation Project Year Two. Technical report, EcoGecko Consultants Ltd, Wellington, New Zealand. 
Bell, T. P. and S. M. Herbert

2017b. Establishment of a self-sustaining population of a long-lived, slow-breeding gecko species (Diplodactylidae: Hoplodactylus duvaucelii) evident 15 years after translocation. Journal of Herpetology, 51(1):37-46.

Berry, O., M. D. Tocher, D. M. Gleeson, and S. D. Sarre

2005. Effect of vegetation matrix on animal dispersal: genetic evidence from a study of endangered skinks. Conservation Biology, 19(3):855-864.

Best, E.

1923. Miramar Island and its history: how Motu-kairangi was discovered and settled by Polynesians, and how, in times long past, it became Miramar Peninsula. Transactions of the New Zealand Institute, 54:779-791.

Bianchi, S., C. Cahalan, S. Hale, and J. M. Gibbons

2017. Rapid assessment of forest canopy and light regime using smartphone hemispherical photography. Ecology and Evolution, 7(24):10556-10566.

Bland, L. M. and M. Böhm

2016. Overcoming data deficiency in reptiles. Biological Conservation, 204.

Böhm, M., B. Collen, J. E. M. Baillie, P. Bowles, J. Chanson, N. Cox, G. Hammerson, M. Hoffmann, S. R. Livingstone, M. Ram, A. G. J. Rhodin, S. N. Stuart, P. P. van Dijk, B. E. Young, L. E. Afuang, A. Aghasyan, A. García, C. Aguilar, R. Ajtic, F. Akarsu, L. R. V. Alencar, A. Allison, N. Ananjeva, S. Anderson, C. Andrén, D. Ariano-Sánchez, J. C. Arredondo, M. Auliya, C. C. Austin, A. Avci, P. J. Baker, A. F. Barreto-Lima, C. L. Barrio-Amorós, D. Basu, M. F. Bates, A. Batistella, A. Bauer, D. Bennett, W. Böhme, D. Broadley, R. Brown, J. Burgess, A. Captain, S. Carreira, M. D. R. Castañeda, F. Castro, A. Catenazzi, J. R. Cedeño-Vázquez, D. G. Chapple, M. Cheylan, D. F. Cisneros-Heredia, D. Cogalniceanu, H. Cogger, C. Corti, G. C. Costa, P. J. Couper, T. Courtney, J. CrnobrnjaIsailovic, P. A. Crochet, B. Crother, F. Cruz, J. C. Daltry, R. J. R. Daniels, I. Das, A. de Silva, A. C. Diesmos, L. Dirksen, T. M. Doan, C. K. Dodd, J. S. Doody, M. E. Dorcas, J. Duarte de Barros Filho, V. T. Egan, E. H. El Mouden, D. Embert, R. E. Espinoza, A. Fallabrino, X. Feng, Z. J. Feng, L. Fitzgerald, O. Flores-Villela, F. G. R. França, D. Frost, H. Gadsden, T. Gamble, S. R. Ganesh, M. a. Garcia, J. E. García-Pérez, J. Gatus, M. Gaulke, P. Geniez, A. Georges, J. Gerlach, S. Goldberg, J. C. T. Gonzalez, D. J. Gower, T. Grant, E. Greenbaum, C. Grieco, P. Guo, A. M. Hamilton, K. Hare, S. B. Hedges, N. Heideman, C. HiltonTaylor, R. Hitchmough, B. Hollingsworth, M. Hutchinson, I. Ineich, J. Iverson, F. M. Jaksic, R. Jenkins, U. Joger, R. Jose, Y. Kaska, U. Kaya, J. S. Keogh, G. Köhler, G. Kuchling, Y. Kumlutaş, A. Kwet, E. La Marca, W. Lamar, A. Lane, B. Lardner, C. Latta, G. Latta, M. Lau, P. Lavin, D. Lawson, M. LeBreton, E. Lehr, D. Limpus, N. Lipczynski, A. S. 
Lobo, M. a. López-Luna, L. Luiselli, V. Lukoschek, M. Lundberg, P. Lymberakis, R. Macey, W. E. Magnusson, D. L. Mahler, A. Malhotra, J. Mariaux, B. Maritz, O. a. V. Marques, R. Márquez, M. Martins, G. Masterson, J. a. Mateo, R. Mathew, N. Mathews, G. Mayer, J. R. McCranie, G. J. Measey, F. Mendoza-Quijano, M. Menegon, S. Métrailler, D. a. Milton, C. Montgomery, S. a. a. Morato, T. Mott, A. Muñoz-Alonso, J. Murphy, T. Q. Nguyen, G. Nilson, C. Nogueira, H. Núñez, N. Orlov, H. Ota, J. Ottenwalder, T. Papenfuss, S. Pasachnik, P. Passos, O. S. G. Pauwels, N. Pérez-Buitrago, V. Pérez-Mellado, E. R. Pianka, J. Pleguezuelos, C. Pollock, P. Ponce-Campos, R. Powell, F. Pupin, G. E. Quintero Díaz, R. Radder, J. Ramer, A. R. Rasmussen, C. Raxworthy, R. Reynolds, N. Richman, E. L. Rico, E. Riservato, G. Rivas, P. L. B. da Rocha, M. O. Rödel, L. Rodríguez Schettino, W. M. Roosenburg, J. P. Ross, R. Sadek, K. Sanders, G. Santos-Barrera, H. H. Schleich, B. R. Schmidt, A. Schmitz, M. Sharifi, G. Shea, H. T. Shi, R. Shine, R. Sindaco, T. Slimani, R. Somaweera, S. Spawls, P. Stafford, R. Stuebing, S. Sweet, E. Sy, H. J. Temple, M. F. Tognelli, K. Tolley, P. J. Tolson, B. Tuniyev, S. Tuniyev, N. Üzüm, G. van Buurt, M. Van Sluys, A. Velasco, M. Vences, M. Veselý, S. Vinke, T. Vinke, G. Vogel, M. Vogrin, R. C. Vogt, O. R. Wearn, Y. L. Werner, M. J. Whiting, T. Wiewandt, J. Wilkinson, B. Wilson, S. Wren, T. Zamin, K. Zhou, and G. Zug

2013. The conservation status of the world's reptiles. Biological Conservation, 157:372-385.

Bolnick, D. I., T. Ingram, W. E. Stutz, L. K. Snowberg, O. L. Lau, and J. S. Paull

2010. Ecological release from interspecific competition leads to decoupled changes in population and individual niche width. Proceedings of the Royal Society B: Biological Sciences, 277(1689):1789-1797.

Bonn, A., a. S. L. Rodrigues, and K. J. Gaston

2002. Threatened and endemic species: Are they good indicators of patterns of biodiversity on a national scale? Ecology Letters, 5(6):733-741.

Bonnet, X., F. Brischchoux, D. Pearson, and P. Rivalan

2009. Beach rock as a keystone habitat for amphibious sea snakes. Environmental Conservation, 36(1):62-70.

Bonnet, X., A. Fizesan, and C. L. Michel

2013. Shelter availability, stress level and digestive performance in the aspic viper. Journal of Experimental Biology, 216:815-822.

Bonnet, X., S. Lecq, J. L. Lassay, J. M. Ballouard, C. Barbraud, J. Souchet, S. J. Mullin, and G. Provost

2016. Forest management bolsters native snake populations in urban parks. Biological Conservation, 193:1-8. 
Bowers, C. F., H. G. Hanlin, D. C. Guynn, J. P. McLendon, and J. R. Davis

2000. Herpetofaunal and vegetational characterization of a thermally-impacted stream at the beginning of restoration. Ecological Engineering, 15(SUPPL. 1):S101-S114.

Bridgman, L. J., J. Innes, C. Gillies, N. B. Fitzgerald, S. Miller, and C. M. King

2013. Do ship rats display predatory behaviour towards house mice? Animal Behaviour, 86(2):257-268.

Bro, E., P. Mayot, E. Corda, and F. Reitz

2004. Impact of habitat management on grey partridge populations: assessing wildlife cover using a multisite baci experiment. Journal of Applied Ecology, 41(5):846-857.

Brooks, T. M., R. A. Mittermeier, C. G. Mittermeier, G. A. Da Fonseca, A. B. Rylands, W. R. Konstant, P. Flick, J. Pilgrim, S. Oldfield, G. Magin, and C. Hilton-Taylor

2002. Habitat loss and extinction in the hotspots of biodiversity. Conservation Biology, 16(4):909-923.

Bruton, M. J., M. Maron, C. E. Franklin, and C. A. McAlpine

2016. The relative importance of habitat quality and landscape context for reptiles in regenerating landscapes. Biological Conservation, 193:37-47.

Buhlmann, K. A. and C. P. Osborn

2011. Use of an artificial nesting mound by wood turtles (Glyptemys insculpta): a tool for turtle conservation. Northeastern Naturalist, 18(3):315-334.

Bullock, D. J., S. G. North, M. E. Dulloo, and M. Thorsen

2002. The impact of rabbit and goat eradication on the ecology of Round Island, Mauritius. In Turning the Tide: the Eradication of Invasive Species, C. R. Veitch and M. N. Clout, eds., Pp. 53-63. Gland, Switzerland and Cambridge, UK: IUCN SSC Invasive Species Specialist Group.

Burnham, K. P. and D. J. Anderson

2002. Model Selection and Multimodel Inference. USA: Springer.

Campbell, M. R. and F. J. Mazzotti

2004. Characterization of natural and artificial alligator holes. Southeastern Naturalist, 3(4):583-594.

Carignan, V. and M.-A. Villard 2002. Selecting indicator species to monitor ecological integrity: a review. Environmental Monitoring and Assessment, 78(1):45-61. 
Carpio, A. J., J. Castro, V. Mingo, and F. S. Tortosa

2017. Herbaceous cover enhances the squamate reptile community in woody crops. Journal for Nature Conservation, 37:31-38.

Carter, E. T.

2012. Impacts of invasive plants on resource selection by the northern copperhead (Agkistrodon contortrix mokasen). Master's thesis, Purdue University, Fort Wayne, Indiana.

Carter, E. T., B. C. Eads, M. J. Ravesi, and B. A. Kingsbury 2015. Exotic invasive plants alter thermal regimes: implications for management using a case study of a native ectotherm. Functional Ecology, 29(5):683-693.

Carter, E. T., M. J. Ravesi, B. C. Eads, and B. A. Kingsbury 2017. Invasive plant management creates ecological traps for snakes. Biological Invasions, 19(1):443-453.

Case, T. J. and D. T. Bolger 1991. The role of introduced species in shaping the distribution and abundance of island reptiles. Evolutionary Ecology, 5(3):272-290.

Castellano, M. J. and T. Valone

2006. Effects of livestock removal and perennial grass recovery on the lizards of a desertified arid grassland. Journal of Arid Environments, 66(1):87-95.

Castilla, A. M. and J. G. Swallow

1995. Artificial egg-laying sites for lizards: a conservation strategy. Biological Conservation, 72:387-391.

Caswell, $\mathrm{H}$.

2001. Matrix population models: Construction, analysis, and interpretation, second edition. Sunderland, Massachusetts U.S.A: Sinauer Associates, Inc. Publishers.

Chao, A., S. Lee, and S. Jeng

1992. Estimating population size for capture-recapture data when capture probabilities vary by time and individual animal. Biometrics, 48(1):201-216.

Chapple, D. G.

2016. New Zealand Lizards. Cham, Switzerland: Springer.

Chapple, D. G., T. P. Bell, S. N. J. Chapple, K. A. Miller, C. H. Daugherty, and G. B. Patterson 2011. Phylogeography and taxonomic revision of the New Zealand cryptic skink (Oligosoma inconspicuum; Reptilia: Scincidae) species complex. Zootaxa, 2782:1-33. 
Chapple, D. G., P. A. Ritchie, and C. H. Daugherty

2009. Origin, diversification, and systematics of the New Zealand skink fauna (Reptilia: Scincidae). Molecular Phylogenetics and Evolution, 52(2):470-487.

Chaudhary, V. and M. K. Oli

2020. A critical appraisal of population viability analysis. Conservation Biology, 34(1):26-40.

Check, A. and M. Bowie

2009. Backyard Biodiversity in Canterbury. Lincoln, New Zealand: Lincoln University.

Cheke, A. S.

1984. Lizards of the Seychelles. In Biogeography and ecology of the Seychelles Islands, D. R. Stoddart, ed., Pp. 221-360. The Hague, the Netherlands: Dr. W. Junk Publishers.

Ciofi, C., J. Puswati, D. Winana, M. E. de Boer, G. Chelazzi, and P. Sastrawan 2007. Preliminary analysis of home range structure in the komodo monitor, Varanus komodoensis. Copeia, 2007(2):462-470.

Cisternas, J., P. M. Wehi, N. Haupokia, F. Hughes, M. Hughes, J. M. Germano, N. Longnecker, and P. J. Bishop

2019. Get together, work together, write together. New Zealand Journal of Ecology, 43(3):110.

Clapcott, L. and R. Gill

2015. Enhancement of floral diversity for Mana Island: Stage one - collation and review of records and data for Friends of Mana Island. Technical report, Commissioned by Friends of Mana Island, Porirua, Wellington.

Collinson, W. J., H. T. Davies-Mostert, and W. Davies-Mostert

2017. Effects of culverts and roadside fencing on the rate of roadkill of small terrestrial vertebrates in northern Limpopo, South Africa. Conservation Evidence, 14:39-43.

Conn, P. B., A. D. Arthur, L. L. Bailey, and G. R. Singleton

2006. Estimating the abundance of mouse populations of known size: promises and pitfalls of new methods. Ecological Applications, 16(2):829-837.

Connor, E. F. and E. D. McCoy

1979. The statistics and biology of the species-area relationship. The American Naturalist, 113(6):791-833.

Cosentino, B. J., R. L. Schooley, B. T. Bestelmeyer, and J. M. Coffman

2013. Response of lizard community structure to desert grassland restoration mediated by a keystone rodent. Biodiversity and Conservation, 22(4):921-935. 
Craig, M. D., R. J. Hobbs, A. H. Grigg, M. J. Garkaklis, C. D. Grant, P. A. Fleming, and G. E. S. J. Hardy

2010. Do thinning and burning sites revegetated after bauxite mining improve habitat for terrestrial vertebrates? Restoration Ecology, 18(3):300-310.

Cree, A.

1994. Low annual reproductive output in female reptiles from New Zealand. New Zealand Journal of Zoology, 21:351-372.

Cree, A. and K. M. Hare

2016. Reproduction and life history of New Zealand lizards. In New Zealand Lizards, Pp. 169-206. Cham, Switzerland: Springer.

Croak, B. M., D. A. Pike, J. K. Webb, and R. Shine

2010. Using artificial rocks to restore nonrenewable shelter sites in human-degraded systems: Colonization by fauna. Restoration Ecology, 18(4):428-438.

Croak, B. M., D. A. Pike, J. K. Webb, and R. Shine

2012. Habitat selection in a rocky landscape: Experimentally decoupling the influence of retreat site attributes from that of landscape features. PLOS ONE, 7(6):e37982.

Croak, B. M., J. K. Webb, and R. Shine

2013. The benefits of habitat restoration for rock-dwelling velvet geckos Oedura lesueurii. Journal of Applied Ecology, 50:432-439.

Cuthbert, R., E. Sommer, and L. S. Davis

2000. Seasonal variation in the diet of stoats in a breeding colony of Hutton's shearwaters. New Zealand Journal of Zoology, 27:367-373.

Cutler, P. L.

1996. Wildlife use of two artificial water developments on the Cabeza Prieta National Wildlife Refuge, Southwestern Arizona. Master's thesis, University of Arizona, Tucson, Arizona, USA.

Dail, D. and L. Madsen

2011. Models for estimating abundance from repeated counts of an open metapopulation. Biometrics, 67(2):577-587.

Daltry, J. C., Q. Bloxam, G. Cooper, M. L. Day, J. Hartley, M. Henry, K. Lindsay, and B. E. Smith

2001. Five years of conserving the 'world's rarest snake', the Antiguan racer Alsophis antiguae. Oryx, 35(2):119-127. 
Daltry, J. C., K. Lindsay, S. N. Lawrence, M. N. Morton, A. Otto, and A. Thibou 2017. Successful reintroduction of the critically endangered Antiguan racer Alsophis antiguae to offshore islands in Antigua, West Indies. International Zoo Yearbook, 51:97-106.

Daugherty, C. H., G. W. Gibbs, and R. Hitchmough 1993. Mega-island or micro-continent? New Zealand and its fauna. Trends in Ecology $\mathcal{E}$ Evolution, 8(12):437-442.

Davies, R., R. Simcock, and R. Toft

2010a. Islands in the sky : Urban biodiversity enhancement in NZ on indigenous living roof landscapes. In 44th Annual Conference of the Architectural Science Association, ANZAScA 2010, Unitec Institute of Technology.

Davies, R., R. Simcock, G. Ussher, C. DeGroot, M. Boult, and R. Toft

2010b. Elevated enclaves - living roof biodiversity enhancement through prosthetic habitats. In Cities Alive! Eighth Annual Green Roof and Wall Conference 2010 Conference Proceedings, Pp. 1-17.

Davis, J. R. and T. C. Theimer

2003. Increased lesser earless lizard (Holbrookia maculata) abundance on Gunnison's Prairie Dog colonies and short term responses to artificial prairie dog burrows. The American Midland Naturalist, 150(2):282-290.

De Lange, P. J.

2014. A revision of the New Zealand Kunzea ericoides (Myrtaceae) complex. PhytoKeys, 40:1-185.

Didham, R. K., J. M. Tylianakis, N. J. Gemmell, T. A. Rand, and R. M. Ewers 2007. Interactive effects of habitat modification and species invasion on native species decline. Trends in Ecology and Evolution, 22(9):489-496.

Dobson, A. P., A. D. Bradshaw, and A. J. M. Baker

1997. Hopes for the future: restoration ecology and conservation biology. Science, 277:515522.

DOC

2005. Attracting lizards to your garden: options for Canterbury. Christchurch, New Zealand: Department of Conservation.

DOC

2009a. Common gecko: lizards in gardens in the lower North Island. Wellington, New Zealand: Department of Conservation. 
DOC

2009b. Common skink: Lizards in gardens in the lower North Island. Wellington, New Zealand: Department of Conservation.

DOC

2009c. Gardening for lizards: how to attract lizards into gardens of the lower North Island and keep them there. Wellington, New Zealand: Department of Conservation.

DOC

2009d. Ornate skink: Lizards in gardens in the lower North Island. Wellington, New Zealand: Department of Conservation.

Dodd, C. K., W. J. Barichivich, and L. L. Smith

2004. Effectiveness of a barrier wall and culverts in reducing wildlife mortality on a heavily traveled highway in Florida. Biological Conservation, 118(5):619-631.

Doherty, T. S., C. R. Dickman, D. G. Nimmo, and E. G. Ritchie 2015. Multiple threats, or multiplying the threats? Interactions between invasive predators and other ecological disturbances. Biological Conservation, 190:60-68.

Doherty, T. S., A. S. Glen, D. G. Nimmo, E. G. Ritchie, and C. R. Dickman 2016. Invasive predators and global biodiversity loss. Proceedings of the National Academy of Sciences of the United States of America, 113(40):11261-11265.

Dowling, Z., T. Hartwig, E. Kiviat, and F. Keesing 2010. Experimental management of nesting habitat for the Blanding's turtle (Emydoidea blandingii). Ecological Restoration, 28(2):154-159.

Downes, S. and R. Shine 1998. Heat, safety or solitude? Using habitat selection experiments to identify a lizard's priorities. Animal Behaviour, 55(5):1387-1396.

Dozeman, V. A.

2004. Use of an artificial pond and marshes by amphibians and reptiles in West Virginia. Master's thesis, Marshall University, Huntington, West Virginia, USA.

Dudek, K., Z. Sajkowska, M. Gawałek, and A. Ekner-Grzyb

2015. Using body condition index can be an unreliable indicator of fitness: a case of sand lizard Lacerta agilis Linnaeus, 1758 (Sauria: Lacertidae). Turkish Journal of Zoology, 39:182184.

Dumont, C. T.

2015. An investigation into declining skink populations and their behavioural responses 
to introduced mammalian predators. Master's thesis, University of Canterbury, Christchurch, New Zealand.

East, K. T., M. R. East, and C. H. Daugherty 1995. Ecological restoration and habitat relationships of reptiles on Stephens Island, New Zealand. New Zealand Journal of Zoology, 22:249-261.

Edgar, P., J. Foster, and J. Baker

2010. Reptile Habitat Management Handbook. Bournemouth, UK: Amphibian and Reptile Conservation.

Emrich, M. E.

1991. Blanding's turtle (Emydoidea blandingii) nesting behaviour and response to an artificial nest habitat. Master's thesis, Bard College, Annandale-On-Hudson, New York, USA.

Enge, K. M. and W. R. Marion

1986. Effects of clearcutting and site preparation on herpetofauna of a North Florida flatwoods. Forest Ecology and Management, 14(3):177-192.

Evans, A. E., D. R. Towns, and J. R. Beggs

2015. Relative importance of sugar resources to endemic gecko populations in an isolated island ecosystem. New Zealand Journal of Ecology, 39(2):262-272.

Ewers, R. M., A. D. Kliskey, S. Walker, D. Rutledge, J. S. Harding, and R. K. Didham 2006. Past and future trajectories of forest loss in New Zealand. Biological Conservation, 133(3):312-325.

\section{Fahrig, L.}

1997. Relative effects of habitat loss and fragmentation on population extinction. The Journal of Wildlife Management, 61(3):603-610.

\section{Fahrig, L.}

2003. Effects of habitat fragmentation on biodiversity. Annual Review of Ecology and Systematics, 34:487-515.

Fea, N., W. Linklater, and S. Hartley

2020. Responses of New Zealand forest birds to management of introduced mammals. Conservation Biology, Accepted Author Manuscript. https:/ /doi.org/10.1111/cobi.13456.

Ferguson, R. S. and S. T. Lovell

2014. Permaculture for agroecology: design, movement, practice, and worldview. a review. Agronomy for Sustainable Development, 34(2):251-274. 
Ficetola, G. F., B. Barzaghi, A. Melotto, M. Muraro, E. Lunghi, C. Canedoli, E. L. Parrino, V. Nanni, I. Silva-Rocha, A. Urso, et al.

2018. N-mixture models reliably estimate the abundance of small vertebrates. Scientific reports, $8(1): 1-8$.

Filazzola, A., M. Westphal, M. Powers, A. R. Liczner, D. A. Smith Woollett, B. Johnson, and C. J. Lortie

2017. Non-trophic interactions in deserts: Facilitation, interference, and an endangered lizard species. Basic and Applied Ecology, 20:51-61.

Fischer, J. and D. B. Lindenmayer

2000. An assessment of the published results of animal relocations. Biological Conservation, 96(1):1-11.

Fischer, J. H., C. F. McCauley, D. P. Armstrong, I. Debski, and H. U. Wittmer

2019. Contrasting responses of lizard occurrences to burrowing by a critically endangered seabird. Community Ecology, 20(1):64-74.

Flannagan, $\mathrm{H}$.

2000. Conservation biology of the goldstripe gecko (Hoplodactylus chrysosireticus) and interactions with Duvaucel's gecko (Hoplodactylus duvavucellii) on Mana Island, Cook Strait, New Zealand. Master's thesis, Massey University, Palmerston North, New Zealand.

Floyd, T. M., K. R. Russell, C. E. Moorman, D. H. van Lear, D. C. J. Guynn, and J. D. Lanham 2002. Effects of prescribed fire on herpetofauna within hardwood forests of the Upper Piedmont of South Carolina: a preliminary analysis. In Proceedings of the Eleventh Biennial Southern Silvicultural Research Conference. Gen. Tech. Rep. SRS-48, Pp. 123-127, Asheville, NC. U.S. Department of Agriculture, Forest Service, Southern Research Station.

Francis, R. A. and J. Lorimer

2011. Urban reconciliation ecology: the potential of living roofs and walls. Journal of Environmental Management, 92(6):1429-1437.

Frank, M. R.

2011. Head-starting as a tool for the reintroduction of extirpated watersnake populations. Master's thesis, Purdue University, Fort Wayne, Indiana, USA.

Freeman, A. B.

1997. Comparative ecology of two Oligosoma skinks in coastal Canterbury: a contrast with central Otago. New Zealand Journal of Ecology, 21(2):153-160.

Frimpong, E. A.

2018. A case for conserving common species. PLOS Biology, 16(2):e2004261. 
Fuller, I. C., M. G. Macklin, and J. M. Richardson

2015. The geography of the anthropocene in New Zealand: differential river catchment response to human impact. Geographical Research, 53(3):255-269.

\section{Gabites, I.}

2015. The Coastal Garden: Design Inspiration from Wild New Zealand. Nelson, New Zealand: Potton and Burton.

Garden, J. G., C. A. McAlpine, and H. P. Possingham

2010. Multi-scaled habitat considerations for conserving urban biodiversity: native reptiles and small mammals in Brisbane, Australia. Landscape Ecology, 25:1013-1028.

Garden, J. G., C. A. McAlpine, H. P. Possingham, and D. N. Jones

2007. Habitat structure is more important than vegetation composition for local-level management of native terrestrial reptile and small mammal species living in urban remnants: A case study from Brisbane, Australia. Austral Ecology, 32:669-685.

Gardner, M. G., C. M. Bull, A. Fenner, K. Murray, and S. C. Donnellan

2007. Consistent social structure within aggregations of the Australian lizard, Egernia stokesii across seven disconnected rocky outcrops. Journal of Ethology, 25(3):263-270.

Garnock-Jones, P., D. Albach, and B. G. Briggs

2007. Botanical names in Southern Hemisphere Veronica (Plantaginaceae): sect. Detzneria, sect. Hebe, and sect. Labiatoides. Taxon, 56(2):571-582.

Gebauer, K., K. J. Dickinson, P. A. Whigham, and P. J. Seddon

2013. Matrix matters: differences of grand skink metapopulation parameters in native tussock grasslands and exotic pasture grasslands. PLoS ONE, 8(10):e76076.

Germano, J. M. and P. J. Bishop

2009. Suitability of amphibians and reptiles for translocation. Conservation Biology, 23(1):715.

Gibson, S., S. Penniket, and A. Cree

2015. Are viviparous lizards from cool climates ever exclusively nocturnal? Evidence for extensive basking in a New Zealand gecko. Biological Journal of the Linnean Society, 115(4):882-895.

Gillies, C. and M. Clout

2003. The prey of domestic cats (Felis catus) in two suburbs of Auckland City, New Zealand. Journal of Zoology, 259(3):309-315. 
Goldingay, R. L. and D. A. Newell

2000. Experimental rock outcrops reveal continuing habitat disturbance for an endangered Australian snake. Conservation Biology, 14(6):1908-1912.

Gollin, J. F.

2016. Quantifying the benefits of rat eradication to lizard populations on Kapiti Island. Master's thesis, Massey University, Palmerston North, New Zealand.

González-Aguilera, D., A. Muñoz-Nieto, J. Gómez-Lahoz, J. Herrero-Pascual, and G. Gutierrez-Alonso

2009. 3D digital surveying and modelling of cave geometry: application to paleolithic rock art. Sensors, 9(2):1108-1127.

Goodman, D.

1987a. Consideration of stochastic demography in the design and management of biological reserves. Natural Resource Modeling, 1(2):205-234.

Goodman, D.

1987b. How do any species persist? Lessons for conservation biology. Conservation Biology, 1(1):59-62.

Green, N.

2001. Resurvey of a lizard community at Turakirae Head, Wellington. Bachelor's with honours thesis, Victoria University of Wellington, Wellington, New Zealand.

Greenberg, C. H.

2001. Response of reptile and amphibian communities to canopy gaps created by wind disturbance in the southern Appalachians. Forest Ecology and Management, 148:135-144.

Greenberg, C. H., D. G. Neary, and L. D. Harris

1994. A comparison of herpetofaunal sampling effectiveness of pitfall, single-ended, and double-ended funnel traps used with drift fences. Journal of Herpetology, 28(3):319-324.

Griffith, B., J. M. Scott, J. W. Carpenter, and C. Reed

1989. Translocation as a species conservation tool: status and strategy. Science, 245(4917):477-480.

Griffiths, R.

1999. The translocation and establishment of spotted skink (Oligosoma lineoocellatum) from Matiu-Somes Island to Mana Island. Master's thesis, Victoria University of Wellington, Wellington, New Zealand. 
Griffiths, R. A., J. Foster, J. W. Wilkinson, and D. Sewell

2015. Science, statistics and surveys: A herpetological perspective. Journal of Applied Ecology, 52(6):1413-1417.

Grillet, P., M. Cheylan, J. M. Thirion, F. Doré, X. Bonnet, C. Dauge, S. Chollet, and M. A. Marchand

2010. Rabbit burrows or artificial refuges are a critical habitat component for the threatened lizard, Timon lepidus (Sauria, Lacertidae). Biodiversity and Conservation, 19(7):2039-2051.

Guillera-Arroita, G. and J. J. Lahoz-Monfort

2012. Designing studies to detect differences in species occupancy: power analysis under imperfect detection. Methods in Ecology and Evolution, 3(5):860-869.

Gyllenberg, M. and I. Hanski

1997. Habitat deterioration, habitat destruction, and metapopulation persistence in a heterogenous landscape. Theoretical Population Biology, 52(3):198-215.

Hadfield, J. D.

2010. MCMC methods for multi-response generalized linear mixed models: the MCMCglmm R package. Journal of Statistical Software, 33(2):1-22.

Hanski, I.

1999. Metapopulation Ecology. Oxford, UK: Oxford University Press.

Hanski, I.

2011. Habitat loss, the dynamics of biodiversity, and a perspective on conservation. AMBIO, 40(3):248-255.

Hanski, I. and O. Ovaskainen

2002. Extinction debt at extinction threshold. Conservation Biology, 16(3):666-673.

Hare, K. M.

2012. Herpetofauna: pitfall trapping. Technical report, DOCDM-760240, Department of Conservation, Wellington, New Zealand.

Hare, K. M., D. G. Chapple, D. R. Towns, and D. van Winkel

2016. The ecology of New Zealand's lizards. In New Zealand Lizards, Pp. 133-168. Cham, Switzerland: Springer.

Hare, K. M. and A. Cree

2005. Natural history of Hoplodactylus stephensi (Reptilia: Gekkonidae) on Stephens Island, Cook Strait, New Zealand. New Zealand Journal of Ecology, 29:137-142. 
Hare, K. M. and A. Cree

2016. Thermal and metabolic physiology of New Zealand lizards. In New Zealand Lizards, Pp. 239-267. Cham, Switzerland: Springer.

Hare, K. M. and J. M. Hoare

2005. Hoplodactylus maculatus (common gecko). Aggregations. Herpetological Review, 36(2):179.

Hartwig, T. S. and E. Kiviat

2007. Microhabitat association of Blanding's Turtles in natural and constructed wetlands in southeastern New York. Journal of Wildlife Management, 71(2):576-582.

Heaney, L. R.

1986. Biogeography of mammals in SE Asia: estimates of rates of colonization, extinction and speciation. Biological Journal of the Linnean Society, 28:127-165.

Hecnar, S. J. and R. T. M'Closkey

1998. Effects of human disturbance on five-lined skink, Eumeces fasciatus, abundance and distribution. Biological Conservation, 85:213-222.

Herbert, S. and T. Bell

2012. Survey design options for monitoring lizards at Baring Head, East Harbour Regional Park. Technical report, EcoGecko Consultants Ltd., New Plymouth, New Zealand.

Herbert, S. and T. Bell

2019. Lizard monitoring at Baring Head / Ōrua-pouanui, East Harbour Regional Park, Wellington: December 2018 season. Technical report, EcoGecko Consultants Ltd, Wellington, New Zealand.

Herbert, S., C. Knox, and T. Bell

2013a. Mt Cass lizard monitoring programme: outcomes from pilot population monitoring and analysis of design. Technical report, EcoGecko Consultants Ltd., New Plymouth, New Zealand.

Herbert, S., C. Knox, and T. Bell

2014a. Mt Cass lizard population monitoring programme: report for 2014 season. Technical report, EcoGecko Cosultants Ltd., Wellington, New Zealand.

Herbert, S., S. Melzer, and O. Spearpoint

2014b. Lizard monitoring at the Baring Head block, East Harbour Regional Park, Wellington: December 2013 season. Technical report, EcoGecko Consultants Ltd., Wellington, New Zealand. 
Herbert, S., S. Melzer, O. Spearpoint, and T. Bell

2013b. Lizard monitoring at the Baring Head block, East Harbour Regional Park, Wellington: summer 2012/13 season. Technical report, EcoGecko Consultants Ltd., Wellington, New Zealand.

Herbert, S., M. Nelson-Tunley, C. Knox, and T. Bell

2015. Report on the lizard salvage and mitigation effort for the Barrhill Chertsey Irrigation Pipeline. Technical report, EcoGecko Consultants Ltd., Wellington, New Zealand.

Herbert, S. M. and T. P. Bell

2018. Lizard monitoring at Baring Head / Ōrua-pouanui, East Harbour Regional Park, Wellington: December 2017 season. Technical report, EcoGecko Consultants Ltd., Wellington, New Zealand.

Hines, J. E.

2006. PRESENCE- Software to estimate patch occupancy and related parameters. USGS-PWRC, Laurel, Maryland, USA. http:/ /www.mbr-pwrc.usgs.gov/software/presence.html.

Hitchmough, R., B. Barr, M. Lettink, J. Monks, J. Reardon, M. Tocher, D. van Winkel, and J. Rolfe

2016a. Conservation Status of New Zealand Reptiles, 2015. Technical report, Department of Conservation, Wellington, New Zealand.

Hitchmough, R. A., L. K. Adams, J. T. Reardon, and J. M. Monks

2016b. Current challenges and future directions in lizard conservation in New Zealand. Journal of the Royal Society of New Zealand, 46(1):29-39.

Hoare, J., D. Hodapp, I. Westbrooke, M. Lettink, and C. O'Donnell

2009. Optimising the sampling of skinks using artificial retreats based on weather conditions and time of day. Applied Herpetology, 6(4):379-390.

Hoare, J. M.

2006. Novel predators and naive prey: how introduced mammals shape behaviours and populations of New Zealand lizards. PhD thesis, Victoria University of Wellington, Wellington, New Zealand.

Hoare, J. M., L. K. Adams, L. S. Bull, and D. R. Towns

2007a. Attempting to manage complex predator prey interactions fails to avert imminent extinction of a threatened New Zealand skink population. Journal of Wildlife Management, 71(5):1576-1584.

Hoare, J. M., S. Pledger, N. J. Nelson, and C. H. Daugherty

2007b. Avoiding aliens: Behavioural plasticity in habitat use enables large, nocturnal geckos to survive Pacific rat invasions. Biological Conservation, 136(4):510-519. 
Hobbs, R. J., E. Higgs, C. M. Hall, P. Bridgewater, F. S. Chapin III, E. C. Ellis, J. J. Ewel, L. M. Hallett, J. Harris, K. B. Hulvey, et al.

2014. Managing the whole landscape: historical, hybrid, and novel ecosystems. Frontiers in Ecology and the Environment, 12(10):557-564.

Hobbs, R. J., E. Higgs, and J. A. Harris

2009. Novel ecosystems: implications for conservation and restoration. Trends in Ecology $\mathcal{E}$ Evolution, 24(11):599-605.

Hoekstra, J. M., T. M. Boucher, T. H. Ricketts, and C. Roberts

2005. Confronting a biome crisis: global disparities of habitat loss and protection. Ecology Letters, 8:23-29.

Holt, R. D.

1977. Predation, apparent competition, and the structure of prey communities. Theoretical Population Biology, 12(2):197-229.

Holt, R. D.

1992. A neglected facet of island biogeography: the role of internal spatial dynamics in area effects. Theoretical Population Biology, 41(3):354-371.

Holt, R. D. and M. B. Bonsall

2017. Apparent competition. Annual Review of Ecology, Evolution, and Systematics, 48(1):447-471.

Holt, R. D. and J. H. Lawton

1994. The ecological consequences of shared natural enemies. Annual Review of Ecology and Systematics, 25:495-520.

Homan, P.

2012. The use of artificial habitat during surveys of small, terrestrial vertebrates at three sites in Victoria. The Victorian Naturalist, 129(4):128-137.

Homyack, J. D. and W. M. Giuliano

2002. Effect of streambank fencing on herpetofauna in pasture stream zones. Wildlife Society Bulletin, 30(2):361-369.

Howard, R., I. Williamson, and P. Mather

2003. Structural aspects of microhabitat selection by the skink Lampropholis delicata. Journal of Herpetology, 37(3):613-617.

\section{Huey, R. B.}

1982. Temperature, physiology and the ecology of reptiles. In Biology of the Reptilia, F. H. P. C. Gans, ed., Pp. 25-91. London, UK: Academic Press. 
Huggins, R.

1989. On the statistical analysis of capture experiments. Biometrika, 76(1):133-140.

Huggins, R.

1991. Some practical aspects of a conditional likelihood approach to capture experiments. Biometrics, 47:725-732.

Inger, R. F. and R. K. Colwell

1977. Organzation of contiguous communities of amphibians and reptiles in Thailand. Ecological Monographs, 47:229-253.

Innes, J., N. Fitzgerald, R. Binny, A. Byrom, R. Pech, C. Watts, C. Gillies, M. Maitland, C. Campbell-Hunt, and B. Burns

2019. New Zealand ecosanctuaries: types, attributes and outcomes. Journal of the Royal Society of New Zealand, 49(3):370-393.

Innes, J., C. M. King, L. Bridgman, N. Fitzgerald, G. Arnold, and N. Cox

2010. Effect of grazing on ship rat density in forest fragments of lowland Waikato, New Zealand. New Zealand Journal of Ecology, 34(2):227-232.

Isaac, L. A. and P. T. Gregory

2004. Thermoregulatory behaviour of gravid and non-gravid female grass snakes (Natrix natrix) in a thermally limiting high-latitude environment. Journal of Zoology, 264(4):403409.

Jackson, S. T. and D. F. Sax

2010. Balancing biodiversity in a changing environment: extinction debt, immigration credit and species turnover. Trends in Ecology and Evolution, 25(3):153-160.

Jellinek, S., D. A. Driscoll, and J. B. Kirkpatrick

2004. Environmental and vegetation variables have a greater influence than habitat fragmentation in structuring lizard communities in remnant urban bushland. Austral Ecology, 29:294-304.

Jellinek, S., K. M. Parris, M. A. Mccarthy, B. A. Wintle, and D. A. Driscoll

2014. Reptiles in restored agricultural landscapes: the value of linear strips, patches and habitat condition. Animal Conservation, 17:544-554.

Jennings, M. D.

2000. Gap analysis: concepts, methods, and recent results. Landscape Ecology, 15:5-20.

Jewell, T.

2011. Reptiles and Amphibians of New Zealand. Auckland, New Zealand: New Holland Publishers (NZ) Ltd. 
Johnson, B. D., J. P. Gibbs, T. A. Bell, and K. T. Shoemaker

2016. Manipulation of basking sites for endangered eastern massasauga rattlesnakes. Journal of Wildlife Management, 80(5):803-811.

Johnson, G.

1995. Spatial ecology, habitat preference, and habitat management of the Eastern Massasauga, Sistrurus c. catenatus in a New York weakly-mineatrophic peatland. PhD thesis, State University of New York, Syracuse, New York.

Johnson, G. and D. T. Leopold

1998. Habitat management for the Eastern Massasauga in a central New York peatland. The Journal of Wildlife Management, 62(1):84-97.

Jones, B., S. F. Fox, D. M. Leslie, D. M. Engle, and R. L. Lochmiller 2000. Herpetofaunal responses to brush management with herbicide and fire. Journal of Range Management, 53(2):154-158.

Jones, C. and T. Bell

2010. Relative effects of toe-clipping and pen-marking on short-term recapture probability of McCann's skinks (Oligosoma maccani). Herpetological Journal, 20:237-241.

Jones, C., G. Norbury, and T. Bell

2013. Impacts of introduced European hedgehogs on endemic skinks and weta in tussock grassland. Wildlife Research, 40(1):36-44.

Karr, J. R.

1981. Assessment of biotic integrity using fish communities. Fisheries, 6(6):21-27.

Kilpatrick, E. S., D. B. Kubacz, D. C. J. Guynn, J. D. Lanham, and T. A. Waldrop 2004. The effects of prescribed burning and thinning on herpetofauna and small mammals in the Upper Piedmont of South Carolina: preliminary results of the national fire and fire surrogate study. In Proceedings of the 12th biennial southern silvicultural research conference. Gen. Tech. Rep. SRS-71, K. F. Connor, ed., Pp. 18-22, Asheville, NC. U.S. Department of Agriculture, Forest Service, Southern Research Station.

King, C. M.

1990. The handbook of New Zealand mammals. Oxford, UK: Oxford University Press.

Kiviat, E., G. Stevens, R. Brauman, S. Hoeger, P. J. Petokas, and G. G. Hollands

2000. Restoration of wetland and upland habitat for the Blanding's Turtle, Emydoidea blandingii. Chelonian Conservation and Biology, 3(4):650-657.

Knox, C. D.

2010. Habitat requirements of the jewelled gecko (Naultinus gemmeus): effects of grazing, 
predation and habitat fragmentation. Master's thesis, University of Otago, Dunedin, New Zealand.

Knox, C. D., A. Cree, and P. J. Seddon

2012. Direct and indirect effects of grazing by introduced mammals on a native, arboreal gecko (Naultinus gemmeus). Journal of Herpetology, 46(2):145-152.

Kremen, C.

2015. Reframing the land-sparing/land-sharing debate for biodiversity conservation. Annals of the New York Academy of Sciences, 1355(1):52-76.

Kuussaari, M., R. Bommarco, R. K. Heikkinen, A. Helm, J. Krauss, R. Lindborg, E. Ockinger, M. Partel, J. Pino, F. Roda, C. Stefanescu, T. Teder, M. Zobel, and I. Steffan-Dewenter 2009. Extinction debt: a challenge for biodiversity conservation. Trends in Ecology and Evolution, 24(10):564-571.

Lagarde, F., T. Louzizi, T. Slimani, H. El Mouden, K. Ben Kaddour, S. Moulherat, and $X$. Bonnet

2012. Bushes protect tortoises from lethal overheating in arid areas of Morocco. Environmental Conservation, 39(2):172-182.

Lardner, B., J. A. Savidge, G. H. Rodda, R. N. Reed, and A. A. Yackel Adams 2009. The results of nocturnal visual surveys are influenced by lamp properties. Applied Herpetology, 6:391-396.

Lardner, B., A. A. Yackel Adams, A. J. Knox, J. A. Savidge, and R. N. Reed 2019. Do observer fatogue and taxon bias compromise visual encounter surveys for small vertebrates? Wildlife Research, 46:127-135.

Lawton, J. H.

1993. Range, population abundance and conservation. Trends in Ecology and Evolution, 8(11):409-413.

Lee, M. S., M. N. Hutchinson, T. H. Worthy, M. Archer, A. J. Tennyson, J. P. Worthy, and R. P. Scofield

2009. Miocene skinks and geckos reveal long-term conservatism of New Zealand's lizard fauna. Biology Letters, 5(6):833-837.

Lelievre, H., G. Blouin-Demers, X. Bonnet, and O. Lourdais

2010. Thermal benefits of artificial shelters in snakes: A radiotelemetric study of two sympatric colubrids. Journal of Thermal Biology, 35:324-331. 
Lennon, $\mathrm{O}$.

2019. Mitigation translocation for conservation of New Zealand skinks. PhD thesis, Victoria University of Wellington.

Lerma, J. L., S. Navarro, M. Cabrelles, and V. Villaverde

2010. Terrestrial laser scanning and close range photogrammetry for 3D archaeological documentation: the Upper Palaeolithic Cave of Parpalló as a case study. Journal of Archaeological Science, 37(3):499-507.

Lettink, M. and A. Cree

2007. Relative use of three types of artificial retreats by terrestrial lizards in grazed coastal shrubland, New Zealand. Applied Herpetology, 4(3):227-243.

Lettink, M. and C. Knox

2011. Looking After Jewelled Geckos and Their Habitats: A Practical Guide for Landowners. Christchurch, New Zealand: Department of Conservation.

Lettink, M. and J. M. Monks

2016. Survey and monitoring methods for New Zealand lizards. Journal of the Royal Society of New Zealand, 46(1):16-28.

Lettink, M., G. Norbury, A. Cree, P. J. Seddon, R. P. Duncan, and C. J. Schwarz

2010. Removal of introduced predators, but not artificial refuge supplementation, increases skink survival in coastal duneland. Biological Conservation, 143(1):72-77.

Leu, S. T. and C. M. Bull

2016. Artificial water point for livestock influences spatial ecology of a native lizard species. PLoS ONE, 11(1):e0147433.

Leynaud, G. C. and E. H. Bucher

2005. Restoration of degraded Chaco woodlands: effects on reptile assemblages. Forest Ecology and Management, 213:384-390.

Liggins, L., D. G. Chapple, C. H. Daugherty, and P. A. Ritchie 2008. A SINE of restricted gene flow across the Alpine Fault: Phylogeography of the New Zealand common skink (Oligosoma nigriplantare polychroma). Molecular Ecology, 17(16):3668-3683.

Linares, A. M. and P. C. Eterovick

2013. Herpetofaunal surveys support successful reconciliation ecology in secondary and human-modified habitats at the Inhotim Institute, Southeastern Brazil. Herpetologica, 69(2):237-256. 
Linklater, W. and J. Steer

2018. Predator Free 2050: A flawed conservation policy displaces higher priorities and better, evidence-based alternatives. Conservation Letters, 11(6):e12593.

Litt, A. R., L. Provencher, G. W. Tanner, and R. Franz

2001. Herpetofaunal responses to restoration treatments of longleaf pine sandhills in Florida. Restoration Ecology, 9(4):462-474.

Lundholm, J. T. and P. J. Richardson

2010. Habitat analogues for reconciliation ecology in urban and industrial environments. Journal of Applied Ecology, 47(5):966-975.

MacArthur, R. H. and E. O. Wilson

1963. An equilibrium theory of insular zoogeography. Evolution, 17(4):373-387.

Mace, G. M., N. J. Collar, K. J. Gaston, C. Hilton-Taylor, H. R. Akcakaya, N. Leader-Williams, E. J. Milner-Gulland, and S. N. Stuart

2008. Quantification of extinction risk: IUCN's system for classifying threatened species. Conservation Biology, 6:1424-1442.

MacKenzie, D. I.

2006. Modeling the probability of resource use: the effect of, and dealing with, detecting a species imperfectly. Journal of Wildlife Management, 70(2):367-374.

MacKenzie, D. I. and L. L. Bailey

2004. Assessing the fit of site-occupancy models. Journal of Agricultural, Biological, and Environmental Statistics, 9(3):300-318.

MacKenzie, D. I. and J. D. Nichols

2004. Occupancy as a surrogate for abundance estimation. Animal Biodiversity and Conservation, 27(1):461-467.

MacKenzie, D. I., J. D. Nichols, J. E. Hines, M. G. Knutson, and A. B. Franklin 2003. Estimating site occupancy, colonization, and local extinction when a species is detected imperfectly. Ecology, 84(8):2200-2207.

MacKenzie, D. I., J. D. Nichols, G. B. Lachman, S. Droege, A. A. Royle, and C. A. Langtimm 2002. Estimating site occupancy rates when detection probabilities are less than one. Ecology, 83(8):2248-2255.

MacKenzie, D. I., J. D. Nichols, J. A. Royle, K. Pollock, L. Bailey, and J. E. Hines 2017. Occupancy estimation and modelling: inferring patterns and dynamics of species occurence, 2nd edition. London, UK: Academic Press (Elsevier). 
Markwell, T. J.

1999. Keystone species on New Zealand offshore islands: ecological relationships of seabirds, rats, reptiles and invertebrates on Cook Strait islands. PhD thesis, Victoria University of Wellington, Wellington, New Zealand.

Maron, M., R. J. Hobbs, A. Moilanen, J. W. Matthews, K. Christie, T. A. Gardner, D. A. Keith, D. B. Lindenmayer, and C. A. McAlpine

2012. Faustian bargains? Restoration realities in the context of biodiversity offset policies. Biological Conservation, 155:141-148.

Márquez-Ferrando, R., J. M. Pleguezuelos, X. Santos, D. Ontiveros, and J. R. FernándezCardenete

2009. Recovering the reptile community after the mine-tailing accident of Aznalcóllar (southwestern Spain). Restoration Ecology, 17(5):660-667.

Marshall, J. M.

1983. Homing and celestial orientation in two lizards Hoplodactylus maculatus and Leiolopisma nigriplantare. Bachelor's with honours thesis, Victoria University of Wellington, Wellington, New Zealand.

Martín, J. and P. Lopez

2002. The effect of Mediterranean dehesa management on lizard distribution and conservation. Biological Conservation, 108:213-219.

Mazerolle, M. J., L. L. Bailey, W. L. Kendall, J. A. Royle, S. J. Converse, and J. D. Nichols 2007. Making great leaps forward: accounting for detectability in herpetological field studies. Journal of Herpetology, 41(4):672-689.

Mcdonald, T., G. D. Gann, J. Jonson, and K. W. Dixon

2016. International standards for the practice of ecological restoration - including principles and key concepts. First Edition. Washington, D.C., U.S.A.: Society for Ecological Restoration.

McDougall, A., R. N. Milner, D. A. Driscoll, and A. L. Smith

2016. Restoration rocks: integrating abiotic and biotic habitat restoration to conserve threatened species and reduce fire fuel load. Biodiversity and Conservation, 25(8):1529-1542.

McEwen, W. M.

1987. Ecological districts and regions of New Zealand (in four 1:500,000 maps). Wellington, New Zealand: New Zealand Biological Resources Centre publication No. 5, Department of Conservation.

McGlone, M. S.

1989. The Polynesian settlement of New Zealand in relation to environmental and biotic changes. New Zealand Journal of Ecology, 12(Suppl.):115-129. 
Melgren, $\mathrm{P}$.

2012. Observations from a goldstripe gecko, Woodworthia chrysosireticus, population in suburban New Plymouth. BioGecko, 1:34-37.

Melzer, S., T. Bell, and G. B. Patterson

2017. Hidden conservation vulnerability within a cryptic species complex: taxonomic revision of the spotted skink (Oligosoma lineoocellatum; Reptilia: Scincidae) from New Zealand. Zootaxa, 4350(3):355-379.

Melzer, S., R. A. Hitchmough, T. Bell, and G. B. Chapple, David G. amd Patterson 2019. Lost and found: taxonomic revision of the speckled skink (Oligosoma infrapunctatum; Reptilia; Scincidae) species complex from New Zealand reveals a potential cryptic extinction, resurrection of two species, and description of three new species. Zootaxa, 4623(3):411-484.

Mensforth, C. L. and C. M. Bull

2008. Selection of artificial refuge structures in the Australian skink, Egernia stokesii. Pacific Conservation Biology, 14:63-68.

Menz, M. H., K. W. Dixon, and R. J. Hobbs

2013. Hurdles and opportunities for landscape-scale restoration. Science, 339(6119):526527.

Michael, D. R., I. D. Lunt, and W. A. Robinson

2004. Enhancing fauna habitat in grazed native grasslands and woodlands: use of artificially placed log refuges by fauna. Wildlife Research, 31:65-71.

Miller, K. A., T. P. Bell, and J. M. Germano

2014. Understanding publication bias in reintroduction biology by assessing translocations of New Zealand's herpetofauna. Conservation Biology, 28(4):1045-1056.

Miller, K. A., M. A. Gruber, S. N. Keall, B. Blanchard, and N. J. Nelson

2010. Changing taxonomy and the need for supplementation in the management of re-introductions of Brothers Island tuatara in Cook Strait, New Zealand. In Global ReIntroduction Perspectives: Additional case-studies from around the globe, P. Soorae, ed., Pp. 9397. Abu Dhabi, UAE: IUCN/SSC Re-introduction Specialist Group \& Environment Agency.

Milne, T., C. M. Bull, and M. N. Hutchinson

2003a. Fitness of the endangered pygmy blue tongue lizard Tiliqua adelaidensis in artificial burrows. Journal of Herpetology, 37(4):762-765. 
Milne, T., C. M. Bull, and M. N. Hutchinson

2003b. Use of burrows by the endangered pygmy blue-tongue lizard, Tiliqua adelaidensis (Scincidae). Wildlife Research, 30(5):523-528.

Miskelly, C.

2010. Mana Island ecological restoration plan review. Technical Report June, Department of Conservation, Wellington, New Zealand.

Monks, A., E. Hayman, and S. Walker

2019. Attrition of recommended areas for protection: clearance of ecologically significant vegetation on private land. New Zealand Journal of Ecology, 43(2):33-67.

Monks, J. M., A. Monks, and D. R. Towns

2014. Correlated recovery of five lizard populations following eradication of invasive mammals. Biological Invasions, 16(1):167-175.

Moulherat, S., V. Delmas, T. Slimani, E. H. El Mouden, T. Louzizi, F. Lagarde, and X. Bonnet 2014. How far can a tortoise walk in open habitat before overheating? Implications for conservation. Journal of Nature Conservation, 22:186-192.

Myers, N., R. A. Mittermeier, C. G. Mittermeier, G. A. Da Fonseca, and J. Kent 2000. Biodiversity hotspots for conservation priorities. Nature, 403(6772):853.

Nelson, N. J., S. N. Keall, D. Brown, and C. H. Daugherty

2002. Establishing a new wild population of tuatara (Sphenodon guntheri). Conservation Biology, 16(4):887-894.

Nelson, N. J., R. L. Romijn, T. Dumont, J. T. Reardon, J. M. Monks, R. A. Hitchmough, R. Empson, and J. V. Briskie

2016. Lizard conservation in mainland sanctuaries. In New Zealand Lizards, Pp. 321-339. Cham, Switzerland: Springer.

Nelson-Tunley, M., M. Morgan-Richards, and S. A. Trewick

2016. Genetic diversity and gene flow in a rare New Zealand skink despite fragmented habitat in a volcanic landscape. Biological Journal of the Linnean Society, 119(1):37-51.

Newman, D. G.

1994. Effects of a mouse, Mus musculus, eradication programme and habitat change on lizard populations of Mana Island, New Zealand, with special reference to McGregor's skink, Cyclodina macgregori. New Zealand Journal of Zoology, 21(4):443-456.

Newman, D. G.

2015. Lizard monitoring at Pukerua Bay: January - March 2015. Technical report, for the Department of Conservation, Wellington, New Zealand. 
Newman, D. G.

2016. Lizard Monitoring at Pukerua Bay: January - March 2016: summary of results and points for discussion. Technical report, for the Department of Conservation, Wellington, New Zealand.

Newman, D. G.

2017. Lizard Monitoring at Pukerua Bay: January - March 2018: summary of results and points for discussion. Technical report, for the Department of Conservation, Wellington, New Zealand.

Newman, D. G.

2018. Lizard Monitoring at Pukerua Bay: January - March 2018 summary of results. Technical Report March, for the Department of Conservation, Wellington, New Zealand.

Nielsen, S. V., A. M. Bauer, T. R. Jackman, R. A. Hitchmough, and C. H. Daugherty

2011. New Zealand geckos (Diplodactylidae): cryptic diversity in a post-Gondwanan lineage with trans-Tasman affinities. Molecular Phylogenetics and Evolution, 59:1-22.

Noon, B. R. and K. S. McKelvey

1996. Management of the spotted owl: a case history in conservation biology. Annual Review of Ecology and Systematics, 27(1996):135-162.

Norbury, G.

2001. Conserving dryland lizards by reducing predator-mediated apparent competition and direct competition with introduced rabbits. The Journal of Applied Ecology, 38(6):13501361.

Norbury, G., A. Byrom, R. Pech, J. Smith, D. Clarke, D. Anderson, and G. Forrester 2013. Invasive mammals and habitat modification interact to generate unforeseen outcomes for indigenous fauna. Ecological Applications, 23(7):1707-1721.

Norbury, G., A. Hutcheon, J. Reardon, and A. Daigneault

2014a. Pest fencing or pest trapping: A bio-economic analysis of cost-effectiveness. Austral Ecology, 39(7):795-807.

Norbury, G., M. Van Den Munckhof, S. Neitzel, A. Hutcheon, J. Reardon, and K. Ludwig $2014 \mathrm{~b}$. Impacts of invasive house mice on post-release survival of translocated lizards. New Zealand Journal of Ecology, 38(2):322-327.

Ohmer, M. E. and P. J. Bishop

2011. Citation rate and perceived subject bias in the amphibian-decline literature. Conservation Biology, 25(1):195-199. 
Oksanen, A. J., F. G. Blanchet, M. Friendly, R. Kindt, P. Legendre, D. Mcglinn, P. R. Minchin, R. B. O. Hara, G. L. Simpson, P. Solymos, M. H. H. Stevens, and E. Szoecs 2019. Package 'vegan'. https://cran.r-project.org, https://github.com/vegandevs/vegan.

O'Shea, M. B.

2005. Methods for assessment and techniques for management of striped legless lizard Delma impar populations in south-eastern Australia. PhD thesis, Victoria University, Melbourne, Australia.

Otis, D. L., K. P. Burnham, G. C. White, and D. R. Anderson

1978. Statistical inference from capture data on closed animal populations. Wildlife Monographs, 62:3-135.

Owen-Smith, N.

2007. Introduction to Modeling in Wildlife and Resource Conservation. Maldon, MA, USA: Blackwell.

Pander, J. and J. Geist

2013. Ecological indicators for stream restoration success. Ecological Indicators, 30:106-118.

Park, G.

1995. Ngā Uruora: Ecology and History in a New Zealand Landscape. Wellington, New Zealand: Victoria University Press.

Paterson, J. E.

2011. Resource selection in a freshwater turtle community in central Ontario. Master's thesis, Laurentian University, Sudbury, Ontario, Canada.

Paterson, J. E., B. D. Steinberg, and J. D. Litzgus

2013. Not just any old pile of dirt: evaluating the use of artificial nesting mounds as conservation tools for freshwater turtles. Oryx, 47(04):607-615.

Patterson, G. B.

1985. The ecology and taxonomy of the common skink Leiolopisma nigriplantare maccani in tussock grasslands in Otago. PhD thesis, University of Otago, Dunedin, New Zealand.

Patterson, G. B.

1992. The ecology of a New Zealand grassland lizard guild. Journal of the Royal Society of New Zealand, 22(2):91-106.

Phillpot, P.

2000. The skinks of North Brother Island: abundance, habitat use and species interactions. Master's thesis, Victoria University of Wellington, Wellington, New Zealand. 
Pianka, E. R.

1967. On lizard species diversity: North American flatland deserts. Ecology, 48:333-351.

Pike, D. A., J. K. Webb, and R. Shine

2011a. Chainsawing for conservation: ecologically informed tree removal for habitat management. Ecological Management and Restoration, 12(2):110-118.

Pike, D. A., J. K. Webb, and R. Shine

2011b. Removing forest canopy cover restores a reptile assemblage. Ecological Applications, 21(1):274-280.

Pillans, B. and P. Huber

1992. Earthquakes and uplift history of Miramar Peninsula, Wellington. Technical report, Geology Department, Research School of Earth Sciences, Victoria University of Wellington, Wellington, New Zealand.

Pilliod, D. S. and E. Wind, eds.

2008. Habitat Management Guidelines for Amphibians and Reptiles of the Northwestern United States and Western Canada. Birmingham, Alabama: Partners in Amphibian and Reptile Conservation.

Pledger, S.

2000. Unified maximum likelihood estimates for closed capture-recapture models using mixtures. Biometrics, 56(2):434-442.

Porter, R.

1982. Aspects of the ecology and distribution of the skinks Cyclodina aenea (Girard) and Cyclodina ornata (Gray) in northern New Zealand. Master's thesis, University of Auckland, Auckland, New Zealand.

Porter, R.

1987. An ecological comparison of two Cyclodina skinks (Reptilia: Lacertilia) in Auckland, New Zealand. New Zealand Journal of Zoology, 14(4):493-507.

Pulsford, S. A., D. A. Driscoll, P. S. Barton, and D. B. Lindenmayer

2017. Remnant vegetation, plantings and fences are beneficial for reptiles in agricultural landscapes. Journal of Applied Ecology, 54(6):1710-1719.

QGIS Development Team

2016. QGIS Geographic Information System v 2.18 'Las Palmas'. Open Source Geospatial Foundation. http: / / qgis.org. 
R Core Team

2018. R: A Language and Environment for Statistical Computing. R Foundation for Statistical Computing, Vienna, Austria. www.r-project.org.

Ramesh, K. and P. McGowan

2009. On the current status of Indian Peafowl Pavo cristatus (Aves: Galliformes: Phasianidae): keeping the common species common. Journal of Threatened Taxa, 1(2):106108.

Rand, A. S.

1964. Ecological distribution in anoline lizards of Puerto Rico. Ecology, 45:745-752.

Ratz, H.

2000. Movements by stoats (Mustela erminea) and ferrets (M. furo) through rank grass of yellow-eyed penguin (Megadyptes antipodes) breeding areas. New Zealand Journal of Zoology, 27:57-69.

Reading, C. J. and G. M. Jofré

2015. Habitat use by smooth snakes on lowland heath managed using 'conservation grazing'. The Herpetological Journal, 25(4):225-231.

Reading, C. J. and G. M. Jofré

2016. Habitat use by grass snakes and three sympatric lizard species on lowland heath managed using 'conservation grazing'. The Herpetological Journal, 26(2):131-138.

Reardon, J. T., N. Whitmore, K. M. Holmes, L. M. Judd, A. D. Hutcheon, G. Norbury, and D. I. Mackenzie

2012. Predator control allows critically endangered lizards to recover on mainland New Zealand. New Zealand Journal of Ecology, 36(2):141-150.

Reid, B. N., R. P. Thiel, and M. Z. Peery

2016. Population dynamics of endangered blanding's turtles in a restored area. Journal of Wildlife Management, 80(3):553-562.

Rey Benayas, J. M., J. M. Bullock, and A. C. Newton 2008. Creating woodland islets to reconcile ecological restoration, conservation, and agricultural land use. Frontiers in Ecology and the Environment, 6(6):329-336.

Ribeiro, R., X. Santos, N. Sillero, M. A. Carretero, and A. L. Gustavo

2009. Biodiversity and land uses at a regional scale: is agriculture the biggest threat for reptile assemblages? Acta Oecologica, 35:327-334. 
Robert, A., B. Colas, I. Guigon, C. Kerbiriou, J. B. Mihoub, M. Saint-Jalme, and F. Sarrazin 2015. Defining reintroduction success using IUCN criteria for threatened species: A demographic assessment. Animal Conservation, 18(5):397-406.

Rodriguez, A., G. Crema, and M. Delibes 1996. Use of non-wildlife passages across a high speed railway by terrestrial vertebrates. Journal of Applied Ecology, 33(6):1527-1540.

Romijn, R.

2007. New Zealand lizards: an environmental education teaching resource for levels 3 and 4. Greater Wellington Regional Council, Wellington, New Zealand.

Romijn, R.

2011. Lizard fauna of Baring Head and Whitireia Park. Technical report, Greater Wellington Regional Council, Wellington, New Zealand.

Romijn, R., L. Adams, and R. Hitchmough

2012. Lizard strategy for the Wellington region 2012-20. Technical report, Wellington Regional Lizard Network, Wellington, New Zealand.

Romijn, R., N. Nelson, and J. Monks

2014. Forest geckos (Mokopirirakau 'Southern North Island') display diurno-nocturnal activity and are not reliant on retreats. New Zealand Journal of Zoology, 41(2):103-113.

Rosenzweig, M. L.

2003. Reconciliation ecology and the future of species diversity. Oryx, 37(2):194-205.

Rosenzweig, M. L.

2016. Green roofs: new ecosystems to defend species diversity. Israel Journal of Ecology $\mathcal{E}$ Evolution, 62(1-2):7-14.

Royle, J. A.

2004. N-mixture models for estimating population size from spatially replicated counts. Biometrics, 60(1):108-115.

Royle, J. A., R. B. Chandler, R. Sollman, and B. Gardner

2014. Spatial Capture-Recapture. Waltham, Massachusetts, USA: Academic Press.

Royle, J. A. and R. M. Dorazio

2008. Hierarchical Modeling and Inference in Ecology: The Analysis of Data from Populations, Metapopulations and Communities. London, UK: Academic Press.

Royle, J. A. and J. D. Nichols

2003. Estimating abundance from repeated presence-absence data or point counts. Ecology, 84(3):777-790. 
Royle, J. A., J. D. Nichols, M. Kéry, E. Ranta, J. A. Royle, J. D. Nichols, and M. Kery 2005. Modelling occurrence and abundance of species when detection is imperfect. Oikos, 110(2):353-359.

Russell, J. C., N. C. Cole, N. Zuël, and G. Rocamora

2016. Introduced mammals on Western Indian Ocean islands. Global Ecology and Conservation, 6:132-144.

Russell, J. C., J. G. Innes, P. H. Brown, and A. E. Byrom 2015. Predator-free New Zealand: Conservation country. BioScience, 65(5):520-525.

Salo, P., E. Korpimaki, P. B. Banks, M. Nordstrom, and C. R. Dickman 2007. Alien predators are more dangerous than native predators to prey populations. Proceedings of the Royal Society B: Biological Sciences, 274(1615):1237-1243.

Sanchez, M.

2012. Mitigating habitat loss by artificial egg laying sites for Reunion day gecko Phelsuma borbonica, Sainte Rose, Reunion Island. Conservation Evidence, 9:17-21.

Santos, T., J. A. Díaz, J. Pérez-Tris, R. Carbonell, and J. L. Tellería 2008. Habitat quality predicts the distribution of a lizard in fragmented woodlands better than habitat fragmentation. Animal Conservation, 11(1):46-56.

Scheibe, J. S.

1987. Climate, competition and the structure of temperate zone lizard communities. Ecology, 68:1424-1436.

Schwarz, C. J.

2001. The Jolly-Seber model: more than just abundance. Journal of Agricultural, Biological, and Environmental Statistics, 6(2):195-205.

Schwarz, C. J. and A. N. Arnason

1996. A general methodology for the analysis of capture-recapture experiments in open populations. Biometrics, 52(3):860-873.

SER

2004. The SER International Primer on Ecological Restoration. Tucson, Arizona, USA: Society for Ecological Restoration International.

Setser, K. and J. F. Cavitt

2003. Effects of burning on snakes in Kansas, USA, tallgrass prairie. Natural Areas Journal, 23(4):315-319. 
Severson, J. P.

2007. Wetland habitat enhancement and shoreline stabilization using riprap breakwaters on Kinkaid Lake in southern Illinois. Master's thesis, Southern Illinois University, Carbondale, Illinois, USA.

Sewell, D., J. M. R. Baker, and R. A. Griffiths

2015. Population dynamics of grass snakes (Natrix natrix) at a site restored for amphibian reintroduction. The Herpetological Journal, 25(3):155-161.

Sewell, D., G. Guillera-Arroita, R. Griffiths, and T. Beebee

2012. When is a species declining? Optimizing survey effort to detect population changes in reptiles. PLoS One, 7(8):e43387.

Shaffer, M. L.

1981. Minimum population sizes for species conservation. BioScience, 31:131-134.

Shine, R., L.-X. Sun, E. Zhao, and X. Bonnet

2002. A review of 30 years of ecological research on the Shedao Pitviper, Gloydius shedaoensis. Herpetological Natural History, 9(1):1-14.

Shoemaker, K. T.

2007. Habitat manipulation as a viable strategy for the conservation of the Massasauga rattlesnake in New York State. Master's thesis, State University of New York, Syracuse, New York.

Shoemaker, K. T., G. Johnson, and K. A. Prior

2009. Habitat manipulation as a viable conservation strategy. In Snakes: Ecology and Conservation, S. J. Mullin and R. A. Seigel, eds., Pp. 221-243. Ithaca, New York, USA: Cornell University Press.

Showler, D. A., N. Aldus, and J. Parmenter

2005. Creating hibernacula for common lizards Lacerta vivipara, The Ham, Lowestoft, Suffolk, England. Conservation Evidence, 2:96-98.

Silcock, D., H. Rushton, J. Rogers, and M. A. Schnabel

2018. Tangible and intangible digital heritage: creating virtual environments to engage public interpretation. Information Technologies in Cultural Heritage, 2:225-232.

Simberloff, D.

1990. Community effects of biological introductions and their implications for restoration. In Ecological Restoration of New Zealand Islands, D. R. Towns, C. H. Daugherty, and I. A. E. Atkinson, eds., Pp. 128-165. Wellington, New Zealand: Conservation Sciences Publication, Department of Conservation. 
Smallwood, K. S.

2001. Linking habitat restoration to meaningful units of animal demography. Restoration Ecology, 9(3):253-261.

Smith, D. C.

1981. Competitive interactions of the striped plateau lizard (Sceloporus virgatus) and the tree lizard (Urosaurus ornatus). Ecology, 62:679-687.

Smith, H. M., C. R. Dickman, and P. B. Banks

2017. Using effect size benchmarks to assess when alien impacts are actually alien. Scientific Reports, 7(38627):1-8.

Smith, L. L. and C. K. Dodd

2003. Wildlife mortality on US highway 441 across Paynes Prairie, Alachua County, Florida. Florida Scientist, 66(2):128-140.

Smith, W. H. and L. J. Rissler

2010. Quantifying disturbance in terrestrial communities: abundance-biomass comparisons of herpetofauna closely track forest succession. Restoration Ecology, 18(SUPPL. 1):195-204.

Somers, A.

2000. A population of bog turtles in the Piedmont of North Carolina: Habitat preferences, capture method efficacy, conservation initiatives, and site enhancement. Technical report, Department of Biology, University of North Carolina at Greensboro, Greensboro, North Carolina.

Souter, N. J., C. M. Bull, and M. N. Hutchinson

2004. Adding burrows to enhance a population of the endangered pygmy blue tongue lizard, Tiliqua adelaidensis. Biological Conservation, 116:403-408.

Spencer, N. J., B. W. Thomas, R. F. Mason, and J. S. Dugdale

1998. Diet and life history variation in the sympatric lizards Oligosoma nigriplantare polychroma and Oligosoma lineoocellatum. New Zealand Journal of Zoology, 25:457-463.

Stebbings, R.

2000. Reptile hibernacula - providing a winter refuge. Enact, Pp. 4-7.

Steen, D.

2013. Reptile assemblage response to restoration of fire-suppressed longleaf pine sandhills. Ecological Applications, 23(1):148-158. 
Steen, D. A.

2010. Snakes in the grass: secretive natural histories defy both conventional and progressive statistics. Herpetological Conservation and Biology, 5(2):183-188.

Steen, D. A., L. L. Smith, G. Morris, L. Mike Conner, A. R. Litt, S. Pokswinski, and C. Guyer 2013. Response of six-lined racerunner (Aspidoscelis sexlineata) to habitat restoration in fire-suppressed longleaf pine (Pinus palustris) sandhills. Restoration Ecology, 21(4):457-463.

Steer, J.

2015. The reconciliation of introduced species in New Zealand: understandings from three 'exceptional' case studies. PhD thesis, The University of Auckland, Auckland, New Zealand.

Stelder, J. J.

2014. Hooves on the heath, scales on the sand. The effects of heathland management and grazing on reptile populations of the Doldersummerveld. Bachelor's thesis, University of Applied Sciences Van Hall Larenstein, Leeuwarden, The Netherlands.

Stephens, C.

2004. Plant succession, ecological restoration and the skinks of Stephens Island / Takapourewa. Master's thesis, Victoria University of Wellington, Wellington, New Zealand.

Stephenson, B.

2012. Suter's skink (Oligosoma suteri) scavenging from a dolphin carcass. BioGecko, 1:44.

Stewart-Oaten, A., W. W. Murdoch, and K. R. Parker 1986. Environmental impact assessment: "pseudoreplication" in time? Ecology, 67(4):929_ 940.

Stone, E.

2010. Assessment of environmental effects for rodent control in the Pukerua Bay operational area. Technical report, Kapiti Area Office, Department of Conservation, Waikanae, New Zealand.

Suding, K. N.

2011. Toward an era of restoration in ecology: successes, failures, and opportunities ahead. Annual Review of Ecology, Evolution, and Systematics, 42:465-487.

Sun, L.

1990. Observation on the pattern of activities of Agkistrodon shedaoensis Zhao. In From Water Onto Land, E. Zhao, ed., Pp. 277-280. Beijing, China: China Forestry Press. 
Sunday, J. M., A. E. Bates, M. R. Kearney, R. K. Colwell, N. K. Dulvy, J. T. Longino, and R. B. Huey

2014. Thermal-safety margins and the necessity of thermoregulatory behavior across latitude and elevation. Proceedings of the National Academy of Sciences of the United States of America, 111(15):5610-5615.

Szaro, R. C., S. C. Belfit, J. K. Aitkin, and J. N. Rinne 1985. Impact of grazing on a riparian garter snake. In Riparian Ecosystems and Their Management: Reconciling Conflicting Uses. United States Forest Service, General Technical Report RM-120, R. Johnson, ed., Pp. 359-363. United States Forest Service.

Teal, R.

2006. The future of indigenous fauna on private land: a case study of the habitat use of the small-scaled skink (Oligosoma microlepis). Master's thesis, Massey University, Palmerston North, New Zealand.

Thompson, S., I. Grüner, and N. Gapare

2003. New Zealand land cover database version 2: illustrated guide to target classes. Ministry for the Environment, Wellington, New Zealand.

Thompson, W. L., ed.

2004. Sampling Rare or Elusive Species: Concepts, Designs, and Techniques for Estimating Population Parameters. Washington, DC, USA: Island Press.

Thoresen, J. J.

2012. Monitoring the impacts of invasive mammals on arboreal geckos' habitat use, cell foam retreat use, and the effectiveness of different monitoring techniques. Master's thesis, Massey University, Auckland, New Zealand.

Thuiller, W., M. Guéguen, J. Renaud, D. N. Karger, and N. E. Zimmermann 2019. Uncertainty in ensembles of global biodiversity scenarios. Nature Communications, 10(1):1-9.

Tichý, L.

2016. Field test of canopy cover estimation by hemispherical photographs taken with a smartphone. Journal of Vegetation Science, 27(2):427-435.

Tilman, D., R. M. May, C. L. Lehman, and M. A. Nowak 1994. Habitat destruction and the extinction debt. Nature, 371(6492):65-66.

Tingley, R., R. A. Hitchmough, and D. G. Chapple

2013. Life-history traits and extrinsic threats determine extinction risk in New Zealand lizards. Biological Conservation, 165:62-68. 
Todd, A. C.

2005. The social mating system of Hoplodactylus maculatus. New Zealand Journal of Zoology, 32(4):251-262.

Towns, D.

1991. Response of lizard assemblages in the Mercury Islands, New Zealand, to removal of an introduced rodent: the kiore (Rattus exulans). Journal of the Royal Society of New Zealand, 21(2):119-136.

Towns, D. R.

1996. Changes in habitat use by lizards on a New Zealand island following removal of the introduced Pacific rat Rattus exulans. Pacific Conservation Biology, 2:286-292.

Towns, D. R., S. B. Borrelle, J. Thoresen, R. T. Buxton, and A. Evans

2016. Mercury islands and their role in understanding seabird island restoration. New Zealand Journal of Ecology, 40(2):235-249.

Towns, D. R. and C. H. Daugherty

1994. Patterns of range contractions and extinctions in the New Zealand herpetofauna following human colonisation. New Zealand Journal of Zoology, 21(4):325-339.

Towns, D. R., C. H. Daugherty, and A. Cree

2001. Raising the prospects for a forgotten fauna: a review of 10 years of conservation effort for New Zealand reptiles. Biological Conservation, 99:3-16.

Towns, D. R. and G. Elliott

1996. Effects of habitat structure on distribution and abundance of lizards at Pukerua Bay, Wellington, New Zealand. New Zealand Journal of Ecology, 20(2):191-206.

Towns, D. R. and S. M. Ferreira

2001. Conservation of New Zealand lizards (Lacertilia: Scincidae) by translocation of small populations. Biological Conservation, 98(2):211-222.

Townsend, A. J., P. J. de Lange, C. A. J. Duffy, C. M. Miskelly, J. Molloy, and D. A. Norton 2008. New Zealand Threat Classification System Manual. Wellington, New Zealand: Science and Technical Publishing, Department of Conservation.

Uetz, P.

2019. The Reptile Database. http:/ / www.reptile-database.org.

Uys, R.

2019. Key native ecosystem programme - small mammal monitoring report - November 2019. Technical report, Greater Wellington Regional Council, Wellington, New Zealand. 
Van Heezik, Y. and K. Ludwig

2012. Proximity to source populations and untidy gardens predict occurrence of a small lizard in an urban area. Landscape and Urban Planning, 104(2):253-259.

van Winkel, D., M. Baling, and R. A. Hitchmough

2018. Reptiles and Amphibians of New Zealand: A Field Guide. Auckland, New Zealand: Auckland University Press.

Vencatasamy, A. D.

2015. Occupancy, detectability and relative abundance of arboreal geckos using bamboohides with ink tracking cards (BH-ITC) on Ile Aux Aigrettes Nature Reserve, Mauritius. Master's thesis, Nottingham Trent University, Nottingham, UK.

Vitousek, P. M., H. A. Mooney, J. Lubchenco, and J. M. Melillo

1997. Human domination of earth's ecosystems. Science, 277(5325):494-499.

Vitt, L. J., T. C. S. Avila-Pires, J. P. Caldwell, and V. R. L. Oliveira

1998. The impact of individual tree harvesting on thermal environments of lizards in Amazonian rain forest. Conservation Biology, 12(3):654-664.

Ward, M.

2016. Mana Island floral diversity enhancement report: stage 2. Technical report, Commissioned by Friends of Mana Island, Inc., Porirua, New Zealand.

Ward, R. J., R. A. Griffiths, J. W. Wilkinson, and N. Cornish

2017. Optimising monitoring efforts for secretive snakes: A comparison of occupancy and N-mixture models for assessment of population status. Scientific Reports, 7(1):1-12.

Watts, C. H. and G. W. Gibbs

2002. Revegetation and its effect on the ground-dwelling beetle fauna of matiu-somes island, new zealand. Restoration Ecology, 10(1):96-106.

Webb, J. K. and R. Shine

2000. Paving the way for habitat restoration: can artificial rocks restore degraded habitats of endangered reptiles? Biological Conservation, 92:93-99.

Webb, J. K., R. Shine, and R. M. Pringle

2005. Canopy removal restores habitat quality for an endangered snake in a fire suppressed landscape. Copeia, 2005(4):894-900.

Werner, Y. L. and A. H. Whitaker

1978. Observations and comments on the body temperatures of some New Zealand reptiles. New Zealand Journal of Zoology, 5(2):375-393. 
Whitaker, A. H.

1973. Lizard populations on islands with and without Polynesian rats, Rattus exulans (Peale). Proceedings of the New Zeland Ecological Society, 20:121-130.

Whitaker, A. H.

1982. Interim results from a study of Hoplodactylus maculatus (Boulenger) at Turakirae Head, Wellington. In New Zealand Herpetology: Proceedings of a Symposium, Victoria University, Wellington, D. G. Newman, ed., Pp. 363-374, Wellington, New Zealand. Occasional Publication 2, New Zealand Wildlife Service, Department of Internal Affairs.

Whitaker, A. H.

1987. The roles of lizards in New Zealand plant reproductive strategies. New Zealand Journal of Botany, 25(2):315-328.

Whitaker, $\mathrm{T}$.

1967. Baiting pitfalls for small lizards. Herpetological Journal, 23:309-311.

White, D., P. G. Minotti, M. J. Barczak, J. C. Sifneos, K. E. Freemark, M. V. Santelmann, C. F. Steinitz, A. Ross Kiester, and E. M. Preston

1997. Assessing risks to biodiversity from future landscape change. Conservation Biology, 11(2):349-360.

White, G. C.

2019. Program MARK: A Gentle Introduction. http:/ /www.phidot.org/software/mark/docs/book.

Whiting, C. and H. J. Booth

2012. Adder Vipera berus hibernacula construction as part of a mitigation scheme, Norfolk, England. Conservation Evidence, 9:9-16.

Wiles, A.

2016. Baseline abundance and habitat preferences of the northern grass skink (Oligosoma polychroma) within a public reserve prior to stock removal. MConBio report, Victoria University of Wellington, Wellington, New Zealand.

Wiles, A., S. Herbert, and O. Spearpoint

2015. Lizard monitoring at the Baring Head block, East Harbour Regional Park, Wellington: December 2014 season. Technical report, EcoGecko Consultants Ltd., Wellington, New Zealand.

Wilgers, D. J. and E. A. Horne

2006. Effects of different burn regimes on tallgrass prairie herpetofaunal species diversity and community composition in the Flint Hills, Kansas. Journal of Herpetology, 40(1):73-84. 
Willson, J. D., C. T. Winne, and B. D. Todd

2011. Ecological and methodological factors affecting detectability and population estimation in elusive species. The Journal of Wildlife Management, 75(1):36-45.

Wilson, D. J., R. L. Mulvey, D. A. Clarke, and J. T. Reardon

2017. Assessing and comparing population densities and indices of skinks under three predator management regimes. New Zealand Journal of Ecology, 41(1):84-97.

Wilson, D. S.

1975. The adequacy of body size as a niche difference. The Amercian Naturalist, 109(970):769-784.

Wittmer, H. U., R. Serrouya, L. M. Elbroch, and A. J. Marshall

2013. Conservation strategies for species affected by apparent competition. Conservation Biology, 27(2):254-260.

Woinarski, J. and A. J. Ash

2002. Responses of vertebrates to pastoralism, military land use and landscape position in an Australian tropical savanna. Austral Ecology, 27(3):311-323.

Woolley, C. K. and S. Hartley

2019. Activity of free-roaming domestic cats in an urban reserve and public perception of pet-related threats to wildlife in New Zealand. Urban Ecosystems, 22:1123-1137.

Woolley, C. K., S. Hartley, R. A. Hitchmough, J. G. Innes, Y. Van Heezik, D. J. Wilson, and N. J. Nelson

2019. Reviewing the past, present and potential lizard faunas of New Zealand cities. Landscape and Urban Planning, 192:103647.

Worthy, T. H.

1987. Osteological observation on the larger species of the sknk Cylclodina and the subfossil occurrence of these and the gecko Hoplodactylus duvavucelii in the North Island, New Zealand. New Zealand Journal of Zoology, 14:219-229.

Worthy, T. H.

2016. A review of the fossil record of New Zealand lizards. In New Zealand Lizards, Pp. 6586. Cham, Switzerland: Springer.

Wotton, D. M.

2002. Effectiveness of the common gecko (Hoplodactylus maculatus) as a seed disperser on Mana Island, New Zealand. New Zealand Journal of Botany, 40(4):639-647. 
Wotton, D. M., D. R. Drake, R. G. Powlesland, and J. J. Ladley

2016. The role of lizards as seed dispersers in New Zealand. Journal of the Royal Society of New Zealand, 46(1):40-65.

Yahner, R. H.

2004. Wildlife response to more than 50 years of vegetation maintenance on a Pennsylvania, U.S., right-of-way. Journal of Arboriculture, 30(2):123-126.

Yahner, R. H., W. C. Bramble, and R. R. Byrnes

2001. Response of amphibian and reptile populations to vegetation maintenance of an electric transmission line right-of-way. Journal of Arboriculture, 27(4):215-221.

Zappalorti, R. T. and H. K. Reinert

1994. Artificial refugia as a habitat-improvement strategy for snake conservation. Contributions to Herpetology, 11:369-375.

Zhao, D., L. Sun, and D. Tang

1990. Studies on the relationship between Agkistrodon shedaoensis Zhao and the Pueraria lobata. In From Water Onto Land, E. Zhao, ed., Pp. 284-286. Beijing, China: China Forestry Press.

Zheng, Y. and J. J. Wiens

2016. Combining phylogenomic and supermatrix approaches, and a time-calibrated phylogeny for squamate reptiles (lizards and snakes) based on 52 genes and 4162 species. Molecular Phylogenetics and Evolution, 94:537-547.

Zipkin, E. F., J. A. Royle, D. K. Dawson, and S. Bates

2010. Multi-species occurrence models to evaluate the effects of conservation and management actions. Biological Conservation, 143(2):479-484. 
Appendix A

Appendix for Chapter 2 
Table A.1: Criteria for inclusion of studies in sample, and reasons for excluding studies

\begin{tabular}{l}
\hline Inclusion criteria \\
Habitat manipulation has \\
a clear conservation or \\
restoration goal
\end{tabular}

\section{Reason for exclusion}

Habitat manipulation solely

due to business-as-usual commercial, infrastructural or subsistence operations

\section{Example(s)}

Enge and Marion (1986) excluded as measured response

to clearcutting and site preparation for commercial forestry

operations. Martín and Lopez (2002) excluded as measured response to culturally traditional management of an agroecosystem (dehesa) without a specific attempt made to promote biodiversity. Rodriguez et al. (1996) excluded because the use of non-wildlife passages across a high speed railway was examined. Leu and Bull (2016) and Dozeman (2004) excluded because construction of the farm pond or artificial watering hole was carried for the benefit of livestock. Jones et al. (2000) excluded as brush management as for livestock pasture management.

Use of artificial refugia Vencatasamy (2015) evaluated gecko species use of constructed evaluated for the sole purpose bamboo hides, but their use as a habitat enhancement was not of reptile population monitoring considered in this study.

Habitat change must be caused by humans Study must be on freeranging populations

Data source must be from the primary reference for a study of quantifiable demographic parameters
Habitat change solely due to one Greenberg (2001) excluded as measured reptile response to or more natural processes canopy gaps in forest created by wind disturbance.

Effect of habitat manipulation Howard et al. (2003) and Mensforth and Bull (2008) excluded performed on captive animals

Study was a review or metaanalysis because habitat selection of artificially created microhabitats were performed on skinks held in outdoor enclosures.

Lundholm and Richardson (2010) and Rey Benayas et al. (2008) were review papers, not case studies or original research. 
Table A.2: Species list. Crocodylians (Allagatoridae) and Lizards 1 (Agamidae Diplodactylidae).

\begin{tabular}{|c|c|c|}
\hline Taxonomy & $\mathbf{N}$ cases & Citation(s) \\
\hline Alligatoridae & 4 & \\
\hline Alligator mississippiensis & 4 & $\begin{array}{l}\text { Bowers et al. (2000); Smith and Dodd } \\
\text { (2003); Campbell and Mazzotti (2004); } \\
\text { Dodd et al. (2004); Aresco (2005) }\end{array}$ \\
\hline Agamidae & 9 & \\
\hline Agama armata & 2 & Collinson et al. (2017) \\
\hline Amphibolurus muricatus & 1 & Pike et al. $(2011 b, a)$ \\
\hline Diporiphora nobbi & 2 & Jellinek et al. (2014) \\
\hline Pogona barbarata & 3 & Michael et al. (2004); Jellinek et al. (2014) \\
\hline Pogona minor & 1 & Craig et al. (2010) \\
\hline Amphisbaenidae & 5 & \\
\hline Amphisbaena alba & 1 & Linares and Eterovick (2013) \\
\hline Amphisbaena bolivica & 1 & Linares and Eterovick (2013) \\
\hline Amphisbaena darwinii & 1 & Linares and Eterovick (2013) \\
\hline Amphisbaena dubia & 1 & Linares and Eterovick (2013) \\
\hline Amphisbaena kingii & 1 & Linares and Eterovick (2013) \\
\hline Anguidae & 6 & \\
\hline Anguis fragilis & 1 & Reading and Jofré (2016) \\
\hline Ophisaurus attenuatus & 3 & $\begin{array}{l}\text { Bowers et al. (2000); Wilgers and Horne } \\
\text { (2006) }\end{array}$ \\
\hline Ophisaurus ventralis & 2 & Bowers et al. (2000); Aresco (2005) \\
\hline Blanidae & 3 & \\
\hline Blanus cinereus & 3 & $\begin{array}{l}\text { Márquez-Ferrando et al. (2009); Carpio } \\
\text { et al. (2017) }\end{array}$ \\
\hline Chamaeloeonidae & 2 & \\
\hline Chamaeleo dilepis & 2 & Collinson et al. (2017) \\
\hline Dactyloidae & 11 & \\
\hline Anolis carolinensis & 11 & $\begin{array}{l}\text { Bowers et al. (2000); Litt et al. (2001); Floyd } \\
\text { et al. (2002); Smith and Dodd (2003); Dodd } \\
\text { et al. (2004); Kilpatrick et al. (2004); Aresco } \\
\text { (2005); Steen (2013) }\end{array}$ \\
\hline Diplodactylidae & 15 & \\
\hline Amalosia lesueurii & 7 & $\begin{array}{l}\text { Goldingay and Newell (2000); Webb and } \\
\text { Shine (2000); Webb et al. (2005); Pike et al. } \\
(2011 b, a) \text {; Croak et al. }(2010,2012,2013)\end{array}$ \\
\hline Diplodactylus polyopthalmus & 1 & Craig et al. (2010) \\
\hline Diplodactylus tessellatus & 3 & Michael et al. (2004); Jellinek et al. (2014) \\
\hline Naultinus gemmeus & 2 & Knox (2010); Knox et al. (2012) \\
\hline Woodworthia 'Otago large' & 1 & Bell and Herbert $(2016,2017 a)$ \\
\hline Woodworthia maculata & 1 & Hoare et al. (2007a); Newman (2018) \\
\hline
\end{tabular}


Table A.3: Species list continued. Lizards 2 (Diploglossidae - Mabuyidae)

\begin{tabular}{|c|c|c|c|}
\hline Taxonomy & & N cases & Citation(s) \\
\hline Diploglossidae & & 1 & \\
\hline Ophiodes striatus & & 1 & Linares and Eterovick (2013) \\
\hline Eublepharidae & & 1 & \\
\hline Coleonyx variegatus & & 1 & Cutler (1996) \\
\hline Gekkonidae & & 5 & \\
\hline Christinus marmoratus & & 3 & Craig et al. (2010); Jellinek et al. (2014) \\
\hline Hemidactylus mabouia & & 1 & Linares and Eterovick (2013) \\
\hline Phelsuma borbonica & & 1 & Sanchez (2012) \\
\hline Gerrhosauridae & & 2 & \\
\hline $\begin{array}{l}\text { Gerrhosaurus } \quad \text { (species } \\
\text { nigrolineatus?) }\end{array}$ & $=$ & 2 & Collinson et al. (2017) \\
\hline Iguanidae & & 1 & \\
\hline Dipsosaurus dorsalis & & 1 & Cutler (1996) \\
\hline Lacertidae & & 24 & \\
\hline Acanthodactylus erythrurus & & 3 & $\begin{array}{l}\text { Márquez-Ferrando et al. (2009); Carpio } \\
\text { et al. (2017) }\end{array}$ \\
\hline Lacerta agilis & & 1 & Reading and Jofré (2016) \\
\hline Podarcis hispanicus & & 4 & $\begin{array}{l}\text { Castilla and Swallow (1995); Márquez- } \\
\text { Ferrando et al. (2009); Carpio et al. (2017) }\end{array}$ \\
\hline Podarcis vaucheri & & 2 & Carpio et al. (2017) \\
\hline Psammodromus algirus & & 3 & $\begin{array}{l}\text { Márquez-Ferrando et al. (2009); Carpio } \\
\text { et al. (2017) }\end{array}$ \\
\hline Timon lepidus & & 5 & $\begin{array}{l}\text { Márquez-Ferrando et al. (2009); Carpio } \\
\text { et al. (2017) }\end{array}$ \\
\hline Zootoca vivipara & & 6 & $\begin{array}{l}\text { Stebbings (2000); Showler et al. (2005); } \\
\text { Whiting and Booth (2012); Stelder (2014); } \\
\text { Reading and Jofré (2016) }\end{array}$ \\
\hline Leiosauridae & & 3 & \\
\hline Enyalius bilineatus & & 1 & Linares and Eterovick (2013) \\
\hline Urostrophus gallardoi & & 1 & Linares and Eterovick (2013) \\
\hline Urostrophus vautieri & & 1 & Linares and Eterovick (2013) \\
\hline Liolaemidae & & 1 & \\
\hline Liolaemus chacoensis & & 1 & Leynaud and Bucher (2005) \\
\hline Mabuyidae & & 1 & \\
\hline Notomabuya frenata & & 1 & Linares and Eterovick (2013) \\
\hline
\end{tabular}


Table A.4: Species list continued. Lizards 3 (Phrynosomatidae - Scincidae (Egerniinae))

\begin{tabular}{|c|c|c|}
\hline Taxonomy & $\mathbf{N}$ cases & Citation(s) \\
\hline Phrynosomatidae & 21 & \\
\hline Callisaurus draconoides & 1 & Cutler (1996) \\
\hline Holbrookia maculata & 2 & $\begin{array}{l}\text { Davis and Theimer (2003); Cosentino et al. } \\
\text { (2013) }\end{array}$ \\
\hline Phrynosoma cornutum & 2 & Wilgers and Horne (2006) \\
\hline Phrynosoma platyrhinos & 1 & Cutler (1996) \\
\hline Phrynosoma solare & 1 & Cutler (1996) \\
\hline Sceloporus magister & 1 & Cutler (1996) \\
\hline Sceloporus undulatus & 10 & $\begin{array}{l}\text { Bowers et al. (2000); Litt et al. (2001); } \\
\text { Floyd et al. (2002); Kilpatrick et al. (2004); } \\
\text { Severson (2007); Steen (2013) }\end{array}$ \\
\hline Urosaurus (species = graciosus?) & 1 & Cutler (1996) \\
\hline Uta stansburiana & 2 & Cutler (1996); Cosentino et al. (2013) \\
\hline Phyllodactylidae & 5 & \\
\hline Homonota fasciata & 1 & Leynaud and Bucher (2005) \\
\hline Phyllopezus pollicaris & 1 & Leynaud and Bucher (2005) \\
\hline Tarentola mauritanica & 3 & $\begin{array}{l}\text { Márquez-Ferrando et al. (2009); Carpio } \\
\text { et al. (2017) }\end{array}$ \\
\hline Polychrotidae & 1 & \\
\hline Polychrus acutirostris & 1 & Linares and Eterovick (2013) \\
\hline Pygopodidae & 9 & \\
\hline Aprasia parapulchella & 4 & McDougall et al. (2016) \\
\hline Delma impar & 2 & Michael et al. (2004); O'Shea (2005) \\
\hline Delma inornata & 3 & Michael et al. (2004); Jellinek et al. (2014) \\
\hline Scincidae (Egerniinae) & 8 & \\
\hline Egernia cunninghami & 1 & Pike et al. $(2011 b, a)$ \\
\hline Tiliqua adelaidensis & 2 & Milne et al. (2003a); Souter et al. (2004) \\
\hline Tiliqua nigrolutea & 1 & Homan (2012) \\
\hline Tiliqua rugosa & 1 & Craig et al. (2010) \\
\hline Tiliqua scincoides & 3 & Homan (2012); Jellinek et al. (2014) \\
\hline
\end{tabular}


Table A.5: Species list continued. Lizards 4 (Scincidae (Eugongylinae - Scincinae)).

\begin{tabular}{|c|c|c|c|}
\hline Taxonomy & & N cases & Citation(s) \\
\hline Scincidae (Eugongylinae) & & 41 & \\
\hline Bassiana duperreyi & & 1 & Homan (2012) \\
\hline Bassiana platynota & & 4 & $\begin{array}{l}\text { Webb et al. (2005); Croak et al. (2010); Pike } \\
\text { et al. (2011b,a); Croak et al. (2012) }\end{array}$ \\
\hline Bassiana trilineata & & 1 & Craig et al. (2010) \\
\hline Carlia tetradactyla & & 4 & Jellinek et al. (2014); Pulsford et al. (2017) \\
\hline $\begin{array}{l}\text { Cryptoblepharus (species } \\
\text { plagiocephalus?) }\end{array}$ & $=$ & 4 & $\begin{array}{l}\text { Michael et al. (2004); Craig et al. (2010); } \\
\text { Jellinek et al. (2014) }\end{array}$ \\
\hline $\begin{array}{l}\text { Cryptoblepharus (species } \\
\text { pulcher?) }\end{array}$ & $=$ & 3 & Croak et al. (2010, 2012); Pike et al. $(2011 b, a)$ \\
\hline $\begin{array}{l}\text { Cryptoblepharus } \quad \text { (species } \\
\text { virgatus?) }\end{array}$ & $=$ & 1 & Webb and Shine (2000) \\
\hline Lampropholis delicata & & 1 & Pike et al. $(2011 b, a)$ \\
\hline Lampropholis guichenoti & & 4 & Jellinek et al. (2014) \\
\hline Menetia greyii & & 4 & $\begin{array}{l}\text { Michael et al. (2004); Craig et al. (2010); } \\
\text { Jellinek et al. (2014) }\end{array}$ \\
\hline Morethia boulengeri & & 3 & Michael et al. (2004); Jellinek et al. (2014) \\
\hline Morethia obscura & & 1 & Craig et al. (2010) \\
\hline Oligosoma aeneum & & 1 & Hoare et al. (2007a); Newman (2018) \\
\hline Oligosoma maccani & & 2 & $\begin{array}{l}\text { Lettink et al. (2010); Bell and Herbert (2016, } \\
\text { 2017a) }\end{array}$ \\
\hline Oligosoma polychroma Clade 1 & & 1 & Hoare et al. (2007a); Newman (2018) \\
\hline Oligosoma polychroma Clade 5 & & 2 & Bell and Herbert $(2016,2017 a)$ \\
\hline Oligosoma whitakeri & & 1 & Hoare et al. (2007a); Newman (2018) \\
\hline Oligosoma zealandicum & & 1 & Hoare et al. (2007a); Newman (2018) \\
\hline Pseudemoia entrecasteauxii & & 1 & Homan (2012) \\
\hline Pseudemoia pagenstecheri & & 1 & Homan (2012) \\
\hline Scincidae (Scincinae) & & 18 & \\
\hline Plestiodon egregius & & 3 & Steen (2013) \\
\hline Plestiodon fasciatus & & 6 & $\begin{array}{l}\text { Hecnar and M'Closkey (1998); Bowers et al. } \\
\text { (2000); Floyd et al. (2002); Kilpatrick et al. } \\
\text { (2004); Aresco (2005); Severson (2007) }\end{array}$ \\
\hline Plestiodon inexpectatus & & 2 & Bowers et al. (2000); Floyd et al. (2002) \\
\hline Plestiodon laticeps & & 5 & $\begin{array}{l}\text { Bowers et al. (2000); Aresco (2005); Steen } \\
\text { (2013) }\end{array}$ \\
\hline Plestiodon obsoletus & & 2 & Wilgers and Horne (2006) \\
\hline
\end{tabular}


Table A.6: Species list continued. Lizards 5 (Scincidae (Sphenomorphinae) - Varanidae) and Snakes 1 (Boidae - Colubridae (Ahaetuliinae).)

\begin{tabular}{|c|c|c|}
\hline Taxonomy & N cases & Citation(s) \\
\hline Scincidae (Sphenomorphinae) & 29 & \\
\hline Ctenotus orientalis & 2 & Jellinek et al. (2014) \\
\hline Ctenotus robustus & 3 & Homan (2012); Jellinek et al. (2014) \\
\hline Ctenotus taeniolatus & 3 & $\begin{array}{l}\text { Croak et al. (2010); Pike et al. }(2011 b, a) \text {; } \\
\text { Croak et al. (2012) }\end{array}$ \\
\hline Eulamprus quoyii & 1 & Pike et al. $(2011 b, a)$ \\
\hline Hemiergis initialis & 1 & Craig et al. (2010) \\
\hline Lerista bougainvillii & 3 & Homan (2012); Jellinek et al. (2014) \\
\hline Lerista distinguenda & 1 & Craig et al. (2010) \\
\hline Lerista punctatovittata & 2 & Jellinek et al. (2014) \\
\hline Scincella lateralis & 13 & $\begin{array}{l}\text { Bowers et al. (2000); Litt et al. (2001); } \\
\text { Floyd et al. (2002); Kilpatrick et al. } \\
\text { (2004); Aresco (2005); Wilgers and Horne } \\
\text { (2006); Severson (2007); Steen (2013) }\end{array}$ \\
\hline Teiidae & 20 & \\
\hline Ameiva ameiva & 2 & $\begin{array}{l}\text { Leynaud and Bucher (2005); Linares and } \\
\text { Eterovick (2013) }\end{array}$ \\
\hline Ameivula ocellifera & 1 & Leynaud and Bucher (2005) \\
\hline Aspidoscelis inornatus & 1 & Cosentino et al. (2013) \\
\hline Aspidoscelis sexlineatus & 8 & $\begin{array}{l}\text { Bowers et al. (2000); Litt et al. (2001); } \\
\text { Aresco (2005); Steen (2013) }\end{array}$ \\
\hline Aspidoscelis tesselatus & 1 & Cosentino et al. (2013) \\
\hline Aspidoscelis tigris & 2 & Cutler (1996); Cosentino et al. (2013) \\
\hline Aspidoscelis uniparens & 1 & Cosentino et al. (2013) \\
\hline Cnemidophorus lemniscatus & 1 & Linares and Eterovick (2013) \\
\hline Salvator merianae & 1 & Linares and Eterovick (2013) \\
\hline Salvator rufescens & 1 & Leynaud and Bucher (2005) \\
\hline Teius teyou & 1 & Leynaud and Bucher (2005) \\
\hline Tropduridae & 4 & \\
\hline Tropidurus etheridgei & 1 & Leynaud and Bucher (2005) \\
\hline Tropidurus oreadicus & 1 & Linares and Eterovick (2013) \\
\hline Tropidurus spinulosus & 1 & Leynaud and Bucher (2005) \\
\hline Stenocercus doellojuradoi & 1 & Leynaud and Bucher (2005) \\
\hline Varanidae & 4 & \\
\hline Varanus gouldii & 2 & Jellinek et al. (2014) \\
\hline Varanus rosenbergi & 1 & Craig et al. (2010) \\
\hline Varanus varius & 1 & Pike et al. $(2011 b, a)$ \\
\hline Boidae & 1 & \\
\hline Epicrates crassus & 1 & Linares and Eterovick (2013) \\
\hline Colubridae (Ahaetuliinae) & 1 & \\
\hline Dendrelaphis punctulatus & 1 & Goldingay and Newell (2000) \\
\hline
\end{tabular}


Table A.7: Species list continued. Snakes 2 (Colubridae (Colubrinae): Cemophora - Pituophis).

\begin{tabular}{|c|c|c|}
\hline Taxonomy & N cases & Citation(s) \\
\hline Colubridae (Colubrinae) & 85 & \\
\hline Cemophora coccinea & 5 & $\begin{array}{l}\text { Bowers et al. (2000); Aresco (2005); Steen } \\
\text { (2013) }\end{array}$ \\
\hline Chionactis occipitalis & 1 & Cutler (1996) \\
\hline Chironius exoletus & 1 & Linares and Eterovick (2013) \\
\hline Chironius quadricarinatus & 1 & Linares and Eterovick (2013) \\
\hline Coluber constrictor & 7 & $\begin{array}{l}\text { Zappalorti and Reinert (1994); Bowers et al. } \\
\text { (2000); Setser and Cavitt (2003); Smith and } \\
\text { Dodd (2003); Dodd et al. (2004); Aresco } \\
\text { (2005); Wilgers and Horne (2006) }\end{array}$ \\
\hline Coronella austriaca & 2 & $\begin{array}{l}\text { Reading and Jofré (2015); Bonnet et al. } \\
\text { (2016) }\end{array}$ \\
\hline Coronella girondica & 1 & Márquez-Ferrando et al. (2009) \\
\hline Dasypeltis scabra & 2 & Collinson et al. (2017) \\
\hline Hemorrhois hippocrepis & 3 & $\begin{array}{l}\text { Márquez-Ferrando et al. (2009); Carpio } \\
\text { et al. (2017) }\end{array}$ \\
\hline Hierophis viridiflavus & 3 & Lelievre et al. (2010) \\
\hline Lampropeltis getula & 6 & $\begin{array}{l}\text { Zappalorti and Reinert (1994); Bowers et al. } \\
\text { (2000); Setser and Cavitt (2003); Aresco } \\
\text { (2005); Wilgers and Horne (2006) }\end{array}$ \\
\hline Lampropeltis triangulum & 5 & $\begin{array}{l}\text { Zappalorti and Reinert (1994); Bowers et al. } \\
\text { (2000); Setser and Cavitt (2003); Wilgers } \\
\text { and Horne (2006) }\end{array}$ \\
\hline Macroprotodon brevis & 1 & Márquez-Ferrando et al. (2009) \\
\hline Masticophis flagellum & 1 & Cutler (1996) \\
\hline Opheodrys aestivus & 3 & $\begin{array}{l}\text { Zappalorti and Reinert (1994); Bowers et al. } \\
\text { (2000); Aresco (2005) }\end{array}$ \\
\hline Opheodrys vernalis & 5 & Yahner et al. (2001); Yahner (2004) \\
\hline Pantherophis emoryi & 3 & $\begin{array}{l}\text { Setser and Cavitt (2003); Wilgers and } \\
\text { Horne (2006) }\end{array}$ \\
\hline Pantherophis guttatus & 4 & $\begin{array}{l}\text { Zappalorti and Reinert (1994); Bowers et al. } \\
\text { (2000); Smith and Dodd (2003); Dodd et al. } \\
\text { (2004); Aresco (2005) }\end{array}$ \\
\hline Pantherophis obsoletus & 5 & $\begin{array}{l}\text { Bowers et al. (2000); Floyd et al. (2002); } \\
\text { Smith and Dodd (2003); Dodd et al. (2004); } \\
\text { Aresco (2005); Severson (2007) }\end{array}$ \\
\hline Phyllorhynchus decurtatus & 1 & Cutler (1996) \\
\hline Pituophis catenifer & 3 & $\begin{array}{l}\text { Setser and Cavitt (2003); Wilgers and } \\
\text { Horne (2006) }\end{array}$ \\
\hline Pituophis melanoleucus & 2 & Zappalorti and Reinert (1994); Cutler (1996) \\
\hline
\end{tabular}


Table A.8: Species list continued. Snakes 3 (Colubridae (Colubrinae: Rhinocheilus - Zamenis) - Colubridae (Dipsadinae: Apostolepis - Phalophis)).

\begin{tabular}{|c|c|c|}
\hline Taxonomy & N cases & Citation(s) \\
\hline Colubridae (Colubrinae) & 85 & \\
\hline Rhinocheilus lecontei & 1 & Cutler (1996) \\
\hline Salvadora hexalepis & 1 & Cutler (1996) \\
\hline Spilotes pullatus & 1 & Linares and Eterovick (2013) \\
\hline Tantilla coronata & 9 & $\begin{array}{l}\text { Bowers et al. (2000); Litt et al. (2001); Floyd } \\
\text { et al. (2002); Kilpatrick et al. (2004); Steen } \\
\text { (2013) }\end{array}$ \\
\hline Tantilla melanocephala & 1 & Linares and Eterovick (2013) \\
\hline Zamenis longissimus & 4 & Lelievre et al. (2010); Bonnet et al. (2016) \\
\hline Zamenis scalaris & 3 & $\begin{array}{l}\text { Márquez-Ferrando et al. (2009); Carpio } \\
\text { et al. (2017) }\end{array}$ \\
\hline Colubridae (Dipsadinae) & 52 & \\
\hline Apostolepis assimilis & 1 & Linares and Eterovick (2013) \\
\hline Boiruna maculata & 1 & Leynaud and Bucher (2005) \\
\hline Carphophis amoenus & 3 & $\begin{array}{l}\text { Bowers et al. (2000); Floyd et al. (2002); } \\
\text { Kilpatrick et al. (2004) }\end{array}$ \\
\hline Carphophis vermis & 2 & Wilgers and Horne (2006) \\
\hline Diadophis punctatus & 11 & $\begin{array}{l}\text { Bowers et al. (2000); Yahner et al. (2001); } \\
\text { Yahner (2004); Floyd et al. (2002); Smith } \\
\text { and Dodd (2003); Dodd et al. (2004); Aresco } \\
\text { (2005); Wilgers and Horne (2006) }\end{array}$ \\
\hline Erythrolamprus aesculapii & 1 & Linares and Eterovick (2013) \\
\hline Erythrolamprus almadensis & 1 & Linares and Eterovick (2013) \\
\hline Erythrolamprus guentheri & 1 & Leynaud and Bucher (2005) \\
\hline Erythrolamprus miliaris & 1 & Linares and Eterovick (2013) \\
\hline Erythrolamprus poecilogyrus & 2 & $\begin{array}{l}\text { Leynaud and Bucher (2005); Linares and } \\
\text { Eterovick (2013) }\end{array}$ \\
\hline Erythrolamprus reginae & 1 & Linares and Eterovick (2013) \\
\hline Erythrolamprus sagittifer & 1 & Leynaud and Bucher (2005) \\
\hline Farancia abacura & 3 & $\begin{array}{l}\text { Bowers et al. (2000); Smith and Dodd } \\
\text { (2003); Dodd et al. (2004); Aresco (2005) }\end{array}$ \\
\hline Farancia erytrogramma & 1 & Bowers et al. (2000) \\
\hline Heterodon platirhinos & 3 & $\begin{array}{l}\text { Zappalorti and Reinert (1994); Bowers et al. } \\
\text { (2000); Floyd et al. (2002) }\end{array}$ \\
\hline Heterodon simus & 1 & Bowers et al. (2000) \\
\hline Hypsiglena torquata & 1 & Cutler (1996) \\
\hline Imantodes cenchoa & 1 & Linares and Eterovick (2013) \\
\hline Oxyrhopus guibei & 1 & Linares and Eterovick (2013) \\
\hline Oxyrhopus rhombifer & 1 & Leynaud and Bucher (2005) \\
\hline Oxyrhopus trigeminus & 1 & Linares and Eterovick (2013) \\
\hline Phalophis tricolor & 1 & Leynaud and Bucher (2005) \\
\hline
\end{tabular}


Table A.9: Species list continued. Snakes 4 (Colubridae (Dipsadinae: Philodryas - Storeria)).

\begin{tabular}{|c|c|c|}
\hline Taxonomy & $\mathbf{N}$ cases & Citation(s) \\
\hline Colubridae (Dipsadinae) & 52 & \\
\hline Philodryas baroni & 1 & Leynaud and Bucher (2005) \\
\hline Philodryas mattogrossensis & 1 & Leynaud and Bucher (2005) \\
\hline Philodryas olfersii & 1 & Linares and Eterovick (2013) \\
\hline Philodryas psammophidea & 1 & Leynaud and Bucher (2005) \\
\hline Phimophis vittatus & 1 & Leynaud and Bucher (2005) \\
\hline Pseudoboa nigra & 1 & Linares and Eterovick (2013) \\
\hline Sibynomorphus lavillai & 1 & Leynaud and Bucher (2005) \\
\hline Sibynomorphus mikanii & 1 & Linares and Eterovick (2013) \\
\hline Taeniophallus affinis & 1 & Linares and Eterovick (2013) \\
\hline Thamnodynastes hypoconia & 1 & Linares and Eterovick (2013) \\
\hline Xenodon merremii & 1 & Leynaud and Bucher (2005) \\
\hline Xenodon pulcher & 1 & Leynaud and Bucher (2005) \\
\hline Colubridae (Natricinae) & 64 & \\
\hline Haldea striatula & 1 & Bowers et al. (2000) \\
\hline Liodytes pygaea & 1 & Aresco (2005) \\
\hline Natrix maura & 1 & Márquez-Ferrando et al. (2009) \\
\hline Natrix natrix & 7 & $\begin{array}{l}\text { Márquez-Ferrando et al. (2009); Whiting } \\
\text { and Booth (2012); Stelder (2014); Sewell } \\
\text { et al. (2015); Bonnet et al. (2016); Reading } \\
\text { and Jofré (2016) }\end{array}$ \\
\hline Nerodia erythrogaster & 1 & Bowers et al. (2000) \\
\hline Nerodia fasciata & 4 & $\begin{array}{l}\text { Bowers et al. (2000); Smith and Dodd } \\
\text { (2003); Dodd et al. (2004); Aresco (2005) }\end{array}$ \\
\hline Nerodia floridana & 1 & Aresco (2005) \\
\hline Nerodia sipedon & 4 & $\begin{array}{l}\text { Floyd et al. (2002); Homyack and Giuliano } \\
\text { (2002); Severson (2007); Frank (2011) }\end{array}$ \\
\hline Nerodia taxispilota & 1 & Bowers et al. (2000) \\
\hline Regina septemvittata & 1 & Homyack and Giuliano (2002) \\
\hline Storeria dekayi & 5 & $\begin{array}{l}\text { Bowers et al. (2000); Smith and Dodd } \\
\text { (2003); Dodd et al. (2004); Wilgers and } \\
\text { Horne (2006); Severson (2007) }\end{array}$ \\
\hline Storeria occipitomaculata & 9 & $\begin{array}{l}\text { Bowers et al. (2000); Yahner et al. (2001); } \\
\text { Floyd et al. (2002); Yahner (2004); Aresco } \\
\text { (2005); Severson (2007) }\end{array}$ \\
\hline
\end{tabular}


Table A.10: Species list continued. Snakes 5 (Colubridae (Dipsadinae: Thamnophis - Virginia) - Pythonidae).

\begin{tabular}{|c|c|c|}
\hline Taxonomy & N cases & Citation(s) \\
\hline Thamnophis elegans & 1 & Szaro et al. (1985) \\
\hline Thamnophis saurita & 4 & $\begin{array}{l}\text { Zappalorti and Reinert (1994); Smith and } \\
\text { Dodd (2003); Dodd et al. (2004); Aresco } \\
\text { (2005) }\end{array}$ \\
\hline Thamnophis sirtalis & 13 & $\begin{array}{l}\text { Zappalorti and Reinert (1994); Bowers et al. } \\
\text { (2000); Yahner et al. (2001); Homyack and } \\
\text { Giuliano (2002); Setser and Cavitt (2003); } \\
\text { Smith and Dodd (2003); Dodd et al. (2004); } \\
\text { Yahner (2004); Aresco (2005); Wilgers and } \\
\text { Horne (2006) }\end{array}$ \\
\hline Tropidoclonion lineatum & 2 & Wilgers and Horne (2006) \\
\hline Virginia valeriae & 8 & $\begin{array}{l}\text { Yahner et al. (2001); Yahner (2004); Steen } \\
\text { (2013) }\end{array}$ \\
\hline Elapidae & 31 & \\
\hline Austrelaps superbus & 1 & Homan (2012) \\
\hline Cryptophis nigrescens & 4 & $\begin{array}{l}\text { Goldingay and Newell (2000); Croak et al. } \\
\text { (2010); Pike et al. }(2011 b, a) \text {; Croak et al. } \\
\text { (2012) }\end{array}$ \\
\hline Hoplocephalus bungaroides & 6 & $\begin{array}{l}\text { Goldingay and Newell (2000); Webb and } \\
\text { Shine (2000); Webb et al. (2005); Croak et al. } \\
\text { (2010); Pike et al. }(2011 b, a) \text {; Croak et al. } \\
\text { (2012) }\end{array}$ \\
\hline Micrurus lemniscatus & 1 & Linares and Eterovick (2013) \\
\hline Micrurus pyrrhocryptus & 1 & Leynaud and Bucher (2005) \\
\hline Naja mossambica & 2 & Collinson et al. (2017) \\
\hline Notechis scutatus & 4 & Craig et al. (2010); Homan (2012) \\
\hline Parasuta flagellum & 4 & Homan (2012) \\
\hline Parasuta nigriceps & 2 & Jellinek et al. (2014) \\
\hline Pseudonaja textilis & 5 & $\begin{array}{l}\text { Michael et al. (2004); Pike et al. }(2011 b, a) \text {; } \\
\text { Homan (2012) }\end{array}$ \\
\hline Suta suta & 1 & Michael et al. (2004) \\
\hline Lamprophiidae & 7 & \\
\hline Atractaspis bibronii & 2 & Collinson et al. (2017) \\
\hline Boaedon capensis & 2 & Collinson et al. (2017)] \\
\hline Malpolon monspessulanus & 3 & $\begin{array}{l}\text { Márquez-Ferrando et al. (2009); Carpio } \\
\text { et al. (2017) }\end{array}$ \\
\hline Leptotyphlopidae & 1 & \\
\hline Rena unguirostris & 1 & Leynaud and Bucher (2005) \\
\hline Pythonidae & 1 & \\
\hline Morelia spilota & 1 & Pike et al. $(2011 b, a)$ \\
\hline
\end{tabular}


Table A.11: Species list continued. Snakes 5 (Typhlopidae - Viperidae), Tuatara, and Testudines 1 (Chelydridae).

\begin{tabular}{lll}
\hline \hline Taxonomy & N cases & Citation(s) \\
\hline Typhlopidae & $\mathbf{8}$ & \\
Anilios bicolor & 2 & Jellinek et al. (2014) \\
Anilios bituberculatus & 2 & Jellinek et al. (2014) \\
Anilios nigrescens & 2 & Jellinek et al. (2014) \\
Anilios proximus & 2 & Jellinek et al. (2014) \\
Viperidae (Crotalinae) & $\mathbf{1 4}$ & \\
Agkistrodon contortrix & 1 & Carter (2012); Carter et al. (2017) \\
Agkistrodon piscivorus & 3 & Bowers et al. (2000); Smith and Dodd \\
& & (2003); Dodd et al. (2004); Aresco (2005) \\
Bothrops neuwiedii & 2 & Leynaud and Bucher (2005) \\
Crotalus durissus & 2 & Linares and Eterovick (2013) \\
Crotalus horridus & 1 & Bowers et al. (2000) \\
Crotalus sp. & 1 & Cutler (1996) \\
Gloydius shedaoensis & 2 & Sun (1990); Zhao et al. (1990); Shine et al. \\
& & (2002) \\
Sistrusus catenatus & 2 & Johnson (1995); Johnson and Leopold \\
Viperidae (Viperinae) & & (1998); Johnson et al. (2016) \\
Bitis arietans & $\mathbf{9}$ & Collinson et al. (2017) \\
Bitis caudalis & 2 & Collinson et al. (2017) \\
Vipera aspis & 2 & Bonnet et al. (2016) \\
Vipera berus & 1 & Stebbings (2000); Whiting and Booth \\
Sphenodontidae & 4 & (2012); Stelder (2014) \\
Sphenodon punctatus & & Nelson et al. (2002) \\
Chelydridae & & Bowers et al. (2000); Aresco (2005); \\
Chelydra serpentina & $\mathbf{1}$ & (2011); Paterson et al. (2013) \\
& 4 & \\
\hline & &
\end{tabular}


Table A.12: Species list continued. Testudines 2 (Emydidae - Trionychidae).

\begin{tabular}{|c|c|c|}
\hline Taxonomy & $\mathbf{N}$ cases & Citation(s) \\
\hline Emydidae & 34 & \\
\hline Chrysemys picta & 2 & $\begin{array}{l}\text { Buhlmann and Osborn (2011); Paterson } \\
\text { (2011); Paterson et al. (2013) }\end{array}$ \\
\hline Clemmys guttata & 1 & Bowers et al. (2000) \\
\hline Deirochelys reticularia & 1 & Aresco (2005) \\
\hline Emys blandingii & 10 & $\begin{array}{l}\text { Emrich (1991); Kiviat et al. (2000); Hartwig } \\
\text { and Kiviat (2007); Dowling et al. (2010); } \\
\text { Paterson (2011); Paterson et al. (2013); Reid } \\
\text { et al. (2016) }\end{array}$ \\
\hline Glyptemys insculpta & 2 & $\begin{array}{l}\text { Buhlmann and Osborn (2011); Paterson } \\
\text { (2011); Paterson et al. (2013) }\end{array}$ \\
\hline Glyptemys muhlenbergii & 1 & Somers (2000) \\
\hline Pseudemys concinna & 4 & Bowers et al. (2000); Aresco (2005) \\
\hline Pseudemys nelsoni & 1 & Smith and Dodd (2003); Dodd et al. (2004) \\
\hline Terrapene carolina & 6 & $\begin{array}{l}\text { Bowers et al. (2000); Floyd et al. (2002); } \\
\text { Kilpatrick et al. (2004); Aresco (2005); } \\
\text { Severson (2007); Buhlmann and Osborn } \\
\text { (2011) }\end{array}$ \\
\hline Terrapene ornata & 3 & Wilgers and Horne (2006); Severson (2007) \\
\hline Trachemys scripta & 3 & $\begin{array}{l}\text { Bowers et al. (2000); Aresco (2005); } \\
\text { Severson (2007) }\end{array}$ \\
\hline Kinosternidae & 8 & \\
\hline Kinosternon baurii & 2 & $\begin{array}{l}\text { Bowers et al. (2000); Smith and Dodd } \\
\text { (2003); Dodd et al. (2004) }\end{array}$ \\
\hline Kinosternon subrubrum & 2 & Bowers et al. (2000); Aresco (2005) \\
\hline Sternotherus odoratus & 4 & $\begin{array}{l}\text { Bowers et al. (2000); Smith and Dodd } \\
\text { (2003); Dodd et al. (2004); Aresco (2005); } \\
\text { Buhlmann and Osborn (2011) }\end{array}$ \\
\hline Testudinidae & 4 & \\
\hline Geochelone pardalis & 2 & Collinson et al. (2017) \\
\hline Gopherus polyphemus & 1 & Aresco (2005) \\
\hline Testudo hermanni & 1 & Ballouard et al. (2013) \\
\hline Trionychidae & 3 & \\
\hline Apalone ferox & 2 & $\begin{array}{l}\text { Smith and Dodd (2003); Dodd et al. (2004); } \\
\text { Aresco (2005) }\end{array}$ \\
\hline Apalone spinifera & 1 & Severson (2007) \\
\hline
\end{tabular}


Appendix B

Appendix for Chapter 3 


\section{B.1 Available cover types at study sites}
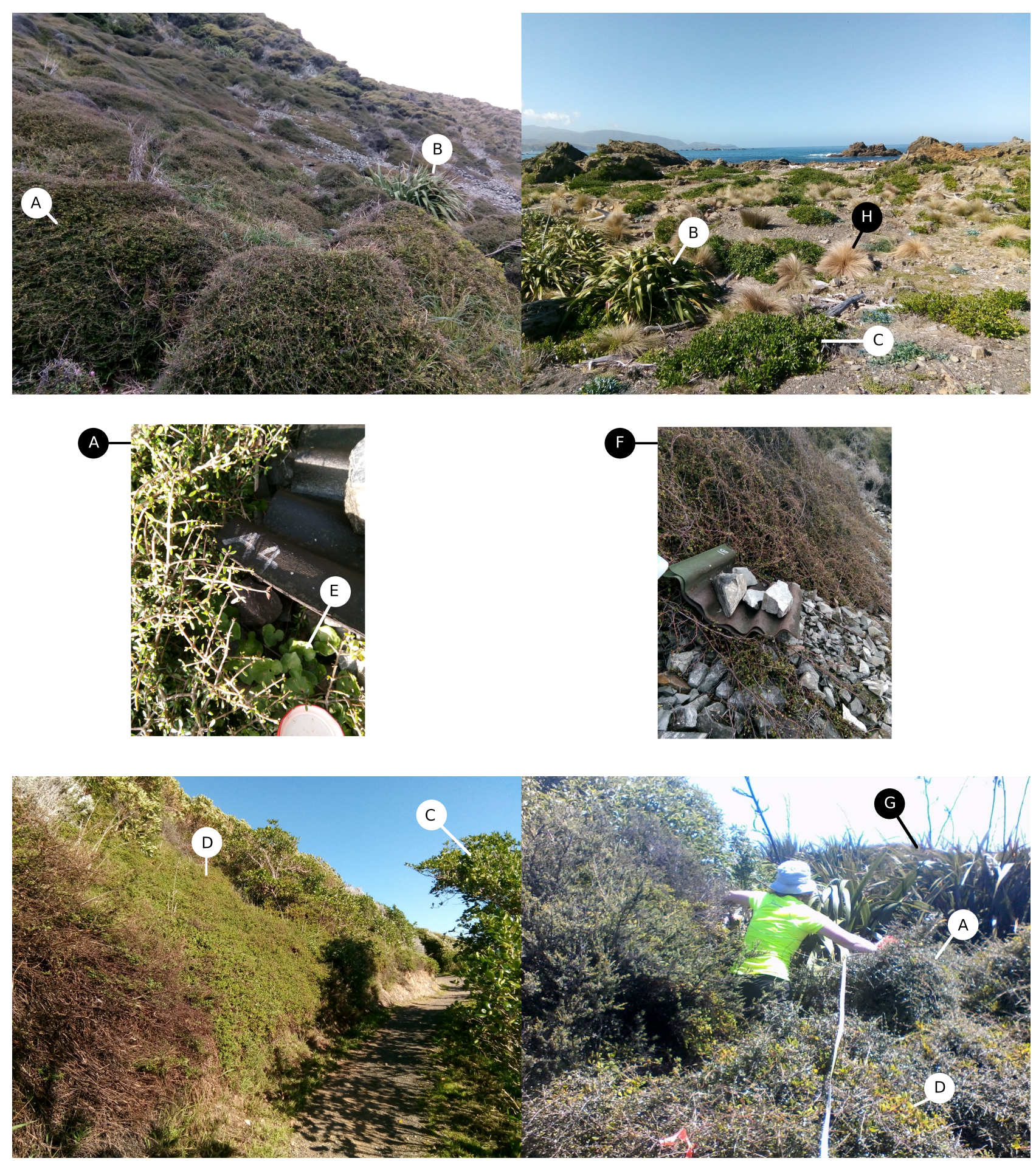

Figure B.1: Pictures of the most common plant species comprising the habitat covariates used for modelling lizard community and population variables. A. Coprosma propinqua (category $=\mathrm{DIVs})$. B. Wharariki (flax) Phormium cookianum $(\mathrm{PHO})$. C. Coprosma repens (COPlg). D. Tetragonia implexicoma (Vines). E. Calystegia soldanella (Vines). F. Muehlenbeckia complexa (MUE). G. Harakeke (flax) Phormium tenax (PHO). H. An example of the grass and sedge (GS) category, the native grass Poa cita. Photographs taken at (clockwise from top left): Pukerua Bay, Miramar Peninsula, Pukerua Bay, Mana Island, Matiu / Somes Island, and Pukerua Bay. 

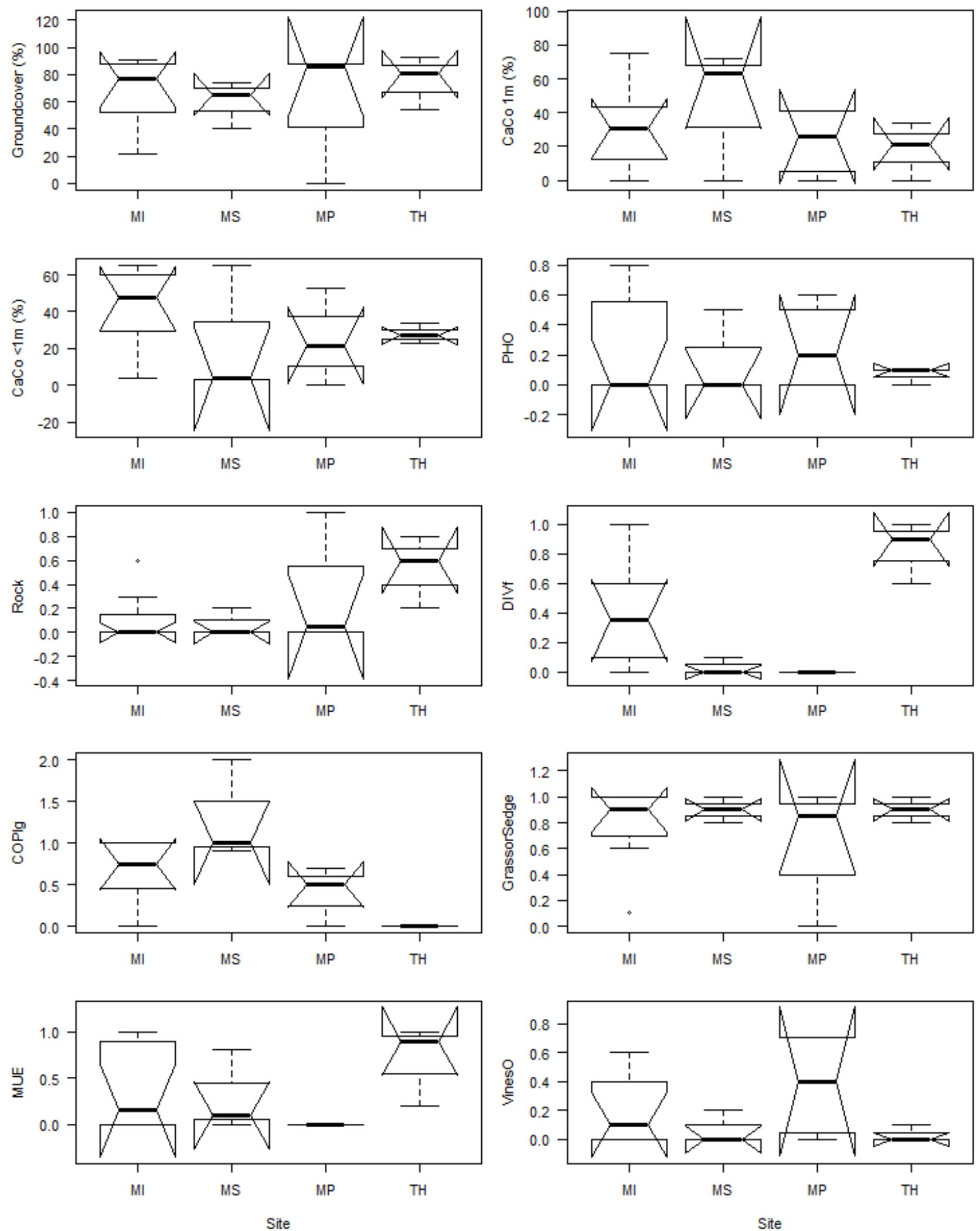

Figure B.2: Summary boxplots of variation in modelled habitat covariates between study sites. $\mathrm{MI}=$ Mana Island (mammal-free), MS = Matiu / Somes Island (mammal-free), MP = Miramar Peninsula, and TH = Turakirae Head. Covariate descriptions are in Table 3.2 in Chapter 3. Notches represent the 95\% confidence interval. The midline of the boxes represents the mean, and the box edges on the y-axis represent the lower and upper quartiles. Notches extend beyond the boxes in cases where the $95 \%$ confidence interval bounds are wider than the interquartile range. 


\section{B.2 Complete lists of $\mathrm{N}$ mixture occupancy models trialled for lizard species}

Table B.1: Full list of $\mathrm{N}$ mixture models trialled for Woodworthia maculata. Weight = AICc weight. The local abundance parameter(s) are $\lambda$ in Poisson models, and $\mu$ and $a$ in negative binomial models. The maximal Poisson model assessed for goodness of fit is indicated with an asterisk.

\begin{tabular}{|c|c|c|c|c|c|}
\hline$\overline{\text { Model }}$ & $\mathrm{AICc}$ & 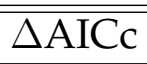 & Weight & Likelihood & N par. \\
\hline$\mu(),. a(),. r()$. & 465.60 & 0.00 & 1.0000 & 1.0000 & 3 \\
\hline$\mu(),. a(),. r($ Pests $)$ & 496.71 & 31.11 & 0.0000 & 0.0000 & 3 \\
\hline $\begin{array}{l}\mu(.), a(.), r(\text { Pests }+ \text { Seffort }+ \text { Date }+ \\
\text { Date }^{2}+\text { TOD }+ \text { TOD } \\
2\end{array}$ & 497.51 & 31.91 & 0.0000 & 0.0000 & 10 \\
\hline$\mu(),. a(),. r\left(T O D+T O D^{2}\right)$ & 506.06 & 40.46 & 0.0000 & 0.0000 & 4 \\
\hline$\mu(),. a(),. r\left(T e m p+T e m p^{2}\right)$ & 509.79 & 44.19 & 0.0000 & 0.0000 & 4 \\
\hline$\mu(),. a(),. r\left(\right.$ Date + Date $\left.^{2}\right)$ & 516.70 & 51.10 & 0.0000 & 0.0000 & 4 \\
\hline$\mu(),. a(),. r($ Seffort $)$ & 517.54 & 51.94 & 0.0000 & 0.0000 & 3 \\
\hline $\begin{array}{l}\lambda(.), r\left(\text { Pests }+ \text { Seffort }+ \text { Date }+ \text { Date }{ }^{2}+\right. \\
\left.T O D+T O D^{2}+\text { Temp }+ \text { Temp }\right)^{2} *\end{array}$ & 560.14 & 94.54 & 0.0000 & 0.0000 & 9 \\
\hline
\end{tabular}

Table B.2: Full list of $\mathrm{N}$ mixture models trialled for Oligosoma polychroma. Weight = AICc weight. The local abundance parameter(s) are $\lambda$ in Poisson models, and $\mu$ and $a$ in negative binomial models. The maximal Poisson model assessed for goodness of fit is indicated with an asterisk.

\begin{tabular}{|c|c|c|c|c|c|}
\hline$\overline{\text { Model }}$ & AICc & $\overline{\mathrm{AAICc}}$ & Weight & Likelihood & N par. \\
\hline$\mu(),. a(),. r()$. & 467.14 & 0.00 & 1.0000 & 1.0000 & 3 \\
\hline $\begin{array}{l}\mu(.), a(.), r(\text { Pests }+ \text { Seffort }+ \text { Date }+ \\
\left.\text { Date }^{2}+T O D+T O D^{2}+\text { Temp }+ \text { Temp } p^{2}\right)\end{array}$ & 509.66 & 42.52 & 0.0000 & 0.0000 & 10 \\
\hline $\begin{array}{l}\lambda(.), r(\text { Mammals }+ \text { Seffort }+ \text { Date }+ \\
\text { Date }^{2}+\text { TOD }+ \text { TOD } \\
2\end{array}$ & 527.33 & 60.19 & 0.0000 & 0.0000 & 9 \\
\hline$\mu(),. a(),. r\left(T O D+T O D^{2}\right)$ & 530.83 & 63.69 & 0.0000 & 0.0000 & 4 \\
\hline$\mu(),. a(),. r($ Seffort $)$ & 540.83 & 73.69 & 0.0000 & 0.0000 & 3 \\
\hline$\mu(),. a(),. r\left(T e m p+T e m p^{2}\right)$ & 547.35 & 80.21 & 0.0000 & 0.0000 & 4 \\
\hline$\mu(),. a(),. r($ Pests $)$ & 551.80 & 84.66 & 0.0000 & 0.0000 & 3 \\
\hline$\mu(),. a(),. r\left(\right.$ Date + Date $\left.^{2}\right)$ & 593.40 & 126.26 & 0.0000 & 0.0000 & 4 \\
\hline
\end{tabular}


Table B.3: Full list of N mixture models trialled for Oligosoma aeneum. Weight = AICc weight. The maximal Poisson model assessed for goodness of fit is indicated with an asterisk.

\begin{tabular}{lccccc}
\hline \hline Model & AICc & $\Delta$ AICc & Weight & Likelihood & N par. \\
\hline$\lambda(),. r()$. & 324.86 & 0.00 & 1.0000 & 1.0000 & 2 \\
$\lambda(),. r\left(\right.$ Temp + Temp $\left.{ }^{2}\right)$ & 345.52 & 20.66 & 0.0000 & 0.0000 & 3 \\
$\mu(),. a(),. r($ Seffort + Date + Date \\
Temp + Temp + TOD + TOD $\left.D^{2}\right)$ & 345.99 & 21.13 & 0.0000 & 0.0000 & 8 \\
$\lambda(),. r\left(\right.$ Seffort + Date + Date ${ }^{2}+$ Temp + & 349.74 & 24.88 & 0.0000 & 0.0000 & 8 \\
Temp ${ }^{2}+$ TOD + TOD $)^{*}$ & & & & & \\
$\lambda(),. r($ Seffort $)$ & 355.87 & 31.01 & 0.0000 & 0.0000 & 2 \\
$\lambda(),. r\left(\right.$ TOD + TOD $\left.{ }^{2}\right)$ & 361.64 & 36.78 & 0.0000 & 0.0000 & 3 \\
$\lambda(),. r($ Temp $)$ & 361.72 & 36.86 & 0.0000 & 0.0000 & 2 \\
$\lambda(),. r($ Date $)$ & 369.62 & 44.76 & 0.0000 & 0.0000 & 2 \\
$\lambda(),. r\left(\right.$ Date + Date $\left.^{2}\right)$ & 372.08 & 47.22 & 0.0000 & 0.0000 & 3 \\
$\lambda(),. r($ TOD $)$ & 375.50 & 50.64 & 0.0000 & 0.0000 & 2 \\
\hline \hline
\end{tabular}




\section{Appendix C}

\section{Appendix for Chapter 4}

\section{C.1 Single season density estimates for Raukawa geckos and northern grass skinks at Turakirae Head}

Table C.1: Single season density estimates for northern grass skinks Oligosoma polychroma at Turakirae Head, 1976 - 2019. CI = confidence interval. ETA = effective trapping area of monitoring grids.

\begin{tabular}{|c|c|c|c|c|}
\hline Year(s) & Site & $\begin{array}{l}\text { Estimate }(95 \% \quad \mathrm{CI}) \\
\text { individuals per ha }\end{array}$ & Estimator & Source \\
\hline 2000 & $\begin{array}{l}\text { Main grid(full - } \\
\left.\text { ETA: } 686 \mathrm{~m}^{2}\right)\end{array}$ & $2,565(1,195-6,545)$ & Chao's $M_{t h}$ & Green (2001) \\
\hline $\begin{array}{l}\text { May } \\
2018\end{array}$ & $\begin{array}{l}\text { THG1 + THG2 } \\
\text { (ETA: } 307 \mathrm{~m}^{2} \\
\text { combined) }\end{array}$ & $\begin{array}{l}\text { NA - not enough } \\
\text { captures }\end{array}$ & NA & This study \\
\hline $\begin{array}{l}\text { Feb } \\
2019\end{array}$ & $\begin{array}{l}\text { THG1 + THG2 } \\
\text { (ETA: } 307 \mathrm{~m}^{2} \\
\text { combined) }\end{array}$ & $4,078(2,055-10,048)$ & Huggins' $M_{t h}$ & This study \\
\hline
\end{tabular}


Table C.2: Single season density estimates for Raukawa geckos Woodworthia maculata at Turakirae Head, 1976 - 2019. CI = confidence interval. ETA = effective trapping area of monitoring grids.

\begin{tabular}{|c|c|c|c|c|c|}
\hline Year(s) & Site & $\begin{array}{l}\text { Estimate }(95 \% \text { CI } \\
\text { individuals per ha }\end{array}$ & & Estimator & Source \\
\hline \multicolumn{6}{|l|}{ WM } \\
\hline 1976 & $\begin{array}{l}\text { Main grid (full - } \\
\text { ETA: } 1,725 \mathrm{~m}^{2} \text { ) }\end{array}$ & 4,100 & & $M_{0}$ & Whitaker (1982) \\
\hline 1983 & $\begin{array}{l}\text { Main grid } \\
\text { (reduced - ETA: } \\
678 \mathrm{~m}^{2} \text { ) }\end{array}$ & 12,000 & & $\begin{array}{l}\text { Schumacher's } \\
\text { method }\end{array}$ & Marshall (1983) \\
\hline \multirow[t]{3}{*}{2000} & $\begin{array}{l}\text { Main grid } \\
(\text { reduced } \\
36 \mathrm{~m}^{2} \text { ) }\end{array}$ & $7,770(6,667-10,833)$ & & $\begin{array}{l}\text { Darroch's } M_{t} \\
\text { MLE (Otis } \\
\text { et al. (1978) } \\
\text { formulation) }\end{array}$ & Green (2001) \\
\hline & $\begin{array}{l}\text { Main grid } \\
\text { (reduced - ETA: } \\
678 \mathrm{~m}^{2} \text { ) }\end{array}$ & $4,970(2,936-9,265)$ & & Chao's $M_{t h}$ & Green (2001) \\
\hline & $\begin{array}{l}\text { Main grid } \\
\text { (reduced - ETA: } \\
678 \mathrm{~m}^{2} \text { ) }\end{array}$ & $2,803(1,992-4,323)$ & & $M_{0}$ & Green (2001) \\
\hline 2018 & $\begin{array}{l}\text { THG1 + THG2 } \\
\text { (ETA: } 291 \mathrm{~m}^{2} \\
\text { combined) }\end{array}$ & NA - no recaptures & & NA & This study \\
\hline 2019 & $\begin{array}{l}\text { THG1 + THG2 } \\
\text { (ETA: } 291 \mathrm{~m}^{2} \\
\text { combined) }\end{array}$ & $\begin{array}{l}38,372 \\
48,291)\end{array}$ & - & Huggins' $M_{t}$ & This study \\
\hline 2019 & $\begin{array}{l}\text { THG1 + THG2 } \\
\text { (ETA: = } 291 \mathrm{~m}^{2} \\
\text { combined) }\end{array}$ & $\begin{array}{l}39,196 \\
49,320)\end{array}$ & - & Huggins' $M_{0}$ & This study \\
\hline
\end{tabular}

\section{C.2 Supplementary information for Ōrua Pouanui / Baring Head}

\section{C.2.1 Mark-recapture lizard monitoring conducted at Baring Head}

Lizard mark-recapture monitoring was conducted at four $100 \mathrm{~m}^{2}$ grids at Baring Head using the same methodology used in Chapters 4 and 5 for the mark-recapture monitoring programmes at Turakirae Head, Pukerua Bay and the Miramar Peninsula. Initially this site was meant to serve as an additional replicate for the 12 monitoring grids on the Miramar Peninsula used for the habitat enhancement before-after-control-impact (BACI) experiment in Chapter 5 (that is, there would have been eight enhancement and eight control grids in total, with two enhancement and two control grids at Baring Head). The decision to drop 
the Baring Head replicates from Chapter 5 was made in winter 2018 when it became apparent that there were enough lizard captures being made in the 12 Miramar grids and I realised that I had underestimated the time required to plant each enhancement grid. However, I thought that the population information collected from lizard mark-recapture Baring Head could be a useful addition to the Chapter 4 analysis, therefore I conducted one final mark-recapture round of these grids in February 2019. Here I present a summary of the data collected.

There were two constraints on placement of the Baring Head mark-recapture grids required by the landowner (Greater Wellington Regional Council; GWRC): they could not be (1) within $50 \mathrm{~m}$ of the GWRC's lizard monitoring sites, or (2) placed at the bottom of the river escarpment due to potential disturbance to locally rare lizards. Baring Head is also divided into five distinctive landform and management units (LMUs). To minimise potential disturbance of the grids by grazing stock, and site heterogeneity, all grids were randomly placed along the top edge of the escarpment in the most lizard-biodiverse LMU, the 'river escarpment' LMU, which is fenced off to exclude grazing stock (Fig. C.1). The mark-recapture monitoring effort was more intensive to offset lower numbers of lizard captures per grid, and the lack of historical data. Four ACO-pitfall grids were established in October 2017 and four closed-capture sessions consisting of 5-9 repeat sessions were completed in November 2017 (0 months after placement), January 2018 (2 mo), March/April 2018 (4 mo) and February 2019 (15 mo). The lizard capture data is summarized below in Table C.3. 


\section{Legend}

- Lizard CMR grids (this study, 2017-2019)

- GWRC lizard monitoring (2012-2019)

- OA distribution (2012-2019)

- OK distribution (2010-2019)

\section{Bait station grids}

Stock exclusion zone Baring Head boundary Land

— Pest monitoring lines

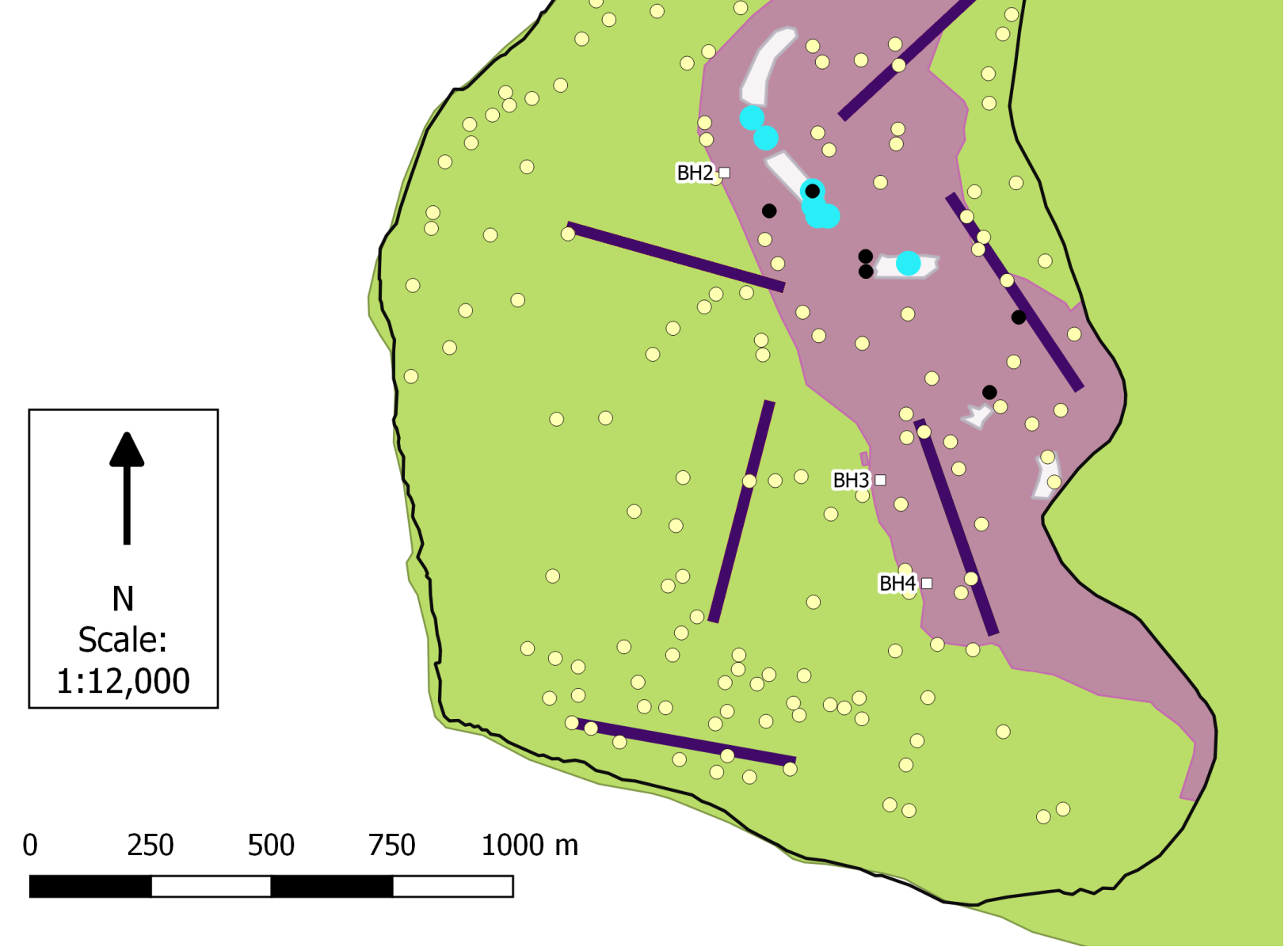

s

Figure C.1: Location of the lizard capture-mark-recapture (CMR) ACO-and-pitfall grids monitored in this study in relation to the lizard pitfall traps monitored by Greater Wellington Regional Council (GWRC) between 2012 and 2018 and known ranges of the two rarer lizard species at Baring Head: copper skinks $(\mathrm{OA}=$ Oligosoma aeneum $)$ and northern spotted skinks (OK = O. kokowai) (Romijn, 2011; Herbert and Bell, 2019). 
Table C.3: Summary of lizard captures in Onduline ACO and pitfall mark-recapture grids at Baring Head. Effort = the number of station-days. A dash indicates that the species was not captured. Otherwise, the number of captures is given in brackets beside the number of individuals. Species: Raukawa gecko (WM), northern grass skink (OP), copper skink (OA), glossy brown skink (OZ). No northern spotted skinks Oligosoma kokowai were captured in these grids despite being present at Baring Head.

\begin{tabular}{lllllll}
\hline \hline Season & Grid & Effort & WM & OP & OA & OZ \\
\hline Oct-Nov & BH1 & 288 & - & $2(2)$ & - & - \\
& BH2 & 288 & - & $5(5)$ & - & - \\
& BH3 & 288 & $3(4)$ & $16(18)$ & - & - \\
& BH4 & 216 & - & $22(33)$ & - & - \\
\hline Jan 2018 & Total & 1,080 & $3(4)$ & $45(60)$ & - & - \\
& BH1 & 288 & - & - & - & - \\
& BH2 & 288 & $2(4)$ & $7(10)$ & - & - \\
& BH3 & 288 & $18(23)$ & $28(42)$ & - & - \\
& BH4 & 288 & $6(12)$ & $48(109)$ & - & - \\
\hline Mar-Apr & Total & 1,152 & $26(39)$ & $83(161)$ & - & - \\
\hline \multirow{2}{*}{ BH1 } & BH1 & 324 & - & $2(2)$ & - & - \\
& BH2 & 324 & $3(3)$ & $5(3)$ & - & - \\
& BH3 & 288 & $15(9)$ & $40(27)$ & - & - \\
& BH4 & 288 & $1(1)$ & $34(24)$ & - & - \\
\hline Feb 2019 & Total & 1,224 & $13(19)$ & $56(81)$ & - & - \\
& BH1 & 180 & $1(1)$ & $3(3)$ & - & - \\
& BH2 & 180 & $6(8)$ & $6(6)$ & - & - \\
& BH3 & 180 & $13(19)$ & $7(7)$ & - & - \\
& BH4 & 180 & $16(27)$ & $22(24)$ & - & - \\
\hline \hline & Total & 720 & $36(55)$ & $38(40)$ & - & - \\
\hline
\end{tabular}




\section{C.3 Field observations of daytime refuge use}

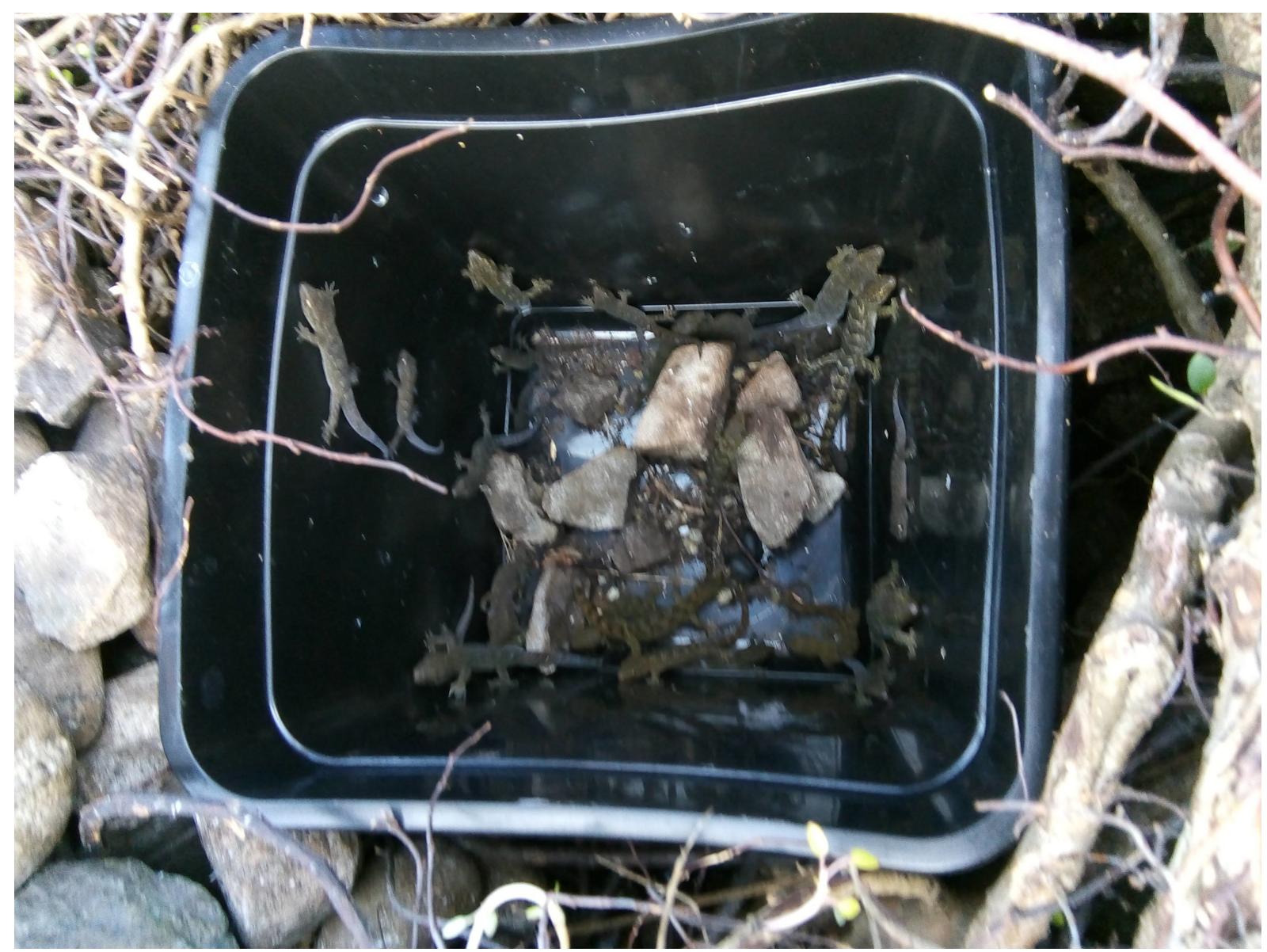

Figure C.2: An example of the large aggregations of Raukawa geckos (Woodworthia maculata) found in closed pitfall traps filled to the brim with rocks at Turakirae Head (particularity in grid TGH1). While there are 20 geckos in this photograph taken in May 2018, aggregations of up to 44 individuals were found together in pitfalls that had been closed by filling with rocks.

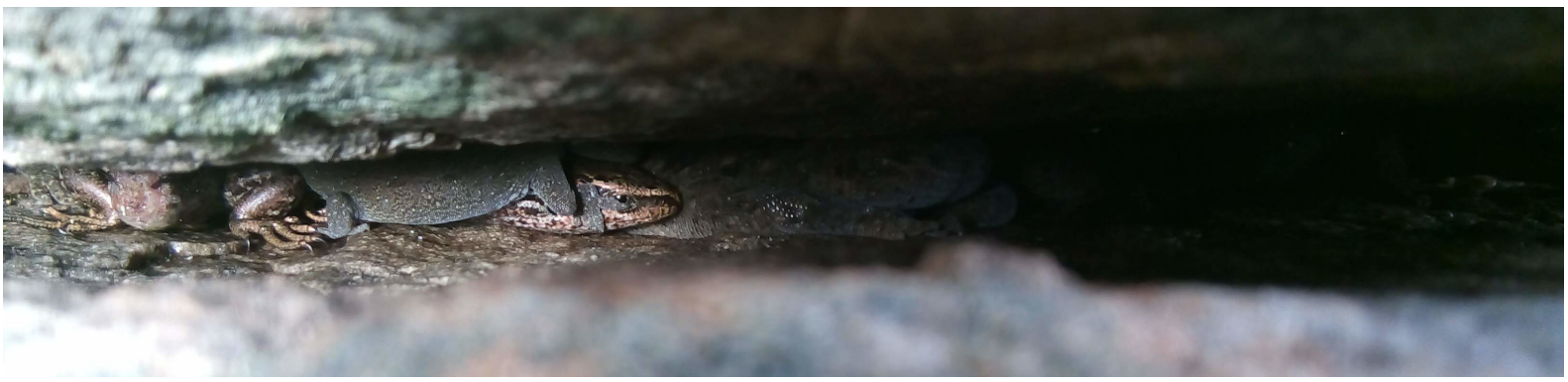

Figure C.3: Refuge sharing observed between a northern grass skink (Oligosoma polychroma) and Raukawa geckos (Woodworthia maculata) in August 2019 at Turakirae Head. The skink and geckos were found in a crevice formed by fracturing of a large ( $>2 \mathrm{~m}$ diameter) rock outcrop . 


\section{Appendix D}

\section{Appendix for Chapter 5}

\section{D.1 Pre-existing habitat in experimental plots}

Before enhancement, a $2 \times 2 \mathrm{~m}$ grid was marked over each site with builder's line and habitat was hand-drawn over $1 \times 1 \mathrm{~m}$ grid squares in a map. This information was used to correct grid outlines from waypoint-averaged grid corner points taken using a handheld GPS (Garmin Oregon 550; $\pm 3 \mathrm{~m}$ error) to classify vegetation in QGIS version 2.18 (QGIS Development Team, 2016) from aerial photographs taken of each sites in summer 2016-2017 (Wellington urban map series $0.1 \mathrm{~m}$ ). Percentage cover was calculated as the sum of the area of polygons per cover type, divided by the total grid area, and is presented in Table D.1. 
Table D.1: Existing features at each grid. Cover types are given as a percentage of total area.

\begin{tabular}{|c|c|c|c|c|c|c|c|c|c|c|c|}
\hline Treatment & Grid & $\begin{array}{l}\text { Area } \\
\left(m^{2}\right)\end{array}$ & $\begin{array}{l}\text { Bare } \\
\text { ground }\end{array}$ & Cobbles & Flax & $\begin{array}{l}\text { Grass } \\
\text { or } \\
\text { herb }\end{array}$ & Rock & Shrub & Vines & Wood & Substrate \\
\hline Control & WP1 & 103.02 & $0.00 \%$ & $0.00 \%$ & $0.00 \%$ & $76.39 \%$ & $0.00 \%$ & $23.61 \%$ & $0.00 \%$ & $0.00 \%$ & Loam \\
\hline Control & WP2 & 123.13 & $7.80 \%$ & $0.72 \%$ & $8.00 \%$ & $67.38 \%$ & $0.00 \%$ & $12.60 \%$ & $3.49 \%$ & $0.00 \%$ & $\begin{array}{l}\text { Mixture of sand and } \\
\text { cobbles }\end{array}$ \\
\hline Enhancement & WP3 & 134.02 & $37.55 \%$ & $33.88 \%$ & $6.61 \%$ & $14.32 \%$ & $2.36 \%$ & $1.48 \%$ & $3.81 \%$ & $0.00 \%$ & Sand or cobbles \\
\hline Enhancement & WP4 & 108.24 & $67.07 \%$ & $0.00 \%$ & $0.00 \%$ & $32.47 \%$ & $0.40 \%$ & $0.00 \%$ & $0.06 \%$ & $0.00 \%$ & $\begin{array}{l}\text { Mixture of sand, } \\
\text { gravel and cobbles }\end{array}$ \\
\hline Control & RE1 & 112.65 & $0.00 \%$ & $0.00 \%$ & $11.44 \%$ & $33.33 \%$ & $0.00 \%$ & $51.61 \%$ & $3.61 \%$ & $0.00 \%$ & Loam \\
\hline Enhancement & RE2 & 141.82 & $0.00 \%$ & $0.00 \%$ & $0.00 \%$ & $68.71 \%$ & $0.00 \%$ & $31.29 \%$ & $0.00 \%$ & $0.00 \%$ & Sand loam \\
\hline Enhancement & RE3 & 115.16 & $0.00 \%$ & $0.00 \%$ & $0.00 \%$ & $55.23 \%$ & $0.00 \%$ & $44.77 \%$ & $0.00 \%$ & $0.00 \%$ & Sand loam \\
\hline Control & RE4 & 92.66 & $0.00 \%$ & $0.00 \%$ & $0.00 \%$ & $56.36 \%$ & $0.00 \%$ & $28.66 \%$ & $14.98 \%$ & $0.00 \%$ & Loam \\
\hline Enhancement & HT1 & 113.35 & $71.14 \%$ & $0.00 \%$ & $0.00 \%$ & $14.78 \%$ & $0.00 \%$ & $13.34 \%$ & $0.74 \%$ & $0.00 \%$ & $\begin{array}{l}\text { Mixture of sand, } \\
\text { gravel and cobbles }\end{array}$ \\
\hline Control & HT2 & 127.19 & $19.03 \%$ & $0.00 \%$ & $33.34 \%$ & $28.06 \%$ & $0.00 \%$ & $5.72 \%$ & $12.58 \%$ & $1.28 \%$ & $\begin{array}{l}\text { Mixture of sand, } \\
\text { gravel and cobbles }\end{array}$ \\
\hline Control & HT3 & 146.34 & $41.72 \%$ & $0.00 \%$ & $4.33 \%$ & $18.68 \%$ & $0.00 \%$ & $32.65 \%$ & $0.00 \%$ & $2.61 \%$ & $\begin{array}{l}\text { Mixture of sand and } \\
\text { gravel }\end{array}$ \\
\hline Enhancement & HT4 & 132.36 & $58.99 \%$ & $0.00 \%$ & $0.00 \%$ & $26.56 \%$ & $0.32 \%$ & $0.00 \%$ & $0.05 \%$ & $0.00 \%$ & $\begin{array}{l}\text { Mixture of sand and } \\
\text { gravel }\end{array}$ \\
\hline
\end{tabular}




\section{D.2 Experimental plot maps and planting plans}




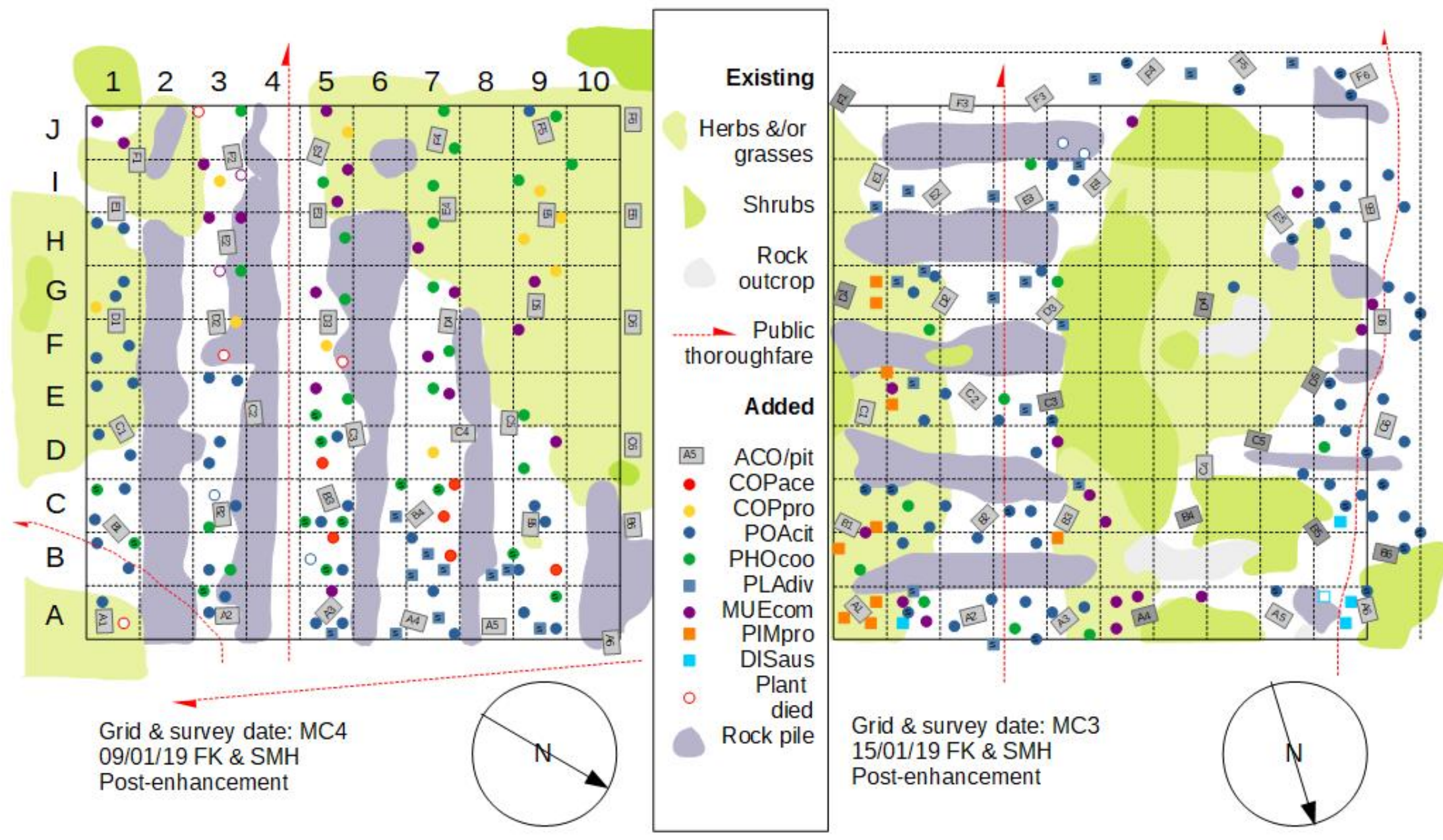

Figure D.1: Post-enhancement maps of enhancement treatment plots WP3 and WP4, showing plantings and constructed rock piles. 

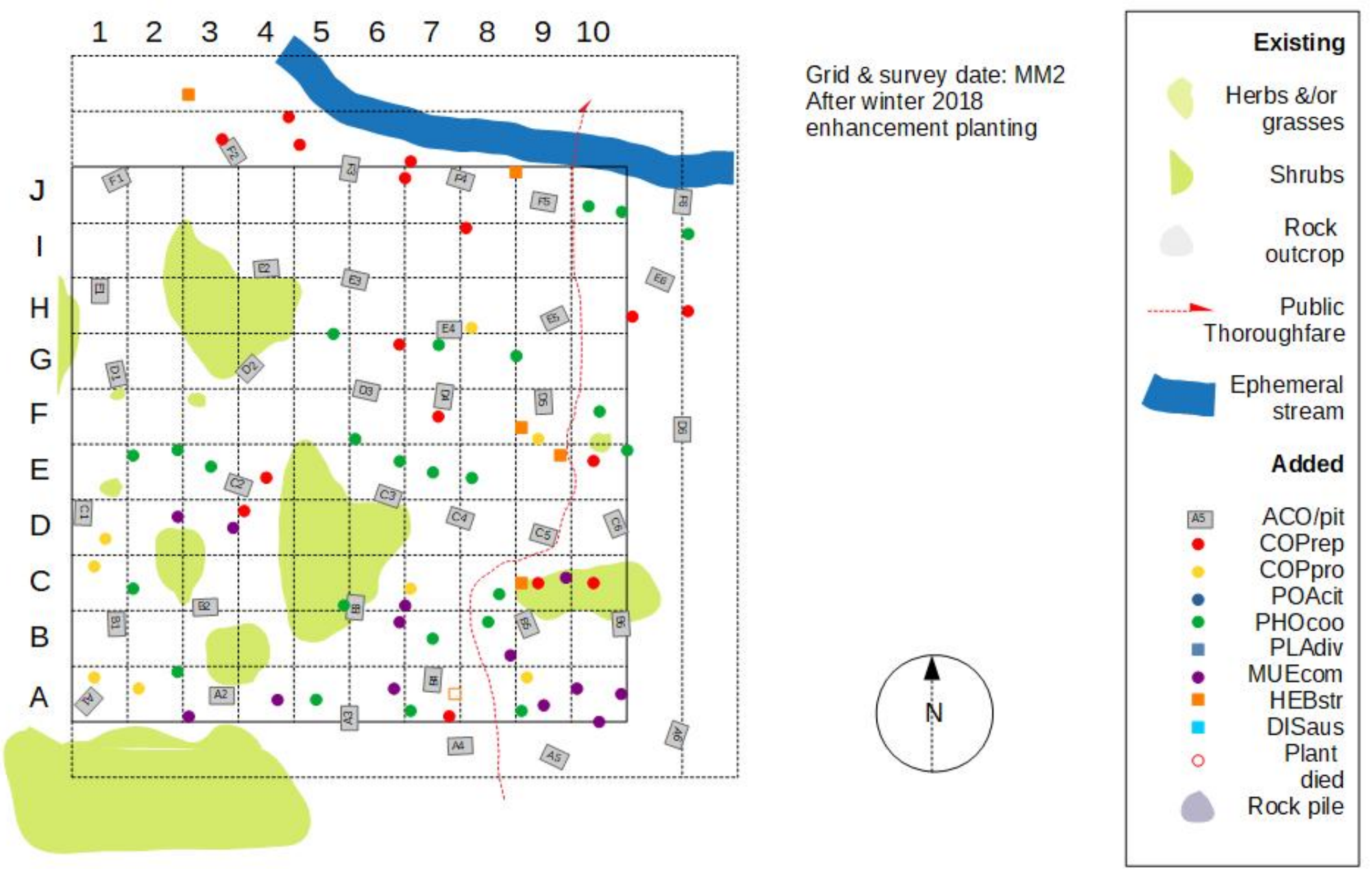

Figure D.2: Map of enhancement treatment plot RE2 showing plantings. 

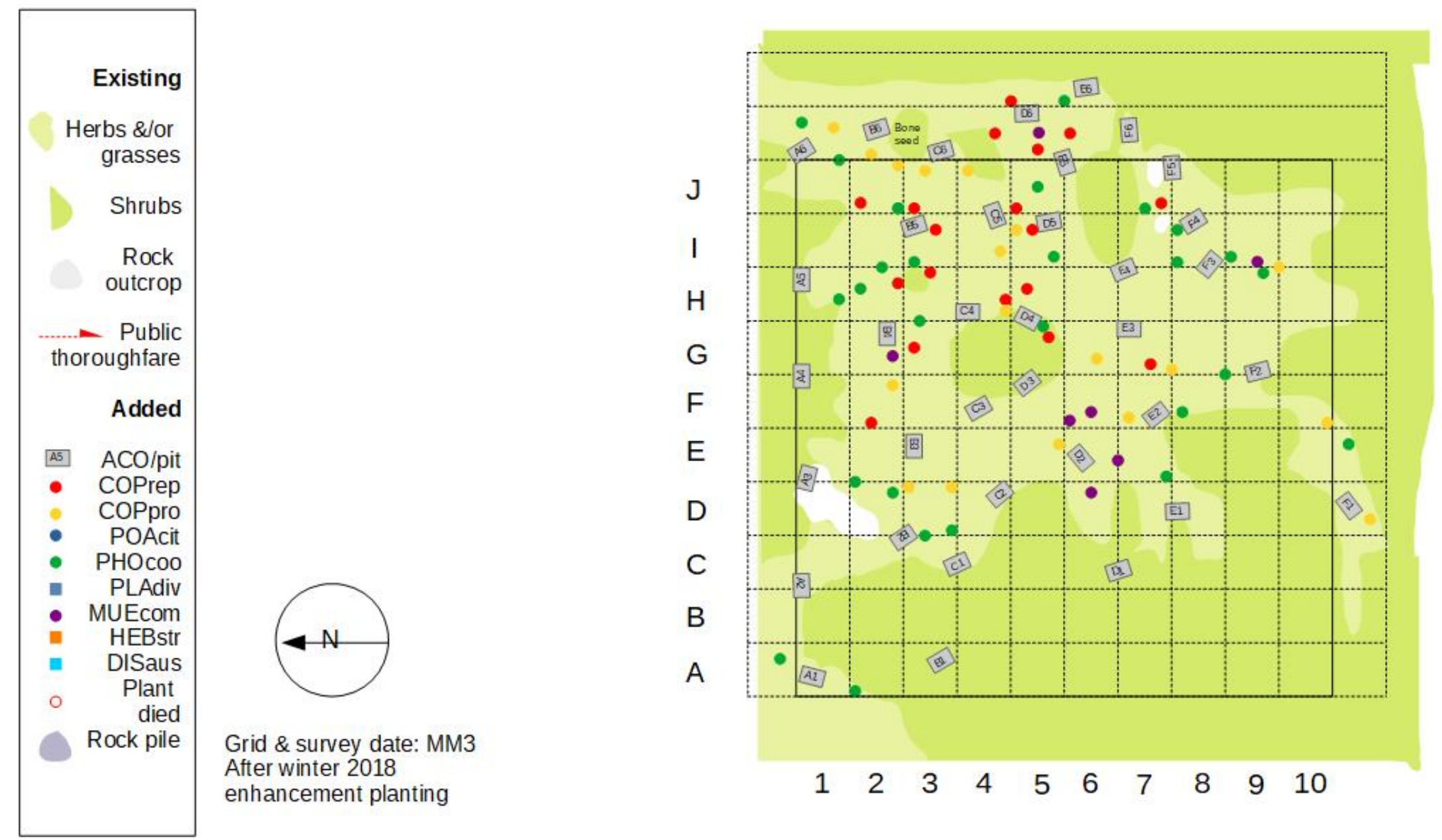

Figure D.3: Map of enhancement treatment plot RE3 showing plantings. 


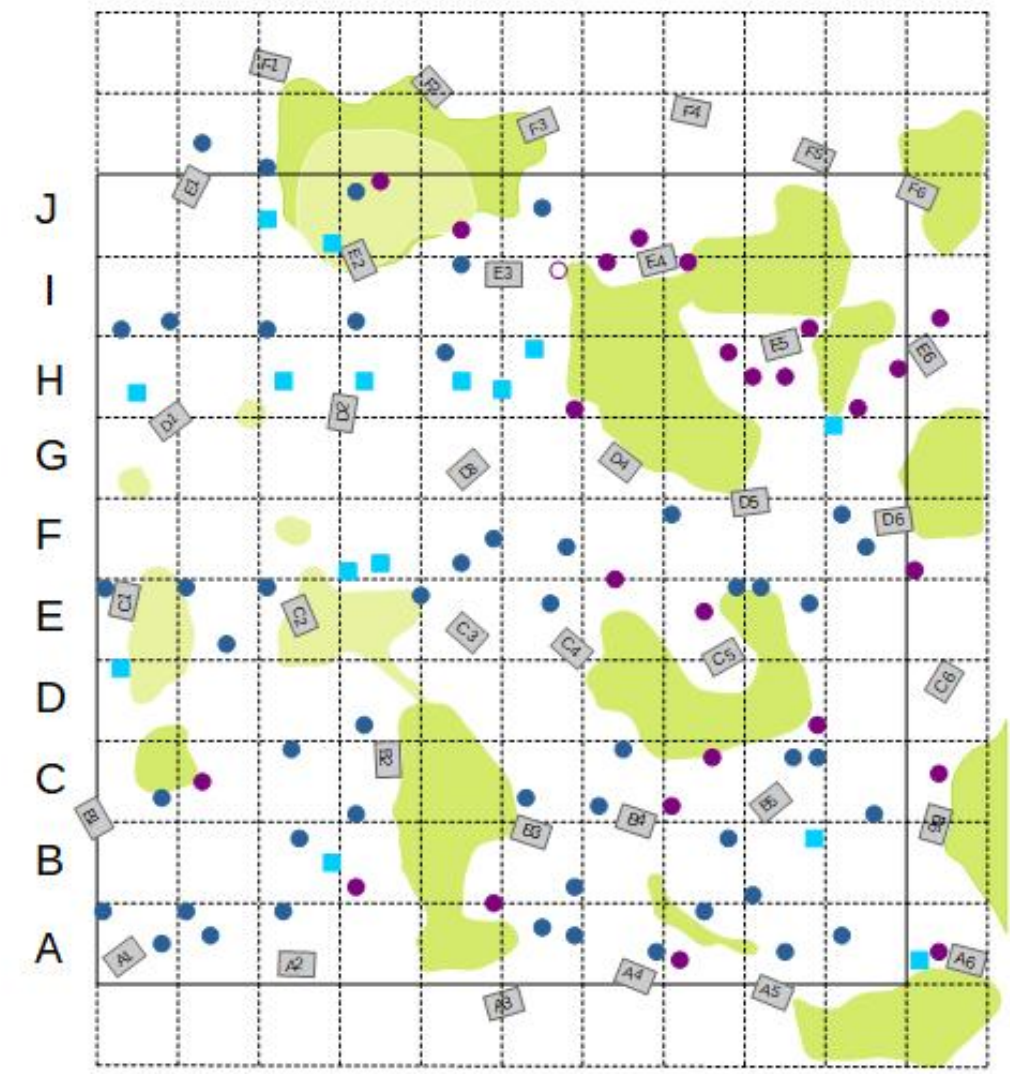

Grid \& survey date: MP1
7/11/18 FK + SH
(post- winter 2018 planting)
outcrop

- Public thoroughfare

Added

A5 ACO/pit

- COPrep

COPpro

POAcit

PHOCOO

PLAdiv

MUEcom

PIMpro
DISaus

Plant

died
Rock pile

Figure D.4: Map of enhancement treatment plot HT1 showing plantings. 


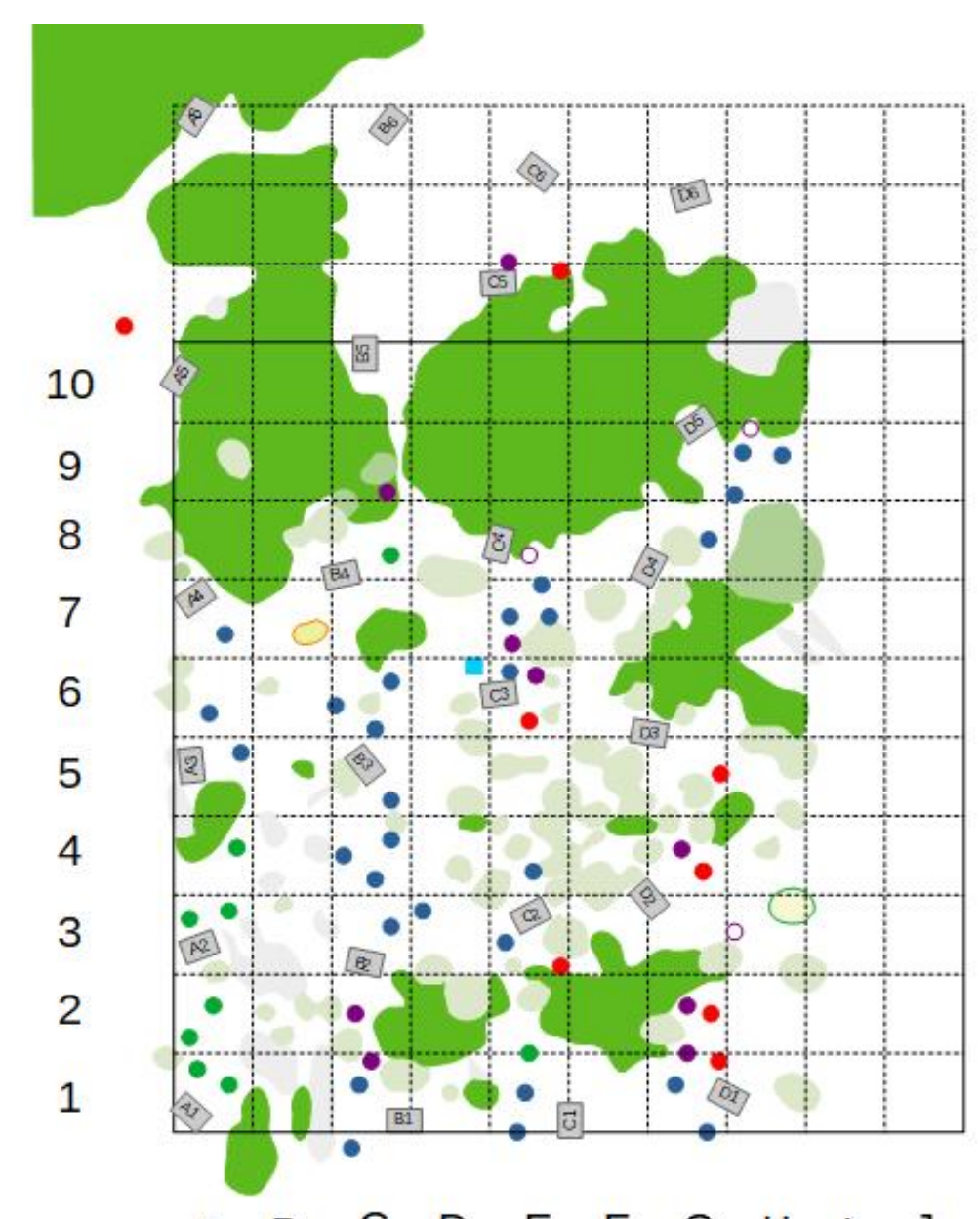

Grid \& survey date: MP4

$1 / 11 / 2017-1 / 7 / 2018$

(pre-enhancement)

\section{Existing}

$\begin{array}{lr}\text { POAcit } & \begin{array}{r}\text { Herbs \&/or } \\ \text { grasses }\end{array} \\ \text { PHOcoo } & \text { Shrubs } \\ \text { PIMpro } & \text { Rock } \\ \text { COPrep } & \text { outcrop } \\ \text { Isolepis } & \text { - Public } \\ & \text { thoroughfare }\end{array}$

Added

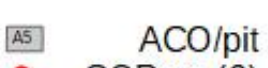

- COPrep (9)

- POAcit (49)

- PHOcOo (9)

- PLAdiv

- MUEcom (17)

PIMpro

- DISaus (20)

- Plant died

- Rock pile

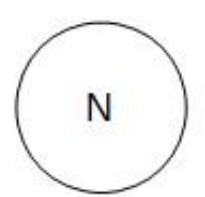

$\mathrm{N}$

Figure D.5: Map of enhancement treatment plot HT4 showing plantings. 